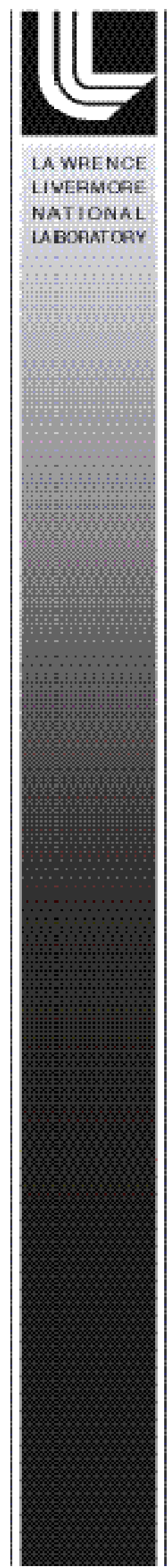

\title{
Environmental Monitoring Plan
}

\section{Gretchen M. Gallegos}

Nicholas A. Bertoldo

Richard G. Blake

Christopher G. Campbell

Allen R. Grayson

Henry E. Jones

Jennifer C. Nelson
Michael A. Revelli

Crystal A. Rosene

Tony Wegrecki

Robert A. Williams

Kent R. Wilson

\section{February 2012}

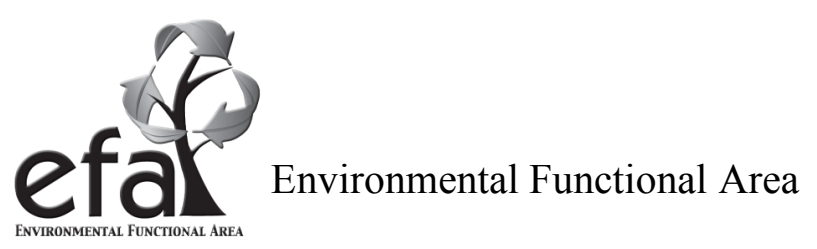


Lawrence Livermore National Laboratory is operated by Lawrence Livermore National Security, LLC, for the U.S. Department of Energy, National Nuclear Security Administration under Contract DE-AC52-07NA27344. 


\section{Environmental Monitoring Plan Revision History}

\begin{tabular}{|c|l|c|l|}
\hline $\begin{array}{c}\text { Revision } \\
\text { number }\end{array}$ & \multicolumn{1}{|c|}{ Date } & \multicolumn{1}{|c|}{$\begin{array}{c}\text { Chapter(s) } \\
\text { revised }\end{array}$} & \multicolumn{1}{|c|}{ Comments } \\
\hline 6 & February 2012 & All & $\begin{array}{l}\text { Update to reflect major } \\
\text { reorganization as well as } \\
\text { general update of text }\end{array}$ \\
\hline 5 & October 2009 & All & $\begin{array}{l}\text { Update and release of entire } \\
\text { document. }\end{array}$ \\
\hline 4 & September 2005 & All & $\begin{array}{l}\text { Reorganization and release of } \\
\text { entire document. }\end{array}$ \\
\hline 3 & February 2002 & All & $\begin{array}{l}\text { Update and release of entire } \\
\text { document. }\end{array}$ \\
\hline 2 & May 1999 & All & $\begin{array}{l}\text { Update and release of entire } \\
\text { document. }\end{array}$ \\
\hline 1 & February 1995 & All & $\begin{array}{l}\text { Update and release of entire } \\
\text { document. }\end{array}$ \\
\hline $0 a$ & April 1992 & All & $\begin{array}{l}\text { Update to reflect major } \\
\text { reorganization within EPD as } \\
\text { well as general update of text. }\end{array}$ \\
\hline 0 & November 1991 & - & Initial document release. \\
\hline
\end{tabular}




\section{Table of Contents}

\section{$1 \quad$ Introduction}

$1.1 \quad$ Purpose of the Environmental Monitoring Plan ..........................................................

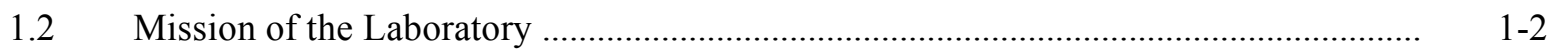

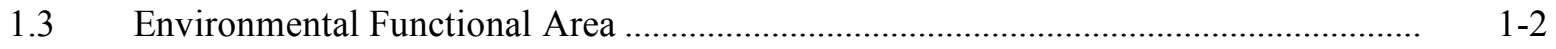

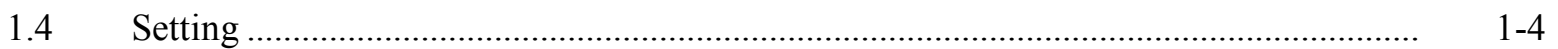

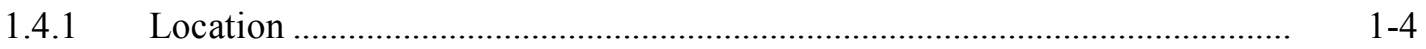

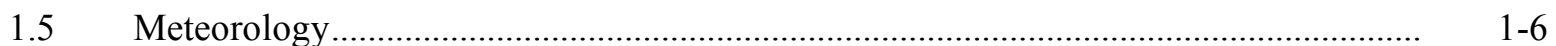

1.5.1 Livermore Site ....................................................................................

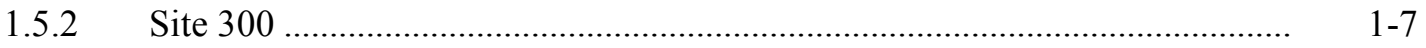

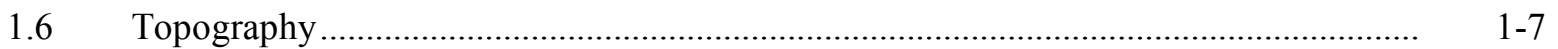

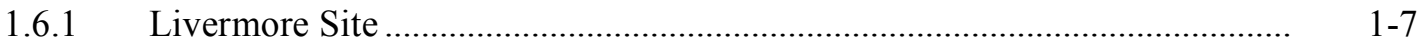

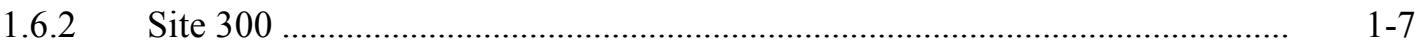

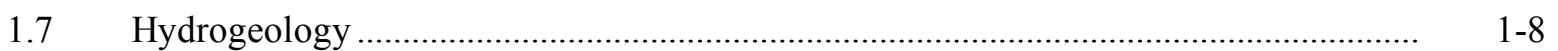

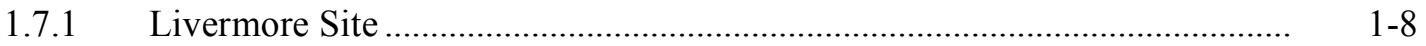

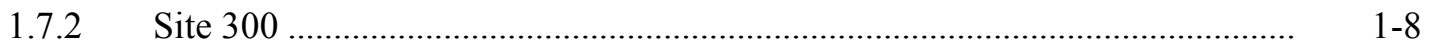

1.8 Environmental Monitoring Activities at LLNL …...................................................

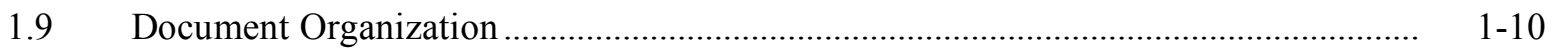

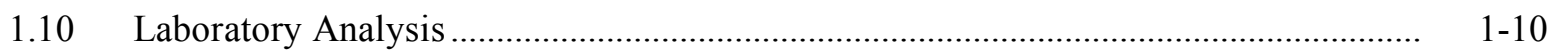

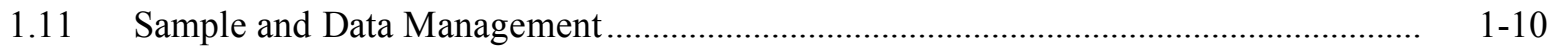

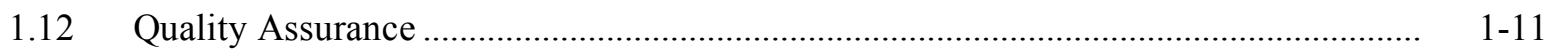

1.12.1 Quality Assurance Program ........................................................................... 1-11

1.12.2 Quality Assurance Documents ....................................................................... 1-11

1.12.3 Nonconformance Reporting and Tracking ................................................... $1-12$

1.12.4 Audits and Assessments........................................................................... 1-12

1.13 Integrated Safety Management ........................................................................ $1-12$

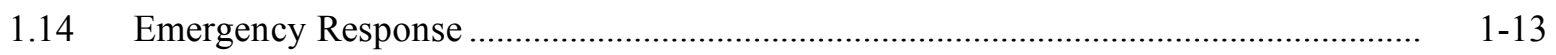

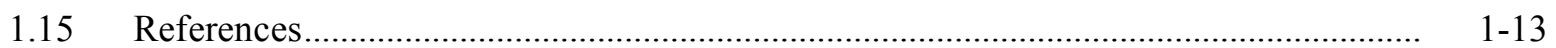

2. Meteorology

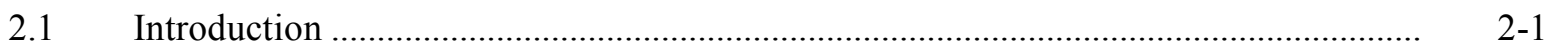

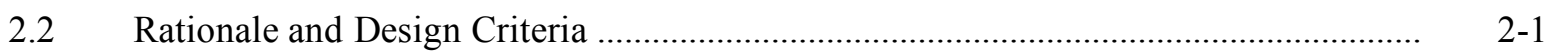

2.2.1 Regulatory Drivers .......................................................................... 2 2-1

2.2.2 Monitoring Objectives ...................................................................... $2-2$

2.2.3 Sources and Analytes ..................................................................................... 2-4

2.2.4 Collection Methods .................................................................................. 2-5

2.3 Extent and Frequency of Monitoring and Measurement ................................................ 2-7

2.3.1 Locations of Monitoring Sites ........................................................................ 2 2-7

2.3.2 Frequency of Sampling ............................................................................... 2-8

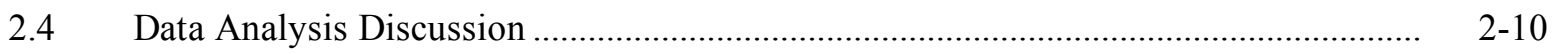

2.4.1 Computed Parameters .......................................................................... 2-10

2.4.2 Wind-Rose Diagram............................................................................. 2 2-11 


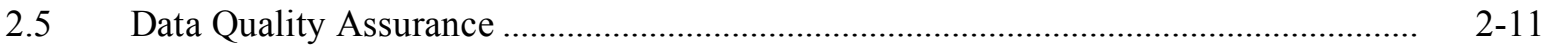

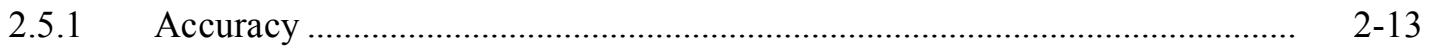

2.5.2 Completeness .......................................................................................... 2- 2-14

2.5.3 Calibration and Audits .............................................................................. 2- 2-14

2.6 Program Implementation Procedures....................................................................... 2-14

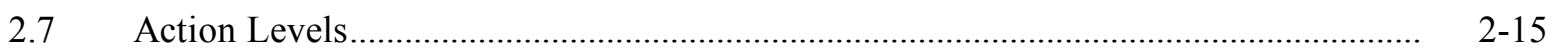

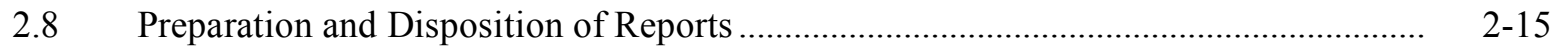

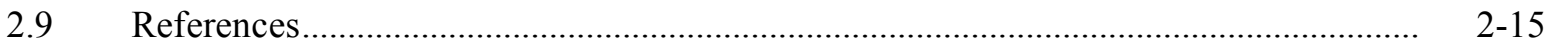

3. Air Effluent

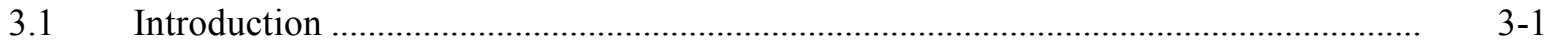

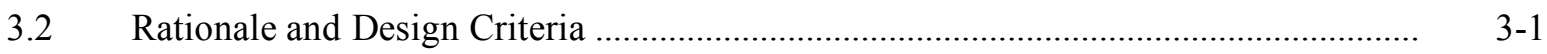

3.2.1 Regulatory Drivers ................................................................................

3.2.2 Monitoring Objectives .......................................................................... 3-2

3.2.3 Sources and Analytes .............................................................................. $3-2$

3.2.4 Collection Methods ............................................................................ 3-3

3.3 Extent and Frequency of Monitoring and Measurement ……...................................... 3-5

3.3.1 Evaluation of the Need for Air Effluent Sampling ........................................ 3-5

3.3.2 Air Effluent Sampling Locations ………................................................... 3-5

3.3.3 Low-Volume Ambient Air Samplers ............................................................ 3-5

3.3.4 Effluent Flow Rate Measurement................................................................ 3-5

3.4 Procedures for Laboratory Analysis....................................................................... $3-6$

3.4.1 Sample Preservation and Handling ............................................................. 3-6

3.4.2 Analytical Methods ...................................................................................

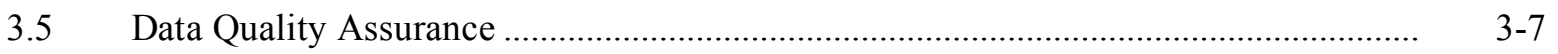

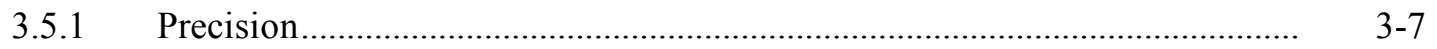

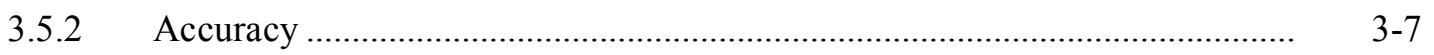

3.5.3 Completeness .......................................................................................

3.5.4 Calibration ...................................................................................

3.6 Program Implementation Procedures......................................................................

3.6.1 Air Effluent Sampling ...............................................................................

3.6.2 Effluent Flow Measurement, Calibration, and Maintenance.......................... 3-9

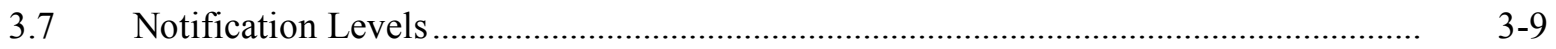

3.8 Preparation and Disposition of Reports ............................................................. $3-10$

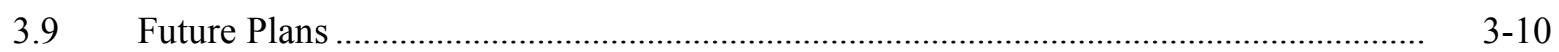

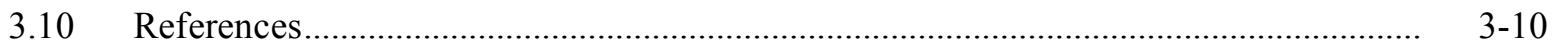

\section{Ambient Air Particulate}

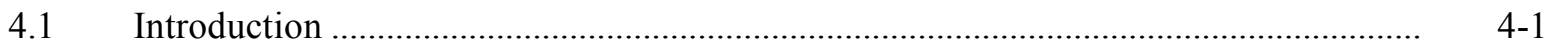

4.2 Rationale and Design Criteria …............................................................................

4.2.1 Regulatory Drivers ................................................................................. 4-2

4.2.2 Monitoring Objectives ......................................................................... $4-2$

4.2.3 Sources and Analytes ............................................................................ 4-3 


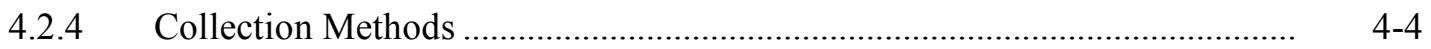

4.3 Extent and Frequency of Monitoring and Measurement .............................................. 4. 4.4

4.4 Procedures for Laboratory Analysis.......................................................................

4.5 Data Quality Assurance …........................................................................................

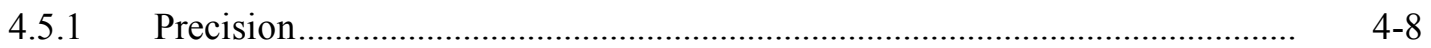

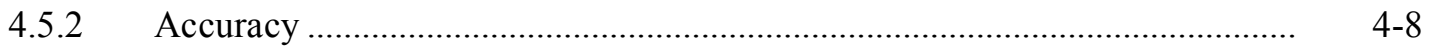

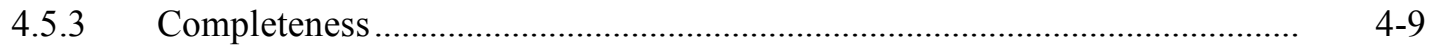

4.6 Program Implementation Procedures .........................................................................

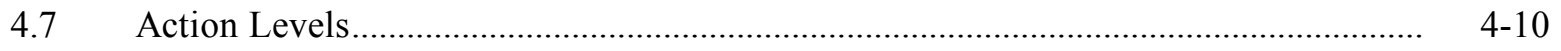

$4.8 \quad$ Preparation and Disposition of Reports .................................................................... $4-11$

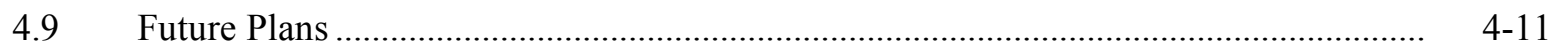

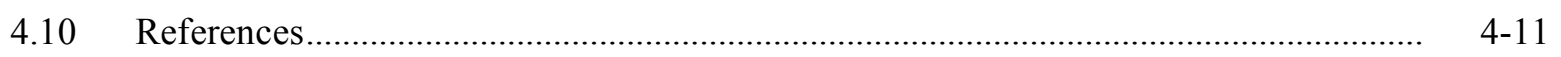

\section{Ambient Air Tritium}

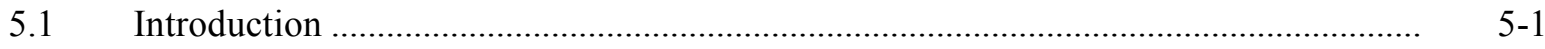

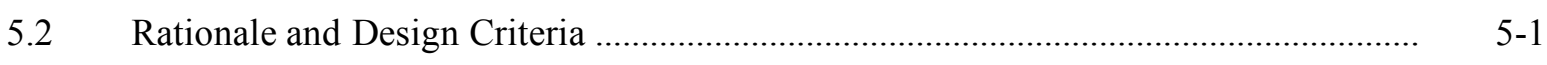

5.2.1 Regulatory Drivers ................................................................................ $5-1$

5.2.2 Monitoring Objectives ......................................................................... $5-2$

5.2.3 Off-Normal Releases.............................................................................. $\quad 5-3$

5.2.4 Sources and Analytes .............................................................................. $5-4$

5.2.5 Collection Methods .................................................................................... $5-4$

5.3 Extent and Frequency of Monitoring and Measurement ............................................ $5-6$

5.3.1 Sampling Locations ............................................................................. 5

5.3.2 Sampling Frequency .................................................................................. 5

5.4 Procedures for Laboratory Analysis....................................................................

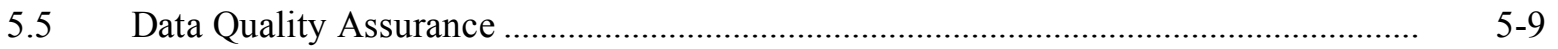

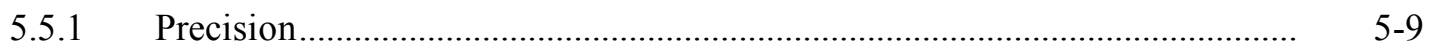

5.5.2 Accuracy …….................................................................................. $5-10$

5.5.3 Completeness .............................................................................. 5

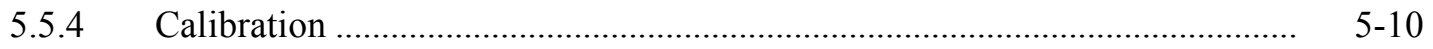

5.6 Program Implementation Procedures ................................................................ $5-11$

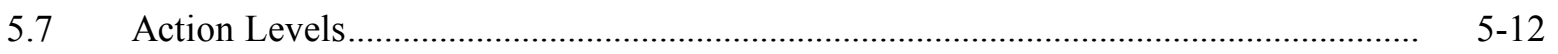

$5.8 \quad$ Preparation and Disposition of Reports ............................................................ $5-13$

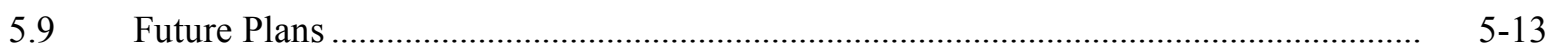

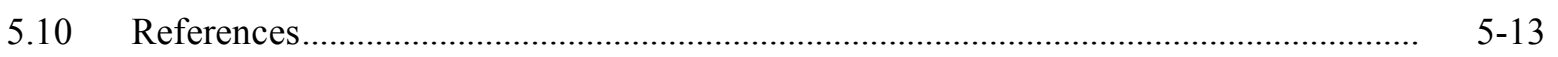

6. Sanitary Sewer

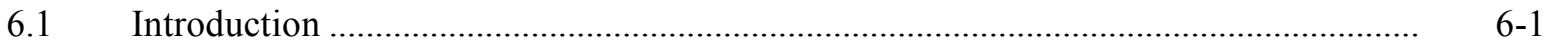

6.2 Sewer Compliance Monitoring Program .................................................................. 6 6-1

6.2.1 Rationale and Design Criteria................................................................... 6-1

6.2.2 Extent and Frequency of Monitoring and Measurements ............................... 6-6

6.2.3 Procedures for Laboratory Analysis............................................................. $\quad 6-8$

6.2.4 Data Quality Assurance …........................................................................... 6-8 
6.2.5 Program Implementation Procedures ........................................................... 6-9

6.2.6 Action Levels................................................................................. 6-10

6.2.7 Preparation and Disposition of Reports .......................................................... 6-10

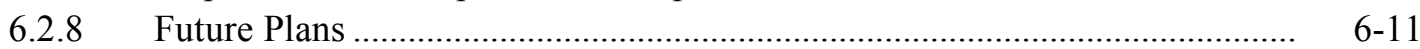

6.3 Sewer Control Monitoring Program …….................................................................. $6-11$

6.3.1 Rationale and Design Criteria.......................................................................... 6- 6-11

6.3.2 Extent and Frequency of Monitoring and Measurements.............................. 6- 6-15

6.3.3 Analysis Procedures ……........................................................................ 6-18

6.3.4 Data Quality Assurance …....................................................................... 6-21

6.3.5 Program Implementation Procedures .......................................................... 6- 6-22

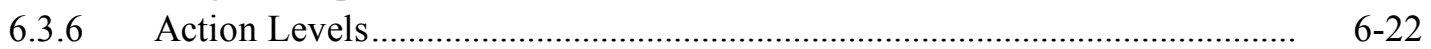

6.3.7 Preparation and Disposition of Reports ........................................................ $\quad 6-22$

6.3.8 Future Plans ................................................................................. 6-23

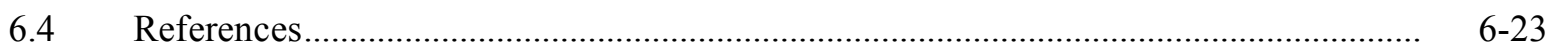

7. Retention Tank Sampling

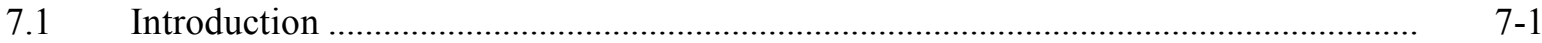

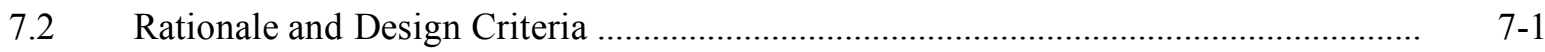

7.2.1 Regulatory Drivers .....................................................................................

7.2.2 Monitoring Objectives ……....................................................................

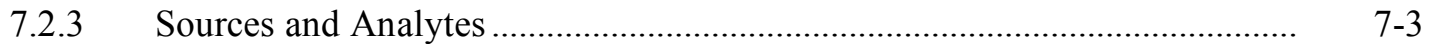

7.2.4 Collection Methods .................................................................................. 7-4

7.3 Extent and Frequency of Monitoring and Measurement ….......................................... 7-5

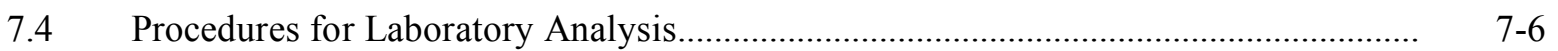

7.5 Data Quality Assurance …....................................................................................

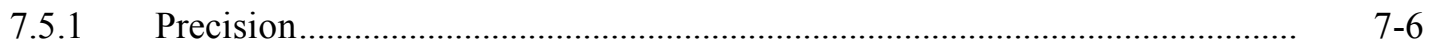

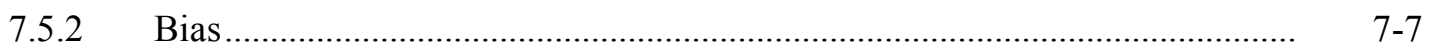

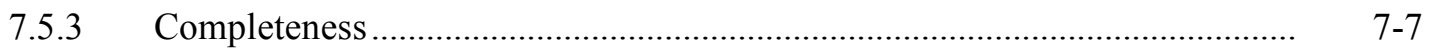

7.6 Program Implementation Procedures...................................................................

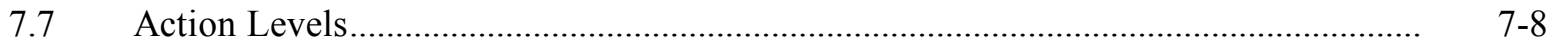

7.8 Preparation and Disposition of Reports .....................................................................

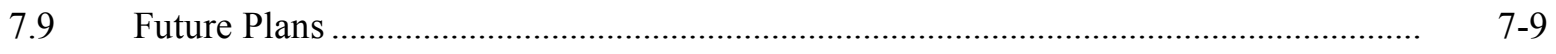

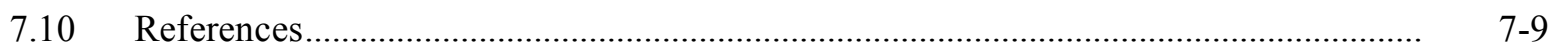

8. Categorical Pretreatment

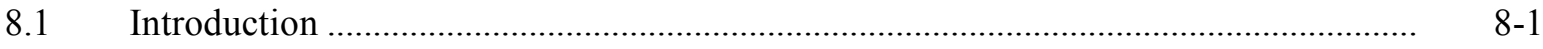

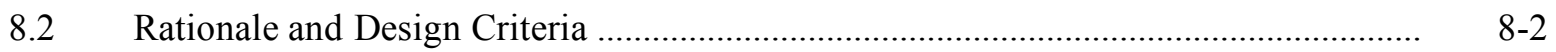

8.2.1 Regulatory Drivers ......................................................................... $8-2$

8.2.2 Monitoring Objectives ………………................................................. 8-3

8.2.3 Sources and Analytes .......................................................................... 8

8.2.4 Collection Methods ......................................................................... 8.

8.3 Extent and Frequency of Monitoring and Measurement ............................................. 8-5

8.4 Procedures for Laboratory Analysis......................................................................... 


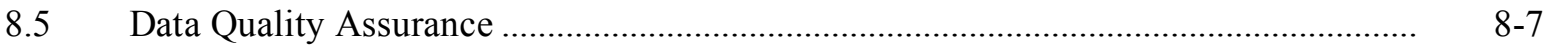

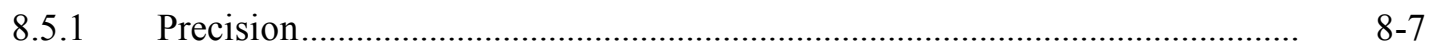

8.5.2 Accuracy ….......................................................................................

8.5.3 Completeness .................................................................................................

8.6 Program Implementation Procedures.................................................................. 8-8

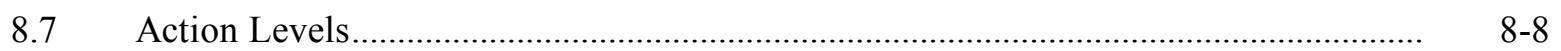

8.8 Preparation and Disposition of Reports ...................................................................

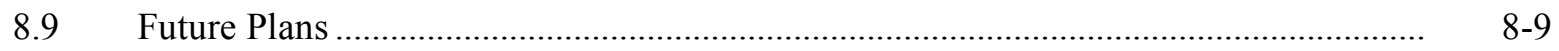

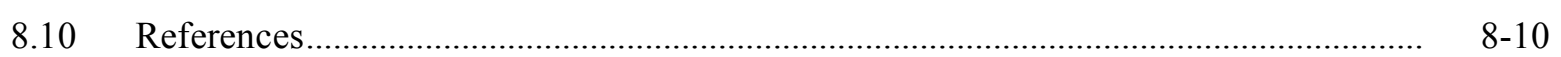

\section{Storm Water}

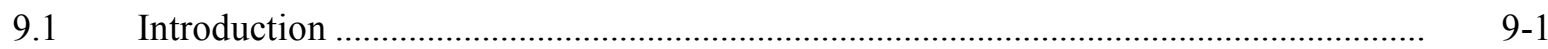

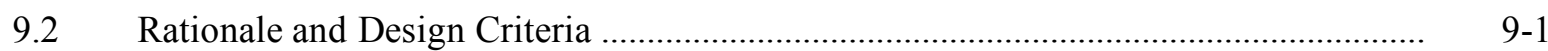

9.2.1 Regulatory Drivers .............................................................................

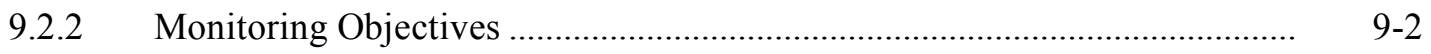

9.2.3 Sources and Analytes .................................................................................. 9- 9-3

9.2.4 Collection Methods ................................................................................... 9-5

9.3 Extent and Frequency of Monitoring and Measurement .............................................. 9-6

9.3.1 Monitoring Requirements for Livermore Site ............................................... 9-6

9.3.2 Monitoring Requirements for Site 300 ......................................................... 9-8

9.3.3 Monitoring Requirements for Construction at Both Site ............................... 9- 9-10

9.4 Procedures for Laboratory Analysis.......................................................................... 9-10

9.5 Data Quality Assurance ...................................................................................... $9-10$

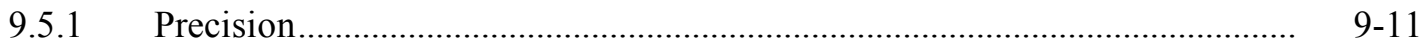

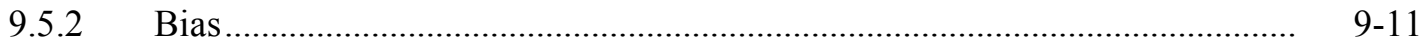

9.5.3 Completeness ................................................................................... 9-11

9.6 Program Implementation Procedures .................................................................... $9-11$

9.7 Action Levels............................................................................................... $9-12$

9.8 Preparation and Disposition of Reports ................................................................. $9-14$

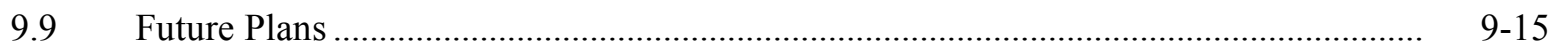

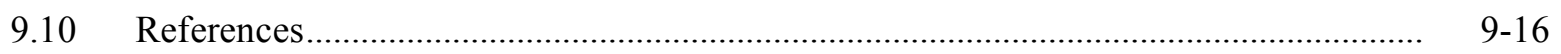

10. Rainwater

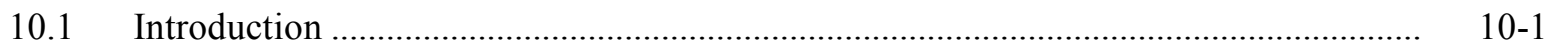

10.2 Rationale and Design Criteria ………..................................................................... $10-1$

10.2.1 Regulatory Drivers ............................................................................ 10 1

10.2.2 Monitoring Objectives ......................................................................... $10-1$

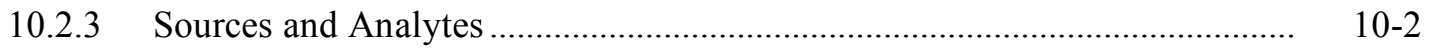

10.2.4 Collection Methods ................................................................................. 10-2

10.3 Extent and Frequency of Monitoring and Measurement ............................................ 10-2

10.4 Procedures for Laboratory Analysis......................................................................... 10-4

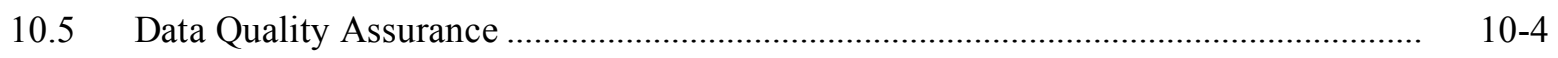

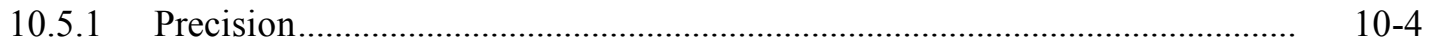




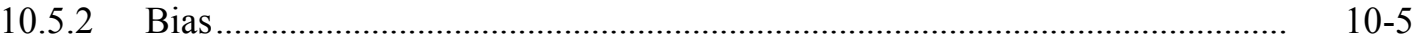

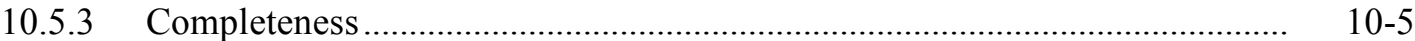

10.6 Program Implementation Procedures ............................................................................ 10-5

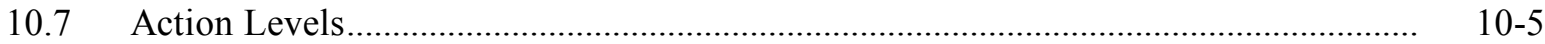

10.8 Preparation and Disposition of Reports .................................................................. $10-6$

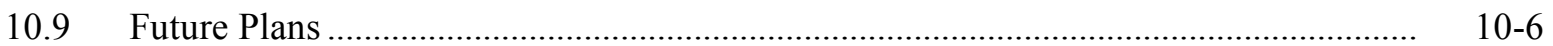

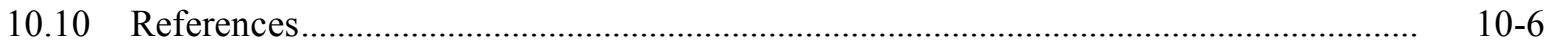

\section{Lake Haussmann Release}

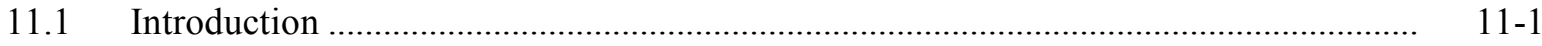

11.2 Rationale and Design Criteria for Lake Haussmann Release Monitoring..................... 11-1

11.2.1 Regulatory Drivers .................................................................................. 11-1

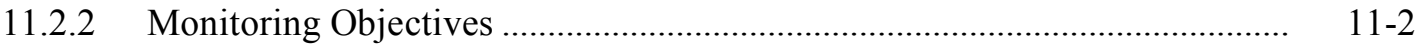

11.2.3 Sources and Analytes ......................................................................... 11-2

11.2.4 Collection Methods ....................................................................... 11-5

11.3 Extent and Frequency of Monitoring and Measurement …............................................ 11-5

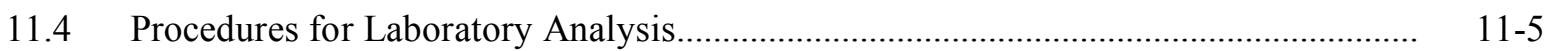

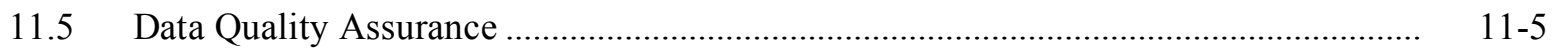

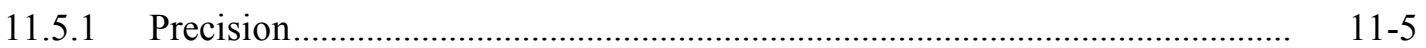

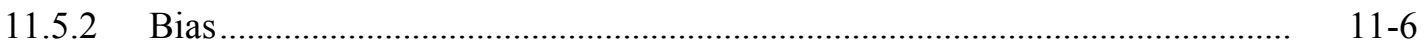

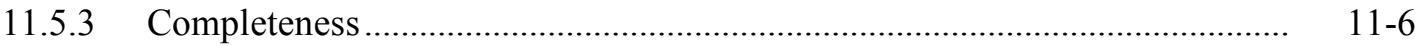

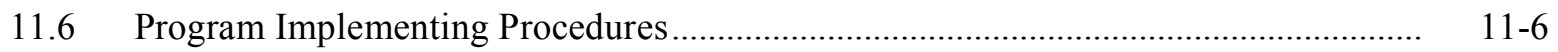

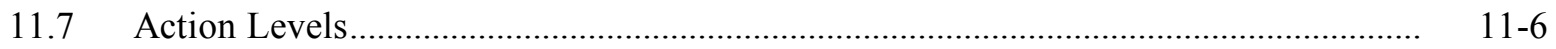

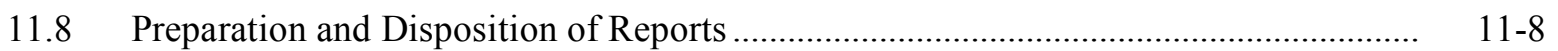

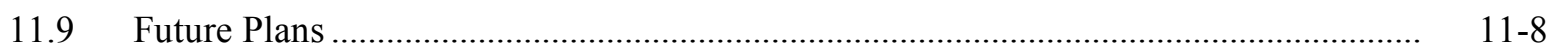

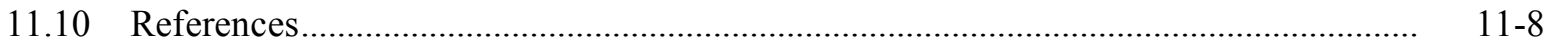

\section{Site 300 Drinking Water Discharges}

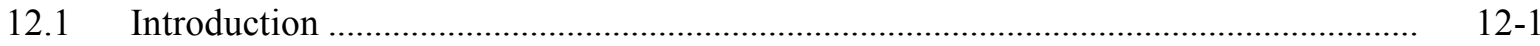

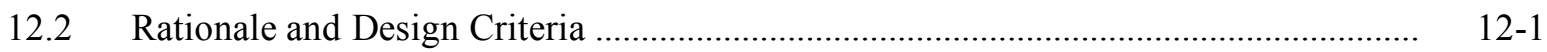

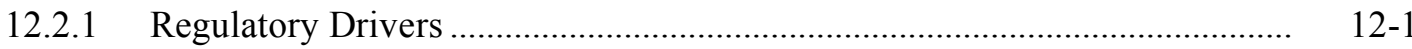

12.2.2 Monitoring Objectives .............................................................................. 12-2

12.2.3 Sources and Analytes .......................................................................... 12-2

12.2.4 Collection Methods ................................................................................ 12-3

12.3 Extent and Frequency of Monitoring and Measurement …......................................... 12-3

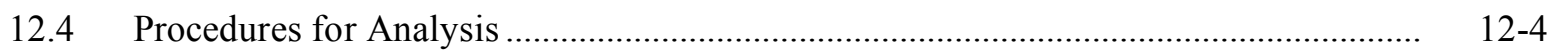

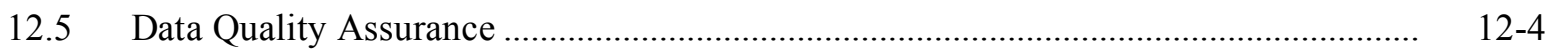

12.5.1 Equipment Calibration for Field Measurements .......................................... 12-5

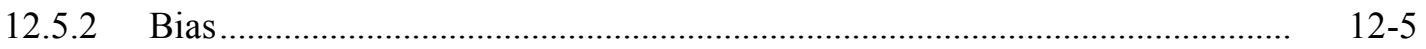

12.5.3 Completeness ................................................................................. 12-5

12.6 Program Implementation Procedures ..................................................................... 12-6

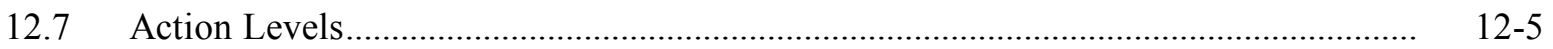




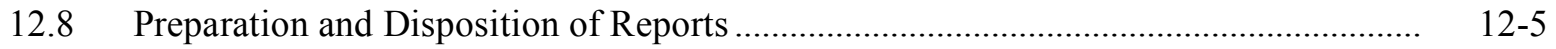

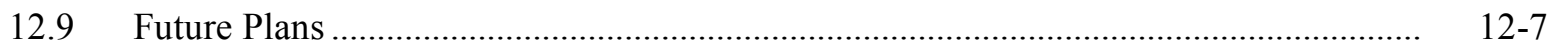

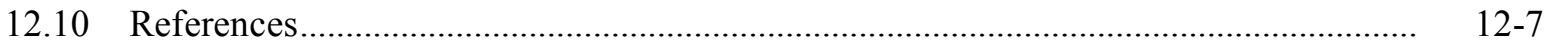

\section{Other Waters}

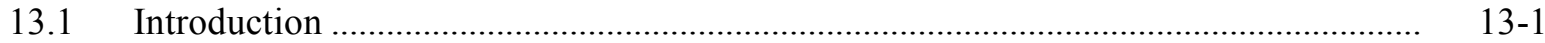

13.2 Rationale and Design Criteria for Other Waters Monitoring ....................................... 13-1

13.2.1 Regulatory Drivers ...................................................................................... 13-1

13.2.2 Monitoring Objectives .................................................................................. 13-1

13.2.3 Sources and Analytes .......................................................................... 13-2

13.2.4 Collection Methods .................................................................................. 13-2

13.3 Extent and Frequency of Monitoring and Measurement ............................................ 13-2

13.3.1 Livermore Site ........................................................................................ 13-2

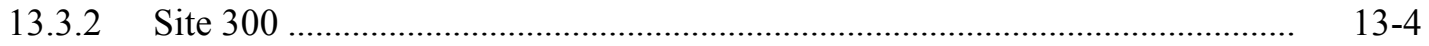

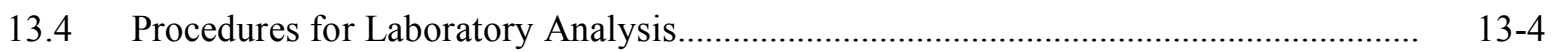

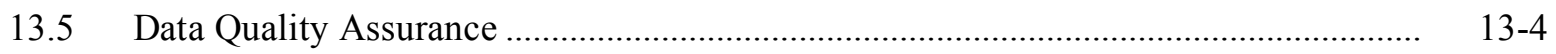

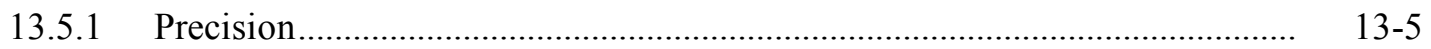

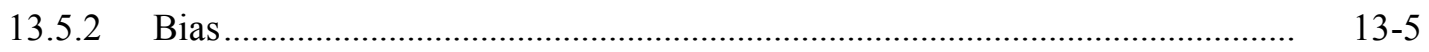

13.5.3 Completeness .............................................................................. $13-5$

13.6 Program Implementation Procedures...................................................................... $13-5$

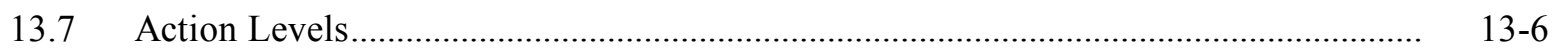

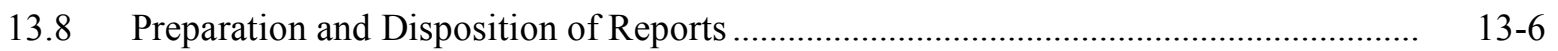

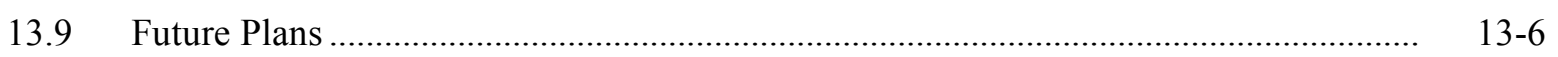

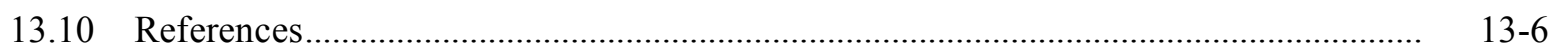

14 Ground Water

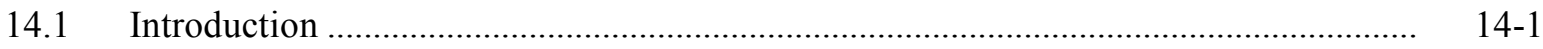

14.2 Rationale and Design Criteria for Surveillance Ground Water Monitoring.................. 14-2

14.2.1 Regulatory Drivers ............................................................................... 14-2

14.2.2 Monitoring Objectives ....................................................................... 14-2

14.2.3 Sources and Analytes ........................................................................... 14-3

14.3 Rationale and Design Criteria for Compliance Ground Water Monitoring ................. 14-14

14.3.1 Regulatory Drivers ............................................................................ 14-14

14.3.2 Monitoring Objectives ....................................................................... 14-16

14.3.3 Sources and Analytes .................................................................................... 14-16

14.4 Ground Water Sample Collection Methods............................................................ 14-26

14.5 Procedures for Laboratory Analysis..................................................................... $14-26$

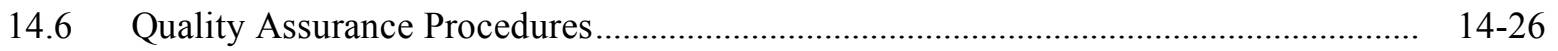

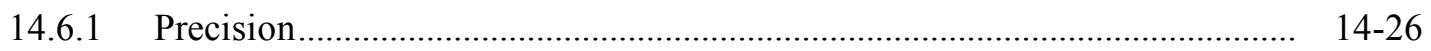

14.6.2 Bias ..................................................................................... 14-27

14.6.3 Completeness ..................................................................................... 14-27

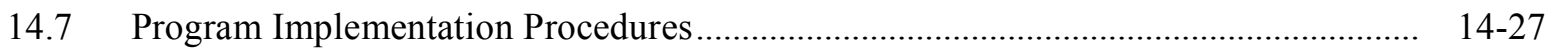

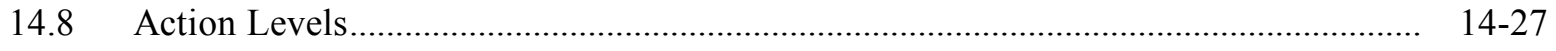




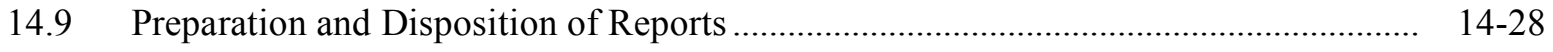

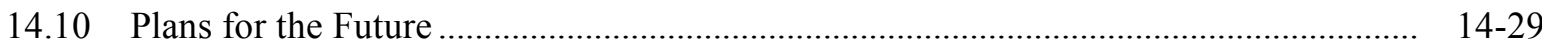

14.10.1 Livermore Site and Livermore Valley Surveillance Monitoring .................. 14-29

14.10.2 Site 300 Surveillance Monitoring............................................................. 14-29

14.10.3 Pit 1 Compliance Monitoring ……........................................................ 14-30

14.10.4 Pit 6 Compliance Monitoring ................................................................... 14-30

14.10.5 Pit 7 Compliance Monitoring …….......................................................... 14-30

14.10.6 Building 829 Compliance Monitoring .................................................... 14-30

14.10.7 Sewage Ponds Compliance Monitoring ...................................................... 14-30

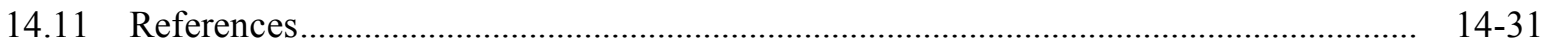

\section{Soil}

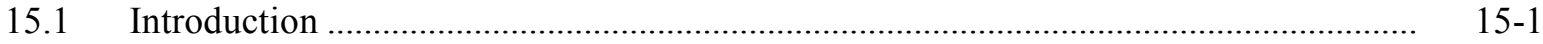

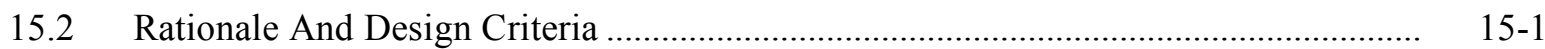

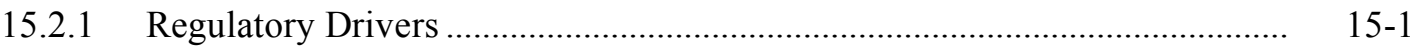

15.2.2 Monitoring Objectives ......................................................................... 15-2

15.2.3 Sources and Analytes ............................................................................... 15-2

15.2.4 Collection Methods .................................................................................. 15-3

15.3 Extent and Frequency of Monitoring and Measurement ….......................................... 15-5

15.3.1 Sampling Locations.......................................................................... 15-5

15.3.2 Sampling Frequency .............................................................................. 15-7

15.4 Procedures for Laboratory Analysis........................................................................ 15-7

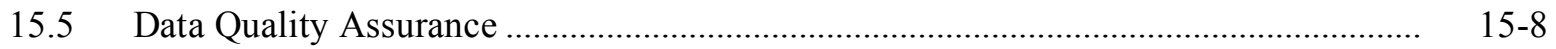

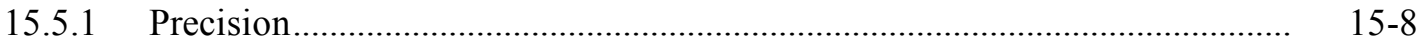

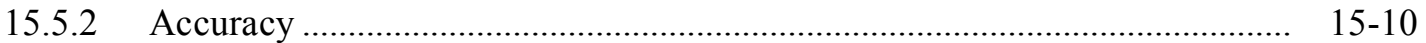

15.5.3 Completeness ........................................................................... 15-10

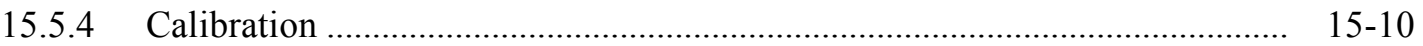

15.6 Program Implementation Procedures..................................................................... 15-11

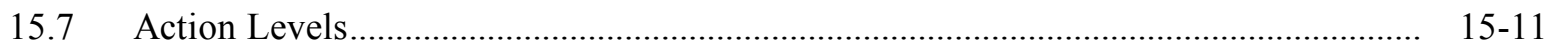

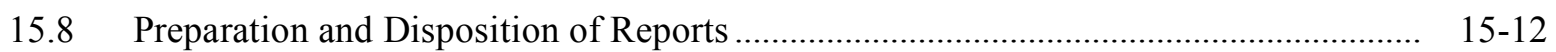

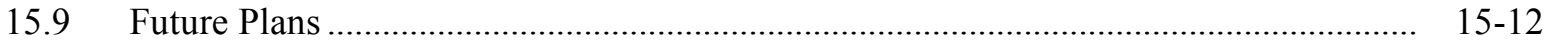

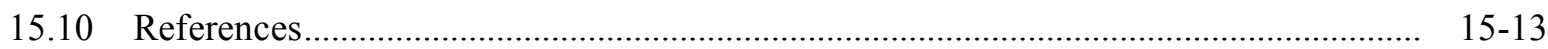

16 Vegetation and Foodstuff

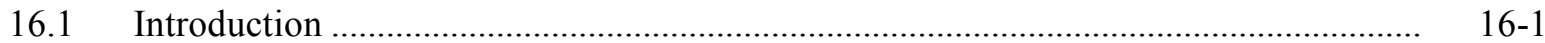

16.2 Rationale and Design Criteria for Vegetable Monitoring .......................................... 16-1

16.2.2 Extent and Frequency of Wine Monitoring and Measurements..................... 16-3

16.2.3 Procedures for Laboratory Analysis.............................................................. 16-6

16.2.4 Data Quality Assurance ......................................................................... 16-7

16.2.5 Program Implementation Procedures ............................................................... 16-8

16.2.6 Action Levels....................................................................................... 16- 16

16.2.7 Preparation and Disposition of Reports ................................................... 16-10

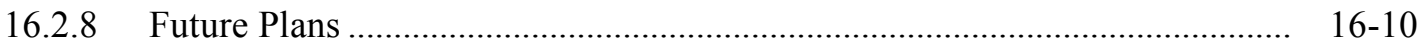

16.3 Wine Monitoring Program................................................................................... 16-10 
16.3.1 Rationale and Design Criteria for Wine Monitoring.................................... 16-10

16.3.2 Extent and Frequency of Wine Monitoring and Measurments....................... 16-11

16.3.3 Procedures for Laboratory Analysis........................................................... 16-12

16.3.4 Data Quality Assurance ......................................................................... 16-12

16.3.5 Program Implementation Procedures ....................................................... 16-13

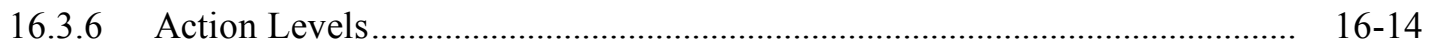

16.3.7 Preparation and Disposition of Reports .................................................... 16-14

16.3.8 Future Plans .................................................................................... 16-14

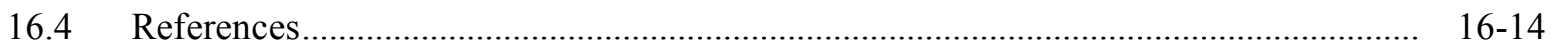

\section{Ambient Radiation}

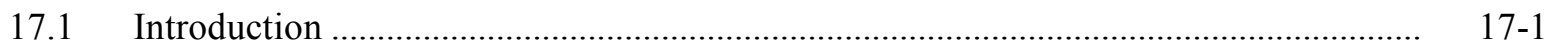

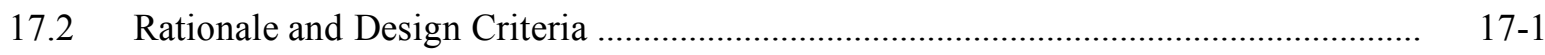

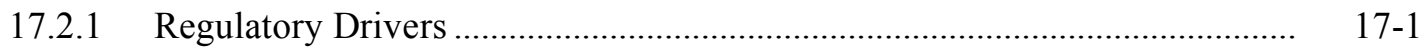

17.2.2 Monitoring Objectives ............................................................................ 17-2

17.2.3 Sources and Analytes ............................................................................ 17-2

17.2.4 Collection Methods .......................................................................... 17-2

17.3 Extent and Frequency of Monitoring and Measurement …........................................ 17-3

17.3.1 Livermore Site and Livermore Valley ...................................................... 17-4

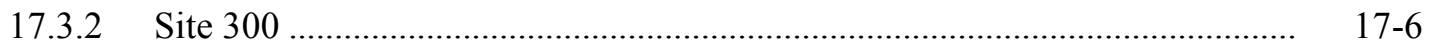

17.3.3 State of California Co-Monitoring …........................................................... 17-7

17.4 Procedures for Laboratory Analysis........................................................................ $17-7$

17.4.1 Calibration ................................................................................ 17-8

17.4.2 TLD Data Analysis................................................................................... 17-8

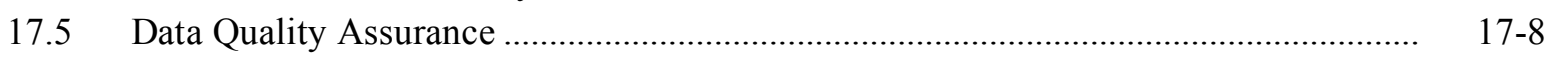

17.5.1 Precision and Accuracy ............................................................................. 17-8

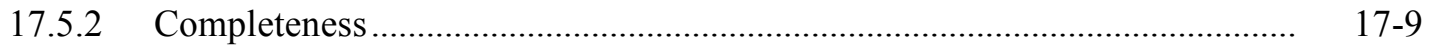

17.6 Program Implementation Procedures ..................................................................... 17-10

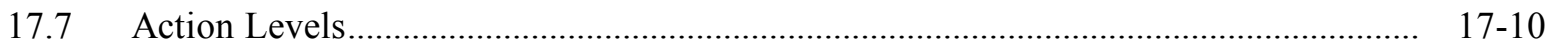

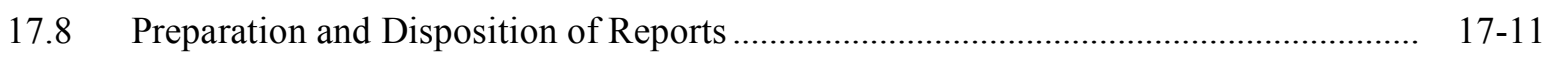

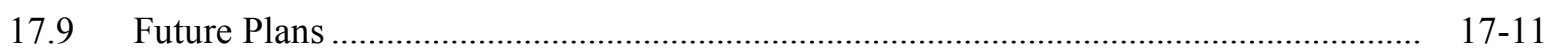

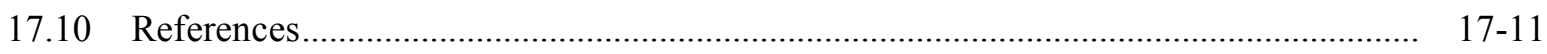

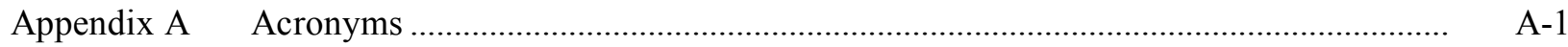




\section{List of Figures}

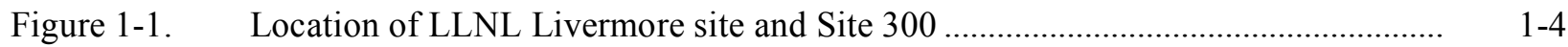

Figure 2-1. Location of the Livermore site meteorological tower .............................................. 2-8

Figure 2-2. Location of the Site 300 meteorological tower......................................................... 2-9

Figure 4-1. $\quad$ Air particulate sampling locations, Livermore site …………................................... $4-5$

Figure 4-2. $\quad$ Air particulate sampling locations, Livermore Valley ............................................... 4-6

Figure 4-3. $\quad$ Air particulate and tritium sampling locations, Site 300 ........................................

Figure 5-1. Comparison of measured (wtd.avg) and modeled (cap.avg) annual mean concentrations of tritiated waer vapor (HTO) $1 \times 10^{-12} \mathrm{Ci} / \mathrm{m}^{3}\left(\mathrm{pCi} / \mathrm{m}^{3}\right)$ in air at

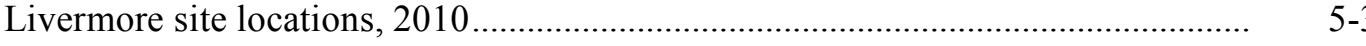

Figure 5-2. Air tritium sampling locations, Livermore site..................................................... $5-7$

Figure 5-3. Air tritium sampling locations, Livermore Valley …….......................................... 5-7

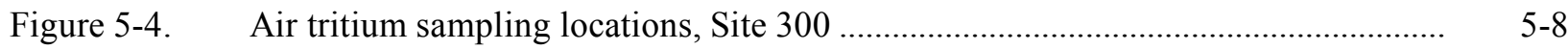

Figure 6-1. Livermore site sewer monitoring network …..........................................................

Figure 6-2. Typical gamma spectroscopy data....................................................................... 6-19

Figure 6-3. X-ray fluorescence analysis configuration for flow-through monitoring of metals

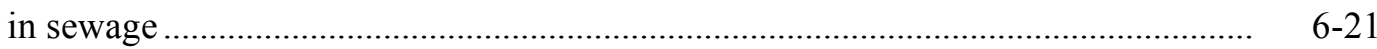

Figure 9-1. Surface waterways in the vicinity of the Livermore site......................................... 9-4

Figure 9-2. Storm water runoff sampling locations at Site 300 and Corral Hollow Creek ......... 9-5

Figure 9-3. Storm water runoff sampling locations, Livermore site and vicinity ....................... 9-7

Figure 10-1. Rainwater and air tritium sampling locations, Livermore site................................ 10-3

Figure 10-2. Rainwater and air tritium sampling locations, Site 300 ....................................... $10-4$

Figure 11-1. Lake Haussmann Release sampling locations, Livermore Site and vicinity ............ 11-2

Figure 12-1. Site 300 surface waters, drinking water tanks, and receiving water monitoring locations

Figure 13-1. $\quad$ Surface and drinking water sampling locations, Livermore Valley ......................... 13-3

Figure 14-1. Livermore site hydrostratigraphic east-west cross section along East Avenue ........ 14-4

Figure 14-2. Livermore site and ground water surveillance monitoring well locations ................ 14-6

Figure 14-3. Livermore Valley ground water surveillance monitoring well locations.................. 14-9

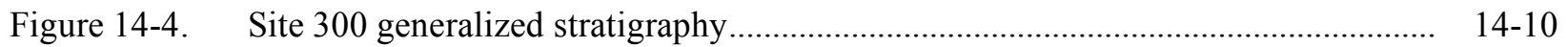

Figure 14-5. Site 300 locations of pits (closed landfills), former HE burn pit, surface impoundments (process water), sewage ponds, and ground water surveillance wells and springs ............................................................................................ $14-12$

Figure 14-6. Location of Pit 1 and its eight compliance detection monitoring wells ................... 14-17

Figure 14-7. Location of Pit 6 and its six compliance detection monitoring wells....................... 14-18 
Figure 14-8. Location of the closed Building 829 burn pit at Site 300 and its three compliance detection monitoring wells

Figure 14-9. Locations of the sewage ponds at Site 300 and their ten compliance detection monitoring wells ......

Figure 14-10. Building 812 monitoring network

Figure 14-11. Building 834 monitoring network

Figure 14-12. Building 850 monitoring network

Figure 14-13. Building 899 monitoring network

Figure 14-14. Location of mechnical equipment wastewater percolation pits.....

Figure 14-15. Location of cooling towers and percolation pits.

Figure 15-1. Soil sampling locations, Livermore site and Livermore Valley

Figure 15-2. Site 300 soil sampling locations

Figure 16-1. Vegetation sampling locations, Livermore site and surroundings.

Figure 16-2. Site 300 vegetation sampling locations......

Figure 17-1. Gamma dosimeter locations, Livermore site

Figure 17-2. Gamma dosimeter locations, Livermore Valley.....

Figure 17-3. Gamma dosimeter locations, Site 300 and vicinity 


\section{List of Tables}

Table 2-2. Standards of accuracy of meteorological parameters

Table 4-1. Air particulate analysis methodology and detection limits

Table 4-2. Action levels for gross alpha, gross beta, isotopic plutonium-239, and beryllium metals.

Table 5-1. Upper warning and action limits for air tritium sampling groups sampling groups in $\mathrm{Bq} / \mathrm{m}^{3}$ and $\mathrm{Bq} / \mathrm{L}$

Table 6-1. Nonradiological pollutant outfall limits specified in the LLNL wastewater discharge permit

Table 6-2. Limits applicable to LLNL for radionuclides in sewage......

Table 6-3. Analytical methods used by off-site contract analytical laboratories.....

Table 6-4. Metals alarm levels

Table 7-1.

LLNL's internal discharge limits for nonradioactive parameters in noncategorical wastewater

Table 7-2. LLNL's internal discharge limits for radioactive parameters in wastewater.

Table 8-1. Typical sampling frequencies and analytes

Table 8-2. LLNL's self-monitoring program for nonradioactive parameters in wastewaters from categorical processes

Table 9-1. $\quad$ Summary of analyses regularly conducted oand EPA methods used on storm water samples.

Table 9-2. LLNL site-specific threshold comparison criteria for storm water constituents of concern. Values were estimated based on historical runoff data.

Table 11-1 Treated ground water and Lake Haussmann discharge analytes for sampling locations CDBX and WPDC.

Table 11-2. Analytes and action levelsw for Lake Haussmann discharge studies for samplilng locations CDBX and WPDC.

Table 14-1. Ground water monitoring, inorganic COCs, analytical methods, reporting limits, and action level concentrations

Table 14-2. Ground water monitoring, organic COCs by EPA analytical mehtod

Table 15-2. Geometric mean and standard deviation for radionuclides, 2000-2004

Table 16-1. Geometric means, geometric standard deviations, and upper warning and action limits for vegetation sampling groups (1999-2003)

Table 16-2. Geometric means, geometric standard deviations, and upper warning and action limits for wine sampling groups (1999-2003). 


\section{Introduction}

\subsection{Purpose of the Environmental Monitoring Plan}

The purpose of environmental monitoring is to promote the early identification of, and response to, potential adverse environmental impacts associated with Lawrence Livermore National Laboratory (LLNL) operations. Environmental monitoring supports the Integrated Safety Management System (ISMS), International Organization for Standardization (ISO) 14001 Environmental Management Systems standard, and U. S. Department of Energy (DOE) Order 458.1, Radiation Protection of the Public and the Environment. Specifically, environmental monitoring enables LLNL to detect, characterize, and respond to releases from LLNL activities; assess impacts; estimate dispersal patterns in the environment; characterize the pathways of exposure to members of the public; characterize the exposures and doses to individuals and to the population; and to evaluate the potential impacts to the biota in the vicinity of LLNL. Environmental monitoring is also a major component of compliance demonstration for permits and other regulatory requirements.

The Environmental Monitoring Plan (EMP) addresses the sample collection and analytical work supporting environmental monitoring to ensure the following:

- A consistent system for collecting, assessing, and documenting environmental data of known and documented quality.

- A validated and consistent approach for sampling and analysis of samples to ensure laboratory data meets program-specific needs and requirements within the framework of a performance-based approach for analytical laboratory work.

- An integrated sampling approach to avoid duplicative data collection.

LLNL prepares the EMP because it provides an organizational framework for ensuring that environmental monitoring work, which is integral to the implementation of LLNL's Environmental Management System, is conducted appropriately. Furthermore, the Environmental Monitoring Plan helps LLNL ensure compliance with DOE Order 231.1 Change 2, Environment, Safety and Health Reporting, which require the publication of an annual report that characterizes the site's environmental management performance. To summarize, the general regulatory drivers for this environmental monitoring plan are ISO 14001, DOE Order 458.1, and DOE Order 231.1.

The environmental monitoring addressed by this plan includes preoperational characterization and assessment, effluent and surveillance monitoring, and permit and 
regulatory compliance monitoring. Additional environmental monitoring is conducted at LLNL as part of compliance with the Comprehensive Environmental Response, Compensation, and Liability Act (CERCLA, also known as Superfund). LLNL coordinates its ground water surveillance monitoring program with the CERCLA monitoring program to gain sampling efficiencies. (See LLNL [1992] and LLNL [2008] for information about LLNL's CERCLA activities)

\subsection{Mission of the Laboratory}

LLNL is a premier research and development institution for science and technology applied to national security. It is responsible for ensuring that the nation's nuclear weapons remain safe, secure, and reliable. LLNL also applies its expertise to prevent the spread and use of weapons of mass destruction and to strengthen homeland security.

LLNL's national security mission requires special multidisciplinary capabilities that are also used to pursue programs in advanced defense technologies, energy, environment, biosciences, and basic science to meet important national needs. These activities enhance the competencies needed for our national security mission.

The Laboratory serves as a resource to the U.S. government and is a partner with industry and academia. Safe, secure, and efficient operations and scientific and technical excellence in our programs are necessary to sustain public trust in the Laboratory.

LLNL's policy is to perform work in a manner that protects the health and safety of employees and the public, preserves the quality of the environment, and prevents property damage. The environment, safety, and health (ES\&H) are to be priority considerations in the planning and execution of all work activities at the Laboratory (LLNL 2011). Furthermore, LLNL has an express environmental policy to comply with applicable ES\&H laws, regulations, and requirements (LLNL 2009).

\subsection{Environmental Functional Area}

All LLNL staff members have responsibilities that include environmental protection and environmental compliance. The level of responsibility is dependent upon the position held by the individual. Document 2.1, "General LLNL Worker ES\&H Responsibilities," in the LLNL Environment, Safety, and Health Manual lists these responsibilities for all levels of staff; however, the Laboratory has designated the Environmental Functional Area (EFA) as the lead organization with responsibility for helping the Laboratory to ensure that operations do not adversely affect the environment or public health. The primary mission of EFA is to support existing operations and related research and development activities at LLNL in the areas of environmental monitoring, and environmental regulatory compliance. EFA assists LLNL programs to develop environmentally sound practices in their everyday tasks through such activities as: 
- Conducting environmental evaluations and addressing requirements under the National Environmental Policy Act (NEPA) and related federal and state requirements.

- Identifying and developing methods to monitor, prevent, reduce, and clean up air emissions, wastewater discharges, and hazardous wastes.

- Obtaining the permits or exemptions for air, water, and hazardous waste activities.

- Ensuring environmental compliance through environmental monitoring, risk assessment, and analysis for Laboratory sites.

- Evaluating the impact of ongoing Laboratory operations on the surrounding environment by sample collection, analysis, data reduction, and other simulation modeling methods for water and air.

- Developing and implementing waste minimization and pollution abatement strategies.

EFA has developed an integrated, multidisciplinary approach to carry out its mission. The combined expertise in the scientific, engineering, technical, and management fields allows the organization to provide a comprehensive, balanced range of resources and disciplines to address environmental issues, identify best management practices, solve environmental problems, and prevent environmental damage. EFA experts provide quality assurance and environmental education, and help ensure regulatory compliance.

LLNL programs are also supported by Environmental Analysts on the two Environment Safety and Health (ES\&H) Teams. The Environmental Analysts on the ES\&H Teams evaluate operations, determine potential environmental impacts, and provide guidance to operating project staff in understanding and meeting their environmental obligations in the many environmental regulations and DOE orders for existing and proposed projects.

The EFA is divided into five groups:

- The Environmental Stewardship Planning and Monitoring (ESPM) group provides programmatic guidance on the regulatory requirements and potential impacts of operations, provides support for NEPA and California Environmental Quality Act (CEQA) reviews, provides National Historic Policy Act reviews, and conducts assessments of LLNL impacts on wildlife.

- The Environmental Support and Programmatic Outreach (ESPO) group helps Laboratory programs operate in an environmentally sound manner with respect to hazardous, radiological, medical and other waste issues and advises Laboratory personnel concerning interactions, inspections, and permits involving federal, state, and local environmental regulatory agencies. 
- The Institutional Environmental Systems (IES) group has the responsibility for Community Right-to-Know reporting and for providing the institutional database for Material Safety Data Sheets and chemical inventory tracking (in an institutional database and associated web interface called ChemTrack).

- The Pollution Prevention and Sustainability (P2S) group has the responsibility for providing guidance to the programs on pollution prevention and sustainability and for meeting DOE and other regulatory reporting requirements pertaining to $\mathrm{P} 2 \mathrm{~S}$.

- The Water, Air, Monitoring and Analysis (WAMA) group has the responsibility for the compliance, surveillance, and effluent monitoring programs described in this EMP, as well as for water and air permitting activities and all associated data management activities. WAMA personnel develop and apply monitoring techniques, source evaluations, and computer models to evaluate the effect of LLNL operations on human health and the environment at both the Livermore site and Site 300.

\subsection{Setting}

\subsubsection{Location}

LLNL consists of two main facilities (Figure 1-1) - the main laboratory site (Livermore site) located in Livermore, California, and the Experimental Test Facility (Site 300) located near Tracy, California. Each site is unique, requiring a different approach for environmental monitoring and protection.

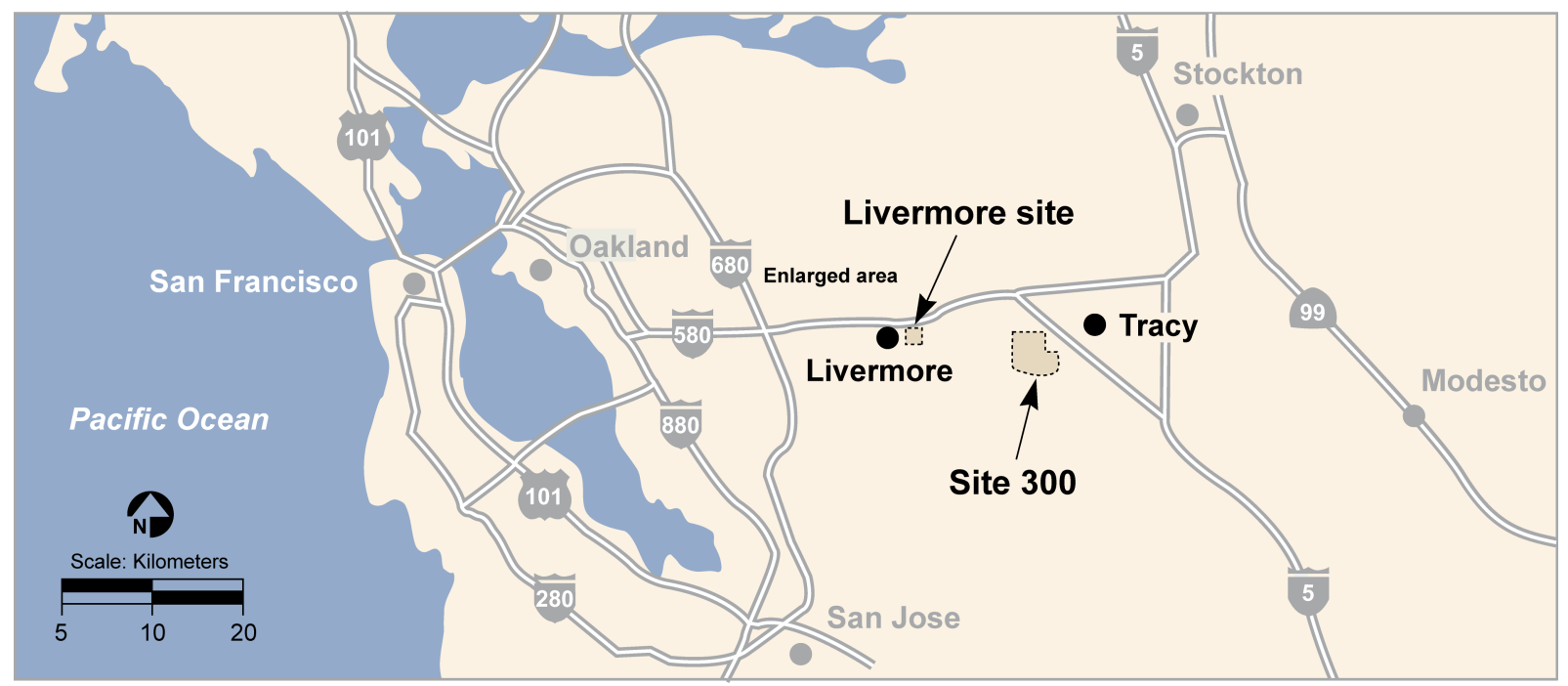

Figure 1-1. Location of LLNL Livermore site and Site 300. 


\subsubsection{Livermore Site}

LLNL was founded at the Livermore site in 1952 at the site of a former U.S. Navy air station. At that time, the location was relatively isolated, being approximately $1.6 \mathrm{~km}$ from the Livermore city limits. Over the years, Livermore evolved from a small town of fewer than 7,000 people to its present population of approximately 80,000. The area's economy diversified from primarily agricultural to include light industrial and business parks. Within the last few years, low-density, single-family residential developments have begun to fill formerly vacant fields, bringing residential areas to LLNL's western boundary. In 2011, the LLNL site was formally brought within Livermore city limits.

LLNL's Livermore site occupies an area of $3.28 \mathrm{~km}^{2}$. Onsite land uses include offices, laboratory buildings, support facilities (such as cafeterias, storage areas, maintenance yards, and a fire station), roadways, parking areas, buffer zones, and landscaping. The site also includes internal utility and communication networks. A 150-meter wide security buffer zone lies along the northern and western borders of the Livermore site.

The Livermore site is bordered on the east by Greenville Road. The property east of Greenville Road is agricultural with a few scattered rural residences and is used primarily for grazing. A Western Area Power Administration (WAPA) electrical substation is on the southeast corner of Greenville Road and Patterson Pass Road. The South Bay Aqueduct, a branch of the California Aqueduct, traverses the land east of the Livermore site in a north-south direction. The Patterson Reservoir and filtration plant for the South Bay Aqueduct are northeast of the Livermore site along Patterson Pass Road.

Patterson Pass Road runs along the northern boundary of the Livermore site. A light industrial park lies across Patterson Pass Road to the north. A Union Pacific Railroad line runs in an east-west direction along the northern boundary of the industrial park. Land uses farther north include vacant land, industrial, and Interstate 580 (I-580). Land northeast of the site is agricultural and used primarily for grazing. Wind turbines are installed on the hills of the Altamont Pass, northeast of the site.

Vasco Road borders the Livermore site to the west. A low-density, single-family residential subdivision begins at the southwest corner of Patterson Pass Road and Vasco Road, and extends south and west. A housing development of attached single-family residences is directly west of the site (north of East Avenue). Medium-density residential areas, mainly apartment complexes, exist on the west side of this development approximately 600 meters west of Vasco Road.

East Avenue borders the Livermore site to the south. Sandia National Laboratories, California (Sandia/California), which has land uses very similar to those at LLNL, is south of East Avenue. There is no public access to East Avenue between Vasco Road and 
Greenville Road. The primary land uses to the east of Sandia/California are rural residential and agricultural (mainly grazing). There is a small light-industrial park on the southwest corner of East Avenue and Vasco Road. Single-family housing has been built south of this industrial park, on both sides of South Vasco Road.

\subsubsection{Site 300}

Site 300, LLNL's Experimental Test Site, is located $20 \mathrm{~km}$ east of the Livermore site in San Joaquin and Alameda counties in the Altamont Hills of the Diablo Range. The site occupies an area of $30.3 \mathrm{~km}^{2}$, of which approximately $28 \mathrm{~km}^{2}$ is undeveloped land. Site 300 is primarily a component test facility for non-nuclear explosives and other nonnuclear weapons. The site has remote explosive testing facilities supported by a chemistry processing area, a weapons test area, maintenance facilities, and a General Services Area (GSA) at the site entrance. About $0.65 \mathrm{~km}^{2}$ at Site 300 has been set aside as the "Amsinckia grandiflora Reserve" to protect the natural habitat of this plant species.

The majority of the existing land uses surrounding Site 300 are agricultural, primarily for grazing cattle and sheep. Two small, privately operated research and testing facilities are located near Site 300. The property east of and adjacent to Site 300 is owned by Fireworks America. A facility operated by SRI International that conducts explosives tests is located approximately $1 \mathrm{~km}$ south of Site 300 .

Corral Hollow Road borders Site 300 on the south. The Carnegie State Vehicular Recreation Area is south of the western portion of Site 300, across Corral Hollow Road. It covers approximately 5000 acres and is operated by the California Department of Parks and Recreation, Off-Highway Motor Vehicle Recreation Division, for the exclusive use of off-highway vehicles. The nearest urban area is the city of Tracy, approximately $3 \mathrm{~km}$ northeast of Site 300. Rural residences are located along Corral Hollow Road, west of Site 300 and the Carnegie State Vehicular Recreation Area. Power-generating wind turbines occupy the land northwest of the site.

\subsection{Meteorology}

\subsubsection{Livermore Site}

Mild, rainy winters and warm, dry summers characterize the climate of the Livermore Valley. The mean annual temperature is $15^{\circ} \mathrm{C}\left(59^{\circ} \mathrm{F}\right)$. Temperatures range from $-7{ }^{\circ} \mathrm{C}$ $\left(19^{\circ} \mathrm{F}\right)$ during the coldest predawn winter mornings to $43^{\circ} \mathrm{C}\left(109^{\circ} \mathrm{F}\right)$ during the hottest summer afternoons.

Prevailing winds from the west and southwest occur about $50 \%$ of the time. These winds are especially prevalent in the summer, as the thermal draw caused by rising air in the warm Central Valley of California results in wind blowing from the cool ocean toward 
the warm valley, increasing in intensity as the valley heats up. Winds from the northeast become more frequent during the winter.

Precipitation also exhibits a strong seasonal pattern, with most of it occurring between October and April, but very little during the warmer months. Snow is uncommon in the Livermore Valley. The 30-year normal annual rainfall is $34.8 \mathrm{~cm}$ (13.68 in.).

\subsubsection{Site 300}

The climate at Site 300, while generally similar to that at the Livermore site, is modified by the higher elevation and more pronounced topographical relief, which significantly influences local wind and temperature patterns. The nighttime temperatures are typically higher (and diurnal temperature range smaller) at Site 300 compared to the Livermore site; stronger winds at a higher elevation prevent formation of strong radiational inversions near the ground. At Site 300, the prevailing winds blow more consistently from the west-southwest and reach greater speeds than at the Livermore site. The 30-year normal annual rainfall for Site 300 is $27.3 \mathrm{~cm}$ (10.76 in.).

\subsection{Topography}

\subsubsection{Livermore Site}

The Livermore site is located in the southeastern portion of the Livermore Valley, a topographic and structural depression oriented east-west within the Diablo Range of the California Coast Range Province. The Livermore Valley, the most prominent valley within the Diablo Range, is an east-west trending structural and topographic trough that is bounded on the west by Pleasanton Ridge and on the east by the Altamont Hills. The valley is approximately $25 \mathrm{~km}$ long and averages $11 \mathrm{~km}$ in width. The valley floor is covered by alluvial, lake, and swamp deposits consisting of gravels, sands, silts, and clays, with an average thickness of about $100 \mathrm{~m}$. The valley floor is at its highest elevation of $220 \mathrm{~m}$ above sea level along the eastern margin and gradually dips to $92 \mathrm{~m}$ at the southwest corner. The valley's major streams, Arroyo del Valle and Arroyo Mocho, drain the southern highlands and flow mostly during the rainy season.

\subsubsection{Site 300}

The topography of Site 300 is much more irregular than that of the Livermore site. It consists of a series of steep hills and ridges oriented along a generally northwestsoutheast trend and separated by intervening ravines. The Altamont Hills, where Site 300 is located, are part of the California Coast Range Province and separate the Livermore Valley to the west from the San Joaquin Valley to the east. The elevation ranges from approximately $150 \mathrm{~m}$ above sea level at the southeast corner of the site to approximately $540 \mathrm{~m}$ in the northwestern portion. 


\subsection{Hydrogeology}

\subsubsection{Livermore Site}

The hydrogeology and the movement of ground water near the Livermore site have been the subjects of several investigations (Stone and Ruggieri 1983; Carpenter et al. 1984; Webster-Scholten and Hall 1988; Thorpe et al. 1990). This section has been summarized from these reports and from data supplied by Alameda County Flood Control and Water Conservation District, Zone 7, which is the agency responsible for ground water management in the Livermore Valley basin (CRWQCB 1995).

The Livermore Formation (and overlying alluvial deposits) contains the aquifers of the Livermore Valley ground water basin and is an important water-bearing formation. Natural recharge occurs primarily along the fringes of the basin and through the arroyos during periods of winter flow. Artificial recharge, if needed to maintain ground water levels, is accomplished by releasing water from Lake Del Valle or from the South Bay Aqueduct into arroyo channels in the east. Ground water flow in the valley generally moves toward the central east-west axis of the valley and then westward through the central basin. Ground water flow in the basin is assumed to be primarily horizontal although a significant vertical component probably exists in fringe areas, under localized sources of recharge, and near heavily used extraction (production) wells.

Beneath the Livermore site, the depth to the water table varies from about 10 to $40 \mathrm{~m}$. At the eastern edge of the Livermore site, ground water gradients (change in vertical elevation per unit of horizontal distance) are relatively steep; but under most of the site and farther to the west, the contours flatten to a gradient of approximately 0.003 . Ground water flow under most of the site is southwesterly. This flow direction diverges from the generally westward regional flow and from flow patterns demonstrated for the site in the 1980s. This shift in flow direction is a consequence of ground water recovery and remediation in the southwest portion of the site and agricultural pumping. Aquifer tests on monitoring wells near the Livermore site indicate that the hydraulic conductivity of the permeable sediments ranges from 1 to $16 \mathrm{~m}$ per day (Isherwood et al. 1991). This, in combination with the observed water table gradients, yields an average ground water velocity estimate of $20 \mathrm{~m} / \mathrm{y}$ (Thorpe et al. 1990). The range in these values reflects the heterogeneity typical of the more permeable of the alluvial sediments that underlie the area.

\subsubsection{Site 300}

Site 300 is generally underlain by gently dipping sedimentary bedrock dissected by steep ravines. The bedrock consists primarily of interbedded sandstone, siltstone, and claystone. Most ground water occurs in the Neroly Formation upper and lower blue 
sandstone aquifers. Significant ground water is also locally present in permeable, quaternary alluvium valley fill. Much less ground water is present within perched aquifers in the unnamed Pliocene non-marine unit.

Perched aquifers contain unconfined water separated from an underlying main body of water by impermeable and permeable layers; normally, they are discontinuous and highly localized. Because water quality is generally poor and yields are low, these perched water-bearing zones do not meet criteria of the state of California for aquifers that are potential drinking water sources.

Fine-grained siltstone and claystone interbeds may confine the ground water and act as aquitards, or perching horizons. Ground water is present under confined conditions in parts of the deeper bedrock aquifers but is generally unconfined elsewhere.

Ground water flow in most aquifers follows the attitude of the bedrock. In the northwest part of Site 300, ground water in bedrock generally flows northeast except where it is locally influenced by the geometry of alluvium-filled ravines. In the southern half of Site 300 , ground water in bedrock flows roughly south-southeast, approximately coincident with the attitude of bedrock strata. The thick Neroly lower blue sandstone, stratigraphically near the base of the formation, generally contains confined water. Wells located in the western part of the General Services Area, near the southeast border of Site 300 , are completed in this aquifer and are used to supply drinking and process water.

Recharge occurs predominantly in locations where saturated alluvial valley fill is in contact with underlying permeable bedrock, or where permeable bedrock strata crop out because of structure or topography. Local recharge also occurs on hilltops, creating some perched water-bearing zones. Low rainfall, high evapotranspiration, steep topography, and intervening aquitards generally preclude direct vertical recharge of the bedrock aquifers.

\subsection{Environmental Monitoring Activities at LLNL}

The current LLNL environmental monitoring program has two major components:

- Monitoring effluents such as stack emissions, wastewater, and storm and sanitary sewer discharges.

- Conducting surveillance monitoring of environmental media that could be impacted by LLNL, including air, surface water, ground water, rainwater, surface runoff, vegetation and foodstuffs, soils and sediments, and ambient radiation. 
The existing monitoring program involves a staff of Laboratory scientists and technologists, who support compliance and surveillance monitoring efforts. The environmental monitoring program collects more than 6400 samples from a variety of environmental media and resulting in more than 42,000 analyses each year. All the environmental media are monitored for radioactivity; in addition, significant effort is undertaken to evaluate the nonradiological constituents of sewer effluent and surface and ground waters.

\subsection{Document Organization}

The LLNL Environmental Monitoring Plan is structured to provide the environmental professional with an understanding of how LLNL fulfills its monitoring obligations. The EMP describes LLNL's environmental monitoring networks; sampling methods, locations, and frequencies; and measured parameters as well as methods and procedures for data collection, analysis, maintenance, reporting, and archiving. It addresses quality assurance for monitoring data and the specifics of sampling and data collection.

Each specific environmental medium has a chapter in this EMP that contains a discussion of the rationale and design criteria for the medium, the extent and frequency of monitoring and measurements, data quality requirements, procedures for laboratory analysis, data quality assurance, program implementation procedures, action levels, preparation and disposition of reports, and future plans for that medium. All future plans described are contingent on regulatory changes, allocation of funding, and the approval of LLNL management.

The monitoring, quality assurance, and data and records management procedures referenced in this EMP are available upon request.

\subsection{Laboratory Analysis}

All laboratory analyses are conducted by either an LLNL analytical laboratory or an offsite analytical laboratory under contract to LLNL. All analytical laboratories used must be accredited by the California Department of Public Health Environmental Laboratory Accreditation Program (ELAP). Conditions and methodology for analyses performed by contract analytical laboratories are specified in an approved Statement of Work (SOW) that is prepared and managed by the LLNL Procurement Department.

\subsection{Sample and Data Management}

Sample and data management requirements are defined in EMP-QA-DM, Sample and Data Management. Sampling plans are documented and revised quarterly and as needed by the EFA Data Management Team (DMT). Field tracking forms (FTFs) are forms used to document sample collection information in the field. A unique FTF containing 
sample identifiers, sampling locations, requested analyses, QC sample identifiers, special instructions, and field notes is prepared for each environmental medium. FTFs are prepared and revised as described in EMP-QA-DM, Sample and Data Management. The responsible environmental analyst must approve all changes to the sampling plan and associated FTFs.

Samples and data are identified and controlled using chain-of-custody (COC) forms and protocol described in EMP-QA-DM, Sample and Data Management. Samples that are submitted to analytical laboratories for analysis are accompanied by COC forms to track custody of the samples as they move from the sampler to the analytical lab and the data as it moves from the lab to the analytical laboratory and finally to the DMT for retention. Collection and analysis of method blanks, matrix spikes, matrix spike duplicate, and laboratory control samples are described in the Statement of Work for analytical laboratories.

Processes to ensure that environmental monitoring samples are handled, stored, and shipped to prevent damage, loss, or deterioration are also described in EMP-QA-DM, Sample and Data Management. Samples are shipped in sealed coolers using either a laboratory courier or a common carrier such as Federal Express.

\subsection{Quality Assurance}

\subsubsection{Quality Assurance Program}

The goal of the Quality Assurance (QA) program is to ensure that adequate and effective QA and ES\&H controls are developed and implemented. ES\&H Manual, Document 41.1, "LLNL Quality Assurance Program," defines the QA program requirements that must be integrated into EFA activities. The QA program is designed to emphasize administrative and oversight functions at the directorate level and operational functions at the group level. The QA program also incorporates applicable elements of the LLNL ISMS to address the needs of EFA's activities and personnel.

\subsubsection{Quality Assurance Documents}

All environmental monitoring and sampling is conducted by LLNL technical staff according to documented standard operating procedures (SOPs), SOP supplements, and instructions. Samples are tracked and submitted for analyses according to SOP EMPQA-DM, Sample and Data Management. Supplements to EMP-QA-DM specify procedures used for completing field tracking forms and chain-of-custody forms. Hazards and controls, including environmental aspects, for each environmental monitoring activity are described in an Integration Work Sheet (IWS). 


\subsubsection{Nonconformance Reporting and Tracking}

Nonconformances are managed in a graded manner, depending on their type and severity. When samples are planned but not collected, the sampling technologist notifies the responsible environmental analyst in writing.

EFA uses the deficiency tracking system described in PRO-0042-00, "Issues and Corrective Action Management" in the $L L N L$ ES\&H Manual, and the occurrence reporting process described in Document 4.4, "Identification, Reporting, and Tracking of Noncompliances with Nuclear Safety Requirements," to identify and track deficiencies to resolution when appropriate.

\subsubsection{Audits and Assessments}

\subsubsection{Management Assessments}

EFA uses management assessments (e.g., walkabouts and prestart reviews) to ensure that work activities are conducted in a safe manner and that quality is achieved.

EFA line managers perform walkabouts of activities for which they are responsible during each year. The majority of walkabouts are related to field and laboratory activities. Identified issues that require follow-up must be agreed upon by personnel involved in the walkabout and tracked to closure. Walkabouts are intended to evaluate the effectiveness of processes and controls (e.g., procedures), observe work conditions and the work environment, identify workplace issues that could potentially have a negative impact on a deliverable, and obtain feedback from activity personnel regarding any ES\&H concerns or potential improvements to an activity or its product.

\subsubsection{Independent Assessments}

External organizations frequently perform independent external assessments to evaluate environmental monitoring activities. These organizations include the LLNL Contractor Assurance Office (CAS), the LLNL Office of Quality, the Environment, Safety \& Health Directorate Assurance Office, and regulatory agencies.

Independent assessments generally result in a formal assessment report and any deficiencies requiring corrective action are entered into the LLNL Issues Tracking System (ITS) application and tracked to closure.

\subsection{Integrated Safety Management}

LLNL implements an ISMS designed to ensure the systematic integration of ES\&H considerations into management and work practices so that missions are accomplished safely. "Safety," used in this context, is synonymous with environment, safety, and health to encompass protection of the public, workers, and the environment, including 
pollution prevention and waste minimization. LLNL regards protection of the environment as an essential component in its overall safety management system. LLNL's ISMS is detailed in the Integrated Safety Management System Description (LLNL 2009a). EFA conducts pre-job briefings prior to work activities to identify and discuss ES\&H issues for the activities.

\subsection{Emergency Response}

Emergency response activities at LLNL are performed according to Document 22.1, "Emergency Preparedness and Response," in the LLNL ES\&H Manual. The objectives of emergency response are to respond to and mitigate potential consequence of onsite emergencies and significant nearby emergencies that could threaten Laboratory workers, the public, national security, or the environment. The Emergency Response Plan further specifies methods to be employed for emergency response including the organizational structure, response procedures, and functional roles of responding personnel.

The Laboratory organization responsible for the initial and ongoing response to an actual operational emergency, and for the mitigation of it, is the Emergency Management Team (EMT). During an emergency, the EMT may be supported by several Department Operation Centers (DOCs), including one within the EFA.

In the event of a large emergency requiring its involvement, EFA will support emergency response efforts by sending a senior member of EFA management to serve as a member of the EMT. For smaller incidents, an ES\&H Environmental Duty Officer (EDO), on call 24 hours a day to support environmental emergency response needs, may report directly to the scene of the emergency.

EFA provides necessary expertise and equipment to ensure that releases of radiological or hazardous materials are assessed for possible environmental impacts. EFA is responsible for identification and implementation of environmental mitigation and corrective actions, environmental monitoring and modeling, notification of regulatory agencies, and preparation of required reports.

\subsection{References}

Carpenter, D. W., J. J. Sweeney, P. W. Kasameyer, N. R. Burkhard, K. G. Knauss, and R. J. Shelmon (1984), Geology of the Lawrence Livermore National Laboratory Site and Adjacent Areas, Lawrence Livermore National Laboratory, Livermore, CA (UCRL-53316). 
CRWQCB (1995), Water Quality Control Plan, San Francisco Bay Basin, (Region 2) California Regional Water Quality Control Board, San Francisco Bay Region, State of California, Oakland, CA. Available at:

http://www.waterboards.ca.gov/sanfranciscobay/water_issues/programs/basin_plan /docs/basin_plan07.pdf

Isherwood, W. F., C. H. Hall, M. D. Dresen, and A. J. Boegel (1991), CERCLA Feasibility Study Report for the LLNL Livermore Site, Lawrence Livermore National Laboratory, Livermore, CA (UCRL-AR-104040).

LLNL (1992), Record of Decision for the Lawrence Livermore National LaboratoryLivermore Site, Lawrence Livermore National Laboratory, Livermore, CA (UCRL-AR-109105).

LLNL (2008), Record of Decision for the Lawrence Livermore National Laboratory Site 300, Lawrence Livermore National Laboratory, Livermore, CA (UCRL-AR236665).

LLNL (2009), Lawrence Livermore National Laboratory Environmental Policy. Available at: https://ems.llnl.gov/policy.html

LLNL (2011), Integrated Safety Management System Program Description, Lawrence Livermore National Laboratory, Livermore, CA (DES 0541 07). Available at https://portal.llnl.gov/portal/page/portal/MYLLNL/ITEMS/DOCUMENTS/BOOK SHELF/ISMS_Description.pdf

Stone, R. and M. R. Ruggieri (1983), Ground-Water Quality and Movement at Lawrence Livermore National Laboratory, Lawrence Livermore National Laboratory, Livermore, CA (UCRL-53474). Available at: https://e-reportsext.llnl.gov/pdf/195585.pdf

Thorpe, R. K., W. F. Isherwood, M. D. Dresen, and C. P. Webster-Scholten (1990), CERCLA Remedial Investigation Report for the LLNL Livermore Site, Volumes 15, Lawrence Livermore National Laboratory, Livermore, CA (UCAR-10299).

Webster-Scholten, C. P. and C. H. Hall (1988), Work Plan, Lawrence Livermore National Laboratory, Livermore Site: CERCLA/SARA Remedial Investigations/ Feasibility Studies, Lawrence Livermore National Laboratory, Livermore, CA (UCAR-10225). 


\section{Meteorology}

Tony Wegrecki $\bullet$ Nicholas A. Bertoldo

\subsection{Introduction}

The Lawrence Livermore National Laboratory (LLNL) uses meteorological data to demonstrate compliance with federal, state, and local laws, regulations, and orders. U.S. Department of Energy (DOE) directives require LLNL to collect sufficient meteorological data to assess the potential or actual impact from toxicological or radiological material releases on the environment and the public. Onsite meteorological monitoring is required to accurately assess the transport and diffusion of airborne materials and the impacts of such planned and unplanned airborne releases on public health.

Meteorological monitoring is part of a comprehensive and continuous environmental program at LLNL (see Chapter 1).

\subsection{Rationale and Design Criteria}

\subsubsection{Regulatory Drivers}

The regulatory drivers for meteorological monitoring are the applicable portions of DOE Orders 458.1 (Change 2), and 151.1C. DOE Order 458.1 (Change 2) establishes requirements to protect the public and environment from undue risk due to radiation from DOE facilities. It requires facilities to perform dose evaluations to demonstrate compliance with the Public Dose Limit specified in the order and to assess collective dose. The evaluations and assessments must include meteorological monitoring sufficient to characterize atmospheric dispersion and to model the potential dose to the public. Furthermore, DOE Order 458.1 requires record keeping of the meteorological data used in assessing dose. DOE Order 151.1C provides the framework for maintenance and development of all emergency planning, preparedness, readiness assurance, and response and recovery for the DOE Emergency Management System. The requirements for meteorological monitoring are discussed in DOE Order 151.1C. Elements of DOE Order 458.1 and the associated regulatory guide, EH-0173T (DOE 2004) require that each DOE site have a meteorological program that should provide the data used in atmospheric transport and diffusion calculations appropriate to the site's activities, topography, and distance to critical receptors. Furthermore DOE Order 
151.1C indicates that real-time meteorological data must be available to the National Atmospheric Release Advisory Center (NARAC) for consequence assessment of actual or potential onsite and offsite emergencies.

Meteorological monitoring data are also required to demonstrate compliance with the National Emissions Standards for Hazardous Air Pollutants (NESHAPs), 40 CFR 61 Subpart H. Subpart H requires DOE sites to have onsite programs that can provide the data (including meteorological data) used to model the required radiological dose calculations.

Off-site meteorological data, such as the data collected at National Weather Service (NWS) stations, may also be used if the meteorological conditions at the NWS station are similar to on-site conditions. However, meteorological conditions at the National Oceanic and Atmospheric Administration (NOAA) observing station closest to the Livermore site (i.e., station KLVK at the Livermore Airport [http://weather.noaa.gov/weather/current/KLVK.html]) do not always accurately represent dispersion conditions at the Livermore site and especially at Site 300. Moreover, the Livermore airport typically reports data only once an hour and occasionally reports are missing. For these reasons LLNL employs meteorological monitoring systems at both the Livermore site and Site 300.

\subsubsection{Monitoring Objectives}

The primary purpose of LLNL's meteorological monitoring is to assess the potential consequences of projected airborne releases of contaminants from new or modified facilities as well as the consequences of actual accidental releases. In doing so, LLNL can demonstrate compliance with regulatory requirements, provide onsite data for the most accurate atmospheric transport and dispersion modeling, and ensure protection of the public and the environment. In addition, the monitoring provides supports facility design, worker safety, and general LLNL operations.

DOE Guides 420.1-1 and 420.1-2 describe the use of meteorological data to aid in identifying conditions that may influence the design and operation of a facility and in mitigating natural phenomena hazards, such as strong winds, hurricanes, tornados, hail, lightning, and snow. Temperature and humidity data can be used to plan efficient air conditioning and space heating of proposed facilities.

Various projects that require meteorological monitoring should not be expected to recreate the monitoring systems currently in place at LLNL. Therefore, it is good business practice for LLNL to centralize ambient meteorological monitoring and make the data available to all. Several DOE orders and guides suggest some of the possible 
uses for meteorological data. For example, DOE Order 151.1C IV.3.b.(5).(b).3, "Consequence Assessment," requires that

All DOE/NNSA facilities/sites that have access to NARAC or procedures in place to activate or request NARAC capabilities must ensure that facility/site meteorological data and information on source terms for actual or potential releases of hazardous materials to the atmosphere are available or can be made available to NARAC in a timely manner to facilitate near real-time computation.

And 151.1C IV.3.b.(6).(d), "Protective Actions," states that

Protective actions must be predetermined for onsite personnel and the public and must include - ... Actions that may be taken to increase the effectiveness of protective actions [i.e., heating, ventilation, and air conditioning (HVAC) shutdown during sheltering];

Presently LLNL is converting Livermore site facility HVAC control units to use the centralized ambient 10-meter temperature and relative humidity data from the LLNL meteorological tower in an effort to reduce the annual energy budget as part of the Energy Saving Performance Contract for LLNL (see DOE Order 430.2B and https://www.eere-pmc.energy.gov/espccoe/About_The_ESPC.aspx). This conservation effort will also permit the use of this same control system to augment the facilities ability to close intake air in the event of a shelter-in-place emergency at those facilities with the new control system.

Examples of other data used in laboratory operations include wind speed and wind direction, temperature, and humidity to support fire-fighting operations; wind speed to curtail operations (the use of cranes during construction activities, etc.) that are affected by wind; calculation of predominant wind directions to strategically position air samplers downwind of potential releases; daily and seasonal temperatures to estimate the electrical load of individual buildings and the site as a whole; discomfort indexes based on measured temperature and humidity to manage or limit physical work outside during the summer season; relative humidity to assist in determining the amount of evaporation from a chemical pool; rainfall to support hydrological monitoring and studies, environmental sampling, and in atmospheric dispersion models to estimate washout from toxic plumes; and atmospheric pressure as an input for experiments and instrumentation. LLNL's meteorological database includes expected annual ranges and distributions of wind direction and wind speed, temperature, humidity, solar and infrared radiation, stability, rainfall, and other variables. 


\subsubsection{Sources and Analytes}

\subsubsection{General Pattern of Wind}

The wind at both the Livermore site and Site 300 is strongly influenced by the sea breeze (Gouveia and Chapman 1989). The wind comes from the southwest and west quadrants more than 50 percent of the time. This surface flow pattern can be enhanced or weakened by large-scale, upper-air circulation. The meteorology at Site 300, while generally similar to the Livermore site, is modified by the higher elevation, the greater distance from the ocean, and the greater topographical relief. At the higher Site 300, winds are stronger with less directional variation; winds blow from west-southwest through west and northwest through north-northwest for nearly $45 \%$ and $25 \%$ of the time, respectively.

During the summer, differential heating between the ocean and land produces afternoon winds that generally are stronger than morning and nighttime winds at both sites. A strong, upper-air, high-pressure circulation frequently occurs, suppressing convection and formation of clouds. The result is warm, dry weather during the summers with a persistent diurnal cycle of winds.

Because differential heating is less in winter than in summer, the sea breeze in winter is less pronounced. The winters commonly feature long periods of weak winds separated by short episodes of strong winds that are associated with winter storms. The winds are generally from the south to southwest during storms and from the northwest to north after storms pass. During the periods of weak, synoptic-scale winds, cold air drainage may occur during the night. The cold air that reaches the Livermore site is drained from the slightly higher elevation toward the southeast.

\subsubsection{Measured Variables}

At both Livermore site and Site 300, LLNL operates a 3-level 52-meter meteorological tower with extensive sensor packages positioned at the 10-, 23-, and 52-m levels. Additional data is collected at or near ground level. Dataloggers continuously measure parameters at all five levels on each tower; the data are recorded at 15-minute intervals and archived to the LLNL Metdat database. The data is available from the database to the public via the world wide web. As the meteorological audience expands, LLNL periodically revises the data format produced for public dissemination.

Wind direction, wind speed, and vertical velocity are measured at the 10-, 23- and 52-m levels. Temperature is measured at the 2-, 10-, 23- and 52-m levels. Relative humidity is measured at the 2- and 10-m levels. Additional measurements include barometric pressure (1-m level), rainfall (30 $\mathrm{cm}$ above ground level), incoming and reflected solar 
radiation, and incoming and reflected infrared radiation (2-m level), soil temperature ( $4 \mathrm{~cm}$ below ground level), soil moisture $(2.5 \mathrm{~cm}$ below ground level), and soil heat flux ( $8 \mathrm{~cm}$ below ground level).

All meteorological instruments must be capable of continuous operation in the expected range of atmospheric conditions at the Livermore site and Site 300. Because of the relatively mild weather conditions in the Livermore area, most meteorological instruments that are designed for routine measurement meet this requirement. Sensors installed at Site 300, especially anemometers, must be checked frequently because of more frequent strong winds at the site.

\subsubsection{On-site Dispersion Modeling}

LLNL uses U.S. Environmental Protection Agency (EPA)-approved dispersion models for compliance with National Emissions Standards for hazardous Air Pollutants (NESHAPs) Subpart H. The meteorological input to the regulatory model CAP88-PC, developed by EPA's Office of Radiation Programs (Parks 1992), includes jointfrequency tables of wind direction, wind speed, and stability, average wind speed for each combination of wind direction and stability class, mixing layer depth, average annual air temperature, and annual rainfall. LLNL uses an Excel workbook to transform a year of data from the archive into the tables that are used as meteorological input to the CAP88-PC code. An average mixing depth is estimated for both the Livermore site and Site 300 .

The real-time availability of the meteorological data is critical in estimating the transport and dispersion of toxic material released into the atmosphere. In the case of accidental air releases, the LLNL Emergency Operations Center (EOC), the Worker Safety and Health Functional Area (WSHFA), Department Operations Center (DOC), and the Environmental Functional Area (EFA) DOC are equipped to apply simple straight-line Gaussian models such as HotSpot (Homann 1994) or EPICode (Homann 1988) for releases of radionuclides or toxic chemicals, respectively. For more sophisticated modeling, the NARAC dispersion models (ARAC; Sullivan et al. 1993) can be executed in order to account for the varying terrain, time- and space-varying meteorological data, and more detailed plots. The Livermore site and Site 300 towers are incorporated automatically in the NARAC models along with the nearby Sandia tower and other regional observations.

\subsubsection{Collection Methods}

Meteorological instruments in use at LLNL are specified in procedure EMP-M-MCA, Meteorological System Maintenance and Sensor Calibration. The horizontal wind 
sensors currently used are cup-and-vane style, the vertical wind sensors are propeller anemometers, the temperature sensors are precision thermistors, the relative humidity instruments use variable capacitance thin film technology, the solar and infrared radiometers are thermopile detectors, and the rain gauges are tipping buckets. A sonic anemometer, which has no moving parts, measures three dimensional wind velocities and calculates temperature at the $10-\mathrm{m}$ level. The temperature sensors are housed in fan-aspirated radiation shields. These shields are adequate for measuring absolute temperature and vertical temperature differences, provided a sufficiently accurate sensor is used. Wind measurements are made at the $10-\mathrm{m}$ level and additional measurements are made at the 23-m and 52-m levels to evaluate releases from stacks. Humidity variables such as dew point temperature, absolute humidity, and specific humidity are calculated using relative humidity and simultaneous temperature measurements.

Measurements of incoming solar radiation, reflected solar radiation, incoming infrared radiation, and reflected infrared radiation are used to estimate net radiation. Net radiation is important in estimating stability and turbulence in the lower atmosphere. All radiation sensors are in locations free of any obstruction to the measurement and away from light-colored walls or artificial sources of radiation.

The rain gauges are mounted on stable platforms and are adjusted so that their openings are horizontal. They are $30 \mathrm{~cm}$ above the ground to prevent surface water splash into the gauges and are shielded from the wind.

Barometers are deployed at both sites at approximately $1 \mathrm{~m}$ above ground level. The inlet port of the barometer is protected from wind effects. The barometer measures actual pressure to allow the most accurate calibration. Actual pressure is preferred to allow LLNL personnel to directly use pressure data without conversion. A pressure reading reduced to sea level (RSL) is also estimated in the datalogger to allow comparison with regional RSL reports.

Other instruments include vertical propeller anemometers at the 10-m, 23-m, and 52-m levels to measure vertical wind speeds and estimate vertical wind fluctuations (turbulence); a sonic anemometer (at the 10-m level) that can provide more accurate estimates of wind speeds and wind fluctuations at low wind speeds than the other wind sensors; a reflectometer that estimates soil moisture $(2.5 \mathrm{~cm}$ below ground level); and a heat flux plate that estimates vertical heat transfer in the soil $(8 \mathrm{~cm}$ below ground level).

Although lightning storms are infrequent at both sites, the meteorological tower and associated systems at both sites are protected from lightning strikes with grounding 
spikes. Other phenomena that could deteriorate performance, such as icing and sea spray, are not problems at either the Livermore site or Site 300.

Based on guidance in meteorological data collection, processing, and archiving (Crutcher 1984; EPA 1990), LLNL's meteorological system provides 15-minute averages of all measured quantities to dispersion models used in emergency response capability, environmental regulations, and safety analysis.

Meteorological data are available in real-time on the LLNL Weather Pages web site. Real-time meteorological data is collected and can also be viewed on the personal computers of the Water, Air, Monitoring and Analysis (WAMA) group. A Laboratory meteorologist or environmental analyst reviews a subset of the data regularly to ensure that the data is current and being appropriately collected at 15 -minute intervals. The data is recorded by a Campbell Scientific data logger in Pacific Standard Time (PST) and stored by Julian date. The 15-minute average data transmitted to a primary metdat PC computer (metdat 1-pc) and a backup metdat PC computer (metdat-pc2) where the data are temporarily stored in 24-hour, 7-day and annual ascii files. The 15-minute data are also uploaded to the Real Time Monitoring Network (RTMN) server and the Environmental Functional Area server (EFA01) where the Metdat databases reside. Finally, the calendar year annual ascii files are archived on a server.

The 15-minute averages are combined into hourly averages, following guidelines in Section 6 of Meteorological Monitoring Guidance (EPA 2000). The hourly averages are used to summarize local climatology data and provide hourly frequency of occurrence tables of dispersion parameters or actual hourly values input to dose models. One-hour averages of all measured quantities are generally considered adequate to assess the consequences of potential releases and to demonstrate compliance with regulatory requirements.

Perl and HTML scripts developed by LLNL make the data available to end users on the World Wide Web at http://www-metdat.llnl.gov/. Data from towers at the Livermore site, Site 300, and Sandia/California are continuously available via the Weather Pages web site (http://www-metdat.llnl.gov/) at the EOC and DOCs for input to local and the LLNL's NARAC transport and dispersion models.

\subsection{Extent and Frequency of Monitoring and Measurement}

\subsubsection{Locations of Monitoring Sites}

Important considerations in choosing a meteorological monitoring site include siting and exposure of meteorological instruments and towers (EPA 2000), local conditions, 
and obstructions. Meteorological monitoring sites should be located in areas that have atmospheric conditions similar to those into which any material potentially would be released. The monitoring location should be away from the influence of man-made and natural obstructions, such as buildings and trees. The onsite meteorological towers at the Livermore site and at Site 300 have been located with these considerations in mind. The locations of the Livermore site and Site 300 meteorological towers are shown in Figures 2-1 and 2-2, respectively.

To minimize the tower's influence on wind measurements, wind and temperature instruments have been mounted on booms extending more than two tower widths from the side of the meteorological tower. They are mounted on the west side of the tower, facing the prevailing wind.

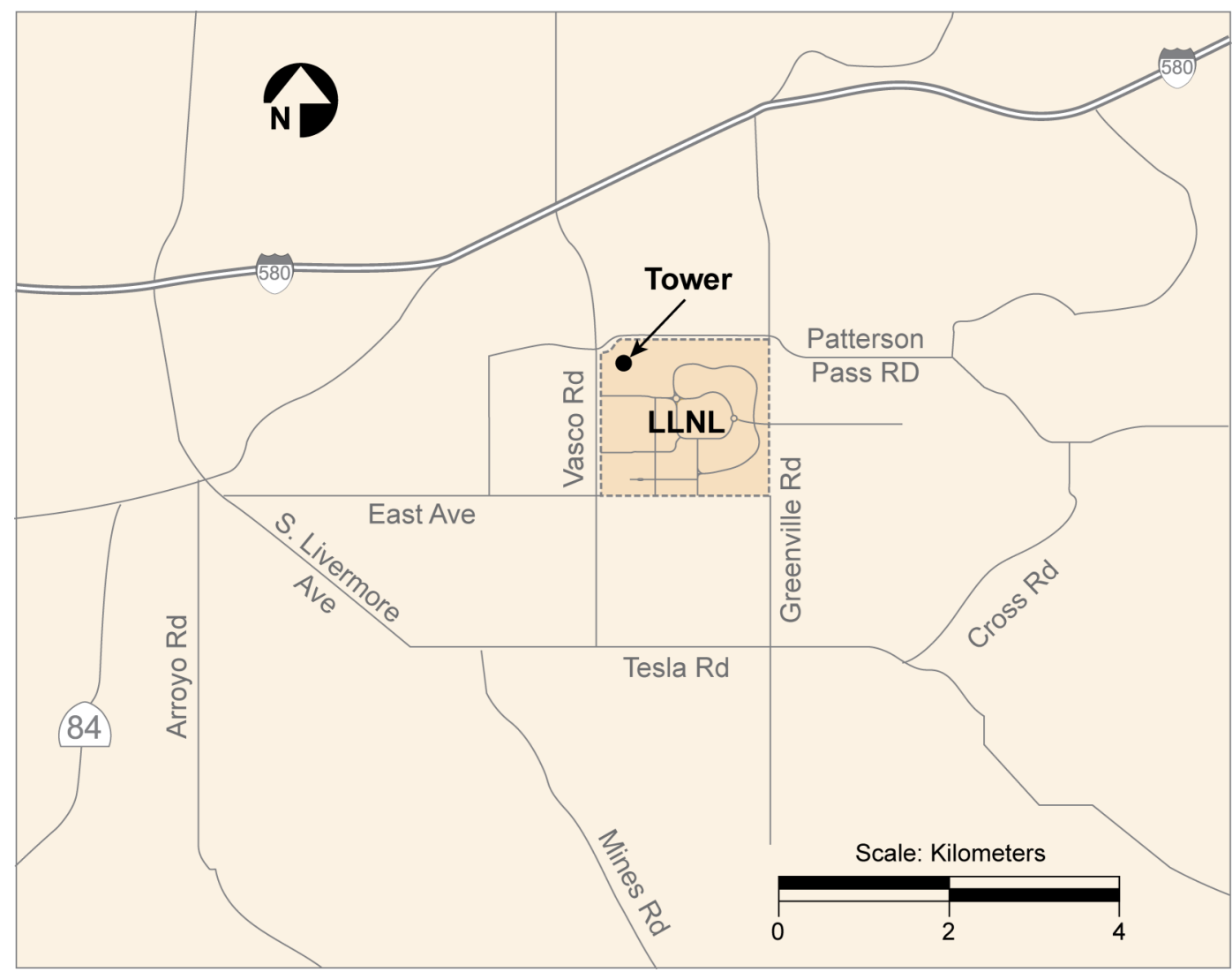

Figure 2-1. Location of the Livermore site meteorological tower.

\subsubsection{Frequency of Sampling}

The data loggers at the meteorological towers sample all instrumentation at the shortest, practical time interval, 1 second. This rate results in a 15-minute sample size of 900 , 
which is large enough to estimate means to within at least $\pm 5 \%$. The sampling rate does not apply to rainfall that is measured by total number of tipping events in the gauges.

The time period represented by the averages should not be less than 10 minutes (EPA 2000); the LLNL data loggers collect 15-minute averages of all meteorological parameters as recommended by DOE (2004). This period is long enough to give good estimates of both mean and turbulence quantities during fairly steady conditions, yet it is short enough to provide adequate frequency during periods of changing conditions for emergency response dispersion modeling. The time associated with each 15-minute average is the ending time in PST. The loggers' averaged values are saved for automatic retrieval, which is conducted within minutes after the sampling period.

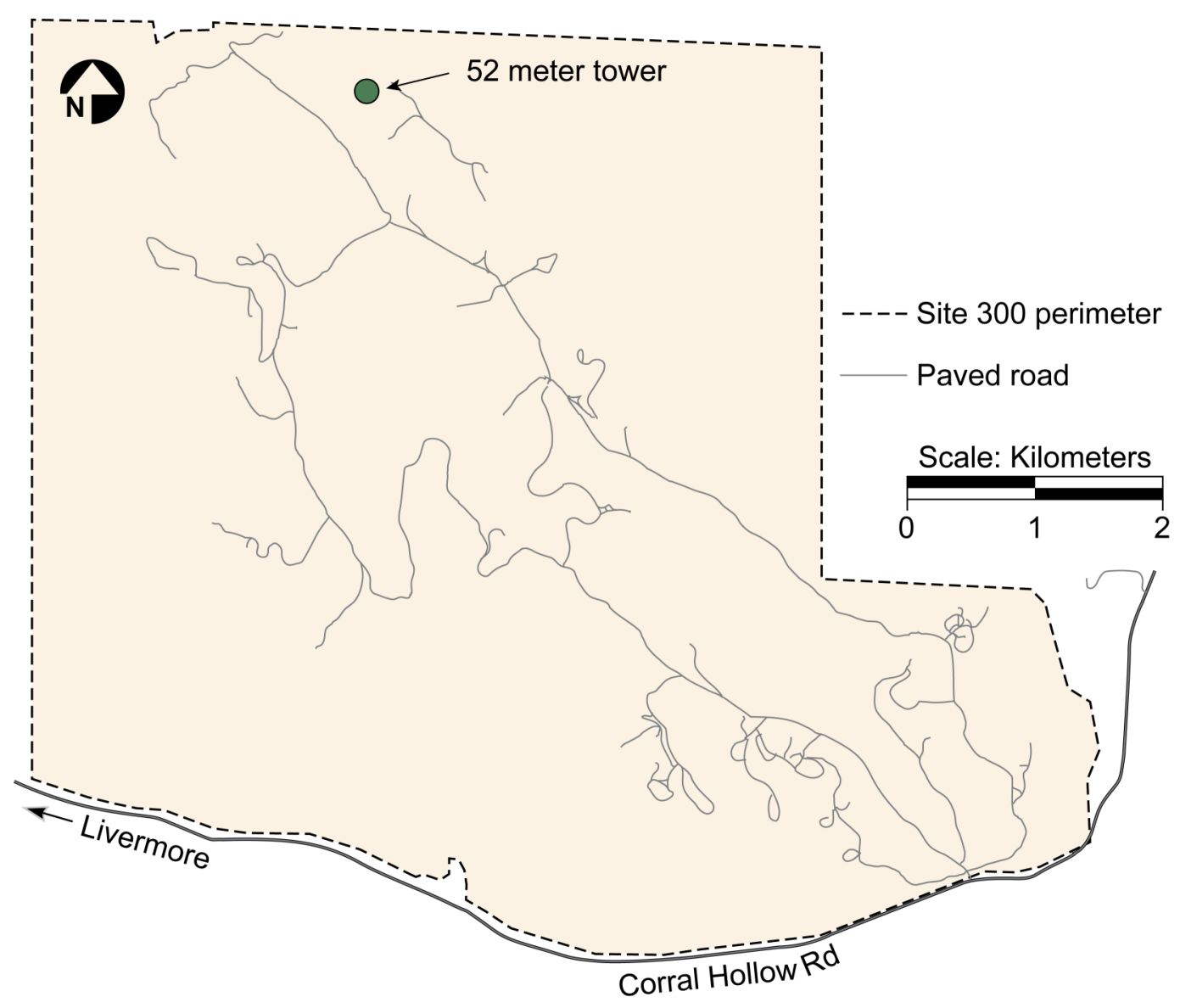

Figure 2-2. Location of the Site $\mathbf{3 0 0}$ meteorological tower. 


\subsection{Data Analysis Discussion}

\subsubsection{Computed Parameters}

Several useful parameters can be computed from the meteorological data, including stability, diffusion coefficients, and boundary layer parameters. Atmospheric stability is important in order to characterize the horizontal and vertical spread of the plume that in turn determines plume concentrations or exposure. LLNL uses the solar radiation-delta T (SRDT) method recommended by the EPA (2000) to estimate stability at both the Livermore site and Site 300 towers. Daytime stability is estimated based on incoming solar radiation (measured by a pyranometer) and wind speed at the 10-m level.

Nighttime stability is estimated from 10-m level wind speed and the difference in temperature between the 2- and 10-m levels $(\Delta \mathrm{T})$.

Other derived parameters from measurements include $\sigma_{\theta}$ and $\sigma_{\varphi}$, the standard deviations of horizontal and vertical wind fluctuations. These turbulence coefficients indicate the amount of horizontal and vertical turbulence and are directly related to the expected downwind plume spreading. The turbulence coefficients can be used to estimate the dispersion coefficients ( $\sigma_{\mathrm{y}}$ and $\sigma_{\mathrm{z}}$ ) used to quantify the spread of plumes in Gaussian and trajectory models. Alternatively, the dispersion coefficients can be estimated from the atmospheric stability class and from the time that has elapsed since a release. Gifford (1976) and Hanna et al. (1977) discuss various methods for determining dispersion coefficients and Draxler (1976) discusses the direct use of measured $\sigma_{\theta}$ and $\sigma_{\phi}$ to more accurately estimate $\sigma_{y}$ and $\sigma_{z}$.

Calculating boundary-layer parameters, such as sensible and latent heat flux, requires accurate temperature and wind speed measurements taken at multiple levels. These parameters are related to atmospheric stability, temperature tendency, soil moisture flux, and mixing depth among others. The sonic anemometer and relative humidity sensor are used to estimate sensible and latent heat fluxes. In addition, a ground heat flux plate and soil moisture sensor just under the soil surface output data to estimate ground heat flux.

Other hygrometric parameters, such as dew point temperature and absolute humidity, are calculated from meteorological data based on air temperature and relative humidity. These parameters are useful when planning efficient air conditioning and space heating of proposed facilities, monitoring heat stress on workers, and as input to atmospheric dispersion models. 


\subsubsection{Wind-Rose Diagram}

The wind-rose diagram displays the frequency of winds coming from 16 compass directions and also retains information on the frequency of wind speed in each sector. Often at low winds, especially at night, wind direction becomes highly variable. At wind speeds lower than the starting threshold of the wind vane, the wind direction value is meaningless. At that time, the wind is considered to be calm, and the wind direction is undefined. Wind speeds below the $0.22 \mathrm{~m} / \mathrm{s}(0.5 \mathrm{mph})$ starting threshold of wind vanes and anemometers occur during nighttime periods at the Livermore site but they rarely occur at the windier Site 300. Even when light winds exceed the instrument-starting threshold, wind directions detected at speeds below $0.5 \mathrm{~m} / \mathrm{s}(\sim 1 \mathrm{mph})$ or so are associated with large spatial and temporal changes in wind direction, thereby limiting their significance in transport and dispersion.

\subsection{Data Quality Assurance}

LLNL maintains a quality assurance (QA) program for its meteorological stations that meets the performance requirements set by DOE and EPA. Regulatory drivers for quality assurance of LLNL's monitoring programs come from DOE Order 414.1D. The primary guidance for quality assurance of LLNL's meteorological monitoring program is contained in the comprehensive EPA document prepared by Thomas Lockhart (EPA 1990). LLNL's meteorological monitoring also reflects the guidance for assessing the validity of meteorological data and the accuracy of meteorological measurement systems contained in Volume IV of EPA's Quality Assurance Handbook for Air Pollution Measurements (EPA 1990).

Regular and frequent routine operational checks of the monitoring system are performed to ensure high data-retrieval rates. These include visual inspections of the instruments for signs of damage or wear, inspections of the recording devices to ensure correct operation and reasonableness of data, and periodic preventive maintenance measures. The latter includes periodic checks of wind speed and direction bearing assemblies, cleaning of aspirated shield screen in temperature systems, clearing the precipitation-gauge funnel of any obstructing debris, and frequent cleaning of the optical surface of the radiometers.

A meteorologist or environmental analyst reviews a subset of the meteorological data regularly to ensure that the data is current and being appropriately collected at 15minute intervals. Periods of missing data are noted and investigated. The EFA database automatically checks the reported values for reasonableness and proper format, and compares captured values with expected values or a range of values. The limits used in the screening test are based upon historical data or physically realistic values. Another screening test, called the rate of change test, compares the difference between data of adjacent time periods. Table 2-1 lists meteorological data screening criteria. 
Selected data are compared to other available, reliable data. Data and averages are thoroughly scanned for quality and consistency each month. Variables measured at more than one level are compared within the month and with the same month in years past. Monthly averages and diurnal variations during the month are examined. Data are also sent to the Bay Area Air Quality Management District (BAAQMD) annually. The BAAQMD review provides a quality check on the data.

Major problems with the meteorological instruments or data are noted in the LLNL issues tracking system (ITS). Appropriate procedures are followed to alleviate the problem, and the ITS item is concluded with an explanation of the corrective action taken. Brief periods of questionable data are deleted from the record. Replacement of questionable data is done carefully and only when large blocks of contiguous data are involved. When available, data from another level of the same tower may be used with the proper adjustments for the magnitude of the wind speed or temperature.

Table 2-1. Meteorological data screening criteria.

\begin{tabular}{|c|c|}
\hline Meteorological variable & Screening criteria: flag the data if the value \\
\hline Wind speed & $\begin{array}{l}\text { - is less than zero or greater than } 20 \mathrm{~m} / \mathrm{s} \\
\text { - does not vary by more than } 0.1 \mathrm{~m} / \mathrm{s} \text { for } 3 \text { consecutive hours } \\
\text { - does not vary by more than } 0.5 \mathrm{~m} / \mathrm{s} \text { for } 12 \text { consecutive hours }\end{array}$ \\
\hline Wind direction & $\begin{array}{l}\text { - is less than zero or greater than } 360^{\circ} \\
\text { - does not vary by more than } 1^{\circ} \text { for more than } 3 \text { consecutive hours } \\
\text { - does not vary by more than } 10^{\circ} \text { for more than } 18 \text { consecutive hours }\end{array}$ \\
\hline Temperature & $\begin{array}{l}\text { - } \text { is greater than } 42^{\circ} \mathrm{C} \\
\text { - } \quad \text { is less than }-5^{\circ} \mathrm{C} \\
\text { - } \quad \text { is greater than a } 5^{\circ} \mathrm{C} \text { change from the previous hour } \\
\text { - } \quad \text { does not vary by more than } 0.5^{\circ} \mathrm{C} \text { for more than } 12 \text { consecutive hours }\end{array}$ \\
\hline $\begin{array}{l}\text { Vertical temperature } \\
\text { difference }\end{array}$ & $\begin{array}{l}\text { - is greater than } 0.1^{\circ} \mathrm{C} / \mathrm{m} \text { during the daytime } \\
\text { - is less than }-0.1{ }^{\circ} \mathrm{C} / \mathrm{m} \text { during the nighttime }\end{array}$ \\
\hline Precipitation & 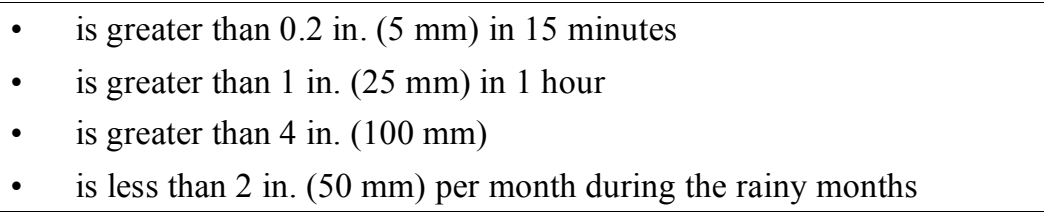 \\
\hline Solar radiation & $\begin{array}{l}\text { - } \quad \text { is greater than zero at night } \\
\text { - } \quad \text { is less than zero at any time } \\
\text { - } \quad \text { is greater than the maximum possible for the date and latitude }\end{array}$ \\
\hline
\end{tabular}

All uses of the meteorological database comply with EPA guidance established in Guideline for Fluid Modeling of Atmospheric Diffusion (EPA 1981), Ambient Air Monitoring Guidelines for Prevention of Significant Deterioration (EPA 1987), and Meteorological Monitoring Guidance for Regulatory Modeling Applications (EPA 2000). 


\subsubsection{Accuracy}

The accuracies of the monitoring measurements should be consistent with the specifications set forth in one of the following:

- Meteorological Monitoring Guidance for Regulatory Modeling Applications (EPA 2000).

- American National Standard for Determining Meteorological Information at Nuclear Power Sites, ANSI/ANS-3.11-2005, published by the American National Standards Institute (ANSI 2005).

The standards in the EPA guidance are usually similar to or stricter than those found in ANS-3.11. Because of EPA guidance and the large frequency of wind speeds below $0.5 \mathrm{~m} / \mathrm{s}$ at the Livermore site, a more stringent anemometer specification for starting speed of less than $0.22 \mathrm{~m} / \mathrm{s}$ is used. Low wind speed threshold wind instruments (vane and anemometer) are also used at Site 300. The instruments in use at both the Livermore site and Site 300 meteorological towers meet or exceed the performance standards of accuracy identified in Table 2-2.

Table 2-2. Standards of accuracy of meteorological parameters.

\begin{tabular}{|l|l|}
\hline \multicolumn{1}{|c|}{ Parameter } & \multicolumn{1}{c|}{ Standard of accuracy } \\
\hline $\begin{array}{l}\text { Horizontal and vertical } \\
\text { wind direction }\end{array}$ & $\begin{array}{l} \pm 5^{\circ} \text { azimuth with a starting threshold of } 0.45 \mathrm{~m} / \mathrm{s} \text {. If the sensor is to be used to } \\
\text { determine } \sigma_{\Theta}, \text { The delay distance }(\mathrm{a}) \text { must not exceed } 2 \mathrm{~m} \text {, and the damping ratio must } \\
\text { be between } 0.4 \text { and } 0.6 .\end{array}$ \\
\hline Wind speed & $\begin{array}{l} \pm 0.22 \mathrm{~m} / \mathrm{s} \text { for speeds less than } 2.2 \mathrm{~m} / \mathrm{s} \text {; within } 5 \text { percent for speeds of } 2.2 \mathrm{~m} / \mathrm{s} \text { or } \\
\text { greater; the starting speed must be less than } 0.45 \mathrm{~m} / \mathrm{s} .\end{array}$ \\
\hline Air temperature & $\pm 0.5^{\circ} \mathrm{C}$ \\
\hline $\begin{array}{l}\text { Vertical air } \\
\text { temperature difference }\end{array}$ & $\pm 0.1^{\circ} \mathrm{C} / 50 \mathrm{~m}$ \\
\hline Relative humidity & \pm 4 percent \\
\hline Dew point temperature & $\pm 1.5^{\circ} \mathrm{C}$ \\
\hline $\begin{array}{l}\text { Solar/terrestrial } \\
\text { radiation }\end{array}$ & $\pm 5 \mathrm{watts} / \mathrm{m}^{2}$ for $<100 \mathrm{watts} / \mathrm{m}^{2}$ \\
\hline Precipitation & \pm 5 percent of observed for $>100 \mathrm{watts} / \mathrm{m}^{2}$ \\
\hline Barometric pressure & $\pm 10 \mathrm{percent}$ of volume \\
\hline Soil temperature & $\pm 1^{\circ} \mathrm{C}$ \\
\hline Soil moisture & \pm 10 percent of actual \\
\hline Time & $\pm 5 \mathrm{~min}$ \\
\hline Source:
\end{tabular}

(Source: DOE 2004)

(a) The delay distance is the length of air, at any wind speed, that must pass through a wind vane during the time it takes the vane to return to $50 \%$ of the initial displacement. 


\subsubsection{Completeness}

LLNL's meteorological system is designed to provide data recovery of at least $90 \%$ on an annual basis. An even higher annual recovery rate of $95 \%$ or higher is strived for. When data from a tower are not available or reliable, representative offsite meteorological data from a nearby tower may be used occasionally. This approach works best for temperature, relative humidity, and solar radiation. Wind speed and direction can vary greatly with increasing distance, so offsite data may not be suitable as a replacement.

\subsubsection{Calibration and Audits}

Routine inspection, scheduled maintenance, and calibration of the meteorological instrumentation and data acquisition system meet the manufacturer's recommendations and are conducted in accordance with LLNL procedure EMP-M-MCA, Meteorological System Maintenance and Sensor Calibration. External audits are performed by an outside, independent contractor at least annually. Calibrations are also performed between the annual audits and when problems are found or instruments switched out. The logs of inspections, maintenance, and calibrations are maintained as permanent records, allowing routine inspection of current data.

\subsection{Program Implementation Procedures}

The following procedures and instructions are used to support and ensure meteorological data collection and analyses:

- $\quad$ EMP-M-MCA, Meteorological System Maintenance and Sensor Calibration.

- $\quad$ EMP-M-D, Meteorological Data Management and Analysis.

- EMP-M-D Instruction \#1, Preparation of Monthly Records of Meteorological Observations for LLNL and Site 300.

- EMP-M-D Instruction \#2, Preparation of Annual Records of Meteorological Observations for LLNL and Site 300.

- EMP-M-D Instruction \#3, Preparation of Graphical Wind Rose.

- EMP-M-D Instruction \#4, LLNL's LoggerNet Admin Software Installation, Configuration, Backup and Restore. 


\subsection{Action Levels}

When a serious problem is discovered with an instrument that provides critical data (wind direction, wind speed, etc.), the problem is addressed immediately. In addition, the meteorologist will notify personnel using the data, such as those supporting emergency preparedness, that the data are invalid. If the problem persists for more than a few hours, a message is placed on Weather Pages website informing users of the problem.

\subsection{Preparation and Disposition of Reports}

Wind roses are generated for the Livermore site and Site 300. Reports requiring the annual wind rose include the annual Environmental Report and the LLNL NESHAPs Annual Report.

The regulatory model, CAP88-PC, requires joint-frequency tables of wind direction, wind speed, and stability. LLNL uses an Excel workbook to transform a year of data from the archive into the tables that are used as meteorological input to the CAP88-PC code. The Excel workbook is described in procedure EMP-M-D Instruction \#2, Preparation of Annual Records of Meteorological Observations for LLNL and Site 300.

\subsection{References}

ANSI (2005), Determining Meteorological Information at Nuclear Facilities, ANSI/ANS 3.11-2005, American National Standards Institute, Washington, D. C.

Crutcher, H. L. (1984), "Monitoring, Sampling, and Managing Meteorological Data," Atmospheric Science and Power Production, U. S. Department of Energy, Washington, D. C. (DOE/TIC-27601).

DOE (2004), Environmental Regulatory Guide for Radiological Effluent Monitoring and Environmental Surveillance, U. S. Department of Energy, Washington, D. C. (DOE/EH-0173T).

DOE Guide 420.1-1, Nonreactor Nuclear safety Design Criteria and Explosives Safety Criteria Guide for use with DOE Order 420.1, Facility Safety, U. S. Department of Energy, Washington, D. C., 2000.

DOE Guide 420.1-2, Guide for the Mitigation of Natural Phenomena Hazards for DOE Nuclear Facilities and Nonnuclear Facilities, U.S. Department of Energy, Washington, D. C., 2000.

Draxler, R. R. (1976), "Determination of Atmospheric Diffusion Parameters," Atmospheric Environment 10, 99-105. 
Environmental Report (annual), Lawrence Livermore National Laboratory, Livermore, CA. (UCRL-50027). Available at https://saer.llnl.gov/

EPA (1981), Guideline for Fluid Modeling of Atmospheric Diffusion, U. S. Environmental Protection Agency, Research Triangle Park, NC (EPA 600/881/009).

EPA (1987), Ambient Air Monitoring Guidelines for Prevention of Significant Deterioration (PSD), U. S. Environmental Protection Agency, Research Triangle Park, NC (EPA 450/4-87/007).

EPA (1990), Quality Assurance Handbook for Air Pollution Measurements Systems: Volume IV - Meteorological Measurements, U. S. Environmental Protection Agency, Research Triangle Park, NC (EPA 600/4-90/003).

EPA (2000), Meteorological Monitoring Guidance for Regulatory Modeling Applications, U. S. Environmental Protection Agency, Research Triangle Park, NC (EPA 454/R-99-005).

Gifford, F. A. (1976), “Turbulent Diffusion-Typing Schemes: A Review," Nuclear Safety 17(1), 68-86.

Gouveia, F. J., and K. R. Chapman (1989), Climatology of Lawrence Livermore National Laboratory, Lawrence Livermore National Laboratory, Livermore, CA (UCID-21686).

Hanna, S. R., G. A. Briggs, J. Deardorff, B. A. Egan, F. A. Gifford, and F. Pasquill (1977), "AMS Workshop on Stability Classification Schemes and Sigma CurvesSummary of Recommendations," Bull. Amer. Meteor. Soc. 58, 305-1309.

Homann, S. G. (1988), Emergency Precaution Information Code (EPICodeTM), Homann Associates Incorporated, Fremont, CA.

Homann, S. G. (1994), HOTSPOT Health Physics Codes for the PC Emergency Precaution Information Code (EPICode ${ }^{\mathrm{TM}}$ ), UCRL-MA-106315, Lawrence Livermore National Laboratory, CA.

LLNL NESHAPs Annual Report, Lawrence Livermore National Laboratory, Livermore, CA (UCRL-ID-113867).

Parks, B. (1992), User's Guide for CAP88-PC, Version 1.0, U. S. Environmental Protection Agency, Office of Radiation Programs, Las Vegas, NV (Report 402-B92-001).

Sullivan, T. J., J. S. Ellis, C. S. Foster, K. T. Foster, R. L. Baskett, J. S. Nasstrom, and W. W. Schalk, III (1993), "Atmospheric Release Advisory Capability; Real-Time Modeling of Airborne Hazardous Materials," Bull. Amer. Meteor. Soc. 74, 23432361 . 


\section{Air Effluent}

Kent Wilson

\subsection{Introduction}

A key monitoring method for evaluation of environmental impacts from facilities having discharges to the atmosphere is the measurement of pollutants at their point of emission. This type of monitoring is part of a comprehensive and continuous environmental program at Lawrence Livermore National Laboratory (LLNL). LLNL performs continuous air effluent sampling of atmospheric discharge points at several facilities that complies with federal laws and industry standards. U.S. Department of Energy (DOE) monitoring guidance specifies that emissions from facilities with radionuclides should be monitored. The LLNL air effluent monitoring program complements the environmental air surveillance monitoring effort (see Chapters 4 and 5); it can confirm or discount specific source locations as being contributors to any release that environmental surveillance monitoring might detect. It can also provide source term information for regulatory compliance or emergency response and air dispersion and dose assessment modeling.

\subsection{Rationale and Design Criteria}

\subsubsection{Regulatory Drivers}

The applicable portions of 40 CFR 61, Subpart $\mathrm{H}$, a regulation promulgated under the Clean Air Act, set requirements for continuous monitoring of radiological discharges and the estimation of radiological dose to the public resulting from operations at DOE facilities. Guidance on dose assessment is provided in EMP-R-DA, Radiological Dose Assessment Guidance Document.

Historically, monitoring of radionuclide air effluents at LLNL has been implemented according to the DOE as low as reasonably achievable (ALARA) policy. The more recent 40 CFR 61, Subpart H, National Emission Standards for Hazardous Air Pollutants (NESHAPs) requires monitoring of radionuclide air effluent if the potential effective dose equivalent (EDE) from a specific emission point exceeds $1 \mu \mathrm{Sv} / \mathrm{y}(0.1 \mathrm{mrem} / \mathrm{y})$ at any point along the fence line. The EDE evaluation is calculated using the air dispersion dose models mandated by the U.S. Environmental Protection Agency (EPA) with no credit for emission control devices per 40 CFR 61.93. 
All LLNL operations having the potential for radiological air emissions are evaluated to determine the need for continuous monitoring. At discharge points having air effluent monitoring, the monitoring results provide the actual source term for determining that the radiological NESHAPs standard of $100 \mu \mathrm{Sv} / \mathrm{y}$ (10 mrem/y) EDE (airborne pathway) from all site operations is not exceeded.

\subsubsection{Monitoring Objectives}

The primary purpose of LLNL's air effluent sampling program is to measure radiological emissions at the point of release. In doing so, LLNL can demonstrate compliance with regulatory requirements and ensure protection of the public and the environment. In addition, sampling provides confirmation of the performance of emission control systems in place at facilities.

\subsubsection{Sources and Analytes}

Researchers at LLNL use a wide variety of radioisotopes for experimental purposes, including uranium and transuranic elements, biomedical tracers, tritium, mixed fission products, and others. The radionuclide with the greatest radioactivity released to the atmosphere from the Livermore site is tritium. In addition to effluent sampling for tritium, a number of facilities at the Livermore site and one facility at Site 300 have air effluent samplers to detect the release of radioactive particulate, primarily uranium and transuranic aerosols. Air effluent monitoring for radioactive iodines began at one facility at the Livermore site in May 2010. The air effluent sampling systems described in this chapter apply to stationary point-source discharges. Sampling methods to evaluate LLNL diffuse sources are described in Chapter 5.

To assess the need for monitoring air effluent discharge points, LLNL conducts evaluations of all operations having the potential to release radionuclides to the atmosphere. The evaluation is intended to demonstrate that LLNL is in compliance with 40 CFR 61, Subpart H section (b)(4) for the regulation of radionuclide emissions from DOE-owned or -operated facilities. Internal to LLNL, the Water, Air, Monitoring and Analysis (WAMA) group in the Environmental Functional Area (EFA) is responsible for radiological NESHAPs evaluations and reporting.

As a result of annual NESHAPs evaluations and the DOE ALARA policy, LLNL as of November 2011 operates 16 continuous samplers in 6 facilities at the Livermore site and one continuous monitoring system at Site 300. Implementation guidance on air effluent sampling is provided in the NESHAPs-cited American National Standards Institute (ANSI) N13.1-1969 and the revision ANSI/HPS N13.1-1999, and in the Environmental Regulatory Guide for Radiological Effluent Monitoring and Environmental Surveillance (DOE 1991). 
LLNL operations that have the potential to release non-radiological pollutants are currently not required to have stack effluent monitoring. Moreover, LLNL is not considered a major source of non-radiological pollutant emissions. However, permits for certain operations must be obtained from the local air districts responsible for enforcement, which are the Bay Area Air Quality Management District (BAAQMD) for the Livermore site and the San Joaquin Valley Air Pollution Control District (SJVAPCD) for Site 300. The WAMA group in EFA is responsible for obtaining necessary permits and exemptions, maintaining permit records, and coordinating inspections.

\subsubsection{Collection Methods}

Elements of the radiological air effluent sampling systems that may affect the representativeness of sampling include the following:

- Sampling location and probe placement.

- Extraction probe design.

- Sample transport line.

- Sample collector.

- Degree of isokinetic sampling.

Air effluent sampling locations must meet the requirements of 40 CFR 60, Appendix A, Reference Method 1 and is required by Subpart $\mathrm{H}$ for particle sampling traverses. Because LLNL facilities were in place before the NESHAPs regulations became effective, meeting the requirement for a minimum of eight duct diameters downstream and two duct diameters upstream from any flow disturbance at some facilities was not feasible. The alternative configuration of two duct diameters downstream and one-half diameter upstream from any disturbance, as allowed in Method 1 section 2.1, was met for these sampling systems to be compliant with NESHAPs.

To achieve representative samples, an extraction probe continuously removes a volume of air from the air effluent discharge duct. For those exhaust points where continuous sampling for aerosols is required, sample extraction probes have been designed, fabricated, and installed to meet the 1999 ANSI guidelines called for by the NESHAPs (ANSI/HPS N13.1-1999). The 1999 ANSI also requires that probe placement in the stack or duct pass performance-based tests to qualify the sample location in lieu of duct diameter evaluation without flow disturbance. Stacks with the 1999 ANSI probe are tested and meet the requirements for probe placement.

The stack sampling systems that were put in place prior to 2003 have extraction probes that meet the grandfathered 1969 ANSI guidelines (ANSI N13.1-1969). The 1969 ANSI extraction probes are sometimes multi-nozzled (i.e., air is withdrawn through nozzles at 
more than one point across the exhaust duct and joined into a collection manifold). For circular ducts, nozzles are located in equal concentric annular areas as per the guidelines. For rectangular ducts, more than one multi-nozzle probe may be used to provide adequate sampling coverage across the cross section of the duct. The extraction at multiple points helps ensure that representative sampling is attained even if particles are not evenly distributed across the cross section of the duct. For smaller circular ducts (less than 8 inches in diameter), only a single point nozzle extraction probe is used. Probes are positioned isoaxially in the exhaust duct and the probe nozzles have tapered edges. The extraction probes meeting the ANSI/HPS N13.11999 are single-point shrouded probes. Both 1969 and 1999 ANSI probe nozzles are made of stainless steel so that no degradation is expected to occur under normal facility operations. Sampling is performed at temperature and humidity conditions similar to that in the facility.

The extracted air passes though a sample transport line and is delivered to the air samplers. In the particle sampling systems, particles in the extracted air are collected on 47-mm diameter membrane filters. Where feasible, the filter collectors are connected to the extraction probe immediately outside the duct to minimize the length of the sample transport line, and therefore, minimize particle loss in the transport line. Bends are also avoided or minimized because of associated particle losses in the transport line. Where bends cannot be avoided, they are made gradually to minimize particle deposition. High efficiency membrane filters are utilized for the collection of radioactive particulate. The membranes used for collection exceed the efficiency requirements of ANSI/HPS N13.1-1999 Section 6.6 Collection of Particle Samples.

Tritium sampling utilizes glycol bubblers that quantify tritium in the vapor (HTO) and gaseous (HT) state. Radioactive iodine sampling is collected on triethylene diamine (TEDA) carbon cartridges for volatile emissions, and on $47 \mathrm{~mm}$ membrane filters for particulate emissions (40 CR 61, App. B). The 1969 ANSI guidelines for sampling radioactive aerosols also require that sampling be isokinetic. The 1999 ANSI allows for the option of either isokinetic or fixed-rate sampling. If sampling at fixed-rate, each probe is rated to sample at a specific flow up to a maximum stack velocity (e.g., a 2-cfm probe is compliant to stack velocities that do not exceed $15 \mathrm{~m} / \mathrm{s}$ ). Isokinetic sampling occurs when the sampler flow rate and extraction nozzle size are such that the velocity through the inlet nozzle is equivalent to the gas velocity in the duct being sampled. This ensures that a representative size distribution of the aerosol is being sampled. For the locations required to have continuous sampling, sample flow rate and extraction probe inlet nozzles have been designed to range from less than isokinetic to $100 \%$ isokinetic. Less than isokinetic sampling guarantees that sampling is conservative in the case where the aerosol distribution being sampled contains particles micron-sized or greater. LLNL has received approval from US EPA Region IX (US EPA 1994) to conduct less than isokinetic sampling. 


\subsection{Extent and Frequency of Monitoring and Measurement}

\subsubsection{Evaluation of the Need for Air Effluent Sampling}

LLNL complies with radiological NESHAPs requirements by performing assessments on the need for new sampling locations. The assessments are performed by WAMA in EFA. Each assessment addresses LLNL air emission points and diffuse sources that have the potential to discharge radionuclides to the atmosphere. The potential EDEs to members of the public from these discharge points are calculated and used to determine if any additional monitoring is required.

\subsubsection{Air Effluent Sampling Locations}

The locations of facilities or buildings at the Livermore site and Site 300 that have air monitoring systems for radiological emissions are listed and updated regularly in EMPAE-ESS, Exhaust Stack Samplers. EMP-AE-ESS also lists the number and type of samplers; identifies the type of EPA-required sampling or sampling for best management practice; includes requirements (as applicable) for quarterly checks, calibration, and maintenance; and includes procedural and applicable ANSI guidelines.

\subsubsection{Low-Volume Ambient Air Samplers}

Two special low-volume ambient air sampling systems support the air effluent sampling network. These samplers are strategically located at the FCC and POOL locations as shown in Figures 4-1 and 4-3 of the Site Annual Environmental Report. The FCC location is used to establish background levels of radioactive iodines (installed 2011 due to the Japanese reactor crisis) for comparison to results from the air effluent samplers monitoring facility discharge points for radioactive iodines. The POOL location is monitoring for tritiated particulate in ambient air. The special sampling systems are very similar to the air effluent samplers, including sampling system design, sampler operation, sample tracking, sample analysis, and results processing.

\subsubsection{Effluent Flow Rate Measurement}

To determine the annual emissions, both the concentration of radiological constituents in the discharge as determined by the continuous sampling systems and the effluent volume from a discharge point must be known. The effluent flow rate from all discharge points having continuous sampling systems is determined by EPA-approved methods (40 CFR 60, Appendix A). At two facilities, periodic measurements of stack flow velocity are made using hot-wire anemometers. Effluent volume is then calculated from the periodic flow rate measurements. At the other facilities, continuous measurements of stack flow rates are made using permanent electronic velocity, or mass flow, probes. These locations are listed in EMP-AE-ESS, Exhaust Stack Samplers. Stack flow rate is 
measured every few seconds and the average rate is calculated and recorded every two hours. Effluent volume is calculated by averaging these data over time.

\subsection{Procedures for Laboratory Analysis}

Air effluent samples are processed and analyzed by the Radiation Measurements Laboratory (RML) in the Environment, Safety, and Health (ES\&H) Directorate, and by the Environmental Monitoring Radioanalytical Laboratory (EMRL) in the Physical and Life Sciences directorate

\subsubsection{Sample Preservation and Handling}

Particulate filter samples taken from field locations are first stored in glassine bags before being routed to the RML or the EMRL. Glycol bubbler bottles are stored and transported to the RML with the bottles capped. No special preservation techniques are necessary for particulate or glycol bubbler bottles for air effluent samples. Sampling for radioactive iodines in the volatile state are collected on TEDA activated carbon cartridges that are transported in a sealed bag and placed on gamma spectroscopy for counting (the samples are normally on the counter the same-day as received).

Prior to submission of samples to the RML, the samples are logged into the sample tracking and receiving (STAR) computer system by EFA environmental monitoring technologists, ES\&H health \& safety technicians, or radiological control technicians (RCTs). Prior to sample submission to the EMRL, a chain-of-custody (COC) form is created by the data management team (DMT) in EFA. Information provided at login or from COCs includes field identification number, origin, sample type, the start and stop date/times, sample flow on/off, liquid volume (for bubbler samples), and the required analyses. Samples received by the RML and EMRL are stored in a specially designated area that includes separate storage for incompatible samples and for volatile or unstable compounds. All personnel delivering samples to the RML or EMRL laboratories are trained in contamination control and taught to segregate any samples with potentially unusual activity.

\subsubsection{Analytical Methods}

Methods used for the analysis of air effluent samples conform to the requirements of 40 CFR 61, Appendix B Method 114, specifically:

- Method A-4 for gross alpha determination.

- Method B-4 for gross beta determination.

- Section 2.5.1 for alpha counting using gas flow proportional counters.

- Method B-5 for beta counting by scintillation counters. 
- Method G-1 for high resolution gamma spectrometry

Gross alpha and gross beta activity from particles collected on air filters are detected with gas flow proportional counters. Samples are not analyzed until at least four days after sampling to allow for the decay of naturally occurring radon daughters. Tritiated particulate collected on filters is counted with liquid scintillation counters. Gamma emitting particulate collected on filters is detected by high-resolution gamma spectrometry. To verify the operation of the counting systems, calibration sources as well as background samples and laboratory blanks are intermixed with the sample filters for analysis. Laboratory blanks serve as indicators of cross-contamination within the counters.

The sample bottles of tritium collected in glycol bubblers are analyzed for tritium activity by liquid scintillation techniques. Radioactive iodines on TEDA cartridges are counted by gamma spectroscopy.

Both the EMRL and the RML have sample handling, equipment operation, and calibration procedures documented, as listed in Section 3.10.

\subsection{Data Quality Assurance}

The quality assurance parameters that are applicable to the NESHAPs program at LLNL are accuracy, precision, and completeness as defined in paragraph 4.4 of Appendix B 40 CFR 61, Subpart H.

\subsubsection{Precision}

Precision is typically evaluated by assessing the degree of similarity of analytical results from replicate and/or co-located samples. Continuous stack sampling does not readily lend itself to either type of sample, and a direct measurement of the precision of air effluent samples is not available. One of the facilities monitored has a co-located continuous filter sampler, and results are regularly reviewed. Further, specific consideration is given to the number of samples above the limit of sensitivity (LOS) for each sampling period and measurement method (e.g., recount).

\subsubsection{Accuracy}

Accuracy in sampling can be affected by the degree of representative monitoring to atmospheric release, maintenance and calibration of samplers, calibration of analytical equipment, and agreement of analytical results with data from standards. Air effluent sampling system design conforms to specifications for continuous sampling systems given in 1969 ANSI and1999 ANSI, and in 40 CFR 61, Subpart H. Specifically, all required air effluent sampling systems in monitored facilities meet the design specifications, location and sample probe placement criteria, and degree of isokinetic 
sampling as applicable to the appropriate ANSI. Operating parameters of the samplers are checked weekly or biweekly, and samplers are calibrated annually as stated in EMP-AEESS, Exhaust Stack Samplers.

The accuracy of sample analytical results is determined by comparison of samples to known concentrations of analytes. Matrix spikes (i.e., samples prepared in the matrix of interest with NIST-traceable standards) are used by the RML and EMRL in their analyses of tritium. Sample batches of tritiated water, filters analyzed for radioactive particulate, and TEDA cartridges for radioactive iodine activity include additional analytical standards. Custom data reduction and report generation software automatically compares pre-determined control limits for analytical standards against the sample values obtained in each analytical run. Procedures are in place to prevent the release of analytical data that do not meet quality control (QC) standards.

\subsubsection{Completeness}

Within the context of NESHAPs compliance, completeness applies both to sampling systems and to laboratory analyses of environmental samples. For the continuous stack samplers, WAMA requires 80 percent completeness of sample collection. That is, over all monitored facilities, samplers must be operational for at least 80 percent of the sampling period. With respect to laboratory analyses, WAMA requires that 90 percent of the samples submitted to, and analyzed by, the RML and EMRL yield valid data. If these completeness criteria are not met, the WAMA environmental analyst and data management team work to resolve the issue(s) with the Facility, program, and/or analytical laboratory.

\subsubsection{Calibration}

The equipment in the RML and EMRL is calibrated with sources that are traceable to National Institute for Standards and Technology (NIST). Calibration follows a variety of methods from calibration by a certified third party (as is done for laboratory balances), to calibration with known standards that are made from traceable materials (as is done for metals and most radiological analyses). Calibration practices are in accordance with standard procedures and are evaluated during audits required for maintenance of certifications.

The EMRL and RML are part of LLNL's calibration program. Calibration records are maintained for each piece of calibrated equipment.

\subsection{Program Implementation Procedures}

EFA is responsible for the LLNL air effluent monitoring program; however, implementation of the program relies strongly on participation by facilities, programs, and the laboratories performing the analysis. 


\subsubsection{Air Effluent Sampling}

Instructions for the collection and replacement of air effluent samples for radionuclides performed by the Environment, Safety and Health (ES\&H) Team health \& safety technician or RCT assigned to the facility are described in the environmental discipline action plan (DAP) for the facility. The DAP specifies step-by-step instructions on sample exchange, sample frequency, bar coding of the sample, COCs, sample delivery, analytes for assay, and all other pertinent information related to stack sampling. The WAMA environmental analyst is responsible for the drafting and revision of the ES\&H field support instructions for air effluent sampling and ensuring that the instructions are implemented by the ES\&H Team health and safety technician or RCT.

The operation and maintenance of the two special low-volume ambient air samplers is performed by the WAMA environmental monitoring technicians. The procedure that describes this activity is EMP-AP-LV, Low-Volume Radiological Air Sampling.

Analytical results of the air effluent samples and low-volume samples are reported to the responsible environmental analyst in WAMA. Air effluent results are also retained in the air effluent database in EFA. The procedure EMP-AE-DAM, Air Effluent Data Analysis and Management, describes the methods used to manage and analyze the data.

\subsubsection{Effluent Flow Measurement, Calibration, and Maintenance}

Effluent flow is determined by measurement of the velocity of the effluent exiting a discharge point and its cross-sectional area. The procedure EMP-AE-MON, Air Effluent Monitoring, describes the methods used to measure:

- Gas velocity and the calculation of flow rate from a discharge point.

- Calibration of mass flow probes.

- Manual and electronic downloading of stack flow data.

- Quarterly response checks to measure calibration drift.

- Annual maintenance and inspection of stack sampling systems.

The activities described in EMP-AE-MON are the responsibility of WAMA in EFA.

\subsection{Notification Levels}

Notification levels are a function of the labs performing the analysis. Both the RML and EMRL have specific notification levels for stack effluent concentrations programmed into their software. A notification level is created specific to the nuclide, or types of nuclides, monitored. Since the LLNL site-wide environmental impact statement has different release levels for different facilities, not all notification levels are the same for every facility. 
The air effluent notification levels are conservative compared to the NESHAPs. The notification levels for all facilities are less than 1\% of the NESHAPs $10 \mathrm{mrem} / \mathrm{y}$ site-wide standard. (For example, at one facility, the tritium concentration notification level is approximately $0.5 \mathrm{Ci}$ for weekly sampling, which is approximately $0.002 \%$ of the NESHAPs $10 \mathrm{mrem} / \mathrm{y}$ standard.)

If a notification level is exceeded, the specialist in the lab performing the analysis notifies the facility contact and WAMA. The WAMA air effluent analyst investigates the result, including such actions as recount, verification of sample location and sample volume, comparison with past data, and communication with the facility. If consecutive results continue to be above the notification level, the analyst works with the facility to determine the source and possibly implement better controls.

\subsection{Preparation and Disposition of Reports}

WAMA is responsible for the reporting of air effluent radionuclide emissions.

Radionuclide emissions are reported in the Site Annual Environmental Report and in the LLNL NESHAPS Annual Report to DOE and EPA, respectively. Because tritium emissions from the Tritium Facility and from the National Ignition Facility are a potential major source of atmospheric radionuclide releases, a summary report of emissions is provided to the facility manager quarterly from the WAMA environmental analyst.

\subsection{Future Plans}

WAMA will:

- Continue to monitor the air effluent and report emissions in the manner described in this chapter.

- Continue to review the need for air effluent sampling from all facilities including new facilities and existing facilities having new and/or modified operations for compliance with the NESHAPs.

- Evaluate new regulations to determine if monitoring for additional substances, such as greenhouse gasses, and implement any required monitoring.

\subsection{References}

ANSI (1969), Guide to Sampling Airborne Radioactive Materials in Nuclear Facilities, ANSI N.13.1-1969 R1993, American National Standards Institute, Inc., New York, NY.

ANSI (1999), Sampling and Monitoring Releases of Airborne Radioactive Substances from the Stacks and Ducts of Nuclear Facilities, ANSI/HPS N13.1-1999, American National Standards Institute, Inc., New York, NY. 
DOE (1991), Environmental Regulatory Guide for Radiological Effluent Monitoring and Environmental Surveillance, U. S. Department of Energy, Washington, D. C. (DOE/EH-0173T).

Environmental Report (annual), Lawrence Livermore National Laboratory, Livermore, CA. (UCRL-50027). Available at https://saer.1lnl.gov/

Hoover, M.D. and G.J. Newton (1991), “Technical Bases for Selection and Use of Filter Media in CAMS for Alpha Emitting Radionuclides," in Inhalation Toxicology Research Institute Annual Report for 1990-1991, LMF-134, December 1991. Inhalation Toxicology Research Institute, Albuquerque, NM.

LLNL NESHAPs Annual Report, Lawrence Livermore National Laboratory, Livermore, CA. (UCRL-ID-113867).

Radiological Measurements Laboratory Gross Alpha-Beta Counter Procedures Manual, Revision 3, Hazards Control Department, Lawrence Livermore National Laboratory, Livermore, CA, January 25, 2000.

Radiological Measurements Laboratory LSC, Liquid Scintillation Counting Procedures Manual, Revision 2, Hazards Control Department, Lawrence Livermore National Laboratory, Livermore, CA, August 18, 2000.

SOP-EM-P557, Preparation of Air Filters for Determination of Gross alpha/beta and Be, Pu, $U$ and Gamma Radioisotopes, Environmental Monitoring Radiological Laboratory, Physical Life Sciences Directorate, Lawrence Livermore National Laboratory, Livermore, CA.

SOP-CES-P810, Data Validation, Environmental Monitoring Radiological Laboratory, Physical Life Sciences Directorate, Lawrence Livermore National Laboratory, Livermore, CA.

SOP-CES-P811, Data Verification, Environmental Monitoring Radiological Laboratory, Physical Life Sciences Directorate, Lawrence Livermore National Laboratory, Livermore, CA.

US EPA (1994), Memorandum from David P. Howekamp, Director, Air and Toxics Division, United States Environmental Protection Agency Region IX, to Terry A. Vaeth, Acting Manager, United States Department of Energy, Oakland Operations Office, Oakland, CA, regarding Lawrence Livermore National Laboratory's satisfactory demonstration of compliance with all requirements of the Federal Facility Compliance Agreement, Docket No. 9-91-17. 


\section{Ambient Air Particulate}

Kent Wilson

\subsection{Introduction}

Ambient air particulate monitoring is part of a comprehensive and ongoing environmental monitoring program (see Chapter 1) for Lawrence Livermore National Laboratory (LLNL). Data collected from air monitoring are used to demonstrate compliance with regulatory requirements, calculate the dose to the public from LLNL activities, and monitor any changes in the activity detected in the airborne particulate levels in and around LLNL.

Typically, air pollutants can be categorized as either particulate matter or gases. Potential air particulate pollutants that can contribute to radiological dose or inhalation hazard from LLNL operations include radioactive particulate and beryllium metals. Air can be a primary exposure pathway for human and ecological impact.

To reduce, control, and eliminate air pollutants from its operations, LLNL employs an array of engineering and administrative controls. LLNL conducts air surveillance monitoring in the environment to assess the adequacy of these controls and to determine the impact, if any, of its air pollutant releases on the environment. Using data obtained from air effluent monitoring (see Chapter 3 ) and air surveillance monitoring, LLNLinduced human-health and environmental impacts can be assessed.

LLNL is not considered a major source of nonradiological air pollutants as defined under the Clean Air Act. These pollutants, known as criteria air pollutants, include carbon monoxide, sulfur dioxide, nitrogen oxides, ozone, particulate matter (particles with an aerodynamic diameter less than or equal to $\left.10 \mu \mathrm{m} ; \mathrm{PM}_{10}\right)$, and lead.

The sources of criteria pollutants from the Livermore site and Site 300 are surface coating operations, internal combustion engines, solvent operations, soil vapor extraction, gasoline dispensing operations, boilers, and open burning (only at Site 300). Operations at both sites also use a variety of chemicals that are considered air toxics. In accordance with the regulatory authority of the local air districts, monitoring for both criteria pollutants and air toxics is managed through permits issued by the air districts. 


\subsection{Rationale and Design Criteria}

\subsubsection{Regulatory Drivers}

Air monitoring regulations are driven by the applicable portions of Department of Energy (DOE) Order 458.1. It is the objective of DOE, via DOE Order 5 458.1, to operate its facilities and conduct its activities so that radiation exposures to members of the public and biota are maintained within the limits established in the order. It is also a DOE objective that potential exposure to members of the public and to biota are as far below limits as is reasonably achievable (ALARA) and that DOE facilities have the capabilities to monitor for such releases.

LLNL is also subject to the National Emission Standards for Hazardous Air Pollutants (NESHAPs) of the Clean Air Act, (40 CFR 61, Subpart H). As part of its compliance with this regulation, LLNL has authorization to use ambient air surveillance monitoring for public dose assessment for minor and diffuse sources. (Harrach et al. 2003 [Attachment 3]).

The Environmental Regulatory Guide for Radiological Effluent Monitoring and Environmental Surveillance (DOE 1991) provides the guidance for ambient air particulate monitoring. In addition to routine monitoring, environmental monitoring during an emergency situation should be considered. LLNL's surveillance air monitoring network is part of the EFA emergency response program.

Sampling for beryllium in ambient air is performed to comply with the Bay Area Air Quality Management District (BAAQMD) Regulation 11, Rule 3. This rule establishes an air concentration limit for beryllium metals of $0.01 \mu \mathrm{g} / \mathrm{m}^{3}$, averaged over a 30-day period.

\subsubsection{Monitoring Objectives}

The primary objective of ambient air particulate monitoring is to assess radiological dose to the public and the environmental impact of routine and nonroutine radiological and beryllium metal airborne releases. The sample results may be used to validate air dispersion models, release calculations, and offsite effects, and to determine future courses of action.

There are several goals for analyzing monitoring data:

- Estimation of concentrations at each sampling point.

- Comparison of current concentrations to previous concentrations in order to identify changes or inconsistencies. 
- Comparison of concentrations to established regulatory limits.

- Comparison of concentrations at a single location, or a group of locations, to control (background) locations and evaluation of the reliability of the comparisons.

- Review of quality assurance data to ensure validity.

\subsubsection{Sources and Analytes}

The air monitoring program at LLNL is designed to identify a problem at the lowest possible level. Analysis of filters involves laboratory analytical results, characterization of respirable particle size distributions, and mass loading.

Aerodynamic diameter size distribution studies using cascade impactors have demonstrated that approximately $80 \%$ of the particles collected on the filters are respirable $(10 \mu \mathrm{m}$ aerodynamic diameter or less) at normal atmospheric conditions. Offnormal conditions, such as forest fires and controlled burns, showed approximately $90 \%$ of the particles were respirable. LLNL takes the conservative approach and considers all particles collected as respirable for purposes of inhalation dose calculations.

Plutonium and uranium are the primary particulate radionuclides of concern at the Livermore site. The major potential source for plutonium is the Building 332 Plutonium Facility. The potential source of uranium is the Building 321 Complex, where milling, shaping, and machining of depleted uranium, as well as other related operations, occur. Other sources include Physical and Life Sciences Directorate facilities, Radioactive and Hazardous Waste Management operations, and the resuspension of plutonium from lowlevel contamination of soil in the southeast quadrant of the Livermore site.

LLNL also analyzes the air samples for gamma-emitting radionuclides, and in doing so, verifies if there is any evidence of release of mixed fission products and radiochemical tracers used by LLNL.

At Site 300, depleted uranium, used in explosive tests, is the primary particulate of concern. Historically explosive tests were conducted on open-air firing tables located at Bunkers 801, 850, and 851. Presently these explosive tests are conducted on Bunker 851 and inside Building 801, the Contained Firing Facility (CFF). Components of depleted uranium include the isotopes uranium-234, uranium-235, and uranium-238.

Beryllium, the primary nonradiological particulate of concern, is used in several facilities at the Livermore site. Testing at Site 300 may include the use of beryllium. Mass loading on filters can help demonstrate if detected beryllium concentrations are a result of laboratory activities or a result of resuspended naturally occurring beryllium. The mass on the filter is compared to local beryllium soil concentrations. 


\subsubsection{Collection Methods}

Air samples are collected on high volume air particulate sampling units (hi-vol) that run continuously at a flow rate of 15 cubic feet per minute ( $\mathrm{cm})$. Sampling units have mass flow controllers that maintain a constant sample flow. This automatic system adjusts the motor speed to compensate for changes in temperature and mass loading that can affect flow rate. The exposed cellulose filters are collected on a fixed schedule that is either weekly or bi-weekly, which is determined by the potential radiological impact at specific sample locations.

For emergency response air monitoring, battery operated portable emergency air samplers are available for deployment. The surveillance and portable air sampling units do not provide data in real time, but they are available if emergency sampling is needed.

\subsection{Extent and Frequency of Monitoring and Measurement}

Air samplers are located to ensure reasonable probability that any significant concentration of particulate effluents of concern from LLNL operations will be detected. Sampling units are placed in all directions from sources and each station was specifically selected to represent a particular region. These include on-site, off-site (upwind and downwind), diffuse or areas of known contamination, and areas within populated city limits. A detailed description of past and present sampling locations is maintained by the EFA Data Management Team.

The configuration of the network involves several elements: proximity to potential sources, their geographical location, historical wind patterns, effects of topography, and access logistics. Through air dispersion modeling, specific locations have been identified as those having the maximum dose to the public, while other sites represent onsite, downwind, upwind and control (background) locations.

The sample locations at the Livermore site are shown in Figure 4-1. Historically, CRED and VIS have represented the primary and secondary site-wide maximally exposed individual (SW-MEI) member of the public. Location SALV is situated in the southeast quadrant of LLNL and in an area of known historical plutonium soil contamination (Sims 1991). The off-site upwind and downwind sampling locations are shown in Figure 4-2. A special interest station is located at LWRP where historical plutonium contamination exists from plutonium released by LLNL to the sanitary sewer during the late 1960s.

The Site 300 on-site and off-site sampling locations are shown in Figure 4-3. WOBS and Tank5 are close to test bunkers and PSTL serves as the SW-MEI. TCDF is the downwind offsite sampling location for Site 300. 
Surveillance of potential emissions from beryllium operations is performed at six locations along the perimeter fence line of the Livermore site (MET, COW, VIS, SALV, CAFE, MESQ). Although under no regulatory requirement to monitor for beryllium at Site 300, as a best management practice beryllium is monitored due to historical shot activity, and for the potential health hazards associated with inhalation of beryllium. LLNL monitors for beryllium at three locations within Site 300 (Tank5, EOBS, GOLF) and at the background location (TCDF).

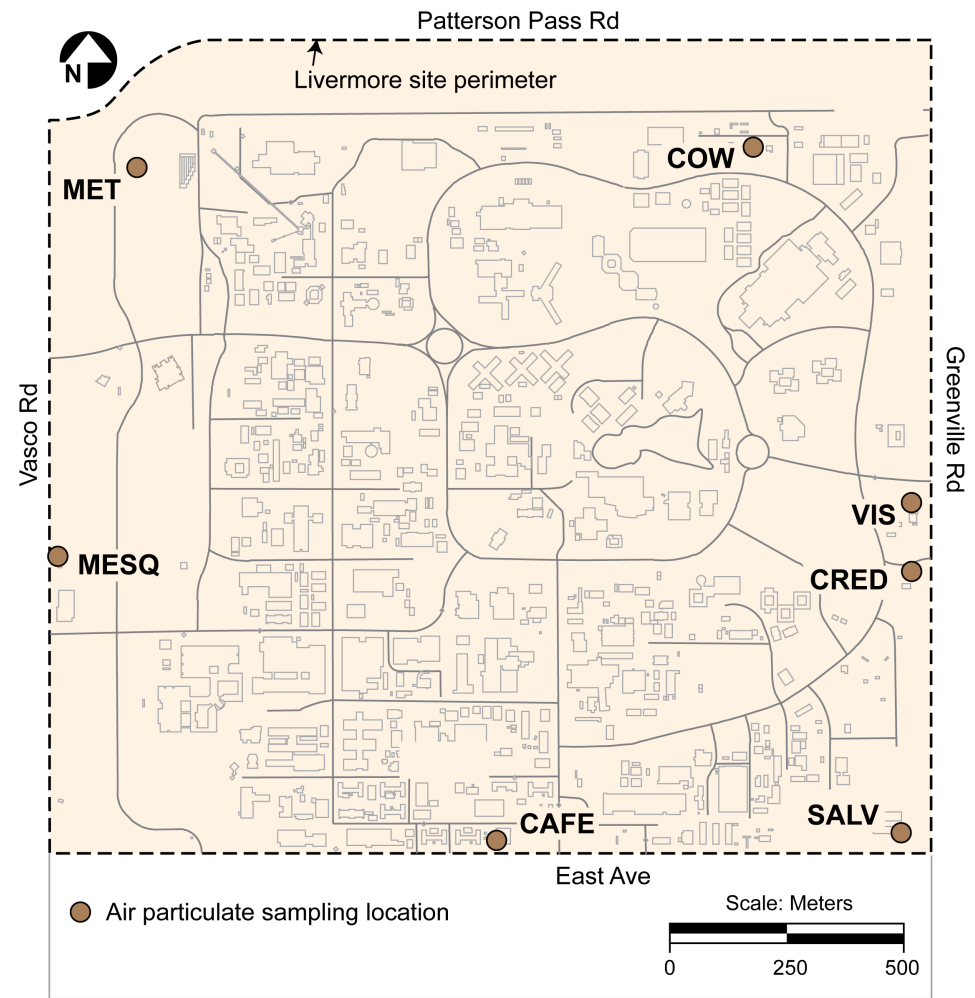

Figure 4-1. Air particulate sampling locations, Livermore site. 


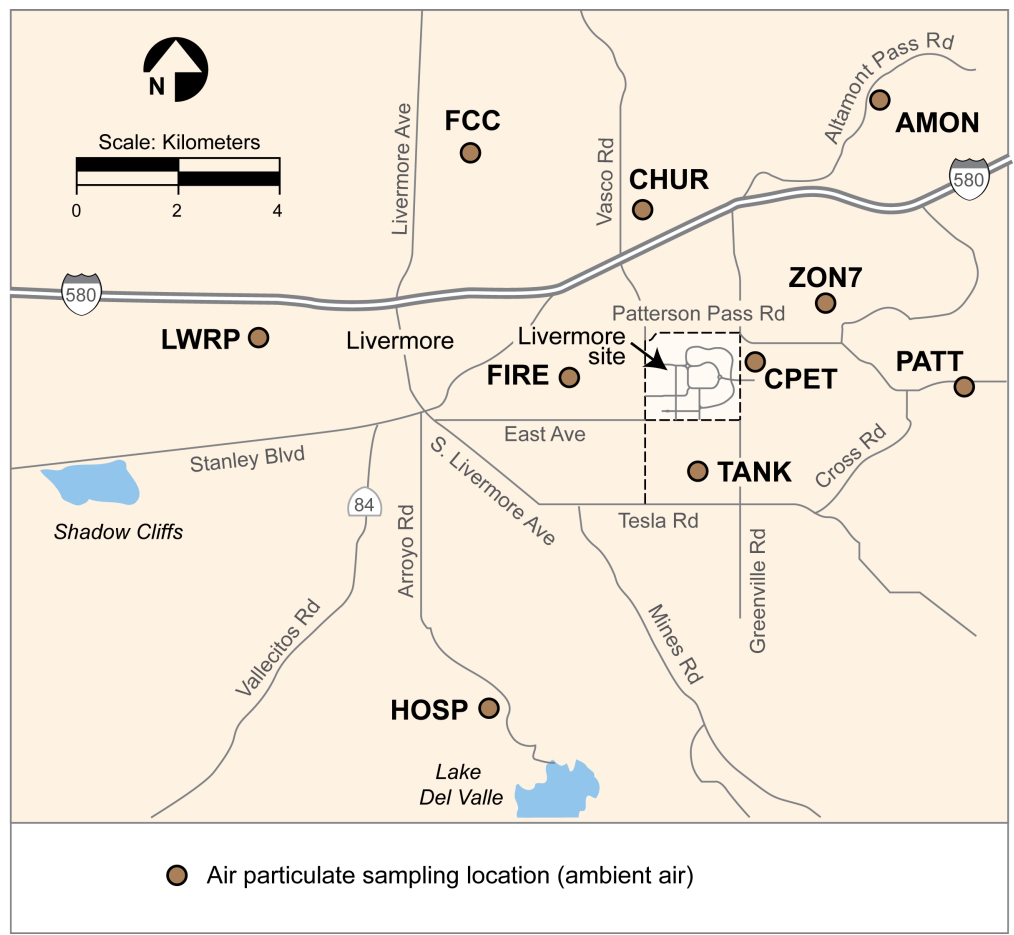

Figure 4-2. Air particulate sampling locations, Livermore Valley.

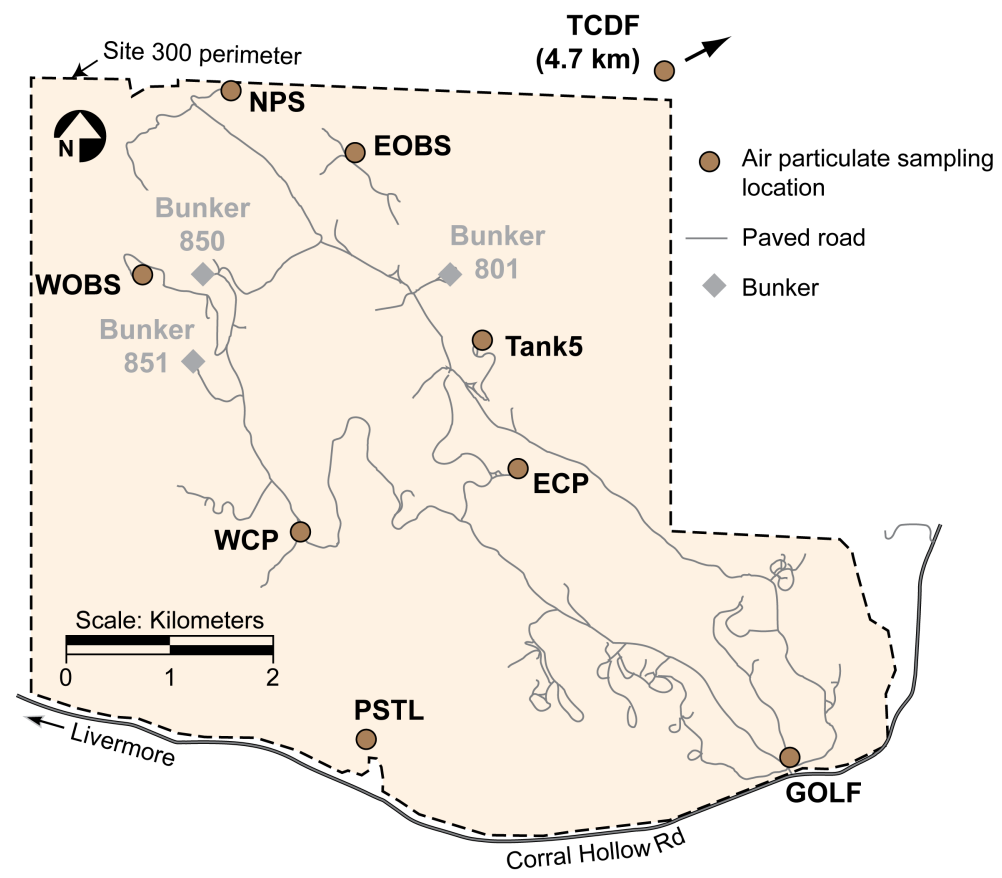

Figure 4-3. Air particulate and tritium sampling locations, Site 300. 


\subsection{Procedures for Laboratory Analysis}

All samples are submitted to the analytical laboratory weekly, or bi-weekly depending on sample collection frequency, where they are analyzed after a 4-day delay to allow for decay of the radon and thoron daughters. Samples are submitted to the laboratory with a chain-of-custody along with a spreadsheet with the flow data for each sample.

Portions of all air particulate samples (including those from Site 300) are screened for gross alpha and nonvolatile beta-emitting isotopes by a gas-flow proportional counting system. Two composite samples are created by the laboratory from portions of LLNL and Site 300 air filters (for the entire month) and then analyzed for gamma emitting isotopes. Isotopic plutonium analysis is then performed on samples collected from the Livermore site locations; isotopic uranium analysis is performed on samples collected from the Site 300 locations. Beryllium analysis is performed on samples from selected on-site locations at both the Livermore site and Site 300 .

Data results from field samples are analyzed based on the area of the filter (per square centimeter) then divided by the flow volume so that the activity provided to the analyst in the data reports is activity per volume. Method blanks, laboratory control samples (LCSs), and field trip blanks have no flow associated with them; therefore, they are reported in activity per area.

A certified on-site analytical laboratory performs all of the air particulate analysis.

Table 4-1 describes the analysis, method of analysis, and the minimum detection limit.

Table 4-1. Air particulate analysis methodology and detection limits.

\begin{tabular}{|l|l|c|}
\hline \multicolumn{1}{|c|}{ Requested Analysis } & \multicolumn{1}{|c|}{ Method } & Detection Limit(a) \\
\hline Gross alpha \& gross beta & Gas-flow proportional counting & $5.0 \times 10^{-15} \mathrm{Ci} / \mathrm{m}^{3}$ \\
Beryllium metal & Inductively Coupled Plasma- Mass Spectrometry & $5.0 \times 10^{-12} \mathrm{~g} / \mathrm{m}^{3}$ \\
Plutonium 239+240 & Alpha Spectrometry & $5.0 \times 10^{-19} \mathrm{Ci} / \mathrm{m}^{3}$ \\
Uranium-235 & Inductively Coupled Plasma- Mass Spectrometry & $7.0 \times 10^{-16} \mathrm{~g} / \mathrm{m}^{3}$ \\
Uranium-238 & & $1.0 \times 10^{-13} \mathrm{~g} / \mathrm{m}^{3}$ \\
Gamma emitters & Gamma Spectroscopy & Depends on isotope \\
\hline
\end{tabular}

(a) Detection limits provided are averages. Individual sample results have detection limits that will vary somewhat based on background counts.

Sample analysis and data reporting are conducted using methodology as detailed in the following Physical and Life Sciences standard operating procedures (SOPS): SOP- EMP557, Preparation of Air Filters for Determination of Gross Alpha/Beta and Be, Pu, $U$, and Gamma Radioisotopes; SOP-EM-P554, Operation of Canberra Alpha Spectrometry Systems; SOP-CES-P512, Reporting CES Analytical Results; SOP-EM-P565, Beryllium Analysis by $I C P / M S$. 


\subsection{Data Quality Assurance}

\subsubsection{Precision}

One duplicate air particulate sampling unit operates at each site. The sampling locations of field duplicate samples are not identified on the filters, so the analytical laboratory does not know where the samples originated (procedure EMP-QA-DM, Sample and Data Management). This information is recorded on field tracking forms (FTFs) that are filled out in the field by the sampling technologist. The hi-vol sampling units for duplicate quality assurance/quality control (QA/QC) samples are rotated among the locations at bimonthly intervals.

After the analyst obtains the laboratory results, the concentrations of duplicates are compared. Different concentrations can be explained by analytical error and natural variability. In most cases, the difference between duplicates can be explained exclusively by analytical error. This is invariably true when concentrations are near the detection limits, which is the case with a majority of the air particulate radiological data. When one of the results in a pair is a nondetection, then the other result should be less than two times the detection limit. Natural variability becomes important at higher concentrations. Nevertheless, if all parts of the sampling system are working properly and no human error is involved, the mean ratio should be between 0.7 and 1.3. (See the Environmental Report, Quality Assurance chapter, for examples of evaluation of duplicate analyses.) If a larger difference is detected, the reason should be investigated by checking the information contained on the FTF. Specifically, the total flow rates and run times should be compared. If the total flow rates are similar, the counts per minute should also be similar during a sampling period. If the magnitude of the differences cannot be explained, the analytical laboratory is contacted to discuss any problems that may have occurred during analysis.

Laboratory batch duplicates (or splits) are created from the field samples collected each sampling period and are introduced blind into sample processing. The relative error ratio is calculated and reported for each split sample. If the control limit of 3.0 is exceeded, the source of the problem is investigated and corrected (EMRL procedures: SOP-CES-P810, Data Validation and SOP-CES-P811, Data Verification).

\subsubsection{Accuracy}

As an additional component of the QA program to ensure data accuracy, the radiological laboratory analyzes blanks and LCSs traceable to standards of the National Institute of Standards and Technology (NIST). The laboratory analyzes clean unexposed blank filters just as it would the routine filters. The laboratory also prepares and analyzes LCSs in 
which blank filters are exposed to known quantities of tracers. Tracer recovery evaluates the effectiveness of sample preparation processes that are used to isolate the radioisotope.

In addition to the lab review process required for data release, the analyst also reviews all quality assurance data (laboratory blanks and control samples). Data released that falls outside the lower control limit of $75 \%$ and above the upper control limit of $125 \%$ are rejected. In this case the laboratory must rerun or reanalyze the samples before delivering the data report.

After receipt of data, the environmental analyst compares the data to the action levels provided in this document. If data is outside the action limits or the analyst has reason to question the value, the analyst may ask for reanalysis.

\subsubsection{Completeness}

On an annual basis, the overall sample completeness is about $99 \%$ or higher. Problems causing loss of field samples include pump or flow controller failure and power outages. At Site 300, access to the sampling unit is often denied due to explosive testing and area closure. In such cases the sample is allowed to run for an extended period of time ( 2 to 3 weeks compared to the normal 1 week sampling interval). Periodic sample loss occurs in the laboratory; however, there is typically extra filter material available to rerun the sample.

With respect to laboratory analyses, the Water, Air, Monitoring and Analysis (WAMA) group requires that $90 \%$ of the samples submitted to and analyzed by the Environmental Monitoring Radioanalytical Laboratory (EMRL) yield valid data.

\subsection{Program Implementation Procedures}

The primary responsibility for activities related to the air particulate monitoring networks is assigned to a WAMA environmental analyst. The analyst is responsible for the design, implementation, and correct operation of the network; the analysis and evaluation of all monitoring results; data trending; documentation; and reporting. The following is a list of the procedures associated with the sampling network:

- EMP-AP-S, Air Particulate Sampling: Details of sampling, processing, and documentation for radiological and beryllium air particulates.

- EMP-AP-CA, Air Particulate Sampler Calibration: Details of calibration protocol.

- EMP-QA-DM, Sample and Data Management: Details how samples are handled, stored, and delivered.

In conjunction with the sampling procedures, the handling and validity of air samples is documented using FTFs, chain of custodies, and nonconformance reports. 
Informal field audits of the sampling procedures are completed periodically by the air particulate analyst.

\subsection{Action Levels}

The warning and action levels for air particulate were determined from data collected in 2010-2011. Table 4-2 provides the warning and action levels for gross alpha, gross beta, plutonium, beryllium, and uranium metals. As a screening tool, gross alpha and gross beta measurements are analyzed weekly or biweekly depending on the sample frequency. Gamma activity, isotopic uranium, isotopic plutonium, and non-radioactive beryllium are screened monthly (composite samples). Isotopes that do not occur naturally are investigated by the WAMA air analyst Warning and action levels for uranium-235 and uranium -238 take into account the isotopic ratio of uranium-235/uranium-238. Naturally occurring uranium (NU) has a ratio of 0.00725 and depleted uranium (DU) has a ratio of 0.002; a ratio in between $0.002-0.00725$ would have a corresponding percentage of uranium in NU and in DU. This ratio is taken into account for warning and action levels in addition to the steps described below.

When a warning level is exceeded, the analyst investigates by checking sampling operations performed by the technologist, reviewing the appropriate field tracking forms, verifying calibration, and doing a field check (or verifying that a field check was performed in the same calendar quarter) to confirm that the sampler is operating correctly and that the flow is comparable to $+/-10 \%$ to a secondary standard. When sample results exceeding action levels are not the result of sampling or field activities, the data are checked for transcription errors and the analytical lab is contacted to determine if any problems occurred during analysis. Reanalysis, including additional isotopic analysis, may be performed for verification of results and identification of detected isotopes (naturally occurring or a result of laboratory activities) for environmental reporting and dose consequences to members of the public. The analyst will also take into account sample location, past results, and whether the sample location is a known area of contamination. The analyst will also investigate if any recent laboratory activities in the area could have contributed to the elevated result.

Action level results are reported to the WAMA group leader by the WAMA air analyst. The action levels for isotopic uranium, isotopic plutonium, and non-radioactive beryllium, are set at less than $1 \%$ of the DOE derived concentration technical standard (DCT) (radiological), EPA NESHAPs (radiological), and the ambient concentration guide (ACG) (non-radioactive beryllium). 
Table 4-2. Action levels for gross alpha, gross beta, isotopic plutonium-239, and beryllium metals.

\begin{tabular}{|c|c|c|c|c|}
\hline Analyte Area & Mean & Standard Deviation & $\begin{array}{c}\text { Warning } \\
\text { Level } \\
\text { (upper) }\end{array}$ & $\begin{array}{c}\text { Action } \\
\text { Limit } \\
\text { (upper) }\end{array}$ \\
\hline Gross Alpha (micro-Bq $/ \mathrm{m}^{3}$ ) & 44 & 18 & 80 & 98 \\
\hline Gross Beta (micro-Bq/m3) & 386 & 271 & 928 & 1,200 \\
\hline Plutonium (nano-Bq/m³) & 20 & 17 & 54 & 71 \\
\hline Beryllium (pico-gram/m³) & 5 & 4 & 13 & 17 \\
\hline Uranium-235 (pico-gram $/ \mathrm{m}^{3}$ ) & 0.23 & 0.42 & 1.1 & 1.5 \\
\hline Uranium-238 (pico-gram $/ \mathrm{m}^{3}$ ) & 32 & 58 & 148 & 206 \\
\hline
\end{tabular}

\subsection{Preparation and Disposition of Reports}

Ambient air monitoring results are reported in the Site Annual Environmental Report (SAER) and the LLNL NESHAPs Annual Report.

The requirement for quarterly beryllium reporting to the BAAQMD was lifted in January 2002. LLNL has an agreement with BAAQMD to notify them within 24 hours should any location exceed the ACL limit of 10,000 pico-grams $/ \mathrm{m}^{3}$ in any 30 day sample interval. Annual reporting for beryllium and compliance with the BAAQMD requirements for regulation 11 rule 3 is done in the SAER. .

\subsection{Future Plans}

Future plans include continuing with the activities described in this chapter, and continuing to assess the need for sampler placement and relevant laboratory analysis based upon changing laboratory activities or changing regulatory requirements.

\subsection{References}

Bay Area Air Quality Management District (BAAQMD) Regulation 11, Rule 3. Available at http://www.baaqmd.gov/

DOE (1991), Environmental Regulatory Guide for Radiological Effluent Monitoring and Environmental Surveillance, U. S. Department of Energy, Washington, D. C. (DOE/EH-0173T).

Environmental Report (annual), Lawrence Livermore National Laboratory, Livermore, CA. (UCRL-50027). Available at https://saer.llnl.gov/

Harrach, R. J., S-R. Peterson, G. M. Gallegos, P. J. Tate, N. A. Bertoldo, and Paris E. Althouse (2003), LLNL NESHAPs 2002 Annual Report, Lawrence Livermore National Laboratory, Livermore, CA (UCRL-ID-113867-02). Attachment 3: Authorization letter for NESHAPs Compliance using surveillance network.

LLNL NESHAPs Annual Report, Lawrence Livermore National Laboratory, Livermore, CA. (UCRL-ID-113867). 


\section{Ambient Air Tritium}

Nicholas A. Bertoldo

\subsection{Introduction}

Potential air pollutants that can contribute to radiological dose or inhalation hazard from Lawrence Livermore National Laboratory (LLNL) operations include tritium, a nonparticulate radioactive isotope of hydrogen. Air can be a primary exposure pathway for human and ecological impact.

To reduce, control, and eliminate air pollutants from its operations, LLNL employs an array of engineering and administrative controls. LLNL conducts air surveillance monitoring in the environment to assess the adequacy of these controls and to determine the impact, if any, of its air pollutant releases on the environment.

Tritiated water and water vapor (HTO) can be incorporated into all biological systems and is readily mobile. It can enter the human body through respiration, ingestion, and absorption through the skin (Okada and Momoshima 1993). If air concentrations of HTO are measured, conservative doses from inhalation and skin absorption of HTO and ingestion of HTO and organically bound tritium (OBT) ${ }^{1}$ can be calculated quite accurately by means of the specific activity model (see Biermann et al. 2001, Appendix A). The specific activity model assumes that the tritium to hydrogen ratio in every environmental compartment is the same as the tritium to hydrogen ratio in air.

Ambient air tritium monitoring is part of a comprehensive and ongoing environmental monitoring program for LLNL. Data collected from air monitoring are used to demonstrate compliance with regulatory requirements and U.S. Department of Energy (DOE) orders, calculate the dose to public from LLNL activities, and monitor any changes in the activity detected in the airborne tritium levels in and around LLNL.

\subsection{Rationale and Design Criteria}

\subsubsection{Regulatory Drivers}

LLNL is subject to the National Emission Standards for Hazardous Air Pollutants

(NESHAPs) of the Clean Air Act (40 CFR 61, Subpart H). As part of its compliance with

1 Organically bound tritium (OBT) is formed during plant photosynthesis from HTO. It is tritium bound to the organic matter of plants. When animals eat these plants, OBT is transferred to the organic matter of the animal. 
this regulation, LLNL has authorization to use ambient air surveillance monitoring for public dose assessment for minor and diffuse sources.

The regulatory drivers for air tritium monitoring also include DOE Orders 458.1 and 231.1B. It is the objective of these DOE orders to operate DOE facilities and conduct DOE activities so that radiation exposures to members of the public are maintained within established limits. It is also a DOE objective that potential exposure to members of the public be kept as far below limits as is reasonably achievable (ALARA) and that DOE facilities have the capabilities to monitor for such releases.

Guidance for monitoring tritium in air is provided in Environmental Regulatory Guide for Radiological Effluent Monitoring and Environmental Surveillance, DOE/EH-0173T (DOE 1991). This document provides guidance on air sampling techniques and methods that apply to the extraction of moisture from the air for sampling HTO in air. Airborne emissions sampling and monitoring system design guidance is provided via this document to help the contractor "demonstrate that quantification of airborne emissions is timely, representative, and adequately sensitive." Additionally, the choice of an appropriate sampling method and precautions associated with sampling is provided. In addition to routine monitoring, environmental monitoring during an emergency situation is also considered. LLNL's surveillance air monitoring network is part of the Environmental program's emergency response program.

\subsubsection{Monitoring Objectives}

Data collected from the surveillance program are used to characterize the radiological conditions of the environment, estimate inhalation doses to the public, and provide compliance data for all applicable environmental regulations. Monitored air concentrations are compared to historical data in order to identify changes that may have occurred or measurement errors that are identified by inconsistencies. Concentrations at a single location or group of locations are compared with control or background locations to evaluate the effect of LLNL operations on the environment or identify reasons for unexpected changes in sample concentrations, (see e.g., Wilson et al. 2011, Section 2.3 Minor Sources).

Monitoring data may be used to validate derived results of dispersion model concentrations by confirming or refuting the model results. Accurate assessment of unknown diffuse emission sources may be made by comparison of the modeled air concentrations to that of measured perimeter air concentrations.

A new approach to this diffuse source term modeling was developed in 2007 and refined in 2008. The approach was applied to the data reported in the annual NESHAPs 
regulatory compliance report to compare the combined effect of the diffuse source terms and known stack emissions on the perimeter dose to the public.

The approach compares measured air concentrations from sampling locations around the Livermore site perimeter with derived air concentrations developed by scaling the diffuse source term parameters that are used as input in the CAP88PC Version 1.0 dispersion model. Parameters that are fixed in the modeling are the known stack emission data. The diffuse source terms are then varied. By minimizing the variance between the observed and expected values, the unknown diffuse term or combined number of terms may be adjusted to determine the best fit to the measured data. Figure 5-1 compares the weighted average of the measured data (wtd.avg, or sample weighted avg. due to its contribution effect) to the air concentration derived by the dispersion model (cap.avg or modeled "CAP-88-PC 1.0 avg).

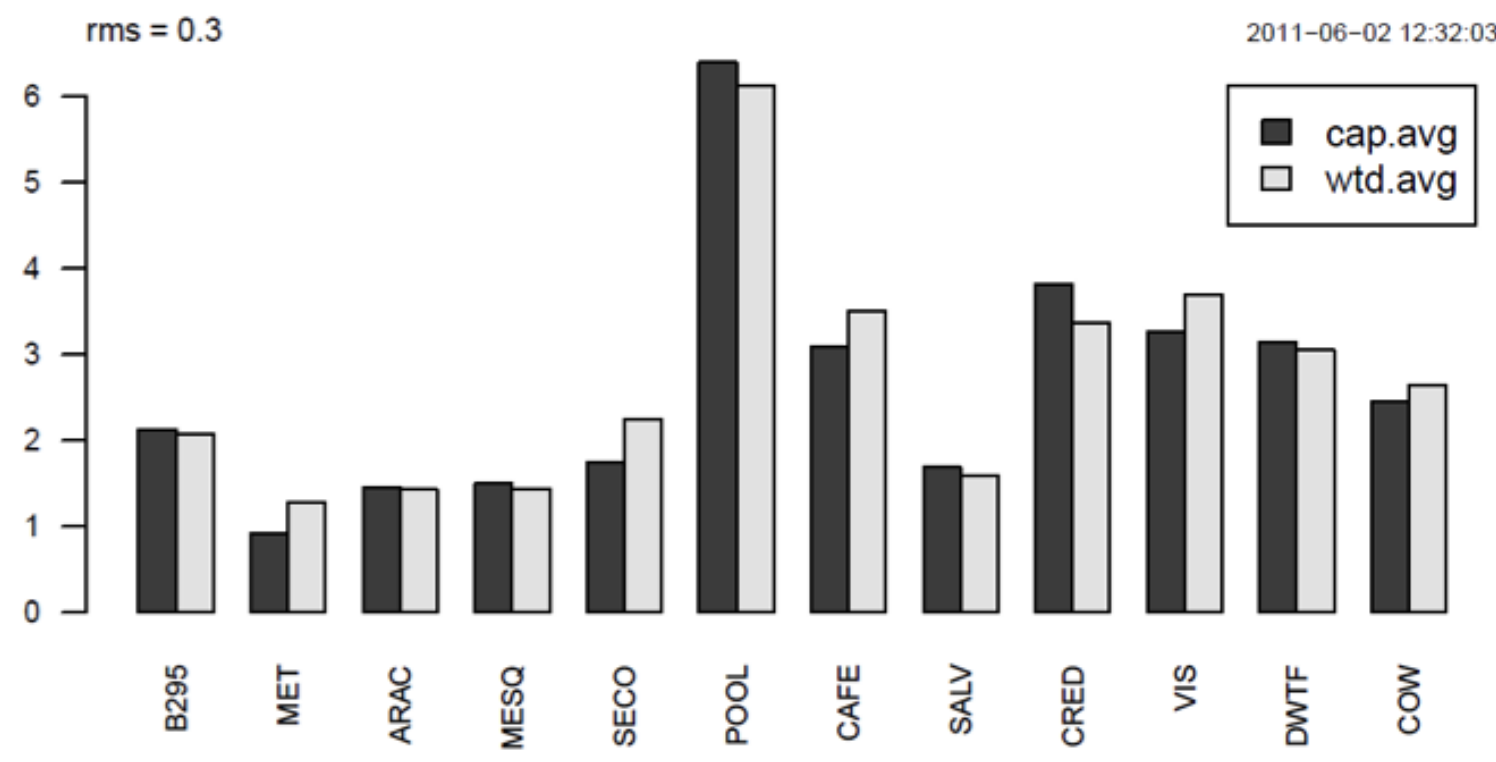

Figure 5.1. Comparison of measured (wtd.avg) and modeled (cap.avg) annual mean concentrations of tritiated water vapor (HTO), $1 \times 10^{-12} \mathrm{Ci} / \mathrm{m}^{3}\left(\mathrm{pCi} / \mathrm{m}^{3}\right)$ in air at Livermore site locations, 2010.

\subsubsection{Off-Normal Releases}

According to DOE/EH-0173T, environmental monitoring during an emergency situation should be considered (DOE 1991). LLNL's routine air monitoring network is part of environmental emergency response program. The air-tritium sampling units do not provide data in real-time, but they are readily available if sampling is needed to confirm elevated concentrations due to an accidental release. 


\subsubsection{Sources and Analytes}

Tritium is the only non-particulate radionuclide from LLNL operations present in the environment at concentrations that warrant monitoring. Historically most tritium is released as tritiated water (HTO) and tritiated hydrogen gas (HT) from the Tritium Facility (Building 331). In recent years, the important contributors to estimated dose have been the Tritium Facility (Building 331 and its associated operations) and the Building 612 Radioactive and Hazardous Waste Management Yard. Operations at the Decontamination and Waste Treatment Facility (DWTF, Building 695) also release tritium, but have been at significantly lower concentrations resulting in insignificant contributions to the site-wide dose by several orders of magnitude (for sample data, see the annual LLNL NESHAPs Report [e.g., Bertoldo et al. 2009]).

Although emissions have been significantly reduced at Building 331, diffuse sources of HT/HTO still exist and are expected to contribute to the site-wide exposure in the future. In addition, the National Ignition Facility has recently come on-line, and it has become an additional emission point source for HTO. Environmental monitoring is conducted routinely by LLNL for HTO only. Monitoring for HT in the environment is unnecessary because the potential inhalation dose from HT is approximately 10,000 times lower than an inhalation dose from a comparable air concentration of HTO and because monitoring for HTO accounts for tritium released both as HTO and as HT that has been converted to HTO in the environment.

Tritiated organics (e.g., tritiated methane) may also be released to the environment. The operations at LLNL are such that the likelihood of such releases is minimal, and the potential dose to the public is below any level of concern.

At Site 300, both past and current activities influence emissions and environmental impacts. Historically, tritium-contaminated material from explosive tests at Site 300 was disposed of in the site's landfills. Tritium purge water from routine monitoring of groundwater wells in areas where elevated tritium levels occur also represents a usually insignificant diffuse source of tritium emissions at Site 300. These sources of tritium may cause slightly elevated air concentrations locally. One air tritium sampler at the location (PSTL) that represents the site-wide maximally exposed individual (SW-MEI) fulfills NESHAP's compliance requirements.

\subsubsection{Collection Methods}

A suitable collection technique for tritium must remove moisture from the air. This is done by pumping a known volume of air through a desiccant that absorbs all the moisture from the air. The length of the sampling period depends on the amount of desiccant used, average absolute humidity, and airflow rate. DOE/EH-0173T (DOE 1991) recommends the use of silica gel as a desiccant, as is done by LLNL. 
The LLNL tritium samplers, operating at a flow rate of approximately $500 \mathrm{~mL} / \mathrm{min}$, use about $700 \mathrm{~g}$ of silica gel desiccant in a cylindrical flask to trap the tritiated water vapor during the two-week sampling cycle. The silica-gel desiccant is changed in the flasks every two weeks. Data collected include location, date on, date off, elapsed sampling time, instantaneous and total flow rates, empty flask weight, flask weight with dry silica gel, and flask weight with wet silica gel. All weights are captured electronically (EMPAT-S Instruction 1, Air Tritium Pre-Sampling Activities). Each sample has a sample identifier that accompanies it through the analysis.

The sample collection for tritium is a simple exchange process (EMP-AT-S Instruction 2, Air Tritium Sampling Activities). The sampling technologist determines the existing flow rate, removes the exposed flask, and places it in the special transport carrier. Then, a replacement flask containing fresh silica gel is placed on the sampling unit. The flow rate is checked, and if necessary, adjusted. The technologist then completes the field tracking form (FTF) in the logbook. About $70 \mathrm{~g}$ of moisture is extracted from the air during the two-week sampling period, but the exact quantity will depend upon the average absolute humidity and the volume of air passed through the sample. If the silica gel indicator has not turned color completely, this indicates that the volumetric sample has not saturated the media (termed, "break-through") and that all air moisture has been removed from the air as it passed through the silica gel during the sample period. A complete, detailed procedure for tritium sample collection is found in procedure EMP-AT-S, Air Tritium Sampling and its five sets of instructions:

1. Air Tritium Pre-Sampling Activities.

2. Air Tritium Sampling Activities.

3. Equipment Maintenance Tracking.

4. Annual Rotameter Calibration Check.

5. Air Tritium Electronic Flow Meter Calibration.

There are very few cross-contamination concerns with air tritium samples because the field technologists never come in physical contact with the silica gel samples. Special care is taken to minimize the possibility of breaking a flask containing an air tritium sample. Each flask is wrapped in plastic mesh to reduce the chance of breakage during transportation. The sample flasks are transported in a Plexiglas transport carrier specifically designed to hold them. 


\subsection{Extent and Frequency of Monitoring and Measurement}

\subsubsection{Sampling Locations}

The configuration of LLNL's air tritium monitoring network is based on the guidance provided by DOE/EH-0173T (DOE 1991). In addition to perimeter locations, off-site tritium monitors are situated in the areas with the potential for the highest air concentrations, background locations, and other locations of interest.

Currently, tritium air samplers operate continuously at 12 locations on the Livermore site (Figure 5-2), at 7 locations in the Livermore Valley (Figure 5-3), and at 1 location near the south boundary of Site 300 (Figure 5-4). In accordance with DOE/EH-0173T (DOE 1991), the air tritium-sampling network includes:

1. CRED (Figure 5-2), the location where the maximum, predicted ground-level concentrations at the perimeter from all releases coincides with the location of a given publicly accessible facility.

2. HOSP (Figure 5-3), the background or control location about 7 or $8 \mathrm{~km}$ from the site in an upwind direction. Although 10-15 km distant is recommended for a background location, concentrations of tritium at HOSP are expected to be below detection limits.

3. FIRE (Figure 5-3), the location in the nearest community (Livermore) within a $15 \mathrm{~km}$ radius.

Resources, manpower, and logistics (such as the availability of electrical power, access, and security) are also considered when selecting a sampling location.

Offsite samplers are placed both upwind (VET) and downwind (ZON7, also the site of a water treatment plant) from LLNL. The tritium-sampling network provides a comprehensive assessment of tritium concentrations in the Livermore Valley. 


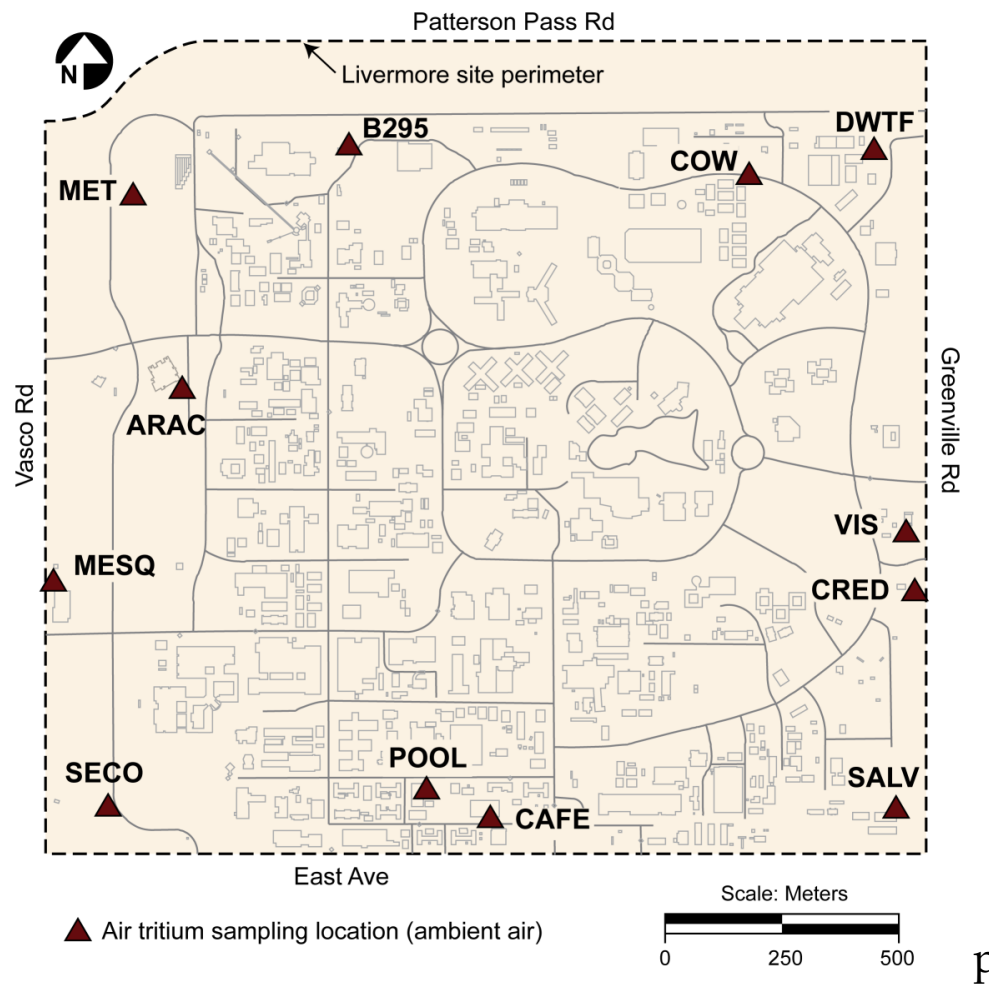

Figure 5-2. Air tritium sampling locations, Livermore site.

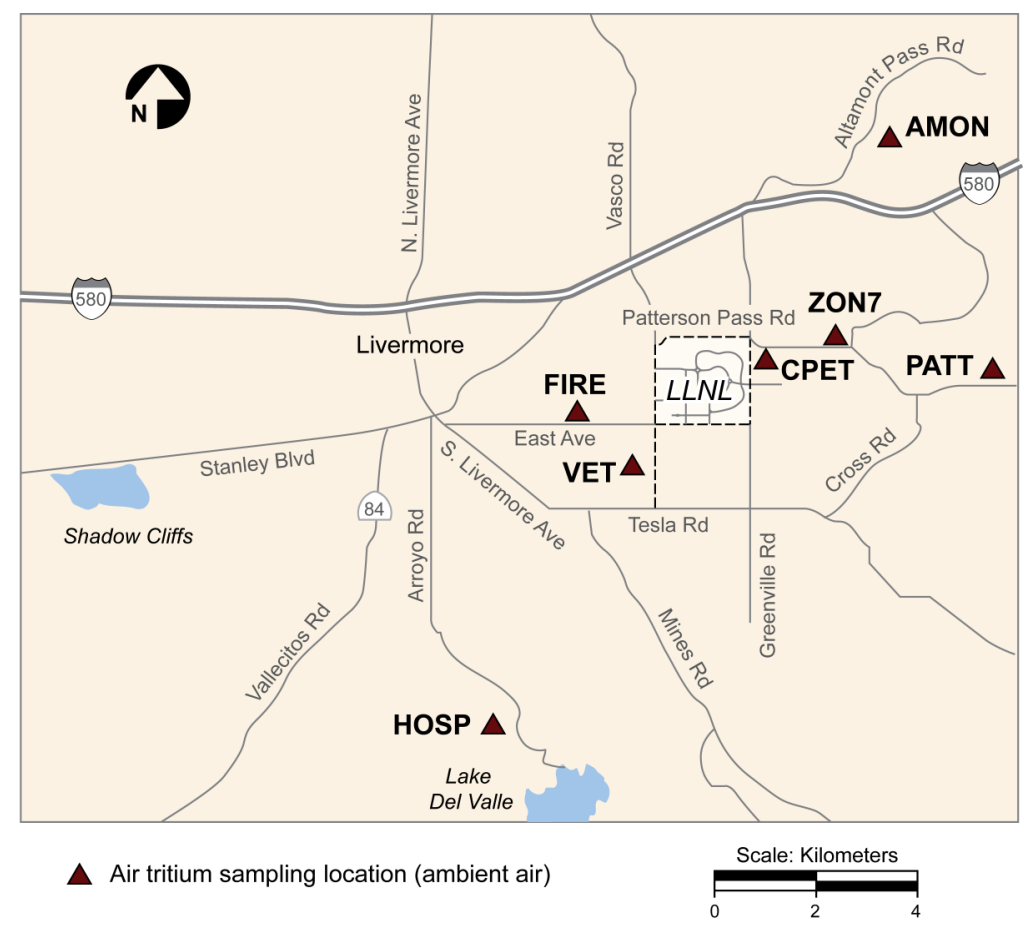

Figure 5-3. Air tritium sampling locations, Livermore Valley. 


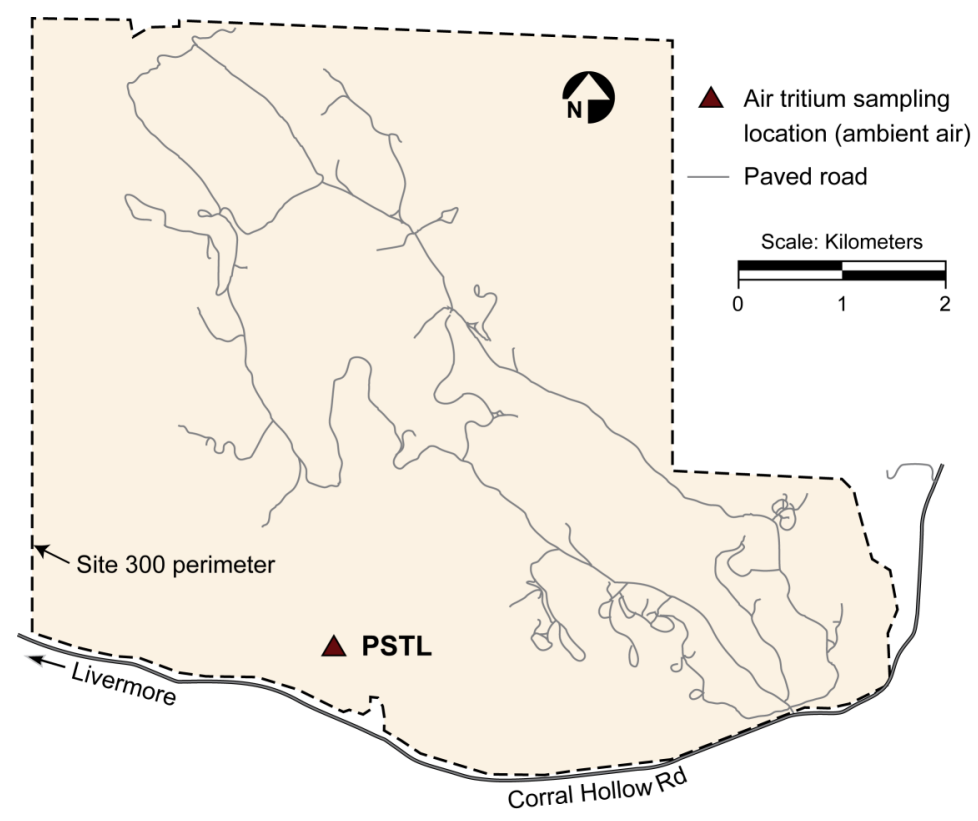

Figure 5-4. Air tritium sampling location, Site 300.

A description of all past and present sampling locations is maintained in a database. The WAMA group maintains a hardcopy of all current sampling locations.

\subsubsection{Sampling Frequency}

Many factors must be considered to determine sampling frequency. These factors include limitations of the sampling units themselves, amounts of moisture required for analysis, flow rates, and sample retrieval time. Typical sampling frequency for tritium is biweekly at LLNL. All routine air tritium sampling, regardless of location, is conducted according to the LLNL procedure EMP-AT-S, Air Tritium Sampling.

As circumstances may dictate, special studies are occasionally instituted in addition to the routine sampling. Past drivers for these have been to answer questions pertaining to site restoration efforts and analysis methods. No special studies are presently planned. LLNL will continue to implement special studies as warranted by circumstances.

\subsection{Procedures for Laboratory Analysis}

Flasks of silica gel that have been in the field for two weeks are taken to the Environmental Monitoring Radioanalytical Laboratory (EMRL). After the sampling technician weighs a flask on properly maintained and calibrated balances (SOP-CESP542, CES Balances) the flask is then placed in the fume hood of the EMRL, and EMRL assumes responsibility for the air tritium samples. All silica gel from each flask is emptied into a jar for freeze-drying. The water extracted by freeze-drying (CES-EMP542, Low-Level Tritium Analysis-Freeze Dry) is counted for HTO by liquid scintillation (SOP-EM-P552, Operation of Packard Tri-Carb LSC for Environmental Samples). 
About $5 \mathrm{~mL}$ of extract is needed for each liquid scintillation sample. A new equation to calculate the corrected concentration is developed for each new batch of silica gel (Guthrie et al. 2002). Equation 5-1 pertains specifically to indicating silica gel, bead size 2.0-5.0 mm (CAS \#7631-86-9) and is recalculated when using different bead size.

$$
\mathrm{C}=1.0309 \mathrm{C}_{\mathrm{m}}{ }^{\prime}[(0.0512+\mathrm{W}) / \mathrm{W}] \quad \text { Eq. } 5-1
$$

Where

$\mathrm{C}=$ corrected concentration (to equal the HTO in sampled air moisture).

$\mathrm{C}_{\mathrm{m}}{ }^{\prime}=\mathrm{HTO}$ measured in the extracted water.

$\mathrm{W}=$ fraction adsorbed water in silica gel $=$ (wet weight of silica gel - dry weight of silica gel)/dry weight of silica gel.

This correction is necessary because about $5 \%$ of the "dry" silica gel is water that cannot be removed unless the silica gel is destroyed. When the tritiated air moisture comes in contact with this residual water in the silica gel, exchange occurs. This results in dilution of the tritium concentration of the ambient air moisture by the water in the silica gel. This effect is greater when less water is extracted from the air relative to the mass of dry silica gel. A new equation will be developed for each new batch of silica gel. Concentrations are reported for the extracted water as the measured value in $\mathrm{pCi} / \mathrm{L}$ and as a calculated value of $\mathrm{pCi} / \mathrm{m}^{3}$ based on the volume of air that has passed through the sample.

\subsection{Data Quality Assurance}

\subsubsection{Precision}

The reporting limits for tritium in extracted air moisture are usually about 2.0 to $3.0 \mathrm{~Bq} / \mathrm{L}$ ( 50 to $80 \mathrm{pCi} / \mathrm{L}$ ). Typically this means that the reporting limits per cubic meter (a derived value) are usually between 0.011 and $0.019 \mathrm{~Bq} / \mathrm{m}^{3}\left(0.3\right.$ to $\left.0.5 \mathrm{pCi} / \mathrm{m}^{3}\right)$.

Two air tritium duplicate samples are taken during each sampling period. The sampling locations of field duplicate samples are not identified on the silica gel flasks, so the analytical laboratory does not know where the samples originated (procedure EMP-QADM, Sample and Data Management). This information is recorded on FTFs that are filled out in the field by the sampling technologist. The tritium air samplers for duplicate QA/QC samples are rotated among the locations at bimonthly intervals.

Upon obtaining analytical results, the sample and duplicate concentrations are compared to verify that the results are not significantly different from each other. Those concentrations that do not appear to be outside the margin of analytical error can be explained by natural 
variability. However, the difference between duplicates in the past has been explained exclusively by analytical error. This is predominately true when concentrations are at or near the detection limits provided by analytical chemistry and counting methods, which occur much of the time in the air tritium network. Natural variability becomes important particularly at higher concentrations.

Two laboratory duplicates (or splits) are created from the field samples collected each sampling period and are introduced blind into sample processing. The relative error ratio is calculated and reported for each split sample. If the control limit of 3.0 is exceeded, the source of the problem is investigated and corrected (EMRL procedures: SOP-CES-P810, Data Validation and SOP-CES-P811, Data Verification).

\subsubsection{Accuracy}

As an additional component of its program to ensure data accuracy, the radiological laboratory runs blank and control samples traceable to standards of the National Institute of Standards and Technology (NIST). Currently, no field blanks are collected. The laboratory blank is obtained by bubbling argon gas through $250 \mathrm{~mL}$ of water known to be free of tritium. The $250 \mathrm{~mL}$ of water is trapped on silica gel and extracted by freezedrying (CES-EM-P542, Low Level Tritium Analysis - Freeze Dry). A laboratory standard of known tritium concentration is prepared similarly to assess the recovery percentage. This efficiency of analytical recovery for the sample is reported for each sampling period and must fall within the EMRL's arbitrarily set internal acceptance criterion of $75 \% \leq$ recovery $\leq 125 \%$.

\subsubsection{Completeness}

Problems causing loss of field samples may include pump failure, power outages, flow meter malfunction, and flask breakage. With respect to laboratory analyses, WAMA requires that ninety percent of the samples submitted to and analyzed by EMRL yield valid data. If these completeness criteria are not met, the issue may be identified in the LLNL Issues Tracking System (ITS).

\subsubsection{Calibration}

Equipment in the EMRL is calibrated with sources that are traceable to NIST. Calibration follows a variety of methods, from calibration by a certified third party, to calibration with known standards that are made from traceable materials. Calibration practices are in accordance with standard procedures, and records are maintained for each piece of calibrated equipment. 


\subsection{Program Implementation Procedures}

The primary responsibility for activities related to the air-tritium monitoring network is assigned to a WAMA environmental analyst. The analyst is responsible for the network design, implementation, and correct operation; the analysis and evaluation of all monitoring results; data trending; documentation; and results reporting.

The laboratory preparation of the silica gel flasks is done by WAMA technologists in accordance with EMP-AT-S, Instruction \#1, Air Tritium Pre-Sampling Activities. Technologists follow EMP-AT-S, Instruction \#2, Air Tritium Sampling Activities, for the work in the field, when silica gel flasks are replaced. These instructions also cover final treatment of the samples before delivery to EMRL. Air tritium samples are submitted for analyses using sample control, chain-of-custody, and documentation procedures (EMPQA-DM, Sample and Data Management). The written procedures include requirements for sample collection and submittal for chemical analysis, keeping a log, and filling out FTFs and chain-of-custody forms. The procedures also require the sampling technologist to alert the environmental analyst about difficulties encountered during any sampling event.

Because the DOE/EH-0173T (DOE 1991) states that the "air sampling rate should not vary by more than \pm 20 percent, and the total air flow or total running time should be indicated", LLNL uses flow meters at the air tritium sampling locations. These flow meters provide the instantaneous flow rate, and the minimum, maximum, and total flow during a sampling period. Electronic flow meters are removed from the field and calibrated either biannually or when the percent difference between the flow off as measured by rotameter (see below) and the flow off measured by flow meter is greater than $15 \%$ for two consecutive sampling periods. Flow calibrations of the electronic flow meters are done according to EMP-AT-S, Instruction \#5, Electronic Flow Meter Calibration.

Gilmont rotameters are used to set the flow rate of the flow meter at the start of the sampling period to $500 \mathrm{cc} / \mathrm{min}$ and to measure the instantaneous flow when the sample flask is changed, which is compared with the indicated flow of the flow meter. Rotameter readings are also used to determine the total flow when a flow meter has failed or the location does not have a flow meter. The rotameter used for tritium air sampling flow adjustments are serviced and calibrated to NIST standards annually by the LLNL Hazards Control Instrument Calibration Laboratory pursuant to EMP-AT-S Instruction \#3, Annual Rotameter Calibration Check. Technologists visually inspect the rotameter for damage prior to use and ensure that the rotameter has been serviced within the past year. When the annual rotameter calibration is due, the WAMA sampling technologist delivers the rotameter to the Environment Safety and Health (ES\&H) Directorate Calibration 
Laboratory, and then picks it up with a new calibration curve when the calibration has been completed.

\subsection{Action Levels}

Table 5-1 shows the upper warning limits and upper action limits for each of the direction-based sampling groups in the air tritium perimeter-monitoring network; concentrations are expressed both in $\mathrm{Bq} / \mathrm{L}$ and $\mathrm{Bq} / \mathrm{m}^{3}$. The warning and action limits shown in Table 5-1 are two times and three times the geometric standard deviation, respectively. These limits were calculated from available data for each group during the period of 2002-2007. Sampling locations do periodically change.

Table 5-1. Upper warning and action limits for air tritium sampling groups by direction in $\mathrm{Bq} / \mathrm{m}^{3}$ and $\mathrm{Bq} / \mathrm{L}$.

\begin{tabular}{|c|c|c|c|c|}
\hline Direction & $\begin{array}{c}\text { Warning } \\
(\mathbf{B q} / \mathbf{L})\end{array}$ & $\begin{array}{c}\text { Action } \\
\mathbf{( B q} / \mathbf{L})\end{array}$ & $\begin{array}{c}\text { Warning } \\
\left(\mathbf{B q} / \mathbf{m}^{\mathbf{3}}\right)\end{array}$ & $\begin{array}{c}\text { Action } \\
\left(\mathbf{B q} / \mathbf{m}^{\mathbf{3}}\right)\end{array}$ \\
\hline $\mathrm{N}$ & 11.2 & 21.4 & 0.1 & 0.2 \\
\hline $\mathrm{NNE}$ & 59.9 & 176.5 & 0.5 & 1.4 \\
\hline $\mathrm{ENE}$ & 17.9 & 36.0 & 0.2 & 0.3 \\
\hline $\mathrm{E}$ & 36.0 & 91.2 & 0.3 & 0.7 \\
\hline $\mathrm{ESE}$ & 21.2 & 43.5 & 0.2 & 0.4 \\
\hline $\mathrm{SE}$ & 24.9 & 66.2 & 0.2 & 0.4 \\
\hline $\mathrm{S}$ & 42.2 & 120.7 & 0.3 & 0.7 \\
\hline WSW-SW & 25.9 & 88.5 & 0.2 & 0.6 \\
\hline $\mathrm{W}$ & 8.0 & 14.3 & 0.1 & 0.1 \\
\hline $\mathrm{NW}$ & 31.0 & 91.2 & 0.2 & 0.6 \\
\hline
\end{tabular}

Note: $\mathrm{Bq} / \mathrm{m}^{3}$ is derived from $\mathrm{Bq} / \mathrm{L}$ based on the total flow that has passed through the silica gel. $\mathrm{Bq} / \mathrm{L}$ is the fundamental measured value; $\mathrm{Bq} / \mathrm{m}^{3}$ is the reporting unit.

Each sampling period, the air tritium sample results for each location are checked to see if they fall within the warning limit. Any data results that are greater than the warning limit must be investigated. The investigation involves checking sampling operations by contacting the technologist who performed the sampling and by reviewing the appropriate FTFs. If the sample results that exceeded warning limits are not the result of sampling or field activities, further investigation is required. The data are checked for transcription errors, and the analytical lab is contacted to determine if any problems occurred during analysis. In some case, re-analysis may be performed. Atmospheric dispersion modeling may be used to assess the possibility that the number is real. Any results outside the action level are also subject to the same investigation as warning levels, but the environmental analyst must notify EFA management. Further action will be taken with EFA management concurrence. 


\subsection{Preparation and Disposition of Reports}

Data are analyzed based on EMP-QA-D, Data Analysis. The air monitoring results and inhalation dose assessments based on these data are reported in the annual Environmental Report. A comparison between mean annual tritium concentrations in air and air concentrations predicted by CAP88-PC is reported in the LLNL NESHAPS Annual Report.

\subsection{Future Plans}

As locations and release rates of tritium sources at LLNL change over time, the need to add, remove, or relocate air tritium samplers will be assessed through dispersion modeling.

\subsection{References}

Biermann, A. H., P. E. Althouse, N. A. Bertoldo, R. G. Blake, S. L. Brigdon, R. A. Brown, C. G. Campbell, E. Christofferson, L. M. Clark, K. J. Folks, G. M. Gallegos, A. R. Grayson, R. J. Harrach, J. M. Larson, D. H. MacQueen, S. Mathews, B. Nisbet, S. R. Peterson, M. J. Taffet, P. J. Tate, R. J. Vellinger, R. A. Williams (2001), Environmental Report 2000, Lawrence Livermore National Laboratory, Livermore, CA (UCRL-50027-00).

Bertoldo, N., G. Gallegos, D. MacQueen, A. Wegrecki, and K. Wilson (2009). LLNL NESHAPs 2008 Annual Report. Lawrence Livermore National Laboratory, Livermore, CA (UCRL-TR-113867-09).

Wilson, K., Bertoldo, N., Gallegos, G. MacQueen, D. and Wegrecki, A. (2010). LLNL NESHAPs 2010 Annual Report. Lawrence Livermore National Laboratory, Livermore, CA (UCRL-TR-113867-11).

DOE (1991), Environmental Regulatory Guide for Radiological Effluent Monitoring and Environmental Surveillance, U. S. Department of Energy, Washington, D. C. (DOE/EH0173T).

Guthrie E, N. Shen, and B. Bandong (2002), Isotope exchange and fractionation corrections for extraction of tritiated water in silica gel by freeze-drying techniques. Lawrence Livermore National Laboratory, Livermore, CA (UCRL-ID-148610) June 2002 .

Okada, S. and N. Momoshima (1993), "Overview of Tritium: Characteristics, Sources, and Problems," Health Physics 65, 595-609. 


\section{Sanitary Sewer}

Henry E. Jones • Robert A. Williams • Allen Grayson

\subsection{Introduction}

The Livermore site of Lawrence Livermore National Laboratory (LLNL) is the largest single source of the sanitary sewage processed by the Livermore Water Reclamation Plant (LWRP). LLNL and Sandia National Laboratories, California (Sandia/California), whose effluent flows into LLNL's, together produce an average of 1 million liters of sewage each day, approximately 4 percent of the volume treated at the LWRP. The combined volume, consisting primarily of sanitary wastewater and cooling tower blowdown water, is discharged to the city of Livermore sewer system from the northwest corner of the Livermore site (Figure 6-1).

After treatment at the LWRP, the wastewater is pumped out of the Livermore Valley through a pipeline shared with four other publicly owned treatment works (POTWs) and discharged into the San Francisco Bay. The sludge produced in the treatment process is disposed of in landfills.

The research and development activities at LLNL require the use of hazardous and radioactive materials; if significant concentrations of these materials were inadvertently discharged to the sanitary sewer, they could seriously impact LWRP operations and potentially degrade the quality of water resources. Programs to control these materials are mandated in federal and state law, U.S. Department of Energy (DOE) orders, and local regulations. In some cases, these requirements impose specific engineering standards for discharge control measures. Generally, though, they impose numerical limits on the presence of pollutants.

\subsection{Sewer Compliance Monitoring Program}

\subsubsection{Rationale and Design Criteria}

\subsubsection{Regulatory Drivers}

Nonradiological pollutants generated at the Livermore site are covered under the wastewater discharge permit issued by the Water Resources Department (WRD) (City of Livermore 2011). The permit is issued following review of an application that provides a comprehensive overview of LLNL wastewater discharges (Grayson 2011). 
Documentation includes a complete listing of chemicals used at the site, process diagrams for specific waste treatment and materials processing operations, a description of retention tank systems, and an overview of the sewer monitoring program. The permit covers reporting and monitoring requirements, as well as specific outfall discharge limits (Table 6-1) and point-source discharge limits as prescribed by the federal Categorical Standards. These standards are discussed in Chapter 8.

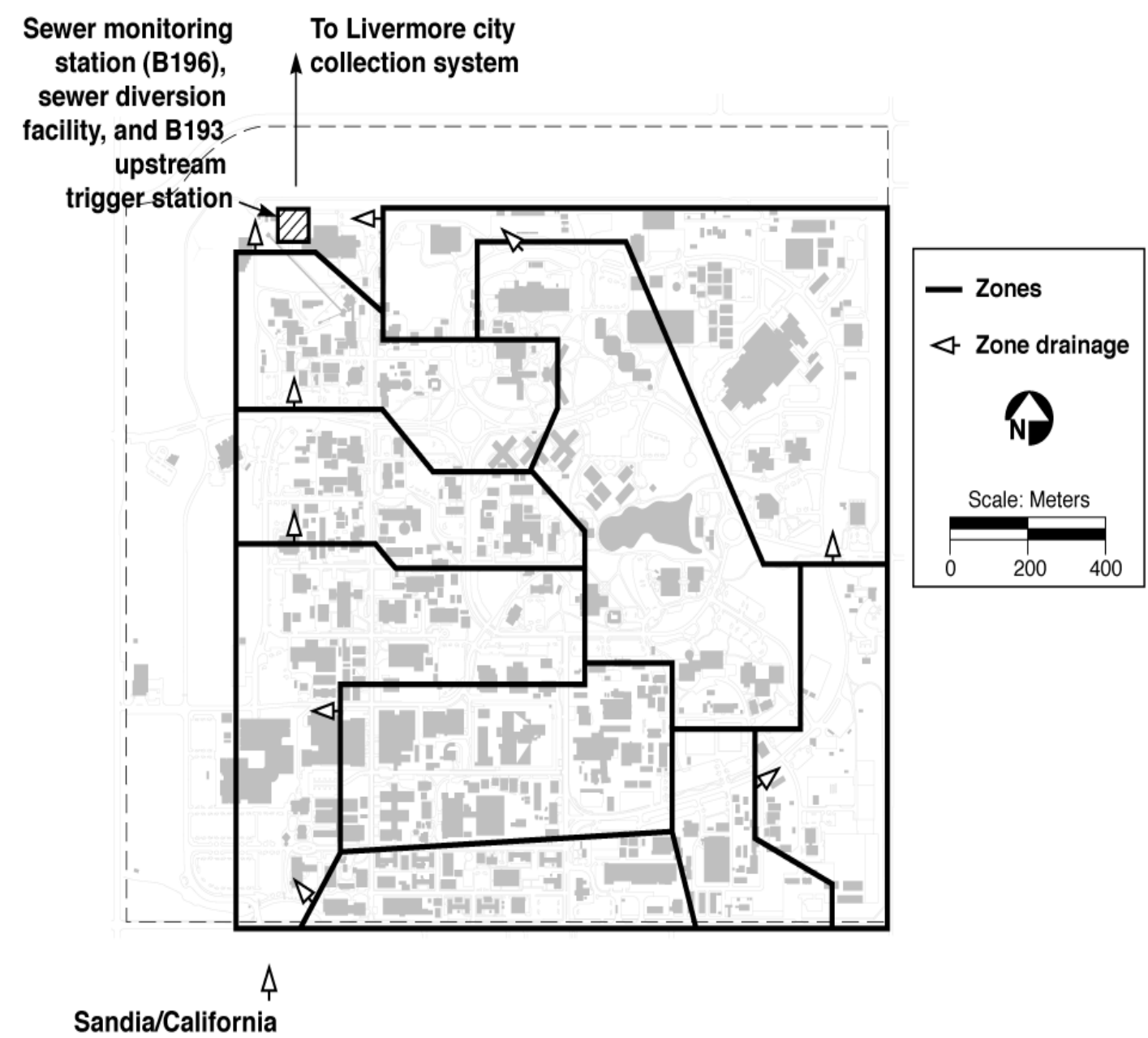

Figure 6-1. Livermore site sewer monitoring network.

General discharge prohibitions are also stated for materials that can contribute, or cause to be contributed, any pollutant or wastewater that will interfere with the operation or performance of the POTW (Permit 1250, §19, A-M):

- Explosive or pyrophoric solids, gases, or liquids.

- Solids or viscous substances.

- Toxic pollutants. 
- Substances that would cause the LWRP to be in noncompliance with sludge use or disposal criteria.

- Noxious or malodorous liquids, gases, or solids that would create a public nuisance or hazard to life.

- Substances that would cause the LWRP to violate its National Pollutant Discharge Elimination System (NPDES) permit or receiving water quality standards.

- Wastewater with objectionable color.

- Heated waters that may inhibit biological activity.

- Pollutants that may cause interference to the LWRP.

- Wastewater that would cause hazard to human life or would create a public nuisance.

- Radioactive wastes or isotopes that exceed limits established by a state or federal regulatory agency.

Table 6-1. Nonradiological pollutant outfall limits specified in the LLNL wastewater discharge permit.

\begin{tabular}{|l|c|}
\hline \multicolumn{1}{|c|}{ Parameter } & Limit (mg/L) \\
\hline Arsenic & 0.06 \\
Cadmium & 0.14 \\
Chromium & 0.62 \\
Copper & 1.0 \\
Lead & 0.20 \\
Mercury & 0.01 \\
Nickel & 0.61 \\
Silver & 0.20 \\
Zinc & 3.0 \\
Cyanide & 0.04 \\
pH & $5-10$ \\
Total toxic organics (TTO) & 1.0 \\
\hline
\end{tabular}

Source: City of Livermore 2011.

Discharge criteria for radiological pollutants are specified in DOE Order 458.1; Code of Federal Regulations (CFR), Title 10, Part 20.2003 (a)4, Subpart K; and the general discharge prohibitions of the wastewater discharge permit issued by the WRD (City of Livermore 2011). Both DOE Order 458.1 and 10 CFR 20 contain concentration-based discharge limits for specific radioisotopes. Also 10 CFR 20.2003 (a)4, Subpart K, contains total annual radioactivity discharge limits. The concentration-based discharge limits from the Derived Concentration Technical Standard (DCTS) pursuant to DOE Order 458.1 and the total annual radioactivity discharge limits from 10 CFR 20 are summarized in Table 6-2. 
Table 6-2. Limits applicable to LLNL for radionuclides in sewage.

\begin{tabular}{|l|l|c|}
\hline \multicolumn{1}{|c|}{ Source } & \multicolumn{1}{|c|}{ Radionuclide } & \multicolumn{1}{c|}{ Limit } \\
\hline 10 CFR 20.2003 (a)4, Subpart K, & Tritium & 5 curies/y $(185 \mathrm{GBq} / \mathrm{y})$ \\
& Carbon-14 & 1 curie/y $(37 \mathrm{GBq} / \mathrm{y})$ \\
& All others & 1 curie $(37 \mathrm{GBq})$ total/y \\
\hline DOE Order 458.1 & Tritium & $350 \mathrm{~Bq} / \mathrm{mL}$ \\
& Potassium-40 & $0.9 \mathrm{~Bq} / \mathrm{mL}$ \\
& Uranium-238 & $0.14 \mathrm{~Bq} / \mathrm{mL}$ \\
& Plutonium-239 & $0.026 \mathrm{~Bq} / \mathrm{mL}$ \\
& Americium-241 & $0.031 \mathrm{~Bq} / \mathrm{mL}$ \\
\hline
\end{tabular}

\subsection{Monitoring Objectives}

The primary goal of the sanitary sewer compliance monitoring program is to evaluate LLNL's compliance with regulatory requirements. The wastewater discharge permit issued to LLNL by the WRD requires continuous outfall $\mathrm{pH}$ and flow monitoring, analysis of weekly flow-proportional composite samples for nine specific metals (Table 6-1), and analysis of daily composite sample for tritium (Table 6-2). The permit also requires monthly analysis of 24-hour flow-proportional composite sample and grab samples.

The composite sample must be analyzed for water quality parameters (biochemical oxygen demand, total dissolved solids, and total suspended solids). The grab samples must be analyzed for an additional suite of pollutants (cyanide in January and July and volatile and semi-volatile organic compounds monthly).

Requirements for the radiation monitoring program are imposed but are less prescriptive. Gross alpha and gross beta analyses of daily flow-proportional composite samples are good screening measures for the presence of radioactivity, but do not give the specific radioisotopic concentrations necessary for comparison with limits contained in 10 CFR 20.2003(a)4, Subpart K and DOE Order 458.1. Gross radiation screening is also not sensitive to very low-energy beta radiation, such as that produced by tritium. For these reasons, the general screening program must include some isotope-specific analysis.

\subsubsection{Collection Methods}

The primary monitoring location, as required by the permit, is located at LLNL's point of discharge to the city collection system. Sampling at this location allows assessment of LLNL's compliance with discharge requirements. Assessment of the impacts of LLNL discharges requires sampling of process waste streams at the LWRP. On-site sampling requirements are discussed below. 
The constituents in sewage are constantly varying. The most representative characterization of the overall quality of wastewater is, therefore, obtained by compositing (that is, small aliquots of the discharge are combined into a large container, which at the end of the sampling period is mixed and decanted into sample bottles). There are two methods of compositing:

- The time-proportional method, which can be used for waste streams with relatively constant flow aliquots are taken at fixed time intervals. This method is not used for compliance samples at LLNL because flow rates vary from 200 to 2,400 L/min during the course of a normal day. It is used for backup sampling equipment.

- The flow-proportional method, in which an integrating flow meter monitors the total volume of wastewater discharged and activates a sampler each time a fixed volume of wastewater is discharged (e.g., once every $3785 \mathrm{~L}$ ). This method is used by the LLNL primary sampling system and provides an accurate daily average of pollutant concentrations when the flow rate varies widely.

The frequency of composite sampling should correspond with what is known about facility discharges and the hydrodynamics of the sewer flow. LLNL facility discharges generally are of two classes: brief releases of small (approximately 4 L) quantities through sinks or other plumbing fixtures, occurring at almost any hour of the day; and discharges on the 4,000 L scale, lasting from 10 to 30 minutes (as constrained by the capacity of most facility connections), and occurring mostly during normal working hours. The primary sources of these discharges are planned releases from boilers, cooling towers, and retention tanks.

Fluctuations of $\mathrm{pH}$ at LLNL are most frequently observed for the first, smaller-volume class of discharge. Monitoring data show that these releases usually last 2 to 10 minutes, so adequate samples should be obtained using flow-proportional compositing with an aliquot acquired every 2 to 5 minutes. At this frequency, the second class of discharges (larger volume, longer duration) will also be adequately sampled.

Compositing is most applicable for analysis of pollutants, such as heavy metals or minerals that are stable over time. Compositing cannot be used for less stable analytes. For example, volatile organic compounds (VOCs) may dissipate during collection and prior to analysis of a composite sample. Certain wastewater-quality parameters may be affected by the biological activity of the sewage, which also precludes the use of 
composite sampling. Grab sampling is used to collect samples for these types of analysis.

\subsubsection{Extent and Frequency of Monitoring and Measurements}

\subsubsection{Sampling Locations and Methodology}

\subsection{On-Site}

The sewer monitoring station (Building 196), as shown in Figure 6-1, is the location for outfall compliance monitoring. As required by the terms of the sanitary sewer permit, the LLNL outfall compliance sampling point is located at the northwest corner of the site, where LLNL sewage is discharged to the city collection system. The flowproportional composite and grab samples acquired here are used to determine the combined contribution of LLNL and Sandia/California discharges to the LWRP. The samples described here are all collected at the LLNL outfall. Two distinct sampling locations are used at the outfall:

- The Sewer Monitoring Station, or Building 196, which serves as the Laboratory's primary monitoring station. B196 daily samples, C196 weekly and grab samples are taken from this point of discharge.

- The flume, located in the vault to the east of Building 196. (The vault contains the flow-monitoring equipment used to trigger the composite sampling systems.)

The Building 196 sampler is activated once every 3785 L of flow (approximately once every two minutes at normal on-shift flow rates, and once every 10 minutes during the off shift). The weekly (designated C196) sampler is activated once every $11,355 \mathrm{~L}$ of flow.

\subsection{Off Site}

As described in procedure EMP-SW-LWRP, Sewage Sampling at WRD, LWRP personnel collect two types of samples for LLNL. Samples of LWRP effluent are used to monitor the release of soluble contaminants to the San Francisco Bay, while samples of the liquid in the aerated digesters are used to track levels of heavy metals and radionuclides that concentrate in the dried sludge. LWRP personnel collect these samples according to their own procedures. LLNL personnel pick up these samples and deliver them to the analytical laboratory for analysis.

\subsubsection{Sampling Frequency and Analytes Measured}

Compliance sampling and analysis follow regular schedules and are subdivided into two types — radiological and nonradiological. 


\subsection{Sampling and Analysis for Radiological Parameters}

Each day, a flow-proportional composite of LLNL effluent is acquired, as described in sampling procedure EMP-SW-B196, Sewage Sampling at B196. Each daily sample is analyzed for tritium activity. Monthly composites of the LLNL daily samples are analyzed for plutonium and cesium-137. A C196 weekly sample of LLNL effluent is also analyzed for tritium and gross alpha and beta activities (see procedure EMP-SWC196, Sewage Sampling at C196). The results of these analyses are used to assess compliance with gross radiation and isotope-specific discharge limitations imposed by 10 CFR 20.2003(a)4, Subpart K, and with the isotope-specific limitations of DOE Order 458.1

As described in procedure EMP-SW-LWRP, Sewage Sampling at WRD, daily composite samples of LWRP effluent are combined to create a monthly composite sample. These monthly composites are analyzed for alpha, beta, and tritium activity as well as for plutonium and cesium-137. Samples of LWRP's microbially activated liquid sludge are collected monthly and analyzed for gross alpha and beta activity. Quarterly composites of these monthly samples are analyzed for plutonium and gamma activity.

\subsection{Sampling and Analysis for Nonradiological Parameters}

The wastewater discharge permit issued to LLNL by the LWRP prescribes the requirements for monitoring nonradiological parameters. As described in sampling procedure EMP-SW-C196, Sewage Sampling at C196, a weekly C196 composite of LLNL effluent is acquired and analyzed for metals content. In addition, 24-hour composite samples and grab samples of LLNL effluent are collected from the B196 sampler once each month. These samples are submitted to be analyzed for water-quality parameters and toxic chemicals. Table 6-3 shows the complete list of parameters that are checked at C196. Rationale, scheduling, and sampling protocols are detailed in EMP-SW-C196.

A pH probe and circular chart recorder operate continuously inside the Building 196 Sewer Monitoring Station to record the $\mathrm{pH}$ levels of the effluent. The rationale and scheduling of routine operations for this equipment are discussed in two procedures: EMP-SW-M, Sewer Equipment Maintenance, and EMP-SW-CA, Sewer Equipment Calibrations.

Limited additional sampling and analysis for nonradiological analytes (not required by the discharge permit) is performed. The LWRP biosolids are analyzed monthly for metals. 
Table 6-3. Analytical methods used by off-site contract analytical laboratories.

\begin{tabular}{|c|c|}
\hline Analyte & Method \\
\hline Total settleable solids & EPA Method 160.5 \\
\hline Total suspended solids & EPA Method 160.2 \\
\hline Total dissolved solids & EPA Method 160.1 \\
\hline Alkalinity & EPA Method 310.1 \\
\hline Total phosphorus & EPA Method 365.4 \\
\hline Anion analysis & EPA Method 300.0 \\
\hline Chemical oxygen demand & EPA Method 410.4 \\
\hline Total organic carbon & EPA Method 415.1 \\
\hline Nutrients & EPA Methods $353.2,351.2$ and 350.1 \\
\hline Volatile solids & EPA Method 160.4 \\
\hline $\begin{array}{l}\text { Aluminum, calcium, chromium, iron, magnesium, } \\
\text { potassium, silver, sodium, and zinc }\end{array}$ & EPA Method 200.7 \\
\hline Arsenic, beryllium, cadmium, copper, lead, nickel, selenium & EPA Method 200.8 \\
\hline Mercury & EPA Method 245.1 \\
\hline Tributyltin & Gas Chromatography/Flame Photometric Detector \\
\hline Total cyanide & EPA Method 335.2 \\
\hline Volatile organics & EPA Method 624 \\
\hline Semivolatile organic compounds & EPA Method 625 \\
\hline Total oil and grease( & EPA Method 1664 \\
\hline Biochemical oxygen demand & SM17-5210B \\
\hline
\end{tabular}

Source: Blanket service agreements between Lawrence Livermore National Security, LLC, and off-site contract analytical laboratories.

\subsubsection{Procedures for Laboratory Analysis}

Radiological analyses of B196 daily samples are performed by the LLNL Radiation Measurements Laboratory (RML). The LLNL Environmental Monitoring Radioanalytical Laboratory performs high-sensitivity analyses for plutonium and cesium as well as for gross alpha, gross beta, and tritium.

Nonradiological analyses are performed by ALAB or by an outside contract laboratory. The LWRP monthly sludge samples are analyzed for metals content by LLNL ALAB using EPA methods. Off-site contract analytical laboratories perform all other nonradiological analyses. The standard analytical methods used by off-site contract analytical laboratories are listed in Table 6-3.

\subsubsection{Data Quality Assurance}

\subsubsection{Precision}

Quality control duplicate samples are collected and analyzed to verify the quality of analytical results. Under the quality assurance program for these monitoring networks, 
duplicate samples are collected according to procedures EMP-SW-C196, Sewage Sampling at C196; EMP-SW-B196, Sewage Sampling at Building 196; and EMP-SWLWRP, Sewage Sampling at WRD. These duplicate samples are submitted to the laboratory for analysis. The results for the duplicate samples are compared by the network analyst upon the receipt of the analytical results from the laboratory. Trip blanks are not necessary for these networks.

\subsubsection{Accuracy}

All quality control information provided by the analytical laboratories, including matrix spikes, matrix duplicates, and calibration standards, are examined by the network analyst to identify any analytical bias. If calibration standards or matrix spikes are consistently high or low, the analyst will contact the laboratory for an explanation.

\subsubsection{Completeness}

Sanitary sewage samples are collected from B196, C196 and LWRP. Given the potential for sample loss due to mechanical failure and laboratory mishaps, our target completeness is $90 \%$.

\subsubsection{Program Implementation Procedures}

The primary responsibility for activities related to the sanitary sewer monitoring networks is assigned to a Water, Air, Monitoring and Analysis (WAMA) group environmental analyst. The analyst is responsible for the network design, implementation, and correct operation of the network; the analysis and evaluation of all monitoring results; data trending; documentation; and reporting. The following procedures are associated with the sanitary sewer monitoring networks:

- EMP-SW-B196, Sewage Sampling at B196: Details the sampling, processing, and documentation for sampling at the B196 Sewer Monitoring Station.

- EMP-SW-C196, Sewage Sampling at C196: Details the sampling, processing, and documentation for sampling at the C196 Sewer Monitoring Station behind Building 196.

- EMP-SW-CA, Sewer Equipment Calibrations: Details the calibration protocol for sewer monitoring equipment.

- EMP-SW-LWRP, Sewage Sampling at WRD: Details the sampling, processing, and documentation for sampling at the LWRP.

- EMP-SW-M, Sewer Equipment Maintenance: Details the maintenance protocol for sewer monitoring equipment at B196.

- EMP-QA-DM, Sample and Data Management: Details how samples are handled, stored, and delivered. 


\subsubsection{Action Levels}

A WAMA analyst routinely checks data against action levels. For gross alpha, gross beta, and tritium analytical results, the informal, internally developed action levels are $3.7 \times 10^{-4} \mathrm{~Bq} / \mathrm{L}(0.01 \mathrm{pCi} / \mathrm{mL}), 0.02 \mathrm{~Bq} / \mathrm{L}(0.5 \mathrm{pCi} / \mathrm{mL})$, and $0.19 \mathrm{~Bq} / \mathrm{L}(5 \mathrm{pCi} / \mathrm{mL})$, respectively. The concentration-based discharge limits of DOE Order 458.1 and annual totals of 10 CFR 20 are considered formal action levels for the radiological analytes.

For nonradiological analytes regulated by LLNL's wastewater discharge permit, the action levels for $\mathrm{pH}$, cyanide, and total toxic organics (TTO) are the discharge limits specified in the permit. Action levels for regulated metals (arsenic, cadmium, copper, chromium, lead, mercury, nickel, silver, and zinc) are 50 percent of the limits specified in the permit for weekly samples and 100 percent of the limits specified in the permit for 24-hour composite samples (see Table 6-1).

If the concentration of an analyte exceeds an action level and the QC data demonstrate sampling and analytical measurement are defensible, the WAMA analyst looks for a correlation between a retention tank discharge and the analyte concentration. Depending upon the outcome, further investigation may be initiated by the WAMA analyst. The investigation may include, but is not limited to, the analysis of archived samples and the collection of non-routine samples using strategically located portable samplers. In cases where the concentration of a regulated metal in a weekly sample exceeds the 50-percent action level, archived 24-hour composite samples (corresponding to the weekly sampling period) must be submitted for analysis to provide direct comparison with LLNL's 24-hour discharge limit. If, in any case, the wastewater discharge permit limit is exceeded, the investigation must include resampling for the analyte in question in order to establish the time that LLNL returned to a state of compliance with the permit; the event is reported to Environmental Functional Area (EFA) management, the WRD, and DOE.

\subsubsection{Preparation and Disposition of Reports}

LLNL's wastewater discharge permit requires that outfall data be reported monthly. The report includes both the radiological and the nonradiological monitoring data received during the month. It discusses any unusual data or data that indicate exceedance of permitted levels, summarizes changes in the monitoring program, and reports on activity in the continuous monitoring program. Data tables present (1) monthly radiation monitoring results for the year to date (tritium, cesium, and plutonium), (2) monitoring results for tritium in LLNL daily sewage samples for the previous month, (3) weekly LLNL effluent metals concentrations for the last three months, (4) results for water quality parameters and toxic substances of regulatory 
concern for the year to date, and (5) monthly supplemental biological oxygen demand (BOD) and total suspended solids (TSS) results from the InSpectra analyzer.

If any analytical results exceed the WRD-issued outfall discharge limits, the wastewater discharge permit requires LLNL to issue a Five-Day Report that details the incident. A copy of this report is sent to DOE. If LLNL receives enforcement action for the event from the WRD, then LLNL prepares an Occurrence Report, as required by Order 232.1A.

The annual Environmental Report includes a summary and analysis of the radiological and nonradiological monitoring results for sewer.

\subsubsection{Future Plans}

New sampling and measurement equipment are constantly under evaluation for use within the existing system to improve performance or reliability. If improvements to the current system are possible then the process of acquiring and installing the upgraded equipment will be initiated.

\subsection{Sewer Control Monitoring Program}

\subsubsection{Rationale and Design Criteria}

\subsubsection{Regulatory Drivers}

Because LLNL is a research and development facility, its discharges of non-domestic wastewater are almost universally batch discharges, as opposed to the continuous discharges typical of many industrial facilities. LLNL has historically contributed between 3 and 5 percent of total LWRP influent, and is a significant contributor of flow. Although it is not technologically possible to monitor continuously for the presence of all contaminants at concentrations near WRD permit levels, LLNL does monitor for critical contaminants at concentrations that could pose an immediate threat to LWRP operations. Should a release of those contaminants occur, LLNL could then notify LWRP personnel to initiate mitigating measures (i.e., diversion of the contaminated influent into a holding pond for special treatment) and provide timely feedback to LLNL response and management personnel so that corrective action (either further training or modification of wastewater handling procedures) could be implemented.

\subsubsection{Monitoring Objectives}

The most important monitoring goal is the detection and containment of releases of radioactive materials that exceed discharge limitations or LLNL best management practices (BMPs), or impact the quality of LWRP solids. Specific monitoring goals are 
based principally upon an institutional evaluation of the probability and potential impact of releases of specific contaminants. Currently, those goals have emphasized the real-time continuous monitoring of $\mathrm{pH}$, flow, metals, and radioactivity. An evaluation of the compliance monitoring data establishes that other parameters of potential concern, such as organic chemicals and cyanide, are generally well within discharge limits and so do not merit the expense and effort of installing and maintaining real-time continuous monitoring capabilities.

\subsubsection{Sources and Analytes}

\subsection{Radioactivity}

LLNL has many radioactive sources that require control. The hazards posed by LLNL's inventory of radioactive materials are mitigated by administrative and engineering controls upstream of the sewer monitoring complex. The Laboratory invested in these controls, and they have been successful in preventing releases that pose a serious threat (as defined in EPA and DOE public-protection standards) to the public welfare.

Most discharge limitations are specified as bounds on the average monthly concentration for a specific radionuclide. See Section 6.2.1.1 for details about regulatory guidance for the average monthly concentration. Evidence that releases have exceeded the discharge concentration limits (DCTSs) of DOE Order 458.1 would require that LLNL implement best available technology to reduce discharges (DOE 2011). LLNL policy is to detect, as soon as possible, any release above the DCTSs so that control measures may be implemented prior to violation of the DCTSs for the month as a whole.

\subsection{Metals}

The primary purpose of the discharge limitations is to prevent disruption of LWRP operations. That purpose is the appropriate context for establishing the goals of LLNL's continuous metals monitoring program.

For metals that do not strongly suppress bacteria, 24 hours is the appropriate time frame for comparison with the discharge limitation; and that is, in fact, generally the enforcement standard that has been applied by the WRD in the recent past.

The metals concentration limits imposed in the permit issued by the WRD are presented in Table 6-1.

\subsubsection{Collection Methods}

A continuous monitoring system requires a complex balance between the desired capabilities and the limitations of the currently available technology. The following sections discuss the issues raised in implementing the available technology. 


\subsection{System Response Time}

The system responsiveness is limited by the mechanical characteristics of the monitoring and sampling equipment. Pumping a sample from the pipe to the monitoring station requires roughly 75 seconds (to ensure the representativeness of the sample, the delivery speed is constrained to the velocities typically observed in sewer systems, or roughly $61 \mathrm{~cm} / \mathrm{s}[2 \mathrm{ft} / \mathrm{s}]$ ). Phase separation equipment retains the liquid for roughly 30 seconds. The pneumatic valves of the Sewer Diversion Facility close approximately 6 seconds following activation. From this information, it can be concluded that performing analyses more frequently than once every 30 seconds would have no practical impact on spill control at the Sewer Diversion Facility. Because of these mechanical limitations to system response time, LLNL installed the Upstream $\mathrm{pH}$ Trigger Station (see Section 6.3.1.4.4).

\subsection{Technologies}

The technologies implemented for metals monitoring and radiation analysis are $\mathrm{x}$-ray fluorescence spectroscopy (XRFS) and gamma spectroscopy, respectively. The ultrasonic sensing technology implemented for flow rate measurement is typical for use in flow-through systems, but XRFS and gamma spectroscopy are usually used in a laboratory setting. The tendency of sewage to foul and clog the monitoring equipment complicates the design of an unattended system. Successful operation requires foulingresistant flow cells and comprehensive maintenance procedures. Furthermore, diagnostic sensors (pressure and voltage gauges, for example) must be used to test for anomalous conditions in the monitoring and flow systems. When equipment is not operating properly, sewage release alarms must be disabled and personnel notified so that normal operation can be restored.

Another issue to be considered is computer hardware and software. XRFS and gamma spectroscopy are complex techniques that require sophisticated signal analysis to generate reliable results. Acquisition of both the monitoring and status information requires complex data acquisition hardware and software. Much of this can be provided by third-party vendors, but LLNL-designed and -implemented software is necessary to control analysis of the data and annunciate alarms that initiate response activities. To ensure the reliability and accuracy of the software, a subset of the Institute of Electrical and Electronics Engineers (IEEE) software QA procedures must be met (ANSI 1983, 1998a, 1998b).

\subsection{Alarm Response}

When a possible contaminant release or system malfunction is identified, sewermonitoring personnel must be notified to control and/or correct the condition. DOE's Environmental Regulatory Guide for Radiological Effluent Monitoring and 
Environmental Surveillance (DOE 1991) requires that the alarm be in a location that is continuously occupied by operations or security personnel.

The alarm response process includes three steps:

1. The system annunciates either a contaminant release or a system malfunction, 24 hours a day, 7 days a week. Automatic diversion occurs when the possibility of a contaminant release exists.

2. Alarm response personnel evaluate the condition causing the alarm and contact WAMA personnel for assistance in determining corrective action (Step 3). The monitoring system must provide access to archive data to aid in the evaluation of the alarm.

3. WAMA personnel determine appropriate action to correct the conditions causing the alarm. At this point, alarm response personnel must be able to adjust monitoring parameters and correct any hardware conditions that may have occurred. If a spill actually appears to have occurred, EFA personnel develop an action plan for identifying and correcting the cause of the release (pre-established action plans are required by DOE [1991]).

All sewer alarm response activities must be thoroughly documented.

\subsection{Upstream pH Trigger Station}

The Upstream pH Trigger Station (Building 193), which is upstream of the Sewer Monitoring Station and the Sewer Diversion Facility (SDF) retention tanks, includes $\mathrm{pH}$ monitoring equipment capable of triggering a diversion at the SDF should the $\mathrm{pH}$ of LLNL effluent go above or below the limits specified in the permit. A sewer vault was installed 32 meters upstream of the diversion valve for the SDF retention tanks in the SDF yard (with $\mathrm{pH}$ monitoring and communications equipment to identify and signal the need for diversion). Grinder vaults were installed on each of the major sewer trunk lines approximately 30 meters upstream of the $\mathrm{pH}$-monitoring vault. Each grinder vault contains a grinder for sewage homogenization. The intent of this upstream trigger is to capture the entirety of a $\mathrm{pH}$ spill before it is released to the Livermore collection system. The leading edge of such a spill could not be contained using the Building 196 real-time continuous monitoring system in the Sewer Monitoring Station because of limitations in the system response time.

On the basis of this analysis, it appears that practical response times should be in the range between 30 seconds and 10 minutes. The upper range is simply a reasonable fraction of the 30-minute period expected for most retention-tank releases and guarantees that a substantial fraction of the volume is retained prior to discharge. 


\subsubsection{Extent and Frequency of Monitoring and Measurements}

\subsubsection{Continuous Sampling}

Continuous sampling for metals, $\mathrm{pH}$, flow, and radioactivity occurs at the Sewer Monitoring Complex (B196). Continuous sampling for $\mathrm{pH}$ occurs at the B193 Upstream pH Trigger Station.

\subsubsection{Alarm Annunciation}

Although sampling is performed continuously, actual alarm analysis is performed by a computer in discrete intervals. The frequency of analysis and the duration of an excursion prior to annunciation of an alarm are based upon four considerations:

- Potential severity of the impact on the LWRP.

- Impact of alarm response activities on monitoring program resources.

- Accuracy of the methods.

- Susceptibility of the equipment to false positives caused by fouling or instability of the monitoring equipment.

Because each sensor system has different design parameters, each contaminant has a different alarm algorithm.

\subsubsection{1 pH Alarm}

The terms of LLNL's discharge permit require that the $\mathrm{pH}$ effluent at the LLNL sewer outfall is no less than 5 and no greater than 10. Between the bounds of 2 and 12.5 (nonhazardous waste lower and upper bounds), the primary goal of the permitted $\mathrm{pH}$ values is to minimize damage to the sewer infrastructure. Alarm response is instantaneous below 5 or above $10 \mathrm{pH}$ units.

"Instantaneous," in this case, is as frequent as monitoring readings are taken. Although it is possible to monitor $\mathrm{pH}$ continuously, the shortest $\mathrm{pH}$ releases appear to be at least 2 minutes in length, with rise times on the order of 30 seconds. Once-a-minute readings are capable of detecting extreme $\mathrm{pH}$ excursions and guarantee that all but the first couple of minutes of a serious spill will be captured by the diversion facility. (Upstream $\mathrm{pH}$ monitoring equipment installed in 1998 captures the first few minutes of low- and high$\mathrm{pH}$ spills. See Section 6.3.1.4.4.) This is, therefore, the measurement frequency used for $\mathrm{pH}$ monitoring.

\subsection{Metals Alarm}

As summarized in Table 6-1, the discharge limitations for metals are in the parts-permillion (ppm) or sub-ppm range. LLNL's goals for metals spill monitoring sensitivity 
are roughly 50 times the values shown, with measurements made no less than once every 10 minutes. In the current system, analysis is performed once every five minutes, with alarm levels set in the 5- to 12-ppm range (see Table 6-4, where the discharge limits are reproduced to facilitate comparison). The measurement results fall in a Gaussian distribution, and the alarm levels are set at some multiple of the width of the distribution.

Table 6-4. Metals alarm levels.

\begin{tabular}{|l|c|c|}
\hline \multicolumn{1}{|c|}{ Metal } & $\begin{array}{c}\text { Permit limit } \\
(\mathbf{m g} / \mathbf{L})\end{array}$ & $\begin{array}{c}\text { Alarm level } \\
(\mathbf{m g} / \mathbf{L})\end{array}$ \\
\hline Arsenic & 0.06 & 5 \\
Cadmium & 0.14 & 5 \\
Chromium & 0.62 & 10 \\
Copper & 1.0 & 11 \\
Lead & 0.20 & 7 \\
Mercury & 0.01 & 7 \\
Nickel & 0.61 & 12 \\
Silver & 0.20 & 5 \\
Zinc & 3.0 & 10 \\
\hline
\end{tabular}

\subsection{Radioactivity Alarms}

In addition to potential interference from flow-cell fouling, the measurements of alarm conditions for radiation monitoring are further complicated by interference among the various decay signals. Radiation monitoring is actually the analysis of three distinct phenomena: gamma emission, beta decay, and alpha decay. Non-contact analyzers are rarely capable of analyzing beta and alpha emission directly, and certainly cannot do so in the case of sewage. The system installed at LLNL instead detects the emission of gamma radiation emitted as an after-effect of alpha and beta decay. Unfortunately, these "follow-on" signals (x-ray emission and bremsstrahlung radiation, respectively) are not as distinctive as the monoenergetic lines from direct gamma decay. In fact, direct gamma decay generally masks both beta and alpha decay, while beta decay masks alpha decay. For this reason, radiation alarms for beta decay are only enabled when no gamma lines are identified in the spectrum, and alpha-decay alarms are only enabled when neither gamma lines nor bremsstrahlung are evident.

While the alpha- and beta-radiation algorithms (described Section 6.3.3.1) are fairly straightforward, the gamma emission algorithm is complex. The algorithm begins with a search for any peaks in the analyzer energy spectrum. Often this analysis is performed against a low-statistics background, and occasionally the algorithm identifies random fluctuations in the background as a peak. When peaks are found, they are typically from medical radioisotopes such as technetium-99, thallium-201, 
iodine-131, or natural radioisotopes such as bismuth-214 and lead-214. The identified peaks are scanned against a peak library to identify radioisotopes that emit at a given energy. To make this algorithm feasible on a workstation computer, this library contains only those radioisotopes most commonly used at LLNL. If an emitted isotope is not in the library, the algorithm attempts to assign its peak lines to other radioisotopes in the library, potentially causing a false alarm. Finally, Compton scattering of gamma radiation can obscure decay lines at lower energies or generate small peaks when fluctuations in the Compton signal occur.

In the alpha and beta analysis, as well as interference from gamma decay, it has been observed that numerous transient phenomena give rise to spurious signals. These transient phenomena include intense sound, ground vibration, and poor electrical connections.

To suppress false positives and interferences, the alarm algorithm requires that the signal be reproduced over two-count intervals. For convenience, the interval is chosen to be the same as the metals analysis interval. This provides a 10-minute alarm cycle, compatible with the requirements outlined in the previous Section.

\subsubsection{Off-Line Sample Analysis}

Given the incidence of false alarms caused by flow-cell fouling and signal interferences, the evaluation of an alarm cannot rest solely on the results of the realtime analysis. To support the evaluation, a grab sample is automatically collected each time an alarm is annunciated. For immediate substantiation of a release, a desktop radiation counter (swipe counter) and $\mathrm{pH}$ probe are kept in the sewer monitoring station. For metals alarms, no immediate means of independently validating the alarm are available.

Even if an alarm can be initially substantiated, the interference and fouling problems described above make it impossible to evaluate the compliance implications of a release with data provided by the continuous monitoring system. For that purpose, portions of the grab sample are submitted for analysis by analytical chemistry laboratories. The preparation and submission of the grab sample are described in monitoring procedures EMP-SW-SWAR, Sewer Alarm Response, and EMP-SW-B196, Sewage Sampling at B196. Off-line analysis is also performed for alarms that cannot be definitively determined to have been false, based on the information preserved in the monitoring records.

Finally, if a release is confirmed, the daily composite sample acquired by the compliance-monitoring program (Section 6.2) is analyzed to assess the impact of the 
release on LLNL's compliance with the discharge limits for the day as a whole. Because these results are reported to the WRD, EPA-approved methods must be used.

Analysis and disposition of material held in the Sewer Diversion Facility are discussed in EMP-SW-DS, Diversion Facility Tank Sampling.

\subsubsection{Analysis Procedures}

The monitoring program uses standard, EPA-approved analytical methods for the analysis of grab samples. For these samples, analysis performed under extreme urgency ( 2 to 3 days) is required to support the timely confirmation of a spill and meet the requirement for a 5-Day Report to the Control Authority.

\subsubsection{Radiation Monitoring}

The sewage is injected into the bottom of a 1-L Marinelli beaker, which surrounds the detector vacuum shield. The analysis flow rate, roughly $4 \mathrm{~L} / \mathrm{min}$, is sufficient to prevent stagnation of the liquid at the bottom of the beaker but does not prevent sediment settling on horizontal surfaces. A typical 5-minute radiation analysis spectrum is shown in Figure 6-2. The region from $40 \mathrm{keV}$ to $2.4 \mathrm{MeV}$ is scanned for gamma peaks, which are then matched against a library of peaks from radioisotopes commonly used at LLNL. The detector efficiency is calibrated annually using a mixed fission product source, and the isotopic activity is determined from the results of the calibration and the total count rate in the highest branching ratio decay line. This industry standard algorithm has two significant deficiencies: it does not use multiline analysis to properly resolve interferences between isotopes with shared lines, and it does not use the activity information available in the side peaks and the Compton scattering edge (from partial conversion of gammas in the germanium detector). The most commonly detected gamma-emitting isotopes are medical isotopes and the radon daughters, bismuth-214 and lead-214.

Pure beta-emitting radioisotopes can be detected through the bremsstrahlung photons emitted by the high-energy electrons as they thermalize through collisions with the sewage itself. Neither the decay electrons nor the bremsstrahlung photons are monoenergetic. The observable impact on the gamma spectrum is an elevated count rate at all gamma energies below the maximum decay energy of the electron, with the greatest relative effect appearing at the lowest energies. The most sensitive measure for beta activity is the total count rate in the spectrum, which shows a significant deviation from background readings well before an alteration to the spectral shape can be discerned. 


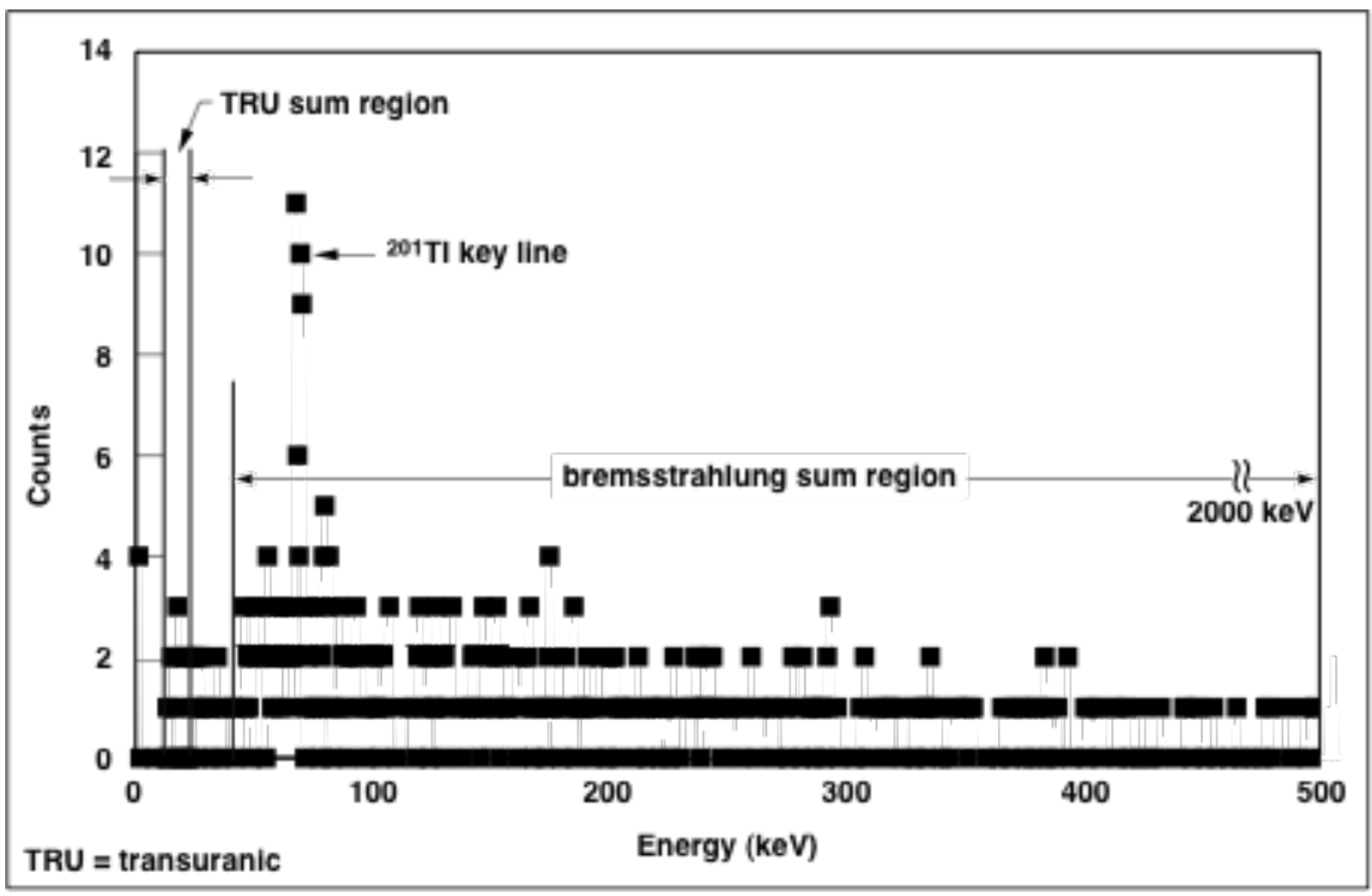

Figure 6-2. Typical gamma spectroscopy data.

Analytical deficiencies with this algorithm are a susceptibility to electronic noise with a characteristic shape, and interference from the Compton photons generated by gammaemitting radioisotopes. In principle, spectral analysis could help to eliminate the electronics background, while an accurate determination of spectral peak heights should allow an accurate subtraction of the Compton background. This has not been attempted. The primary failing of this method is a lack of specificity and, therefore, an inability to perform a meaningful calibration of the detector; true quantification of detector readings must occur through off-line analysis.

Analysis for alpha-emitting radioisotopes is very similar to the x-ray fluorescence technique used for metals monitoring. Alpha emitters are generally heavy atoms, and the departing helium nucleus usually ejects several inner-shell electrons. As the innershell electronic states of the daughter atom are filled, X rays are emitted in the 12- to $20-\mathrm{keV}$ energy range. Although these should in principle be resolvable as pure spectral lines, in the normal operating configuration the low-energy resolution and efficiency of the detector do not allow elemental identification. Thus, the analysis algorithm is again a simple comparison of the total count rate with the normal background, although this analysis is limited to the $12-$ to $20-\mathrm{keV}$ range. The lack of spectral information makes the analysis susceptible to interference from electronics noise, bremsstrahlung, and partial conversion (Compton scattering in the detector). Calibration is also problematic, 
although a check source of dilute plutonium solution has been used to establish the sensitivity of the method to alpha activities near the DCTSs of DOE Order 458.1 (DOE 2011).

\subsubsection{Metals Monitoring}

Adaptation of the x-ray fluorescence technique for flow-through analysis required significant technical innovation. A cross-section of the flow cell, with the attached $\mathrm{X}$-ray generator and the detector, is shown in Figure 6-3. The base geometry is standard for $\mathrm{x}$-ray fluorescence (XRF) analysis, with the generator positioned at right angles to the detector to minimize backgrounds from elastic scattering of the exciting $x$ rays. The detector is a $\mathrm{Si}(\mathrm{Li})$ crystal, with a $30-\mathrm{mm}^{2}$ active area and $3-\mathrm{mm}$ thickness. The flow cell is a three-piece construction with an aluminum base plate, an aluminum body plate, and a plastic cover. The x-ray generator illuminates a 4-cm hole in the center of the flow cell. A heavy Kapton sheet, glued to the cover, defines the rear of the analysis volume, while the front surface is bounded by spectroscopy-quality plastic films: a 0.04-cm Mylar film on the sample side provides water resistance, and a $0.04-\mathrm{cm}$ Kapton film provides tensile strength. The thickness of the analysis volume is considerably less than that of the body plate itself. Finally, a 1-cm, leaded plastic shield provides radiation shielding in the forward beam direction. Shielding in the reverse direction is provided by the material of the x-ray tube, the flow cell, the detector, and the mounting block that orients the system components.

Sewage is injected perpendicular to the plate. The body plate serves to blunt the force of the flow, which develops into a laminar stream prior to entering the restricted area of the analysis volume. In the system as currently configured, sewage flows from the bottom to top of the cell; in the reverse configuration, a large air pocket remains trapped in the cell when flow is introduced. Unfortunately, the current configuration encourages the accumulation of heavy phases, including silt and sand, in the flow cell.

Currently, no routine check of the system calibration has been developed. The calibration procedure takes several days and serves primarily as a performance check. Monitoring the total detector count rate can assess gross stability, and the energy calibration is readily assessed by monitoring the position of fluorescence lines from common sewage constituents and the x-ray filters. The metals calibration coefficients are assumed to be stable on the basis of the stability of these other parameters.

Finally, because of the phase separation in the preparation of the sample stream for analysis, the metals monitoring results do not include a true proportional contribution from the heaviest solids, which encompass everything from gravel to bolts. Reviews of 
the summary of operational impacts at the LWRP indicate that these settleable, nonleachable solids do not pose an operational concern.

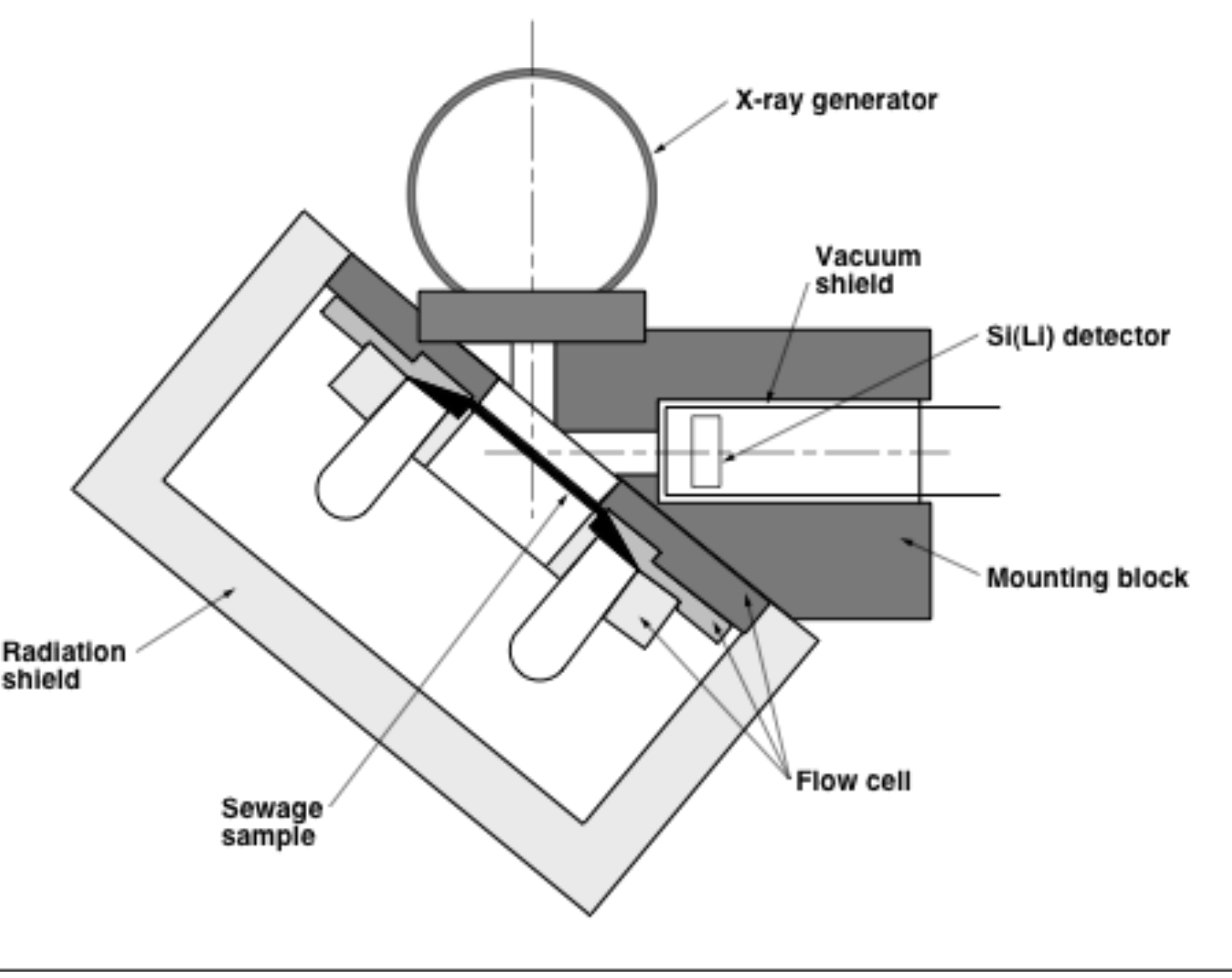

Figure 6-3. X-ray fluorescence analysis configuration for flow-through monitoring of metals in sewage.

\subsubsection{Data Quality Assurance}

\subsubsection{Precision}

Monitoring results are compared to analytical results from grab samples collected during an alarm event. Monitoring equipment is calibrated with certified standards.

\subsubsection{Accuracy}

All quality check information provided by the analytical laboratories, including matrix spikes, matrix duplicates, and calibration standards is examined by the network analyst to identify any analytical bias. If calibration standards or matrix spikes are consistently high or low, the analyst will contact the laboratory for an explanation. 


\subsubsection{Completeness}

The sanitary sewer is monitored continuously. Given the potential for system downtime due to mechanical failure, our target completeness is to maintain monitoring capability $90 \%$ of the time.

\subsubsection{Program Implementation Procedures}

The primary responsibility for activities related to the sewer monitoring networks is assigned to a WAMA environmental analyst. The analyst is responsible for the network design, implementation, and correct operation of the network; the analysis and evaluation of all monitoring results; data trending; documentation; and reporting. The following procedures are associated with the sewer monitoring networks:

- EMP-SW-B196, Sewage Sampling at B196: Details of sampling, processing, and documentation for sampling at the B196 Sewer Monitoring Station.

- EMP-SW-CA, Sewer Equipment Calibrations: Details of calibration protocol for sewer monitoring equipment.

- EMP-SW-DS, Diversion Facility Tank Sampling: Details of sampling, processing, and documentation for sampling sewage diverted by the B196 Monitoring Station.

- EMP-SW-M, Sewer Equipment Maintenance: Details of maintenance protocol for sewer monitoring equipment at B196.

- EMP-SW-SWAR, Sewer Alarm Response: Details of activities to be performed when responding to alarms at the B196 Sewer Monitoring Station.

- $\quad$ EMP-UT-M, UB193A, pH Monitoring Station Maintenance: Details of sampling and maintenance protocols for the UB 193 upstream $\mathrm{pH}$ monitoring station.

- EMP-QA-DM, Sample and Data Management: Details how samples are handled, stored, and delivered.

\subsubsection{Action Levels}

Action levels for the sewer control monitoring program are described in Section 6.2.6.

\subsubsection{Preparation and Disposition of Reports}

LLNL's wastewater discharge permit requires that outfall data be reported monthly. The report summarizes activity for both the compliance and control monitoring programs. Five-Day Reports are also required under the terms of the permit (see Section 6.2.7). The annual Environmental Report includes a summary and analysis of the control monitoring results. 


\subsubsection{Future Plans}

\subsubsection{Sampling Evaluation}

Improvements in the sewage sampling system will focus on upgrading the hardware and software that operate the sample pumps. As the need for additional improvements is identified, they will be scheduled for implementation.

\subsubsection{Real-Time Continuous Monitoring System}

Future improvements in the continuous sewage monitoring system will focus on the performance of the XRF metals monitoring equipment and the radiation monitoring equipment and software. As the need for additional improvements is identified, they will be scheduled for implementation.

\subsection{References}

ANSI (1983), IEEE Standard for Software Test Documentation, ANSI/IEEE Std 8291983, American National Standards Institute, Institute of Electrical and Electronic Engineers, Inc., New York, NY (AS 4006).

ANSI (1998a), IEEE Guide to Software Requirements Specifications, ANSI/IEEE Std 830-1998, American National Standards Institute, Institute of Electrical and Electronic Engineers, Inc., New York, NY.

ANSI (1998b), IEEE Standard for Software Verification and Validation Plans, ANSI/IEEE Std 1012-1998, American National Standards Institute, Institute of Electrical and Electronic Engineers, Inc., New York, NY.

City of Livermore (20011), Wastewater Discharge Permit/Chemical Storage Permit \#1250 (2011-2012), City of Livermore, Livermore, CA.

DOE (1991), Environmental Regulatory Guide for Radiological Effluent Monitoring and Environmental Surveillance, U.S. Department of Energy, Washington, D.C. (DOE/EH-0173T).

DOE (2011), Radiation Protection of the Public and the Environment, U. S. Department of Energy, Washington, D. C. (DOE/458.1).

DOE (2011), Derived Concentration Technical Standard, U.S. Department of Energy, Washington, D.C. (DOE-STD-1196-2011).

Grayson, A. R. (2012), Wastewater Discharge Permit Application, Lawrence Livermore National Laboratory, Livermore, CA (UCRL-AR-106905-12). 


\section{Retention Tank Sampling}

Allen Grayson

\subsection{Introduction}

Retention tank sampling is part of a comprehensive and ongoing environmental monitoring program for Lawrence Livermore National Laboratory (LLNL) (see Chapter 1). Data from retention tank sampling are used to determine disposition for tank contents and demonstrate compliance with regulatory requirements.

\subsection{Rationale and Design Criteria}

LLNL's wastewater retention systems consist of on ground tanks, underground tanks, aboveground tanks, piping, pumps, and ancillary equipment for collecting dilute rinse water and wastewater generated by LLNL research activities. These rinse waters and wastewaters can be hazardous, nonhazardous, radioactive, or mixed (i.e., hazardous and radioactive) wastes. Most systems collect and temporarily store dilute, nonhazardous rinse water from materials fabrication or finishing operations, or semiconductor research. The retention tank systems ensure that discharges to the LLNL sanitary sewer system are within internal discharge parameters designed to meet permit limits at the point of compliance. This policy ensures nonsewerable wastewater is properly stored until appropriate disposal or treatment can take place. ${ }^{(1)}$ This program provides the main component of a Slug Discharge Plan.

Installation of a retention tank system is based upon the potential for chemical and radiological inventories and operations at a facility to impact the Livermore Water Reclamation Plant (LWRP) operations. During normal operation, a retention tank collects small-quantity discharges that, given measures implemented at the source, usually comply with internal discharge limits. When the tank becomes full, the contents are sampled and analyzed to validate their suitability for discharge. If the content concentrations are below internal discharge limits, the contents are released to the sanitary sewer (see Section 7.2.1 for information about internal discharge limits). When pollutant concentrations are above internal discharge limits, the collected wastewater is transferred to the on-site Department of Toxic Substances Control (DTSC)-permitted Radioactive and Hazardous Waste Management (RHWM) facility.

(1) Federal law and the LLNL Permit 1250 prohibit the discharge of hazardous waste into the sanitary sewer. 
By law, all hazardous wastewater retention tank systems are required to have secondary containment capacity. This capacity is usually provided by a berm around the retention tank and all aboveground piping. During the rainy season, storm water that falls into the berm can present maintenance and operational challenges. Most serious is the management of rainwater captured within bermed containment of hazardous waste retention tank systems (ES\&H Manual, Document 32.2, "Management of Hazardous Waste Retention Tank Systems").

Many systems in place do not have features to control berm water and so must be drained rapidly following any significant rainfall. By agreement with the Central Valley and San Francisco Bay Regional Water Quality Control Boards (Fisher 1995; SFBRWQCB 1995), and the City of Livermore Water Resources Division (WRD), LLNL discharges uncontaminated berm water to the sanitary sewer provided specific administrative controls are met. These controls include screening the berm water to determine whether the $\mathrm{pH}$ is within an acceptable range; reviewing maintenance records and spill logs; and visually inspecting the tank system and the contained liquid.

\subsubsection{Regulatory Drivers}

Except for waste streams that are federally regulated under the Categorical Pretreatment Standards (see Chapter 8), the criteria for discharge authorization into the LLNL sanitary sewer are established by internal policy; LLNL internal policy is designed to ensure that wastewater leaving the site meets the outfall limits specified in LLNL's wastewater discharge permit (\#1250, City of Livermore). As enforced by the LWRP, the site outfall limits apply to the combined volume released to the city sewerage, rather than to individual processes. The outfall limits apply to both radiological and nonradiological contaminants. This allows LLNL some flexibility in developing internal criteria for releases from retention tanks consistent with permit limits. For these reasons, LLNL developed uniform release criteria for most of its retention tank systems. (The one notable exception, the Sewer Diversion Facility, is discussed below.)

Although preferable in principle, uniform release criteria cannot completely encompass the complexity of actual operations and in-place facilities. Predicting the impact of a tank discharge on pollutant concentrations at the site outfall requires some assumptions concerning the rate of release from the tank and the flow rate at the outfall. To derive its internal discharge limits, the Environmental Protection Department (the organizational predecessor to the Environmental Functional Area [EFA]) conducted a study using six years of retention tank release data coupled with time-proportional flow data. The internal limits were derived using conservative assumptions concerning release capabilities and discharge conditions. 
Isotope-specific discharge limits on radioactivity in sewage specified by DOE Order 458.1, Derived Concentration Technical Standards (DCTSs), and 10 CFR 20, subpart 20, are also applied at the LLNL site outfall, rather than on wastewater released from individual processes. For most radionuclides, isotope-specific activity released is far less than the isotope-specific concentration limits. Moreover, U.S. Department of Energy (DOE) Order 458.1 contains narrative requirements limiting the total activity to levels that prevent "long-term buildup of radionuclides in solids" and exposures to members of the public (principally publicly owned treatment works operators) "exceeding a small fraction of the basic annual dose limit". Concentrations of radionuclides in wastewater shall be controlled so that long-term buildup of radionuclides in solids will not present a handling and disposal problem at the LWRP (DOE 1993). In addition, for radioactivity, 10 CFR 20.2003 (a) 4, Subpart K, limits the total activity released during any one year to 1 curie (excluding tritium and carbon-14). To address these requirements, as well as concentration limits, the internal release criteria constrain the total radioactivity that can be released from all retention tanks during a single day.

\subsubsection{Monitoring Objectives}

It is the objective of this Program to ensure that wastewater leaving the site meets the outfall limits specified in LLNL's Wastewater Discharge Permit \#1250 (issued by the City of Livermore). Additional objectives include the protection of workers, both LLNL and City of Livermore personnel, who may be exposed to excessive contaminants as a function of their job responsibilities and the protection of LLNL property from the effects of chemical or radiological contaminates above preset limits.

\subsubsection{Sources and Analytes}

The criteria derived from these considerations are presented to the LLNL work force in the ES\&H Manual, Document 32.4, "Discharges to the Sanitary Sewer System." The internal discharge limits derived from the criteria, presented in Tables 7-1 and 7-2, indicate the scope and sensitivity of LLNL's retention tank sampling program.

Absent from Table 7-2 are release limits for specific radioisotopes other than tritium. Instead, limits are imposed on gross alpha and gross beta activities. This simplification reflects the practical aspect of managing a retention tank program: when retention tanks are at full capacity, the time between sampling and the return of analytical results imposes costs on the facility, either in the form of reduced storage capacity, the need to pay for additional storage capacity, or operational delays. Secondly, the cost of the analysis must be reasonable. 
Table 7-1. LLNL's internal discharge limits for nonradioactive parameters in noncategorical wastewater. (a)

\begin{tabular}{|l|c|}
\hline \multicolumn{1}{|c|}{ Parameter } & Limit (mg/L) \\
\hline Beryllium & 0.20 \\
Cadmium & 1.4 \\
Chromium & 6.2 \\
Copper & 10 \\
Mercury & 0.10 \\
Nickel & 6.1 \\
Lead & 2.0 \\
Silver & 2.0 \\
Zinc & 30 \\
Cyanide & 0.4 \\
Arsenic & 0.6 \\
pH & $5-10$ \\
Total toxic organics (TTO) & 4.57 \\
\hline
\end{tabular}

(a) These limits are calculated using internal flow characteristics and are applied only to upstream tank releases.

Table 7-2. LLNL's internal discharge limits for radioactive parameters in wastewater.

\begin{tabular}{|l|c|c|}
\hline \multicolumn{1}{|c|}{ Parameter } & Individual discharges & Total daily limit for site \\
\hline Gross alpha & $300 \mathrm{pCi} / \mathrm{L}$ & $5.0 \mu \mathrm{Ci}$ \\
Gross beta & $3000 \mathrm{pCi} / \mathrm{L}$ & $50.0 \mu \mathrm{Ci}$ \\
Tritium & $10 \mathrm{mCi}$ & $20 \mathrm{mCi}$ \\
Gamma & (a) & (a) \\
\hline
\end{tabular}

Source: ES\&H Manual, Document 32.4

(a) There is no gross gamma limit; isotope-specific limits apply.

Radioisotopic analysis, unfortunately, is both time-consuming and expensive. As a practical compromise, retention tank samples are analyzed for gross alpha and gross beta activity, and the release criteria are based upon the permissible release concentrations of the commonly available alpha- or beta-emitting isotope with the lowest discharge limits. The values of Table 7-2 assume uranium-238 as the alpha emitter and strontium-90 as the beta emitter.

\subsubsection{Collection Methods}

The retention tank sampling protocols must guarantee that a representative sample of the wastewater is collected for analysis. The analysis protocols must ensure that a meaningful assessment can be made of wastewater against the established discharge criteria. Both 
protocols must be structured to minimize the time between when the tank has been filled and the final disposition of its contents.

The pollutants that can be found in a specific tank are dependent on the types of processes that discharge to the tank. Operations in a specific LLNL facility may change as research and development activities change, and so the potential contaminants can change over time. As a result, the Retention Tank Analysis List (RTAL) is updated with sampling requirements for each retention tank system. This list is reviewed periodically, (at least annually). Changing analytical requirements are communicated through the distribution of the RTAL each time an update occurs. To obtain analytical results quickly, the tank is sampled as soon as possible when it becomes full.

Procedures for obtaining a representative sample from a retention tank vary from location to location, depending on the system design. For tank systems with recirculation capability, the waste should be recirculated for a minimum of three tank volumes. For tank systems without recirculation capability, appropriate sampling equipment should be used.

Field and trip blanks should be utilized, along with equipment blanks when samples are not transferred directly from the tank to the sample containers (e.g., coliwasas or pumps are used). Additionally, consideration should be given to a comprehensive analysis of random samples each year to validate the process by which the RTAL is developed.

\subsection{Extent and Frequency of Monitoring and Measurement}

There are approximately 51 in-service wastewater retention tank systems at LLNL, including those at Site 300. Sampling frequency for retention tanks is determined by operations:

- Nonhazardous waste tanks and radioactive waste tanks are sampled whenever the tank is full.

- Hazardous waste and mixed waste tanks are sampled and emptied within 90 days of the time they begin receiving waste.

Samples are collected by the RHWM Sampling Team, RHWM field technicians, technicians from EFA or, in isolated circumstances, Environment, Safety and Health Directorate or LLNL program representatives. Sampling technicians use the RTAL to determine which analyses are required and to sample accordingly.

Special protocols are followed for sampling sewage diverted into the Sewer Diversion Facility. The tank contents are analyzed only for $\mathrm{pH}$, normality, and the specific pollutant detected by the continuous monitoring system (see Chapter 6). Samples are taken by EFA 
technicians who follow procedure EMP-SW-DS, Diversion Facility Tank Sampling. Analysis is performed by either an off-site State-certified analytical laboratory under contract to LLNL or in the event of an unusual analysis or for rapid turnaround of the data, an internal LLNL analytical laboratory.

\subsection{Procedures for Laboratory Analysis}

Retention tank sample analyses are performed according to standard EPA procedures. For screening purposes, a few analyses of non-regulated wastewater (e.g., field $\mathrm{pH}$ measurements) are done using non-certified methods. Samples are generally analyzed by offsite state-certified laboratories; however in instances where unusual analysis are required or in instances of spill response, an onsite laboratory may be employed to facilitate disposition.

When the data package is received from the laboratory, results are reviewed to determine whether the contents meet discharge requirements specified in LLNL guidance documents (see ES\&H Manual, Documents 32.1, "Managing Discharges to Water and Land" and 32.4, "Discharges to the Sanitary Sewer System"), which are based upon WRD permit limitations and categorical pretreatment requirements in federal law (see Chapter 8). The evaluation of the analytical results is the responsibility of EFA Water Team members, who issue a Wastewater Disposition Authorization Record (WDAR) authorizing disposal of the tank contents. These records are maintained and stored within the TEIMS database.

\subsection{Data Quality Assurance}

Although most sampling and analysis of retention tank volumes are not under the direct control or authority of EFA personnel, protocols exist to ensure that quality objectives for these functions are met. Currently, EFA uses the procedures and quality control manuals of the RHWM Sampling Team and the offsite, state-certified analytical laboratory to ensure the dependability of the results used in determining the deposition of the waste volumes from retention tanks.

\subsubsection{Precision}

Quality control samples including field blanks, duplicate samples, and trip blanks are collected according to RHWM Procedure AP 158, Waste Sampling Quality Assurance and Control Plan. Sample results are compared with historical data maintained on each retention tank system by EFA staff. Unusual results are followed up by discussions with the analytical laboratory, sampling technician, responsible ES\&H Team 2 Environmental Analyst, and/or the facility tank operator. If an error in sampling or analysis is 
determined, or an improper discharge to the retention system occurred, the issue will be tracked in the LLNL Issues Tracking System (ITS).

\subsubsection{Bias}

All quality check information provided by the analytical laboratory, including laboratory control standards, matrix spikes, matrix duplicates, and calibration standards, are examined by the retention tank network analyst (or Discharge Authorization Manager) to identify any analytical bias. If calibration standards or matrix spikes are consistently high or low, the analyst will contact the applicable contract laboratory for an explanation.

\subsubsection{Completeness}

Retention tank system samples used for content characterization are collected from each discrete tank volume from each system. Profiling is not performed due to the variability of operations and LLNL research needs. The overall tank characterization process will be considered a success, or complete, only when each tank volume is sampled and analyzed (or evaluated using other means). Post-discharge sampling and characterization is allowed only in isolated cases when program needs would be negatively impacted if usual sampling procedures were followed.

\subsection{Program Implementation Procedures}

The primary responsibility for determining disposition of retention tank contents is assigned to an EFA environmental analyst. This position has been given the title Discharge Authorization Manager (DAM). The DAM oversees the design, implementation, and maintenance of the retention tank sampling program. The environmental analyst determines analytes, collection methods, and analytical methods; reviews and analyzes the data; follows trends in data; and reports results as required.

Although the facility users at LLNL are responsible for the operation and maintenance of the retention tank systems that service the facility, EFA is responsible for overseeing the sampling; determining appropriate analytes (with input from facility users and knowledge of operations that discharge to the tank), collection methods, and analytical methods; evaluating the subsequent data and their quality; communicating and coordinating retention tank network activities among sampling technicians and analytical personnel; and reporting the results. RHWM personnel manage removal of the waste volume, followed by any required treatment and off-site shipment. In a small number of cases, tank contents may be treated at the facility rather than removed, using a state-licensed transportable treatment unit (TTU). Following this treatment, the waste volume is 
sampled, analyzed, and reviewed following the same procedures as non-TTU treated volumes.

Retention tank samples are collected by RHWM technicians following RHWM Procedure 411, Sampling Containerized Liquids. Sampling locations are at the point of discharge from the retention tank and are permanently marked with location and tankspecific identification. The written procedures include requirements for collecting samples and submitting them for chemical analysis, keeping a field log, and filling out a chain of custody (COC) form. The procedures also require the technicians to alert the Waste Generation Services Technical Lead if any difficulties or anomalies are encountered during the sampling event.

\subsection{Action Levels}

When the data package is received from the analytical laboratory, the EFA staff member responsible for discharge authorizations begins the processes of evaluation against the internal discharge criteria shown in Tables 7-1 and 7-2. Release authorization is granted as described in the procedure, EMP-WD-AR, Wastewater Discharge Authorization. This procedure states that sample data are reviewed and, for the majority of tank systems, compared with the internal discharge limits. For the small number of tank systems dedicated to accepting waste streams from categorical processes, predetermined federal limits apply (for a more thorough discussion of categorical processes, see Chapter 8). Prior to completion of the WDAR, the data package sample numbers from the sample strategy form, the waste analysis request form, and the laboratory data report are reviewed to ensure that the results correspond to the waste volume intended. If the data indicate that contaminant loads are below numerical discharge limits, authorization for discharge to sewer is given via a WDAR. If they are above numerical limits, the waste volume is handled for treatment by the on-site RHWM facility or shipped to an off-site permitted treatment, storage, and disposal facility.

\subsection{Preparation and Disposition of Reports}

A WDAR is generated for each tank sampling event and is kept on file for a minimum of five years. The form includes the final disposition alternative determined by EFA discharge control personnel (following procedure EMP-WD-AR, Wastewater Discharge Authorization) and records the date, time, and circumstances under which the tank was drained.

An RTAL is generated at least annually to keep sampling technicians apprised of any changes in retention tank analytical requirements. 
General engineering information about retention tanks and the Sewer Diversion Facility is included in LLNL's annual wastewater discharge permit application (e.g., Grayson 2011), which is submitted annually to the WRD.

\subsection{Future Plans}

No significant changes to the sampling program are anticipated. The program does change as needed, to adapt to process changes, and to ensure compliance with any changes to regulatory requirements. Efforts to improve the efficiency of the retention tank sampling program and the associated data management are continual.

\subsection{References}

10 CFR 20, Subpart 2003. Code of Federal Regulations, Title 10, Part 20, Subpart 2003, Disposal by Release into Sanitary Sewerage, Office of the Federal Register, Washington, D. C.

City of Livermore, Wastewater Discharge Permit/Chemical Storage Permit \#1250 (current version), City of Livermore, Livermore, CA.

Fisher, D. (1995), Letter to Central Valley Water Quality Control Board, April 18, 1995, Livermore, CA.

Grayson, A. R. (2011), Wastewater Discharge Permit Application, Lawrence Livermore National Laboratory, Livermore, CA (UCRL-AR-106905-2011).

SFBRWQCB (1995), Waste Discharge Requirements for U. S. Department of Energy and Lawrence Livermore National Laboratory, Order No. 95-174, National Pollutant Discharge Elimination System No. CA0030023, San Francisco Bay Regional Water Quality Control Board, Alameda County, August 23, Oakland, CA. 


\section{Categorical Pretreatment}

Allen R. Grayson

\subsection{Introduction}

The General Pretreatment Regulations for Existing and New Sources of Pollution "establishes responsibilities of federal, state, and local government, industry and the public to implement National Pretreatment Standards to control pollutants which pass through or interfere with treatment processes in Publicly Owned Treatment Works (POTWs) or which may contaminate sewage sludge." (40 CFR 403.1)

The objectives of the National Pretreatment Program are achieved by applying and enforcing three types of discharge standards:

- Prohibited discharge standards.

- Categorical standards.

- Local limits.

Prohibited discharge standards are somewhat general, national standards applicable to all industrial users of a POTW. These standards are designed to protect against pass-through and interference, to protect the POTW collection system, and to promote worker safety and beneficial biosolids use. These standards are listed in 40 CFR 403.5

Categorical pretreatment standards are limitations on pollutant discharges to POTWs, promulgated by the U.S. Environmental Protection Agency (EPA) in accordance with Section 307 of the Clean Water Act, that apply to specific process wastewaters of particular industrial categories. These are national, technology-based standards that apply regardless of whether or not the POTW has an approved pretreatment program or the industrial user has been issued a permit. Such industries are called Categorical Industrial Users. The standards applicable to industrial discharges to a POTW collection system are designated in the Effluent Guidelines \& Limitations (40 CFR Parts 405-471).

Local limits are developed to reflect specific needs and capabilities at individual POTWs. They are designed to protect the POTW receiving waters. Regulations at $40 \mathrm{CFR}$ 403.8(f)(4) state that POTW Pretreatment Programs must develop local limits or demonstrate that they are unnecessary; 40 CFR 403.5(c) states that local limits are needed when pollutants are received that could result in pass through or interference at the 
POTW. Essentially, local limits translate the general prohibited discharge standards of 40 CFR 403.5 to site-specific needs.

\subsection{Rationale and Design Criteria}

\subsubsection{Regulatory Drivers}

The Federal Water Pollution Control Act of 1972, as amended, grants authority to the EPA to establish and enforce National Pretreatment Standards for the indirect discharge of industrial wastewater. The intent of these regulations is to prohibit the discharge of wastes that are incompatible with wastewater treatment plant processes.

Unlike other environmental programs that rely on federal or state governments to implement and enforce specific requirements, the Pretreatment Program places the majority of the responsibility on local municipalities. Specifically, section 403.8(a) of the General Pretreatment Regulations states that any POTWs that meet specified design criteria (or combination of treatment plants operated by the same authority) with a total design flow greater than 5 million gallons per day and smaller POTWs with Significant Industrial Users (SIUs) must establish a local pretreatment program.

The local limits and prohibited discharge standards to the sanitary sewer are discussed in greater detail in Chapters 6 and 7.

Categorical pretreatment standards (i.e., categorical standards) are national, uniform, technology-based standards that apply to discharges to POTWs from specific industrial categories (i.e., indirect dischargers) and limit the discharge of specific pollutants. Categorical standards apply to regulated wastewaters (i.e., wastewater from an industrial process that is regulated for a particular pollutant by a categorical pretreatment standard). Therefore, demonstrating compliance with categorical pretreatment standards is intended to be based on measurements of waste streams containing only the regulated process wastewater. These standards are codified (40 CFR 405-471) and specify quantities or concentrations of pollutants that may be discharged to a sanitary sewer from specific industrial categories of wastewater-generating processes. Separate standards are established for specific industrial processes, in addition to the general prohibitions established in the National Pretreatment Standards. The intent of the requirements is to ensure that industrial wastewater effluent does not disrupt the ability of a treatment plant to treat wastewater. In the specific case of LLNL wastewaters, disrupting Livermore Water Reclamation Plant (LWRP) operations could cause contamination of the receiving waters of San Francisco Bay. 
There are 46 specific operations defined within the metal finishing category (40 CFR 433). The first six processes are considered primary operations and define the applicability of the standard. These defining processes are electroplating, electroless plating, anodizing, conversion coating (e.g., chromating, phosphating, coloring), chemical etching and milling (e.g., bright dip, electropolish), and printed circuit board production. A number of the subsequent 40 metal-finishing processes are also likely to be conducted at LLNL. If these processes do not support one of the six primary operations, the requirements of 40 CFR 433 may not apply.

Because there are a number of these regulated processes in use at the Livermore site, LLNL is required by our Wastewater Discharge Permit (City of Livermore) to maintain a categorical pretreatment program (40 CFR 403.6). This program consists of administrative and engineering controls and procedures, coupled with process monitoring of nondomestic, industrial wastewater sources with specific discharge standards identified in 40 CFR 403.5.

The LLNL categorical, pretreatment, self-monitoring program is also mandated under the terms of the Wastewater Discharge Permit/Chemical Storage Permit No. 1250 issued by the City of Livermore Water Resources Division (WRD) to LLNL governing the discharge of all wastewater from the Livermore site to the city's sewer system. Authority to enforce federal, state, and local limits on waste streams discharged to the Livermore sanitary sewer system lies with the WRD under the authority of the San Francisco Bay Regional Water Quality Control Board (SFBRWQCB).

\subsubsection{Monitoring Objectives}

Pretreatment sampling is required by 40 CFR 403.2 "(a) to prevent the introduction of pollutants into publicly owned treatment works (POTWs) which will interfere with the operation of a POTW, including interference with its use or disposal of municipal sludge; (b) to prevent the introduction of pollutants into POTWs which will pass through the treatment works or otherwise be incompatible with such works; and (c) to improve opportunities to recycle and reclaim municipal and industrial wastewaters and sludges."

Categorical pretreatment monitoring is part of a comprehensive and ongoing environmental monitoring program at LLNL (see Chapter 1). Data from categorical pretreatment monitoring are used to demonstrate compliance with regulatory requirements. 


\subsubsection{Sources and Analytes}

The Code of Federal Regulations (40 CFR 405-471) contains 55 industry-specific categories of guidelines. Three operations that fall within these categories are performed at LLNL: plastics molding and forming, metal-finishing operations, and electrical and electronic component (semiconductor) production. However, only metal finishing and semiconductor production are included in the pretreatment monitoring program permit requirements; LLNL received an exemption from the standard for plastics processing from the City of Livermore WRD.

LLNL metal finishing processes (40 CFR 433, Subpart A), such as metal plating and bright dipping, are located in the Building 322 Plating Shop, and certain semiconductor processes (40 CFR 469, Subpart A), such as the microfabrication for developing semiconductor and micromechanical devices, occur in Building 153.

Metal finishing processes are sampled for $\mathrm{pH}$, metals, cyanide, and total toxic organics (TTO). Semiconductor processes are sampled for $\mathrm{pH}$, TTO, and arsenic. Table 8-1 shows typical sampling frequencies and analytes. The current Permit \#1250 (City of Livermore) lists specific analytes and sampling frequencies for each regulated process.

Analytes for regulated processes that discharge to a dedicated retention tank system are specified in the current retention tank analysis list (RTAL), found in EMP-WD-RTAL, Retention Tank Analysis List.

Table 8-1. Typical sampling frequencies and analytes.

\begin{tabular}{|c|c|c|}
\hline Sample Type & Sample Frequency & Typical Analysis \\
\hline Baseline & $\begin{array}{l}3 \text { samples within a two week } \\
\text { period at process start-up }\end{array}$ & Process dependent \\
\hline $\begin{array}{l}\text { Compliance-Electrical/ } \\
\text { Electronic Component } \\
\text { (semiconductor) }\end{array}$ & Semiannual & $\begin{array}{l}\text { Arsenic } \\
\mathrm{pH} \\
\text { TTO }\end{array}$ \\
\hline Compliance-metal finishing & Semiannual & $\begin{array}{l}\text { Cyanide } \\
\text { Metals }(\mathrm{Cd}, \mathrm{Cr}, \mathrm{Cu}, \mathrm{Pb}, \mathrm{Ni} \text {, } \\
\mathrm{Ag}, \mathrm{Zn}) \\
\text { pH } \\
\text { TTO }\end{array}$ \\
\hline $\begin{array}{l}\text { Retention tanks accepting only } \\
\text { regulated (categorical) waste } \\
\text { streams. }\end{array}$ & Each tank volume & See RTAL \\
\hline
\end{tabular}




\subsubsection{Collection Methods}

A grab sample is collected over a period of time not exceeding 15 minutes for categorical process monitoring (40 CFR 136). Composite sampling is not appropriate because volumes from these processes are extremely small and flows are not continuous. Also, samples containing some constituents, such as cyanide, cannot be held for an extended period of time because of biological, chemical, or physical interactions after sampling that affect the results. A more detailed description of grab sampling for categorical process monitoring is available in EMP-PT-S, Pretreatment Sampling of Rinsewater.

\subsection{Extent and Frequency of Monitoring and Measurement}

In its December 1996 written Inspection Summary of the June 1995 EPA/LWRP Facility Audit of LLNL, the EPA determined that LLNL wastewater generating processes that meet the following defining criteria must comply with the applicable Categorical Standards:

- The process must discharge to the sanitary sewer, either directly or indirectly. (Processes that have their waste removed by means other than discharge to the sanitary sewer are not regulated under the Categorical Standards.)

- The process must not use radioactive materials. (Those processes are regulated under separate LWRP Permit conditions and U.S. Department of Energy (DOE) orders.)

- The process must generate sufficient volumes of wastewater to potentially impact the environment, which is currently considered to be 50-100 gallons per day or per batch discharge.

- The process must support other programmatic or institutional needs. If the process under evaluation exists solely for a research and development (R\&D) project, that process is not defined as a regulated categorical process. However, if that process discharges to sewer and supports widespread programmatic work or has other institutional customers, then that process is considered regulated under the applicable categorical standard.

As a result of this EPA decision, in July 1997 LLNL renewed its compliance with all of the administrative and monitoring requirements for the Categorical Standards contained in 40 CFR 403.6; 40 CFR 433, Subpart A; and 40 CFR 469, Subpart A for those processes identified by the newly implemented defining criteria. These administrative and monitoring requirements are specified in LLNL's Wastewater Discharge Permit, \#1250, issued by the City of Livermore WRD. LLNL samples, reports, and inspects two discharging processes: the Building 321 water-jet, and the Building 153 microfabrication 
shop (monitoring occurs at the dedicated retention tank system which captures process wastewaters from this shop). Routine process review and evaluation occurs at least semiannually. Due to evolving LLNL programmatic needs and project funding, the number of identified categorical processes may fluctuate over time.

Monitoring for all categorical processes occurs at the point of discharge to the sanitary sewer. For instance, if the identified process discharges to a sink connected to the sewer, compliance samples are taken at the sink. If the process discharges to a retention tank dedicated to that process waste, the tank is sampled prior to discharge into the sanitary sewer collection system. The number of sampling locations is determined by the number of categorical processes that discharge to the sanitary sewer. Currently 12 metal finishing and 2 semiconductor processes are identified at LLNL. Of those, two discharge to the sanitary sewer. These two (the Building 321 abrasive jet machining and Building 153 microfabrication unit) are the only processes that are inspected and sampled, with results reported to the LWRP in semiannual wastewater reports. The number of identified categorical processes at LLNL can change over time reflecting the diversity of the LLNL R\&D mission.

The WRD establishes sampling frequency and analytes for pretreatment sampling in the annual Wastewater Discharge/Chemical Storage Permit (City of Livermore). Sampling requirements are specified in 40 CFR, Parts 433 and 469.

Pretreatment samples are collected and analyzed for one of three purposes:

1) As a baseline when a new regulated process begins. Baseline sampling consists of three consecutive samples taken within a period of two weeks.

2) To demonstrate compliance for existing regulated processes according to the frequency defined in the LLNL Wastewater Discharge/Chemical Storage Permit (generally semiannually, except when regulated processes discharge to a dedicated retention tank system. Those retention tanks must be sampled prior to each discharge).

3) As a function of the pretreatment regulations implemented through Permit \#1250, LWRP conducts annual inspections and sampling of each regulated process that discharges to sanitary sewer, whether it discharges to a dedicated retention tank, or directly to the sewer. Whenever the WRD collects samples, Environmental Functional Area (EFA) staff must collect split samples. Where split samples are not possible, duplicate samples may be used.

Table 8-1 summarizes categorical pretreatment sampling frequencies and analytes. 


\subsection{Procedures for Laboratory Analysis}

Categorical pretreatment samples are delivered to offsite, state-certified analytical laboratories for analysis as described in EMP-QA-DM, Sample and Data Management. Samples are analyzed using approved, standard EPA methodology.

\subsection{Data Quality Assurance}

\subsubsection{Precision}

LLNL collects duplicate samples for quality control of sampling technique and analysis. When determining whether to collect a duplicate, the sampler must consider the amount of sample material required and the total volume available. Overall, the total number of duplicates should be at least $10 \%$ of the cumulative total of sample locations (processes). The sampler submits quality control (QC) samples as "blind" - the sample location identifier on the chain-of-custody (COC) form is coded in such a way that the analytical laboratory cannot tell that the sample is a duplicate. During data review, the network environmental analyst (EA) compares the results of duplicate and routine samples to ensure they are within approximately $\pm 10 \%$. Trip blanks (sampling bottles prefilled with deionized water) are not necessary for this network.

\subsubsection{Accuracy}

The duplicate samples are collected for every analyte at that location and submitted to the lab for analysis, each with a unique sample identifier. Upon receipt of the analytical results, the network analyst evaluates the results for the duplicate location sample and actual location sample. Trip blanks (sampling bottles prefilled with deionized water) are not necessary for this network.

All quality checks on information provided by the analytical laboratories, including lab control standards, matrix spikes, matrix duplicates, and calibration standards, are examined by the network analyst to identify any analytical bias. If calibration standards or matrix spikes are consistently high or low, the analyst will contact the laboratory for an explanation.

\subsubsection{Completeness}

Samples from identified categorical processes are collected twice per year as dictated by Permit \#1250. Samples are only collected when the processes are operational. No mockup sampling is performed. Collection of all required samples at each identified process location plus an annual quality assurance (QA) sample would be considered $100 \%$ compete. 


\subsection{Program Implementation Procedures}

The primary responsibility for activities related to categorical pretreatment monitoring is assigned to an EFA network analyst. The analyst designs, implements, and maintains the sampling network. The analyst determines analytes, collection methods, and analytical methods; coordinates network activities with sampling technologists and analytical laboratory personnel; reviews and analyzes the data; performs dose assessments; follows trends in data; and reports results.

Pretreatment samples are collected and managed according to procedure EMP-PT-S, Pretreatment Sampling of Rinsewater, which is reviewed annually and revised at least once every three years. The handheld $\mathrm{pH}$ meter is calibrated as described in EMP-W-S, Water Sampling. Samples are submitted for analyses using sample control, chain-ofcustody, and documentation procedures (EMP-QA-DM, Sample and Data Management). The written procedures include requirements for sample collection and submittal for chemical analysis, keeping a log, and filling out field tracking forms (FTFs) and COC forms. The procedures also require the sampling technologist to alert the EA about difficulties encountered during any sampling event that may result in a compromise to the LLNL compliance posture.

\subsection{Action Levels}

Sample analyses results are checked against the federal Categorical Discharge Standards by the network analyst. The concentration-based discharge limits in 40 CFR 433, Subpart A, and 40 CFR 469, Subpart A, are considered formal action levels for the regulated pollutants. The discharge limits specified in the federal standards and implemented via the permit are provided in Table 8-2.

If the concentration of any regulated pollutant exceeds a discharge limit and the QC data are acceptable, the network analyst contacts the LLNL Program representative responsible for that specific wastewater generating process. This inquiry will determine if the process was operated in any unusual manner or used in a different configuration than normal. Depending upon the outcome of that inquiry, further investigation may be initiated by EFA. The investigation may include, but is not limited to, inspection of the usage logs, base material used, and any chemicals or reagents used in the process. Additional samples will be taken to determine if the process is still out of compliance or to establish a time that marks the return to a state of compliance with the Categorical limit. After the issue of noncompliance is confirmed, it is reported to the City of Livermore WRD and DOE within 24 hours. This verbal report is followed by a Five-Day Report to the WRD and the information in the Five-Day Report is included in the applicable semiannual wastewater report. 
Table 8-2. LLNL's self-monitoring program for nonradioactive parameters in wastewaters from categorical processes.

\begin{tabular}{|l|c|c|}
\hline \multirow{2}{*}{\multicolumn{1}{|c|}{ Parameter }} & \multicolumn{2}{|c|}{$\begin{array}{c}\text { Categorical Discharge Standards } \\
\text { (mg/L) }\end{array}$} \\
\cline { 2 - 3 } & Metal finishing & Semiconductor \\
\hline Arsenic & - & 0.83 \\
Cadmium & 0.07 & - \\
Chromium (total) & 1.71 & - \\
Copper & 2.07 & - \\
Cyanide(b) & 0.65 & - \\
Lead & 0.43 & - \\
Nickel & 2.38 & - \\
Silver & 0.24 & - \\
Zinc & 1.48 & 1.37 \\
\hline Total toxic organics (TTO) & 2.13 & $5-10$ \\
\hline pH (units) & $5-10$ & - \\
\hline
\end{tabular}

(a) These standards are specified in 40 CFR 433, Subpart 13, and 40 CFR 469, Subpart 17. Noncategorical discharge limits apply when no other standard is specified.

(b) Limits apply to $\mathrm{CN}$ discharges other than $\mathrm{CN}$ salts. $\mathrm{CN}$ salts are classified by the State of California as "extremely hazardous waste" and cannot be discharged to the sewer.

\subsection{Preparation and Disposition of Reports}

All monitoring results, as well as the current status of the identified wastewater generating processes, are reported in Semiannual Wastewater Point-Source Monitoring Reports. These reports are submitted to the LWRP every January and July (e.g., Grayson 2011), as required in Attachment A-2 of the LLNL Wastewater Discharge Permit \#1250 (City of Livermore). As indicated in Section 8.7, Five-Day Reports are also required as necessary.

\subsection{Future Plans}

The most important goal for the categorical pretreatment monitoring program is to maintain an effective level of effluent discharge control ensuring full compliance under the appropriately applied regulatory standards. Due to the criteria for defining regulated processes, future resources will be best focused on those wastewater-generating activities that have the greatest potential to adversely affect water quality and cause interference or pass-though to the LWRP. 


\subsection{References}

City of Livermore, Wastewater Discharge Permit/Chemical Storage Permit \#1250 (current version), City of Livermore, Livermore, CA.

Grayson, A. R., (2011), Semiannual Wastewater Point-Source Monitoring Report, Lawrence Livermore National Laboratory, Livermore Site, July 2011, Lawrence Livermore National Laboratory, Livermore, CA (UCAR-10204-11-1). 


\section{Storm Water}

Chris G. Campbell • Michael A. Revelli

\subsection{Introduction}

Lawrence Livermore National Laboratory (LLNL) monitors storm water runoff at its Livermore site, as well as at Site 300. Water samples are analyzed for certain radionuclides, explosive compounds, total organic carbon (TOC), total suspended solids (TSS), electrical conductivity, $\mathrm{pH}$, chemical oxygen demand (COD), total dissolved solids (TDS), oil and grease, metals, minerals, anions, nutrients, physical parameters, and a wide range of organic compounds. In addition, fish bioassays are performed on storm water leaving the Livermore site via Arroyo Las Positas.

\subsection{Rationale and Design Criteria}

\subsubsection{Regulatory Drivers}

U.S. Department of Energy (DOE) Order 458.1 is a primary regulation driving the radiological monitoring of storm water runoff at LLNL. The order states that DOE Facilities must:

Ensure that storm water runoff containing radionuclides from DOE activities is considered, as appropriate, as a pathway of exposure that has the potential for on- and off-site impacts. Using a graded approach, the receiving ecosystem including, but not limited to, wetlands, floodplains, streams, ponds, basins and lakes must be monitored to evaluate human or ecological impacts when warranted based on site specific risk. (DOE O 458.1, section 4.g.11)

In addition, the Federal Water Pollution Control Act (Clean Water Act, 1972, 33 USC 1251) was enacted to restore and maintain the chemical, physical, and biological integrity of waters of the United States. To this end, Section 402 established the National Pollutant Discharge Elimination System (NPDES) to set the conditions under which pollutants could be discharged to navigable waters. NPDES requires industries to obtain permits before discharging storm water associated with industrial activities from their facilities. Specific U.S. Environmental Protection Agency (EPA) requirements applicable to LLNL's NPDES permits are contained in Title 40 of the Code of Federal Regulations (CFR), Part 122, EPA Administered Permit Programs: The National Pollutant Discharge Elimination System. NPDES permits requiring storm water runoff monitoring at the Livermore site and Site 300 are issued in California as Waste Discharge Requirements 
(WDRs) by the regional water quality control boards or as General Orders issued by the State Water Resources Control Board. These permits regulate storm water discharges associated with municipal and industrial activities, construction projects of one acre or greater, and low-threat, non-storm water discharges, such as air-conditioner condensate. The following WDR permits are the regulatory drivers for LLNL's industrial storm water runoff monitoring:

- Order No. 95-174, Waste Discharge Requirements and National Pollutant Discharge Elimination System (NPDES) for U.S. Department of Energy and Lawrence Livermore National Laboratory, issued by the San Francisco Bay Regional Water Quality Control Board (SFBRWQCB 1995) for the Livermore site and continued by letter (SFBRWQCB 2000).

- Order No. 97-03-DWQ, Statewide General National Pollutant Discharge Elimination System (NPDES) Permit for Storm Water Discharges Associated with Industrial Activities, Permit No. CAS000001, issued by the State Water Resources Control Board (SWRCB 1997). In addition, Site 300 storm water monitoring meets the requirements of the Post-Closure Plan for the Pit 6 Landfill Operable Unit (Ferry et al. 1998).

- Order No. 2009-0009-DWQ, California NPDES General Permit for Storm Water Discharges Associated with Construction Activity (SWRCB 2009).

\subsubsection{Monitoring Objectives}

The California SWRCB and its associated RWQCBs administer LLNL's site-specific NPDES permits. The LLNL NPDES storm water monitoring programs meet permit requirements by:

- Aiding in the implementation of Storm Water Pollution Prevention Plans (SWPPPs).

- Measuring the effectiveness of best management practices (BMPs) in reducing or eliminating specific pollutants in storm water discharges.

- Ensuring that storm water discharges comply with discharge prohibitions and receiving water limitations as specified in LLNL's storm water discharge permits.

- Determining that facility practices to control storm water pollution are evaluated and modified to meet changing conditions.

In addition to the NPDES requirements already stated, DOE's Environmental Regulatory Guide for Radiological Effluent Monitoring and Environmental Surveillance (DOE 1991) describes the environmental monitoring objectives applicable to runoff:

The purpose of the surveillance program is to characterize the radiological conditions of the off-site environs and, if appropriate, estimate public 
doses related to these conditions, confirm predictions of public doses based on effluent monitoring data, and, where appropriate, to provide compliance data for all applicable regulations. The results of this evaluation should" be documented in the site Environmental Monitoring Plan.

Ambient water quality monitoring should be conducted through a network of fixed stations from which data will establish well-defined histories of the physical, biological, and chemical conditions of local bodies of water and sediments.

Analysis of data collected from a fixed station monitoring network should support:

- Characterizing and defining trends in the physical, chemical, and biological conditions of surface waters.

- Establishing baselines of water quality.

- A continuing assessment of water pollution control programs.

- Identifying new water quality problems.

- Detecting, characterizing, and reporting unplanned releases and their effects on water quality.

\subsubsection{Sources and Analytes}

Storm water runoff at the Livermore site flows through the LLNL storm drainage system to either Arroyo Las Positas or Arroyo Seco. These two arroyos merge and flow into Arroyo Mocho west of the Livermore site (Figure 9-1). Arroyo Mocho flows toward the west where it merges with other arroyos in the west end of the Livermore Valley. There they form the southward-flowing Arroyo de la Laguna, a tributary to the Alameda Creek drainage system, which eventually flows to San Francisco Bay. At Site 300, storm water flows south and southeasterly through natural features and the LLNL storm drainage system and on-site surface waters into Corral Hollow Creek, which flows eastward into the San Joaquin Valley west of Tracy where it dies out and infiltrates into valley alluvial sediments and never reaches the San Joaquin River. A small number of unnamed drainages at Site 300 flow northerly toward Tracy (Figure 9-2).

\footnotetext{
"The term should in this quotation identifies a DOE "high-priority element."
} 


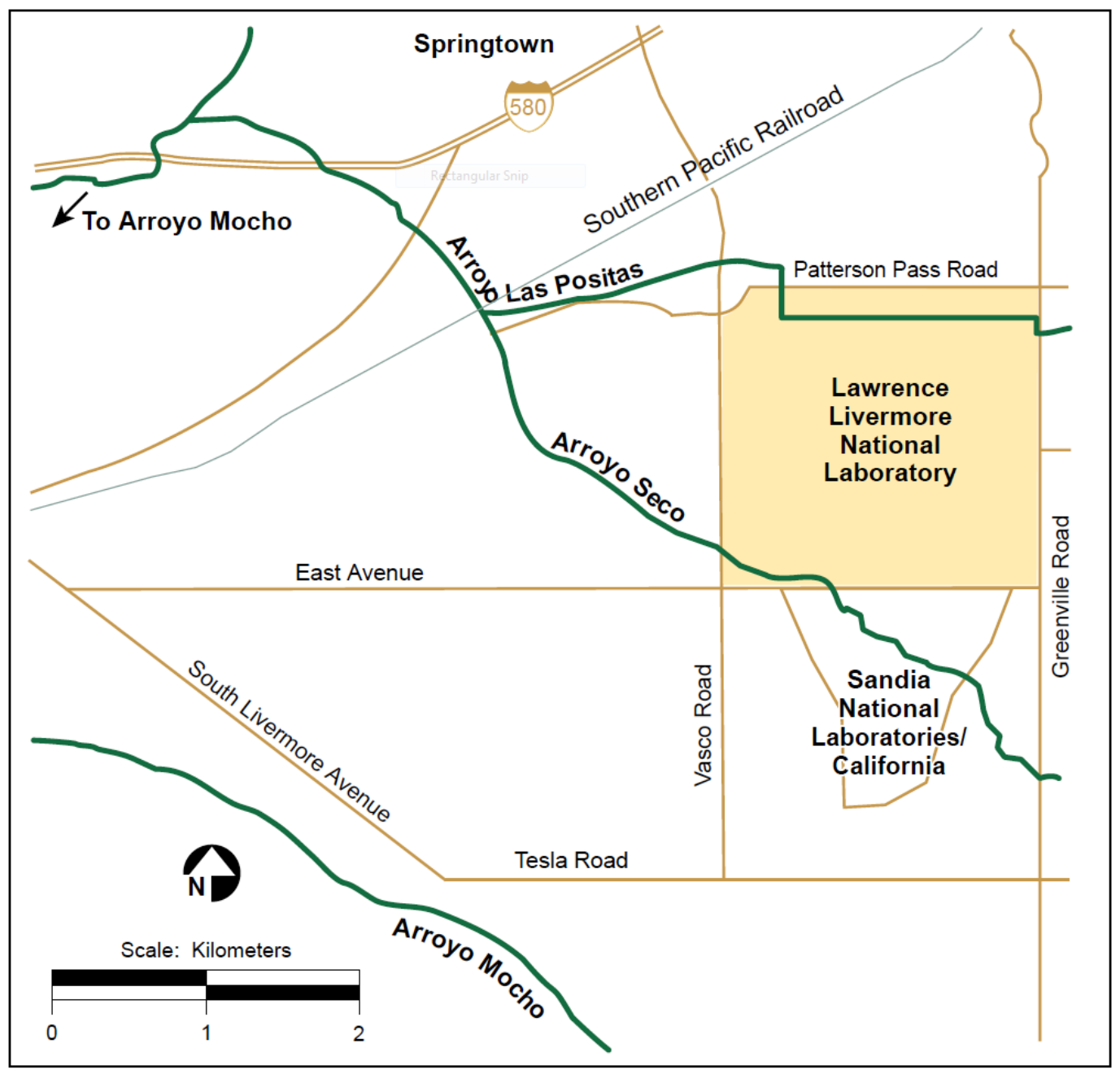

Figure 9-1. Surface waterways in the vicinity of the Livermore site.

The LLNL storm water program meets specific permit requirements and supports the DOE orders described above. Required analyses and additional analyses conducted on Livermore site and Site 300 storm water samples are summarized in Table 9-1. Analyses are conducted for constituents that may be present in storm water discharges in significant quantities. Storm water on the Livermore site can acquire contaminants from a variety of sources, such as neighboring agricultural land, parking lots, and landscaped areas. Possible off-site sources and the wide range of activities conducted at the Livermore site make it necessary to analyze this runoff for a wide range of constituents. In contrast, storm water runoff at Site 300 is sampled at locations targeting specific industrial activities and potential contaminants (see Section 9.3.2). 


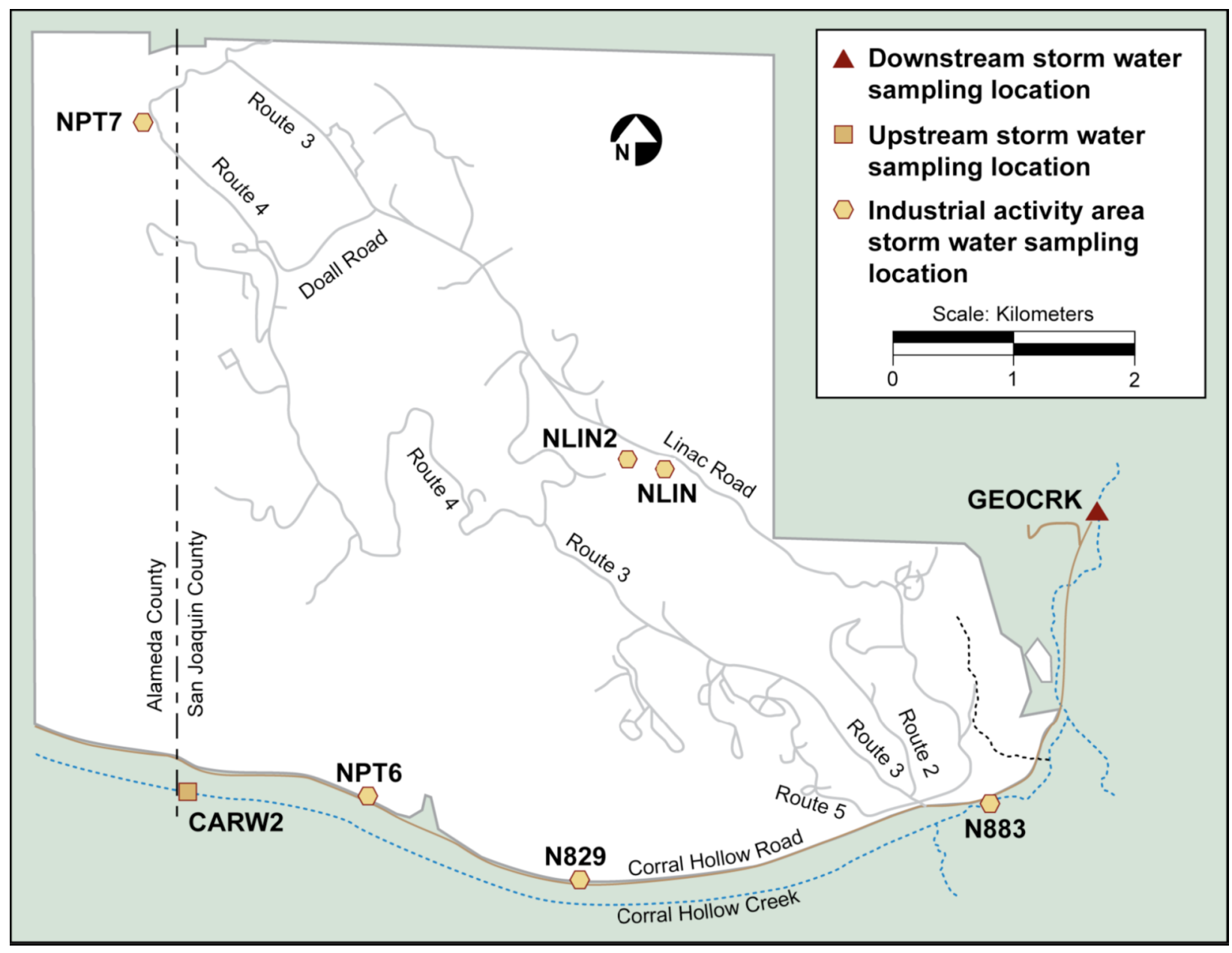

Figure 9-2. Storm water runoff sampling locations at Site 300 and Corral Hollow Creek.

\subsubsection{Collection Methods}

Samples are collected by grab sampling from the runoff flow at specified locations. Portable parastoltic pumps may be used for sampling. If the water to be sampled is accessible to the technician, grab samples are collected by partially submerging sample bottles directly into the water and allowing them to fill with the sample water. Sampling is conducted away from the edge of the water, when possible, to minimize the collection of sediment with the sample matrix. Sample vials for volatile organics analyses are filled first, before sample vials for all other constituents and parameters. After the bottles are filled, they are dried, labeled, packaged, and placed in an ice chest.

Sample bottle requirements, special sampling techniques, and preservation requirements for each analyte are specified in procedure EMP-W-S, Water Sampling and instruction EMP-WSS-RO, Storm Water Runoff Sampling. Sample bottle requirements are provided 
by the analytical laboratories in their bid packages and the requirements are incorporated into the Taurus Environmental Information Management System (TEIMS) database.

Table 9-1. Summary of analyses regularly conducted and EPA methods used on storm water samples.

\begin{tabular}{|l|l|}
\hline \multicolumn{1}{|c|}{ Livermore site } & \multicolumn{1}{|c|}{ Site 300 } \\
\hline Chemical oxygen demand (EPA 410.4) & Chemical oxygen demand (EPA 410.4) \\
Dissolved oxygen (EPA 360.1) & Cyanide (EPA 335.2) \\
Oil and grease (EPA 1664) & Oil and grease (EPA 1664) \\
pH (EPA 150.1, 9040, or calibrated field instrument) & pH (EPA 150.1 or 9040) \\
Turbidity (EPA 180.1 or calibrated field instrument) - & Turbidity (EPA 180.1 or calibrated field instrument) - \\
construction only & construction only \\
Total dissolved solids (EPA 160.1) & Specific conductance (EPA 120.1 or 9050)Total \\
Total suspended solids (EPA 160.2) & dissolved solids (EPA 160.1) \\
Anions (EPA 300.0, 365.1, or 365.2) & Total suspended solids (EPA 160.2) \\
Metals (EPA 200.7 or 200.8) & Ammonia (EPA 350.2) \\
Total organic carbon (EPA 9060) & Potassium (EPA 200.7) \\
Fish bioassay (fathead minnow) (EPA 1000 and 2000) & Hardness (SM2320B) \\
Diuron (EPA 632) & Metals (EPA 200.7, 210.2, 245.1, or 200.8) \\
Glyphosphate (EPA 547) & Explosives (EPA 8330) \\
Volatile organic compounds (EPA 601) & Volatile organic compounds (EPA 624) \\
Semivolatile organic compounds (EPA 525.2) & Semivolatile organic compounds (EPA 625) \\
Hardness (SM2320B) & Dioxins (EPA 8290) \\
Gross alpha and gross beta radioactivity (EPA 900) & Chlorinated pesticides and polychlorinated biphenyls \\
Tritium (EPA 906) & (EPA 608) \\
Plutonium (alpha spectroscopy) & Gross alpha and gross beta radioactivity (EPA 900) \\
& Tritium (EPA 906) \\
& Depleted uranium (alpha spectroscopy) \\
\hline
\end{tabular}

\subsection{Extent and Frequency of Monitoring and Measurement}

\subsubsection{Monitoring Requirements for Livermore Site}

The NPDES permits for storm water discharges associated with industrial activities specifically require visual observations at storm water discharge points during the dry and wet seasons. In general, the wet season occurs between October 15 and April 1; however, this is a regulatory definition and is defined differently in different cases. At the Livermore site, the wet season is defined as October 1 - April 30. NPDES permits for storm water require LLNL to visually inspect the storm drainage system monthly during the wet season (if significant storm events occur). The regulations require analysis of storm water from two storm events during which runoff occurs. This includes the first storm event of the season when possible. Additionally, LLNL must visually inspect the 
storm drainage system twice (once each quarter) during the dry season to identify any dry weather flows.

The storm water surveillance monitoring network for the Livermore site consists of nine sampling locations, each with a unique identifier (Figure 9-3). Descriptions of the sampling locations are maintained by the Data Management Team in the Environmental Functional Area (EFA).

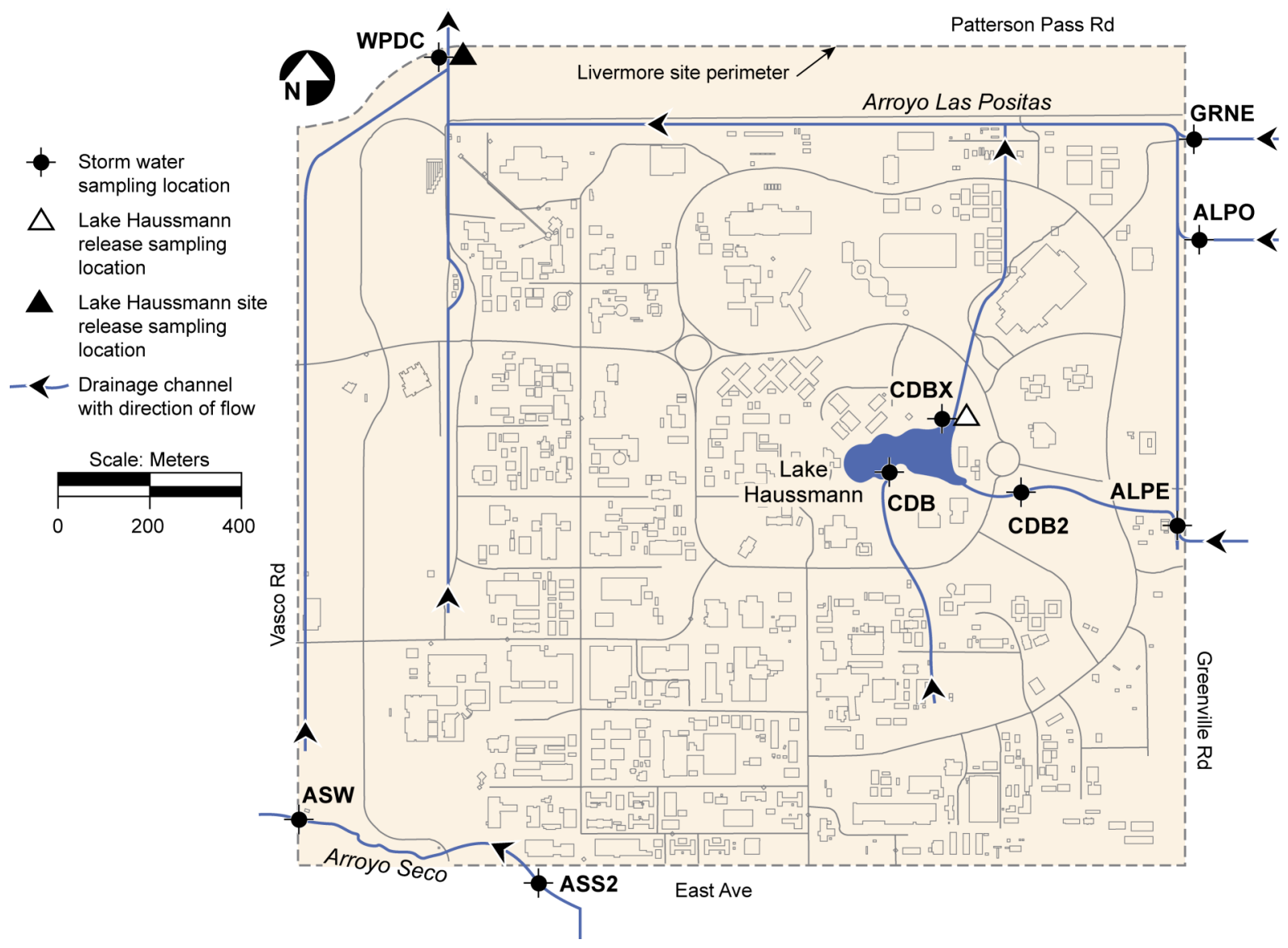

Figure 9-3. Storm water runoff sampling locations, Livermore site and vicinity.

NPDES monitoring points required by permit are ALPE, ALPO, ASW, ASS2, GRNE, and WPDC, a subset of the overall surveillance monitoring network. Of the nine locations in the Livermore site storm water sampling network (Figure 9-3), six characterize storm water either entering (influent-ALPE, ALPO, GRNE, and ASS2) or exiting (effluent-WPDC and ASW) the site, as required by the NPDES permit. Three additional locations (CDB, CDB2, and CDBX) serve the monitoring of influent and effluent locations of Lake Haussmann. Although the Lake Haussmann locations are not required in the storm water NPDES permits, they are sampled as part of the storm water network in order to improve the efficiency of administration and sample collection. 


\subsubsection{Monitoring Requirements for Site 300}

The wet season at Site 300 is defined by the General Storm Water Permit as October 1 May 30. Similar to the Livermore site, wet and dry season observations are required as well as sampling two storms per year. Visual inspections at each storm water monitoring location are made monthly during the wet season. Two dry season visual inspections are conducted (once per quarter). The general industrial permit requires analysis of storm water from two storm events. This includes the first storm even of the season if possible. Based on field examinations of Site 300 drainage (performed during storm events), communications with Central Valley RWQCB, and a review of the "industrial activity" criteria in the NPDES General Permit for discharges of storm water associated with industrial activities (SWRCB 1997), seven monitoring locations are used at Site 300 (shown in Figure 9-2). Five locations (NPT7, NPT6, N829, N883, NLIN2) monitor runoff related to specific industrial activities, one location (CARW2) monitors water quality upstream of Site 300 in Corral Hollow Creek, and one location (GEOCRK) monitors water quality downstream of Site 300 in Corral Hollow Creek. (The original NLIN location was moved 1,200 meters upstream to NLIN2 for better access.)

The canyon below the Chemistry Area in the southern portion of Site 300 is a natural drainage for the Explosives Burn Pits at the Building 829 Complex. Monitoring location N829 sits where this canyon exits the Site 300 perimeter. The Building 829 Treatment Facility, located in the Explosives Process Area in the south-central sector of Site 300, operated as a permitted Resource Conservation and Recovery Act (RCRA) facility and is monitored under "Sector K" in the NPDES WDR 97-03-DWQ, from California EPA's Department of Toxic Substances Control (DTSC). The complex consisted of three separate burn pits and an explosives combustion unit known as the "iron horse." It was used to burn explosive wastes generated by Explosives Process Area operations. The complex was closed under RCRA in 1998. LLNL continues to monitor storm water runoff from the closed facility, when there is runoff from the canyon.

The Building 883 Facility (also a "Sector K" facility), a hazardous waste container storage area, is located in the General Services Area (GSA) in the southeast corner of Site 300. This RCRA-permitted facility stores containerized wastes awaiting off-site disposal by the Radioactive and Hazardous Waste Management (RHWM) Division. The facility design includes engineered controls that catch storm water in a sump, where it is pumped into barrels or drums, pending analysis and disposal. Roof runoff from this facility flows through storm drains in the GSA and exits Site 300 along Corral Hollow Road at monitoring location N883.

Location NLIN2 is used to monitor runoff from several closed landfills at Site 300 that fall under both "Sector K" and "Sector L" for landfills. Pits 1 and 2 are landfills 
(Sector L) located south of the East Observation Post in the upper central portion of Site 300. Pits 3, 4, 5, and 7 lie directly north of the West Observation Post in the northwest quadrant. Pit 8 is located in the northeastern portion of the site, just east of the 801 Facility, and Pit 9 is located near Building 845. These landfills hold debris from past experiments conducted at Site 300. A history of each pit's contents can be found in the Final Site-Wide Remedial Investigation Report (Webster-Scholten 1994). Although these landfills are capped, so that the contents do not come in contact with storm water runoff, the general industrial permit requires sampling of associated runoff.

NLIN2 is used to monitor drainage from the closed landfills (except Pit 6 and some drainage from Pit 7), which flows southeasterly through the upper reaches of Elk Ravine until it passes through a culvert off Linac Road, and then it exits Site 300 via Elk Ravine to the east. Elk Ravine has no safe or accessible sampling point at the Site 300 boundary. No industrial activity occurs south of Building 812 and the final Elk Ravine exit point. However, just south of Building 812 there are two California red-legged frog mitigation pools. Samples are collected at NLIN2 at a point below Spring 8 but above the mitigation pools. Although Building 850 does not conduct industrial activities as defined by the federal storm water regulations, samples representing possible contamination at this source are evaluated for dioxins.

Location NPT6 is used to monitor Pit 6 runoff under Section K of the general industrial storm water permit. Drainage from the region surrounding the Pit 6 cap is diverted by a ditch and culvert north of the pit to prevent intermittent sheet flow over the landfill. Runoff is sampled at the fence line to the south of Pit 6 (NPT6) at Corral Hollow Road when runoff occurs. Post-closure monitoring at Pit 6 (Ferry et al., 1998) requires analysis for potassium, beryllium, mercury, total dissolved solids, and a wide range of organic constituents (EPA Methods 608, 624, and 625). Pit 6 and the canyon to the west of Pit 6 are part of the rifle range at the Site 300 Small Arms Firing Range Facility.

The Pit 7 cap includes a graded concrete drainage system that directs flow away from the pit. Consequently, a portion of this storm water runoff now flows north and is monitored at location NPT7.

Slightly south of Site 300 near its western border is background sample location CARW2, where technical staff collect samples from Corral Hollow Creek. Because this location is upstream of any significant discharge from Site 300 and the water contains constituents and parameters considered typical of the region, CARW2 samples aid LLNL in determining the water quality of storm water not impacted by Site 300 operations. Formerly location CARW was used as the upstream background location but due to accessibility issues it was moved downstream to CARW2 in 2007. 
Sampling location GEOCRK lies downstream of Site 300 in Corral Hollow Creek. This location helps LLNL assess the potential influence of Site 300 on water quality in Corral Hollow Creek. This location also receives water from a perennial stream, but during storm water runoff events is dominated by the storm water flow. This location is also downstream of a ranch where cattle graze in the creek bed and downstream of the Carnegie State Vehicular Recreation Area, run by the California Department of Parks and Recreation.

\subsubsection{Monitoring Requirements for Construction at Both Sites}

Monitoring associated with the Construction General Permit depends upon the project Risk Level (1, 2, or 3); projects are reviewed by LLNL based upon permit guidelines and risk levels assigned during the permit application process. In Risk Level 1, monitoring is typically visual inspections with the potential for water sampling for non-visible pollutants in the case of pre-existing contamination or a spill. In Risk Level 2, monitoring includes visual inspections along with water sampling for $\mathrm{pH}$, turbidity, and non-visible pollutants, as appropriate. Risk Level 3 monitoring includes visual inspections along with water sampling for $\mathrm{pH}$, turbidity, suspended sediment concentration (if a turbidity numeric effluent limit is exceeded), and non-visible pollutants as appropriate. In some rare cases, bioassessment monitoring is required for Risk Level 3 projects over 30 acres in size. This sampling will be project-specific and will most often be performed by construction project sub-contractor staff or other trained LLNL staff.

Inspections and sampling collection must occur in accordance with the permit subsequent to a qualifying rain event producing 0.5 inches or more precipitation at the time of discharge. Inspections and sampling only need to occur during business hours.

\subsection{Procedures for Laboratory Analysis}

All water quality chemical and radioactivity analyses, including fish toxicity testing, are performed by California-certified off-site contract laboratories using appropriate EPA standard methods. Analyses for specific alpha particle-emitting radionuclides, such as plutonium-239 or uranium-238, use methods specific to each laboratory for detecting radiation from alpha particles (see Table 9-1). A standard chain of custody form is used to track samples, double-check bottle labels, and exchange information with contract laboratories. Calibrated field meters may be employed for $\mathrm{pH}$, turbidity, and specific conductance, as appropriate.

\subsection{Data Quality Assurance}

Field activities are recorded on field tracking forms and/or in logbooks, and sample tracking is maintained through the chain-of-custody process. EFA data management guidance document EMP-RTMN-DM ensures that all laboratory measurements are 
received, accurately recorded, and properly stored in a computer database for easy and fast retrieval. Hard copies of the data are also archived by the EFA Data Management Team.

\subsubsection{Precision}

Under the quality assurance program for this monitoring network, a duplicate sample is collected from a single location from each site (Livermore site and Site 300) for each storm water runoff event. The duplicate location is randomly chosen from the available locations, excluding locations around Lake Haussmann and location WPDC for the first storm. This last exclusion is due to difficulties in duplication of fish toxicity analyses.

The duplicate samples are collected for every analyte at that location and submitted to the lab for analysis, each with a unique sample identifier. The results for the duplicate location sample and actual location sample are compared by the network analyst upon the delivery of the analytical results from the laboratory. Trip blanks, sampling bottles prefilled with deionized water, are not necessary for this network.

\subsubsection{Bias}

All quality check information provided by the analytical laboratories, including lab control standards, matrix spikes, matrix duplicates, and calibration standards are examined by the network analyst to identify any analytical bias. If calibration standards or matrix spikes are consistently high or low, the analyst will contact the laboratory for an explanation.

\subsubsection{Completeness}

Storm water runoff samples are collected for two storm events per year as dictated by permit. Given the potential for sample loss due to broken bottles our target completeness is $90 \%$ for the Livermore site. At Site 300, there may not be sufficient storms to collect samples for two runoff events within working hours during a year. Often only one storm per water year produces significant runoff and some locations (NPT6 and N829) have not produced runoff samples for several years. Therefore, target completeness for Site 300 is $90 \%$ of all sampling locations where with storm water runoff was flowing during working hours.

\subsection{Program Implementation Procedures}

Storm water runoff sampling is conducted by LLNL technical staff according to procedure EMP-W-S, Water Sampling, and instruction EMP-WSS-RO, Storm Water Runoff

Sampling. Methods used to prevent cross-contamination are similar throughout all sampling events. They include wearing disposable gloves when collecting samples, discarding gloves between sampling locations, keeping the work area clean, not placing 
open sample bottles or caps on any surface (sample bottles should be kept closed until used), and not touching the insides of the sample bottles.

Sample preservation and handling practices are performed according to the analytical method requirements, and are specified in laboratory contracts and included in the TEIMS database. Conditions identified during each sampling event are recorded on a Field Tracking Form (FTF). This information, in conjunction with sampling results, provides a complete summary for each representative sampling location. The FTF may also provide information in the form of comments and in situ measurements that may be useful to the analyst. Chain-of-custody forms document the sample from collection in the field through receipt of the data results from the analytical laboratories. Samples are submitted for analyses and resulting analytical results are managed using sample control instructions related to procedure EMP-W-S, Water Sampling.

\subsection{Action Levels}

No numeric water quality criteria for industrial storm water discharges from LLNL currently exist, other than derived concentration guidelines (DCGs) for specific radionuclides according to DOE Order 458.1. In order to provide stringent criteria relevant to the environment around both LLNL sites, site-specific comparison criteria have been calculated for a select group of parameters based on historical concentrations in runoff samples (Campbell and Mathews 2006). A storm water concentration exceeds the threshold if it is greater than the 95 percent confidence limit computed for the historical mean concentration for a specific analyte (Table 9-2).

Construction storm water samples must comply with Numeric Effluent Limits for $\mathrm{pH}$ (6.0 to 9.0) and turbidity (500 Nephelometric Turbidity Units [NTUs]). Numeric Action Levels ( $\mathrm{pH}$ outside 6.5 to 8.5 and turbidity in excess of $250 \mathrm{NTUs}$ ) are also required in the Construction General Permit and trigger a construction site and run-on evaluation to determine whether pollutant source(s) associated with the site's construction activity may have caused or contributed to the exceedance. Any corrective actions needed shall be implemented immediately. This evaluation must be documented in the construction SWPPP and specifically address whether the source(s) of the pollutants causing the exceedance are related to the construction activities or run-on associated with the construction site, as well as what additional BMPs are required to reduce or prevent pollutants from causing exceedances in receiving waters. 
Table 9-2. LLNL site-specific threshold comparison criteria for storm water constituents of concern. Values were estimated based on historical runoff data.

\begin{tabular}{|c|c|c|}
\hline Parameter & Livermore site & Site 300 \\
\hline Total suspended solids (TSS) & $750 \mathrm{mg} / \mathrm{L}^{(\mathrm{a})}$ & $1,700 \mathrm{mg} / \mathrm{L}^{(\mathrm{a})}$ \\
\hline Chemical oxygen demand (COD) & $200 \mathrm{mg} / \mathrm{L}^{(\mathrm{a})}$ & $200 \mathrm{mg} / \mathrm{L}^{(\mathrm{a})}$ \\
\hline $\mathrm{pH}$ & $<6.0,>8.5^{(\mathrm{a})}$ & $<6.0,>9.0^{(b)}$ \\
\hline Nitrate $\left(\right.$ as $\left.\mathrm{NO}_{3}\right)$ & $10 \mathrm{mg} / \mathrm{L}(\mathrm{a})$ & not monitored \\
\hline Orthophosphate & $2.5 \mathrm{mg} / \mathrm{L}^{(\mathrm{a})}$ & not monitored \\
\hline Mercury & above $\mathrm{RL}^{(\mathrm{c})}$ & $0.001 \mathrm{mg} / \mathrm{L}^{(\mathrm{a})}$ \\
\hline Beryllium & $0.0016 \mathrm{mg} / \mathrm{L}^{(\mathrm{a})}$ & $0.0016 \mathrm{mg} / \mathrm{L}^{(\mathrm{a})}$ \\
\hline Chromium (VI) & $0.015 \mathrm{mg} / \mathrm{L}^{(\mathrm{a})}$ & not monitored \\
\hline Copper & $0.036 \mathrm{mg} / \mathrm{L}^{(\mathrm{a})}$ & not monitored \\
\hline Lead & $0.015 \mathrm{mg} / \mathrm{L}^{(\mathrm{d})}$ & $0.030 \mathrm{mg} / \mathrm{L}^{(\mathrm{a})}$ \\
\hline Zinc & $0.35 \mathrm{mg} / \mathrm{L}^{(\mathrm{a})}$ & not monitored \\
\hline Diuron & $0.014 \mathrm{mg} / \mathrm{L}^{(\mathrm{a})}$ & not monitored \\
\hline Oil and grease & $9 \mathrm{mg} / \mathrm{L}^{(\mathrm{a})}$ & $9 \mathrm{mg} / \mathrm{L}^{(\mathrm{a})}$ \\
\hline Tritium & $36 \mathrm{~Bq} / \mathrm{L}^{(\mathrm{a})}$ & $3.17 \mathrm{~Bq} / \mathrm{L}^{(\mathrm{a})}$ \\
\hline Gross alpha radioactivity & $0.34 \mathrm{~Bq} / \mathrm{L}^{(\mathrm{a})}$ & $0.90 \mathrm{~Bq} / \mathrm{L}^{(\mathrm{a})}$ \\
\hline Gross beta radioactivity & $0.48 \mathrm{~Bq} / \mathrm{L}^{(\mathrm{a})}$ & $1.73 \mathrm{~Bq} / \mathrm{L}^{(\mathrm{a})}$ \\
\hline \multicolumn{3}{|c|}{$\begin{array}{l}\text { (a) Site-specific value calculated from historical data and studies. These values are lower than the MCLs and EPA benchmarks } \\
\text { except for zinc, TSS, and COD. }\end{array}$} \\
\hline \multicolumn{3}{|c|}{ (b) EPA benchmark. } \\
\hline (c) $\mathrm{RL}=$ reporting limit (normally) $=$ & & \\
\hline
\end{tabular}

In addition, LLNL storm water analysis results are compared with other water quality criteria. The U.S. EPA established benchmark values for 41 parameters in the multisector permit (EPA 2000), but stressed that these concentrations should not be interpreted as effluent limitations. Rather, they are the levels that EPA uses to determine whether storm water discharges from specific categories of industrial facilities merit further monitoring. LLNL storm water analysis results are compared with water quality criteria listed in Water Quality Control Plan, San Francisco Bay Basin (CRWQCB 1995) and Central Valley Water Quality Control Plan: the Sacramento River Basin and the San Joaquin River Basin (CVRWQCB 1998). Criteria in the Water Quality Control Plans include surface water quality objectives for the protection of aquatic life, and water quality objectives for waters designated as domestic, municipal, or agricultural supply. Water Quality Control Plan criteria also list the California drinking water Maximum Contaminant Levels (MCLs) for drinking water. LLNL storm water analysis results are also compared with EPA's MCLs and Ambient Water Quality Criteria (AWQC) for the protection of freshwater organisms, as well as California's AWQC. 
To evaluate LLNL storm water effluent, analysts carry out the following ordered sequence (Campbell et al. 2004; Campbell and Mathews 2006):

1. Compare storm water effluent concentrations with the above criteria.

2. If an effluent concentration exceeds any criterion, compare effluent value with corresponding influent concentration.

3. If an effluent concentration is lower than the influent concentration, assume that the source is off site or naturally occurring, and take no further action.

4. If data for a given calendar year or wet season indicate that more than 25 percent of effluent concentrations for a particular constituent on a particular flow path (i.e., Arroyo Seco or Arroyo Las Positas) exceed both a criterion and the corresponding influent concentration, develop a historical trend plot.

5. If (a) the historical trend indicates that concentrations are consistently increasing, or if (b) data for a given calendar year or wet season indicate that more than 50 percent of effluent concentrations for a particular constituent on a particular flow path exceed both a criterion and the corresponding influent concentrations, initiate a detailed investigation.

6. A single, unusually high concentration may, by itself, trigger a detailed investigation.

Detailed investigations may include elements such as:

- Management notification.

- Re-analysis of the samples.

- Analysis of subsequent storm events. (Routinely, two storm events are sampled each year. During a detailed investigation, the storm event immediately following a finding may also be sampled for further evaluation.)

- Source investigation. (Results are compared with findings from other monitoring networks [e.g. air, rain, or sediments], and LLNL activities that may have contributed to the result are investigated.)

- Expanded monitoring (more locations).

- Increased monitoring frequency (i.e., more storm events sampled per wet season).

\subsection{Preparation and Disposition of Reports}

Storm water monitoring findings are presented in the surface water monitoring section of the annual LLNL Environmental Report. In addition, storm water sampling results are transmitted annually in two reports to regulatory agencies. Livermore site findings are 
reported to the San Francisco RWQCB, and Site 300 results are reported to the Central Valley RWQCB (e.g., Revelli 2011a; Revelli 2011b). Both reports follow the Storm Water Annual Report format stipulated by the California SWRCB in the General Permit and are due on July 1 (Site 300) and August 1 (Livermore site) of each year. All storm water data are reported and summarized, trends are discussed, and efforts to reduce constituent loadings in storm water are evaluated.

\subsection{Future Plans}

Future plans for storm water monitoring include NPDES permit renewals, which have the potential for requiring changes to monitoring requirements. Future plans are still in the formative stages until the SFBRWQCB and the SWRCB act on the respective permit renewals. Therefore, only very preliminary plans can be provided in the sections below.

Order 95-174, which regulates storm water discharges at the Livermore site, expired in 2000. LLNL initiated the permit renewal process by submitting a Report of Waste Discharge in February 2000 (Mathews 2000), the required 180 days in advance of the expiration date. In April 2000, the SFBRWQCB issued a written administrative continuance for WDR 95-174, until a new permit is adopted. Additionally, the federal Phase II storm water regulations went into effect in March 2003. The SFBRWQCB is currently in the process of designating institutional facilities that operate storm drainage systems, such as the LLNL Livermore site, as requiring a municipal storm water permit. The General Permit for small municipal separate storm sewer systems (MS4s) is currently in a draft revision that includes designation of all non-traditional systems, such as LLNL. This will require LLNL to apply for coverage under the revised MS4 General Permit. At that time LLNL will likely also apply for coverage under the Industrial General Permit or negotiate with the Water Board to revise the existing individual permit (replacing 95-174). These upcoming changes in the regulatory permits and programs that govern the Livermore site storm water discharges are expected to have a significant affect on the storm water monitoring program.

Order 97-03-DWQ, the Industrial General Permit issued by the SWRCB, expired in 2002. The State initiated the public process to revise Order 97-03-DWQ. Once the revised permit is adopted by the State, the Site 300 storm water monitoring program will be revised to meet it requirements. Based upon the draft permit released by the State for public comment, significant changes are expected to be required for the Site 300 storm water monitoring program. If the permit is applied to the Livermore site, it will also result in significant changes in the monitoring program. 


\subsection{References}

Campbell, C. G. and S. Mathews (2006), An Approach to Industrial Stormwater Benchmarks: Establishing and Using Site-Specific Threshold Criteria at Lawrence Livermore National Laboratory. Paper presented at the California Stormwater Quality Association 2006 Conference, Sacramento. CA (UCRL-CONF-224278).

Campbell, C. G., K. Folks, S. Mathews, R. Mortinelli (2004), Investigating sources of toxicity in stormwater: algae mortality in runoff upstream of Lawrence Livermore National Laboratory. Environmental Practice 6(1): 23-35.

CRWQCB (1995), Water Quality Control Plan, San Francisco Bay Basin (Region 2) California Regional Water Quality Control Board, San Francisco Bay Region, State of California, Oakland, CA.

CVRWQCB (1998), The Water Quality Control Plan (Basin Plan) for the California Regional Water Quality Control Board, Central Valley Region, the Sacramento River Basin and the San Joaquin River Basin, California Regional Water Quality Control Board, Central Valley Region, State of California, Sacramento, CA.

DOE (1991), Environmental Regulatory Guide for Radiological Effluent Monitoring and Environmental Surveillance, U. S. Department of Energy, Washington, D. C. (DOE/EH-0173T).

EPA (2000), Notice: Final Reissuance of National Pollutant Discharge Elimination System (NPDES) Storm Water Multi-Sector General Permit for Industrial Activities, U.S. Environmental Protection Agency, Federal Register, Volume 65, No. 210 (October 30, 2000).

Ferry, L., T. Berry, and D. MacQueen (1998), Post-Closure Plan for the Pit 6 Landfill Operable Unit, Lawrence Livermore National Laboratory, Site 300, Lawrence Livermore National Laboratory, Livermore, CA (UCRL-AR-128638).

Isherwood, W. F. (1993), letter to the Central Valley RWQCB, January 22, 1993.

Mathews, S. (2000), Technical Report for the Report of Waste Discharge to Renew NPDES Permit No. CA0030023, Lawrence Livermore National Laboratory, Livermore CA (UCRL-AR-137314).

Revelli, M. A. (2011a), Lawrence Livermore National Laboratory Livermore Site Annual Storm Water Monitoring Report for Waste Discharge Requirements 95-174 Annual Report 2010-2011, Lawrence Livermore National Laboratory, Livermore, CA (UCRL-AR-126783-11).

Revelli, M. A. (2011b), Lawrence Livermore National Laboratory Site 300 Annual Storm Water Monitoring Report for Waste Discharge Requirements 97-03-DWQ. Livermore, CA: Lawrence Livermore National Laboratory, UCRL-AR-144362-11. 
SFBRWQCB (1995), Waste Discharge Requirements and National Pollutant Discharge Elimination System (NPDES) Permit for U. S. Department of Energy and Lawrence Livermore National Laboratory, San Francisco Bay Regional Water Quality Control Board, Order No. 95-174, NPDES No. CA0030023, August 23, 1995.

SWRCB (1997), Statewide General National Pollutant Discharge Elimination System (NPDES) Permit for Storm Water Discharges Associated with Industrial Activities.

SWRCB (1999), Waste Discharge Requirements for Discharges of Storm Water Runoff Associated with Construction Activity. State Water Resources Control Board, Water Quality Order 99-08-DWQ, NPDES General Permit CAS000002, Sacramento, CA.

SFBRWQCB (2000), Letter from Stephen Morse, San Francisco Bay Regional Water Quality Control Board, to Dennis Fisher, Lawrence Livermore National Laboratory. Re: Renewal of National Pollutant Discharge Elimination System (NPDES) Permit No. CA0030023, Lawrence Livermore National Laboratory (LLNL). Dated November 8, 2000.

File No. 2199.9026

Webster-Scholten, C. P., ed. (1994), Final Site-Wide Remedial Investigation Report, LLNL Site 300, Lawrence Livermore National Laboratory, Livermore, CA (UCRLAR-108131). $\pi$ 


\section{Rainwater}

Jennifer C. Nelson

\subsection{Introduction}

This chapter describes the program for monitoring tritium activity in rainwater at the Livermore site and at Site 300 in the Altamont Hills. Rainwater monitoring is part of a comprehensive and ongoing environmental monitoring program for Lawrence Livermore National Laboratory (LLNL) (see Chapter 1).

\subsection{Rationale and Design Criteria}

\subsubsection{Regulatory Drivers}

Although no state or federal laws require rainwater monitoring, U.S. Department of Energy (DOE) Order 548.1 objectives for environmental monitoring apply for monitoring tritium activity in rainwater at LLNL. The Order states, in part, "Site-specific environmental monitoring criteria must be established to ensure that representative measurements of quantities and concentrations of radiological contaminants are conducted and that the effects from DOE radiological activities on members of the public and the environment are monitored sufficiently to demonstrate compliance with this Order."

DOE's Environmental Regulatory Guide for Radiological Effluent Monitoring and Environmental Surveillance (DOE 1991) describes the environmental surveillance monitoring objectives applicable to tritium activity in rainwater:

"The purpose of the surveillance program is to characterize the radiological conditions of the off-site environs and, if appropriate, estimate public doses related to these conditions...." and "The extent of each environmental surveillance program is to be determined by the responsible DOE field organization, based on the applicable regulations, the hazard potential of the effluents, the quantities and concentrations of effluents, the specific public interest, and the nature of potential or actual impacts on air, land, biota, and water."

\subsubsection{Monitoring Objectives}

The specific purpose of monitoring rainwater at LLNL is to determine the impact, if any, of tritium emissions from LLNL on levels of tritium in rainfall at and in the vicinity of LLNL. 


\subsubsection{Sources and Analytes}

Livermore Site. Tritium activity in air-moisture and, thence, in rainwater at the Livermore site and in the Livermore Valley, results primarily from atmospheric emissions of tritiated water vapor (HTO) from operations at LLNL's Tritium Facility (Building 331), the National Ignition Facility (NIF), and hazardous and radioactive decontamination and treatment facilities at Buildings 612, 693, 695, and 696.

Site 300. Minute quantities of tritium are approved for use in open-air explosive experiments on firing tables at Site 300. Tritium is present in groundwater at Site 300 and groundwater release at the surface during treatment activities or natural spring discharges are possible.

\subsubsection{Collection Methods}

Rainwater is collected using rain gauges mounted at fixed locations about 1.5 meters above ground within the Livermore site and at Site 300. Rainwater samples for tritium analysis are decanted directly from the collecting rain gauges following procedures EMP-W-S, Water Sampling, and supplement EMP-WSS-RA, Livermore and Site 300 Rain. Field measurements and observations are documented on field tracking forms according to procedure EMP-QA-DM, Sample and Data Management, and supplement EMP-QAS-FTF, Completing Field Tracking Forms.

\subsection{Extent and Frequency of Monitoring and Measurement}

Livermore Site. Rainwater sampling locations at the Livermore site are shown in Figure 10-1. Rainwater samples are collected whenever storm water runoff samples are collected, typically for two events per calendar year. Rainwater sampling is currently conducted at sampling locations at the four corners around the perimeter of the Livermore site, and adjacent to four air-moisture tritium sampling locations. Airmoisture containing HTO is rapidly entrained and precipitated locally during rainwater events. Co-location of rainwater and air-moisture tritium sampling allows for comparison of results for these media. Air-moisture sampling locations have been sited based on knowledge of local HTO source locations and wind directions. Winds are typically southwesterly during rainwater events, but are occasionally northeasterly. Northwesterly or southeasterly winds are rare during rainwater events.

Although total HTO emissions have declined significantly since 1988, emissions continue from Building 331 and NIF operations. Historical tritium activity measurements demonstrate that tritium activity in rainwater decreases exponentially with distance from the Livermore site. Previously, the rainwater sampling network was more extensive but sampling at the more distant locations was curtailed because the results at those locations consistently yielded data below the reporting limits. 


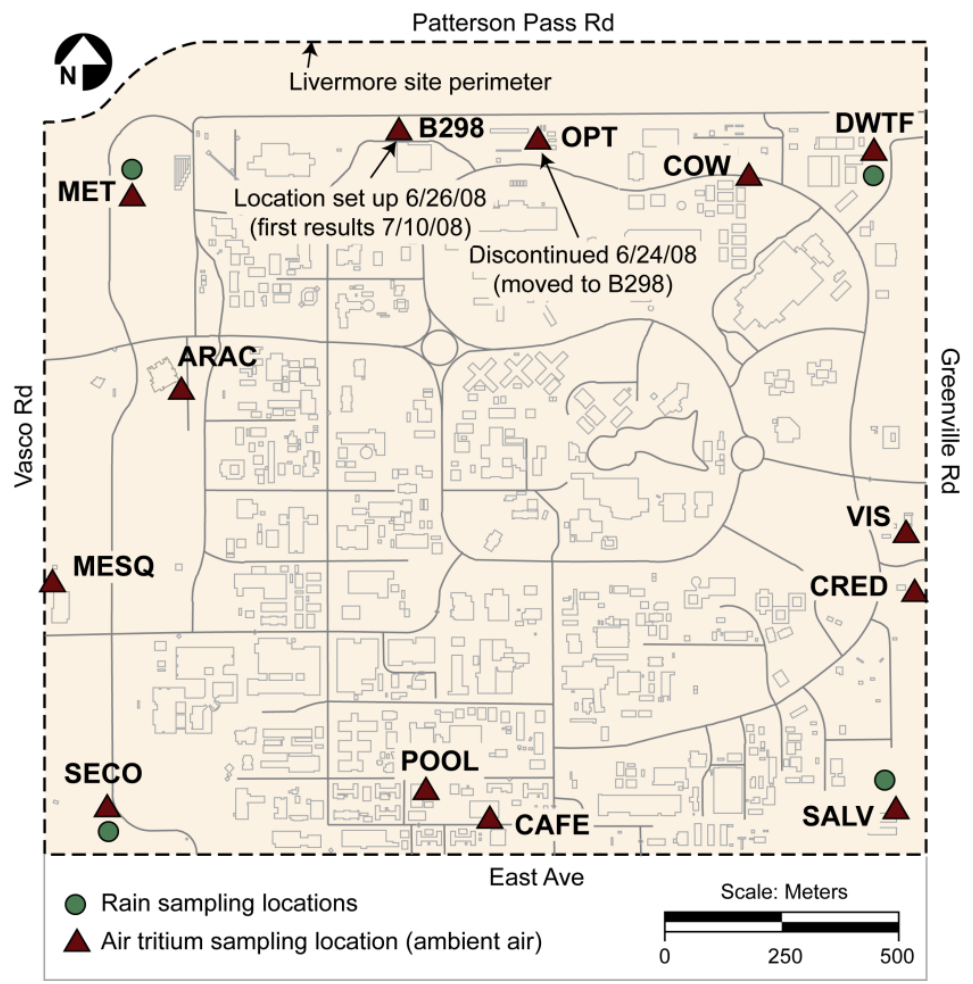

Figure 10-1. Rainwater and air tritium sampling locations, Livermore site.

Monitoring tritium in rainwater at location DWTF, in the northeastern corner of the Livermore site, adjacent to air-moisture tritium sampling location DWTF, began in 2003. This location is used to monitor the effect on rainfall of low-level HTO emissions from the Decontamination and Waste Treatment Facility (DWTF).

Site 300. Figure 10-2 shows the locations of the two rainwater monitoring stations at Site 300. Winds are stronger and show less directional distribution than at the Livermore site, with winds most often from the west-southwest through west. Site 300 is semi-arid with an average rainfall of about 10.5 inches a year. Because of reduced rainfall there, it is not always possible to sample two rain events each year.

Historically, rainwater samples were collected at Site 300 from a single central location (COMP) that was adjacent to the previous location of the meteorological tower (Figure 10-2). The tritium activity in the rainwater samples obtained historically from location COMP has all been below the reporting level (RL) of about $4 \mathrm{~Bq} / \mathrm{L}(100 \mathrm{pCi} / \mathrm{L})$. To determine if tritium activity in rainwater at Site 300 was being adequately monitored, two additional rainwater sampling locations were added in 1999; one on the site to the north of location COMP (TNK5, Figure 10-2) and one off the site to the east of location 


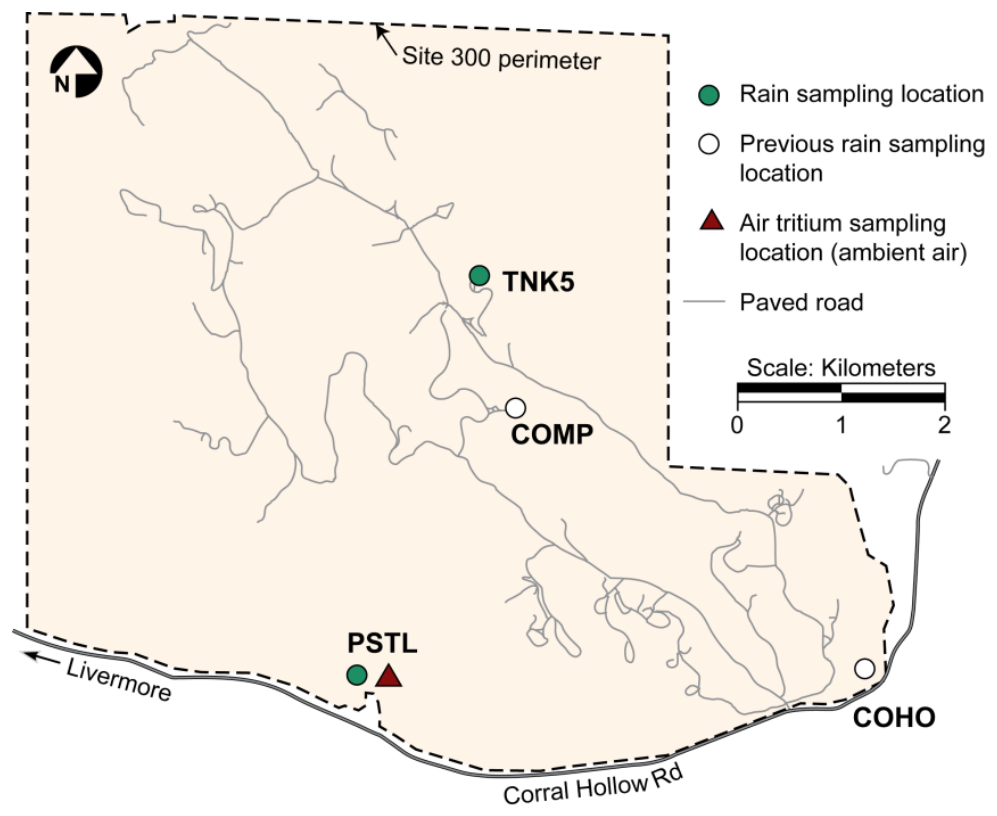

Figure 10-2. Rainwater and air tritium sampling locations, Site 300.

COMP (PRIM, not shown in Figure 10-2). However, location PRIM was abandoned in 2002 because of continued disappearance of the rainwater collection bucket. To replace PRIM, location COHO (Figure 10-2) was established in 2002 in the southeastern corner of Site 300, adjacent to the air-moisture tritium sampler there. Since 1999, no tritium activity in rainwater above the RL has been measured at any of the three Site 300 locations. In April 2006, the location COHO was replaced by the PSTL location, which is the location of maximum radiological exposure to an individual for the purpose of National Emission Standards for Hazardous Air Pollutants (NESHAPS) compliance (see 40 CFR 61, Subpart H).

\subsection{Procedures for Laboratory Analysis}

Radioactivity and radioisotope measurements are currently performed off site by contract analytical laboratories according to conditions and methodology specified in an approved Statement of Work (SOW). The EPA-approved method of scintillation counting (EPA Method 906) is employed to measure tritium activity in rainwater samples. This method is cost-effective and it provides accurate measurements down to approximately $3.8 \mathrm{~Bq} / \mathrm{L}(100 \mathrm{pCi} / \mathrm{L})$, equal to $1 / 200$ of the state and federal MCL of $740 \mathrm{~Bq} / \mathrm{L}(20,000 \mathrm{pCi} / \mathrm{L})$ for tritium activity in drinking water.

\subsection{Data Quality Assurance}

\subsubsection{Precision}

Under the quality assurance program for this monitoring network, a duplicate sample is collected from a single location for each rain event. The duplicate location is randomly 
chosen from the available locations, if rain sample volume is sufficient. If the rain sample volume is insufficient at the preselected location, an alternative location may be used. This duplicate sample is submitted to the laboratory for analysis with a unique sample identifier. The results for the duplicate location sample and actual location sample are compared by the network analyst upon the delivery of the analytical results from the laboratory. Trip blanks (sampling bottles prefilled with deionized water) are not necessary for this network.

\subsubsection{Bias}

All quality check information provided by the analytical laboratories including matrix spikes, matrix duplicates, and calibration standards, are examined by the network analyst to identify any analytical bias. If calibration standards or matrix spikes are consistently high or low, the analyst will contact the laboratory for an explanation.

\subsubsection{Completeness}

Rainwater is collected from a given site if storm water samples are collected or if the analyst specifically requests samples. Therefore, planned rain sampling includes two sampled storm water events and any additional sampling deemed necessary by the analyst. Sampling of all locations during the two storms sampled at each site (Livermore site and Site 300 ) would be considered 100\% completeness. Given the potential for sample loss due to broken bottles, target completeness is $90 \%$ for each site (Livermore site and Site 300).

\subsection{Program Implementation Procedures}

Rainwater sampling is conducted by LLNL technical staff according to procedure EMP-W-S, Water Sampling, and supplement EMP-WSS-RA, Livermore and Site 300 Rain. Sample bottle requirements for tritium analysis are specified in the Sample Collect table of the Taurus Environmental Information Management System (TEIMS) database. Sample and data management requirements, including documentation and the process used for submitting samples to analytical laboratories, are defined in EMP-QA-DM, Sample and Data Management. Supplements to EMP-QA-DM define processes that must be used for completing field tracking forms (EMP-QAS-FTF, Completing Field Tracking Forms) and chain-of-custody forms (EMP-QAS-COC, Completing Chain of Custody Forms). Sample locations are recorded and tracked in TEIMS.

\subsection{Action Levels}

Tritium activities in rainwater samples are compared with the drinking water MCL and with historical activity data trends for each sampling location. If any sample result exceeds the drinking water MCL of $740 \mathrm{~Bq} / \mathrm{L}(20,000 \mathrm{pCi} / \mathrm{L})$ or shows an increase that is significantly above the historical trend, the responsible environmental analyst would 
notify LLNL Environmental Functional Area (EFA) management of the event. An investigation of the cause for the increase(s) could ensue and may include elements such as:

- Re-analysis of the samples.

- Source investigation. (Rainwater tritium results are compared with tritium data from other monitoring networks such as air-moisture and storm water run-off. LLNL tritium-handling activities that may have contributed to any marked increase are investigated and documented.)

- Expanded monitoring (more locations).

- Increased monitoring frequency.

\subsection{Preparation and Disposition of Reports}

Rainwater monitoring results are described in the water monitoring section of the annual LLNL Environmental Report. The Environmental Report summarizes the rainwater tritium activity data, discusses trends, and includes a brief statement regarding the impact, if any, of LLNL tritium-handling operations on the local environment.

\subsection{Future Plans}

The sufficiency of rainwater sampling (frequency and locations) is reviewed annually by the responsible analyst. Should LLNL HTO emissions increase significantly in the future, more distant sampling locations could be added to better encompass the impacted area.

New sources of HTO vapor will be considered and appropriate changes to the rainwater monitoring program will be made as they occur.

\subsection{References}

DOE (1991), Environmental Regulatory Guide for Radiological Effluent Monitoring and Environmental Surveillance, U. S. Department of Energy, Washington, D. C.

(DOE/EH-0173T).

Environmental Report (annual), Lawrence Livermore National Laboratory, Livermore, CA. (UCRL-TR-50027). Available at https://saer.llnl.gov 


\section{Lake Haussmann Release}

Crystal Rosene and Christopher Campbell

\subsection{Introduction}

This chapter describes the program for monitoring releases of water from Lake Haussmann, an ornamental pond near the center of the LLNL Livermore site (it was formerly called the Drainage Retention Basin [DRB]). General information regarding the Environmental Monitoring Plan and the facilities at Lawrence Livermore National Laboratory (LLNL) can be found in Chapter 1.

Lake Haussmann lies in the central area of the LLNL main site. It covers 1.6 hectares and contains up to $45.6 \mathrm{~m}^{3}$ (37 acre-feet) of water. Remediation action studies undertaken as part of Comprehensive Environmental Response, Compensation and Liability Act (CERCLA) cleanup indicated that infiltration of collected storm water from the original basin, which was unlined, caused increased dispersal of ground water contaminants. Therefore, the basin was lined to halt infiltration of water collected in that area. Lining was completed in March 1992 and monitoring of releases from Lake Haussmann began that same year. Lake Haussmann discharges into LLNL's storm drainage system and eventually to Arroyo Las Positas, a navigable water of the United States (see Figure 11-1).

\subsection{Rationale and Design Criteria for Lake Haussmann Release Monitoring}

\subsubsection{Regulatory Drivers}

Lake Haussmann is an ornamental pond that collects storm water and ground water that prevents large-scale infiltration of water that would impact CERCLA cleanup at the Livermore site.

Because Lake Haussmann was constructed using CERCLA remediation funding, its discharges have been monitored in a manner similar to treated ground water from other LLNL CERCLA cleanup activities, and LLNL has reported monitoring results as part of the CERCLA process. LLNL has also monitored Lake Haussmann discharges as an NPDES discharge point. 


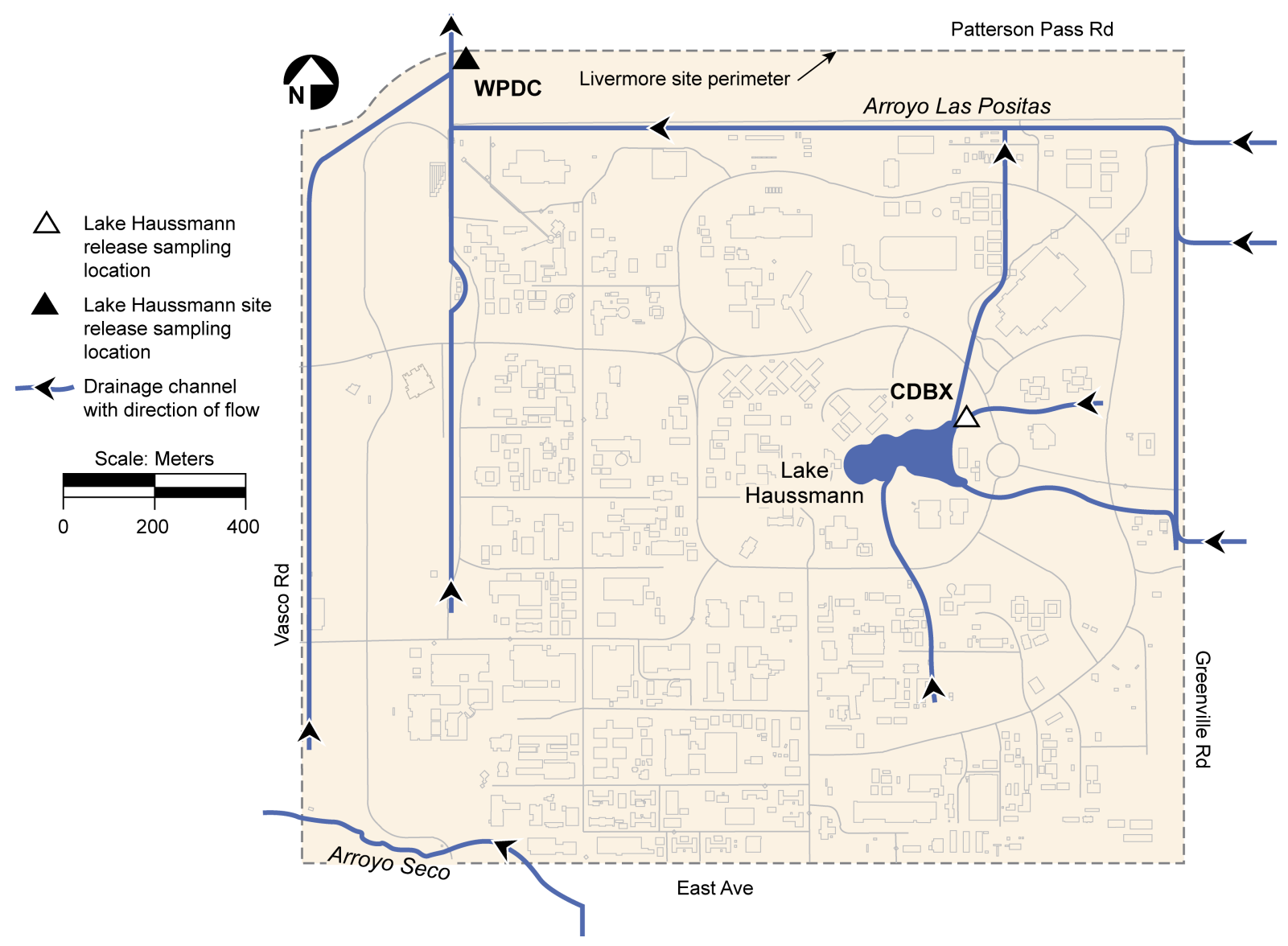

Figure 11-1. Lake Haussmann Release sampling locations, Livermore site and vicinity.

\subsubsection{Monitoring Objectives}

The primary objective of monitoring Lake Haussmann releases is to ensure that concentrations of metals, organics, and physical properties, remain within acceptable levels as identified by best management practices, and comply with requirements DOE Order 458.1

\subsubsection{Sources and Analytes}

Two sources of water fill and maintain Lake Haussmann:

- Water generated from ground water treatment units that discharge to Lake Haussmann directly from the treatment units or indirectly through the existing storm water drainage system or pipelines.

- Storm water runoff (drainage from approximately one-fourth of the Livermore site and adjacent watershed east of LLNL).

From 1993 through 1997, storm water runoff was the primary source of water to Lake Haussmann, and the treated ground water contribution was only minor in both the wet 
and dry season. Since 1997, dry season discharges to Lake Haussmann have become dominated by treated ground water discharges as more treatment facilities began discharging to the lake. However, storm water continues to be the major source water during the wet season.

Potential pollutant sources discharging to Lake Haussmann either directly or through storm water runoff include:

- Storm water runoff from parking lots (a potential source of metals, petroleum products, and sediment).

- Landscape irrigation runoff (a potential source of nutrients and pesticides).

- Pesticides washed in from applications upstream of Lake Haussmann.

- Sediments from adjacent construction projects and multiple upstream sources.

- Excessive quantities of wildlife excrement, such as goose droppings (a potential source of nutrients).

- Unplanned releases of materials to the ground or water.

For compliance monitoring, the constituents of concern for Lake Haussmann and their action levels are listed in Table 11-1.

For surveillance monitoring, the 96-hour acute toxicity test using fathead minnow (Pimephales promelas) was added to test for general toxicity. This test was conducted from 1993 to 2011, and all results indicated that acute toxicity was not an issue so the test was discontinued in 2012. Three chronic toxicity tests are performed using fathead minnow, the daphnid (Ceriodaphnia dubia), and green alga (Selenastrum capricornutum). Sampling for PCBs was added when PCBs were found in soil and cleaned up just east of Lake Haussmann. A special study for the pesticides/herbicides bromicil, glyphosate and diuron was added after one brief toxic event traced to either tanbark or weed spraying inside the berm surrounding Lake Haussmann. 
Table 11-1. Treated ground water and Lake Haussmann discharge analytes for sampling locations CDBX and WPDC.

\begin{tabular}{|c|c|c|c|c|}
\hline \multirow{2}{*}{ Constituent } & \multirow{2}{*}{ Location } & \multirow{2}{*}{ Frequency (a) } & \multicolumn{2}{|c|}{ Investigation Level } \\
\hline & & & Dry season $(b)$ & Wet season $(c)$ \\
\hline \multicolumn{5}{|l|}{ Metals $(\mu \mathrm{g} / \mathrm{L})$} \\
\hline Antimony & CDBX, WPDC & $\mathrm{W} \& \mathrm{D}$ & 6 & (d) \\
\hline Arsenic & CDBX, WPDC & $\mathrm{W} \& \mathrm{D}$ & 50 & 10 \\
\hline Beryllium & CDBX, WPDC & $\mathrm{W} \& \mathrm{D}$ & 4 & (d) \\
\hline Boron & CDBX, WPDC & $\mathrm{W} \& \mathrm{D}$ & (d) & (d) \\
\hline Cadmium & CDBX, WPDC & $\mathrm{W} \& \mathrm{D}$ & 5 & 2.2 \\
\hline Chromium (total) & CDBX, WPDC & $\mathrm{W} \& \mathrm{D}$ & 50 & (d) \\
\hline Chromium (VI) & CDBX, WPDC & $\mathrm{W} \& \mathrm{D}$ & (d) & 22 \\
\hline Copper & CDBX, WPDC & $\mathrm{W} \& \mathrm{D}$ & 1,300 & 23.6 \\
\hline Iron & CDBX, WPDC & W \& D & (d) & (d) \\
\hline Lead & CDBX, WPDC & W \& D & 15 & 6.4 \\
\hline Manganese & CDBX, WPDC & W \& D & (d) & (d) \\
\hline Mercury & CDBX, WPDC & W \& D & 2 & 2 \\
\hline Nickel & CDBX, WPDC & $\mathrm{W} \& \mathrm{D}$ & 100 & 320 \\
\hline Selenium & CDBX, WPDC & $\mathrm{W} \& \mathrm{D}$ & 50 & 10 \\
\hline Silver & CDBX, WPDC & W \& D & 100 & 8.2 \\
\hline Thallium & CDBX, WPDC & $\mathrm{W} \& \mathrm{D}$ & 2 & (d) \\
\hline Zinc & CDBX, WPDC & $\mathrm{W} \& \mathrm{D}$ & (d) & 220 \\
\hline \multicolumn{5}{|l|}{ Physical } \\
\hline $\mathrm{pH}$ (units) & CDBX, WPDC & $\mathrm{W} \& \mathrm{D}$ & $6.5-8.5$ & $6.5-8.5$ \\
\hline \multicolumn{5}{|l|}{ Toxicity } \\
\hline Aquatic survival bioassay ( 96 hours) & CDBX, WPDC & $\mathrm{W} \& \mathrm{D}$ & $90 \%$ survival median, 90 & ot less than $70 \%$ survival \\
\hline E1000 & CDBX & $\mathrm{W}$ & (d) & (d) \\
\hline E1002 & CDBX & $\mathrm{W}$ & (d) & (d) \\
\hline E1003 & CDBX & $\mathrm{W}$ & (d) & (d) \\
\hline \multicolumn{5}{|l|}{ Organics $(\mu \mathrm{g} / \mathrm{L})$} \\
\hline Trichloroethylene (TCE) & CDBX & $\mathrm{W}$ & 5 & 5 \\
\hline Vinyl chloride & CDBX & $\mathrm{W}$ & 2 & 2 \\
\hline \multicolumn{5}{|l|}{ Radiological (Bq/L) } \\
\hline Tritium & CDBX & $\mathrm{W}$ & 740 & 740 \\
\hline
\end{tabular}

Source: LLNL 1992

a $\quad$ W $=$ Monitoring occurs at the first Lake Haussmann discharge of the wet season and at one or more additional discharges associated with storm water runoff monitoring. Toxicity testing is required only on the first release.

$\mathrm{D}=$ Monitoring occurs at each dry season release or monthly during continuous release. For purposes of discharge sampling, the dry season is defined to occur from June 1 through September 30.

b Dry season limits apply to CDBX from April 1 to November 30.

c Wet season limits apply to CDBX from December 1 to March 31.

d No limit specified. 


\subsubsection{Collection Methods}

During release sampling, grab samples are collected according to procedure EMP-W-S, Water Sampling, and supplement EMP-WSS-RE, Lake Haussmann Release Sampling. Sample bottle and preservation requirements for each analyte are specified on the field tracking form (FTF). All instruments used for field measurements (e.g., pH, temperature, and turbidity) are calibrated prior to use following manufacturer instructions. Field measurements and observations are documented on FTFs according to procedure EMPQA-DM, Sample and Data Management, and supplement EMP-QAS-FTF, Completing Field Tracking Forms.

\subsection{Extent and Frequency of Monitoring and Measurement}

The sampling frequency for releases from Lake Haussmann was determined in agreement with the San Francisco Bay RWQCB (Isherwood 1993; Galles 1997; Jackson 2002). Samples are collected from the first wet season release and from at least one subsequent wet season release. The second wet season release is sampled in conjunction with storm water runoff (see Chapter 9). During the dry season, samples are collected during each release or monthly if the release is continuous. For the purpose of Lake Haussmann releases, the dry season is defined as June 1 through September 30. Flow from Lake Haussmann is typically continuous except for brief periods when maintenance is performed.

Releases from Lake Haussmann are sampled at two locations: Lake Haussmann's outfall (CDBX) and the Livermore site storm drain outfall (WPDC) as shown in Figure 11-1.

Special studies are occasionally implemented to address specific issues that may arise in managing Lake Haussmann. They may include increased monitoring frequencies for specific analytes, additional toxicological testing, adding constituents or field measurements, and supplemental biological or microbiological monitoring.

\subsection{Procedures for Laboratory Analysis}

Analysis of Lake Haussmann release samples is currently performed off site by contract analytical laboratories according to conditions and methodology specified in an approved Statement of Work (SOW).

\subsection{Data Quality Assurance}

\subsubsection{Precision}

Random duplicate samples are collected at either of the two sampling locations to meet the minimum 10\% QA sample requirement. These duplicate samples are submitted to the lab for analysis with a unique sample identifier. The results for the duplicate samples and 
routine sample are compared by the network analyst upon the delivery of the analytical results from the laboratory. Trip blanks (sampling bottles prefilled with deionized water) are not necessary for this network.

\subsubsection{Bias}

All quality control sample information provided by the analytical laboratories, including matrix spikes, matrix duplicates, and calibration standards, are examined by the network analyst to identify any analytical bias. If calibration standards or matrix spikes are consistently high or low, the analyst will contact the laboratory for an explanation.

\subsubsection{Completeness}

Lake Haussmann release samples are collected during the first wet season release from the Lake, and at least once more in conjunction with storm water runoff monitoring. Samples are collected at each dry season release or monthly if the release is continuous. Samples collected at all these times would be considered $100 \%$ complete. Given the potential for sample loss due to broken bottles our target completeness is $90 \%$.

\subsection{Program Implementing Procedures}

Lake Haussmann release sampling is conducted by LLNL technical staff according to procedure EMP-W-S, Water Sampling, and supplement EMP-WSS-RE, Lake Haussmann Release Sampling. Sample bottle requirements for tritium analysis are specified on the FTF. Sample and data management requirements, including documentation and the process used for submitting samples to analytical laboratories, are defined in EMP-QADM, Sample and Data Management. Supplements to EMP-QA-DM define processes that must be used for completing field tracking forms (EMP-QAS-FTF) and chain-of-custody forms (EMP-QAS-COC), and for controlling sample locations (EMP-QAS-LOC). Sample locations are tracked in a database.

\subsection{Action Levels}

Limits for discharging treated ground water into the storm drainage system, are listed in Table 11-1. Additional parameters for surveillance monitoring and their action levels are listed in Table 11-2. 
Table 11-2. Analytes and action levels for Lake Haussmann discharge studies for sampling locations CDBX and WPDC.

\begin{tabular}{|l|c|c|c|}
\hline \multicolumn{1}{|c|}{ Constituent } & Location & Frequency (a) & Investigation level \\
\hline Organics $(\boldsymbol{\mu}$ g/L) & & & \\
Polychlorinated biphenyls & CDBX, WPDC & W \& D & NA \\
Chemical oxygen demand & CDBX & W & 20 \\
Herbicides (E507-Bromicil, E547- & CDBX & W & NA \\
Glyphosate, E632-Diuron) & CDBX & W & NA \\
Total organic carbon & & & \\
Physical & CDBX, WPDC & W \& D & 15 \\
Turbidity (NTU) (b) & CDBX, WPDC & W \& D & NA \\
Total suspended solids & CDBX, WPDC & W & 900 \\
Conductivity ( $\mu$ S/cm) & CDBX, WPDC & W & 360 \\
Total dissolved solids (mg/L) & & & \\
General minerals & CDBX & W & $<50$ \\
Total alkalinity (mg/L) & CDBX & W & 0.2 \\
Nitrate (as N) (mg/L) & CDBX & W & 0.2 \\
Nitrite (as N) (mg/L) & & W & 0.56 \\
Radiological (Bq/L) & CDBX & W & 1.85 \\
Alpha & CDBX & & \\
Beta & & & \\
\hline
\end{tabular}

Source: LLNL 1992

(a) $\quad \mathrm{W}=$ Monitoring occurs at the first Lake Haussmann discharge of the wet season and at one or more additional discharges associated with storm water runoff monitoring. Toxicity testing is required only on the first release.

$\mathrm{D}=$ Monitoring occurs at each dry season release or monthly with continuous release. For purposes of discharge

(b) sampling, the dry season is defined to occur from June 1 through September 30.

Nephelometric turbidity units.

LLNL responses to Lake Haussmann release water above release limits may include some or all of the steps listed below. A single, unusually high concentration may, by itself, trigger a detailed investigation. Detailed investigations may include elements such as:

- Management notification.

- Re-analysis of the samples.

- Additional sampling and analysis of water contained within Lake Haussmann or analysis of subsequent releases. During a detailed investigation, a release occurring immediately following a finding may be sampled to confirm or negate the concentration being investigated or to determine whether the finding was a single or chronic occurrence. 
- Source investigation. Results are compared with findings from other monitoring networks (e.g., air, rain, and storm water), and LLNL activities that may have contributed to the result are investigated.

- Expanded monitoring to additional locations.

- Increased monitoring frequency.

In addition, findings of concentration levels not meeting release limits are evaluated to determine if an occurrence report is also required.

\subsection{Preparation and Disposition of Reports}

Since September 1993, results from Lake Haussmann release monitoring have been reported to the San Francisco Bay RWQCB regulatory agencies in quarterly and annual ground water project reports submitted by LLNL's Environmental Restoration Department. Monitoring results are also reported in the annual Environmental Report. These reports note any releases exceeding limits and contain information on the nature, time, duration, cause of the finding, and a description of any measures taken to remedy it and to prevent its recurrence.

\subsection{Future Plans}

No changes in Lake Haussmann release monitoring are planned at this time.

\subsection{References}

Berg, L., E. Folsom, M. Dresen, R. Bainer, A. Lamarre (Eds.) (1997), Explanation of Significant Differences for Metals Discharge Release Limits at the Lawrence Livermore National Laboratory Livermore Site, Lawrence Livermore National Laboratory, Livermore, CA. (UCRL-AR-125927).

Environmental Report (annual), Lawrence Livermore National Laboratory, Livermore, CA. (UCRL-50027). Available at https://saer.llnl.gov/

Galles, H. L. (1997), letter to Joseph Chow of the San Francisco Bay Regional Water Quality Control Board, Lawrence Livermore National Laboratory Drainage Retention Basin Monitoring Plan Amendments (WGMG97:439, December 9, 1997).

Isherwood, W. F. (1993), letter to Elizabeth Adams of the San Francisco Bay Regional Water Quality Control Board, "Discharge Release From Lawrence Livermore National Laboratory Central Drainage Retention Basin (NPDES No. CA0029289)," (PRA92-572, January 5, 1993).

Jackson, C. S. (2002), "Drainage Retention Basin Monitoring Plan," letter to Naomi Feger, San Francisco Bay Regional Water Quality Control Board, December 6, 2002.

LLNL (1992), Record of Decision for the Lawrence Livermore National Laboratory, Livermore Site, Lawrence Livermore National Laboratory, Livermore, CA. (UCRLAR-109105). 


\section{Site 300 Drinking Water Discharges}

Michael A. Revelli

\subsection{Introduction}

This chapter describes the program for monitoring Drinking Water System Discharges at the Lawrence Livermore National Laboratory (LLNL) Experimental Test Site (Site 300). General information regarding the Environmental Monitoring Plan and the facilities at LLNL can be found in Chapter 1.

LLNL Site 300 operates a nontransient, noncommunity water system. Water is pumped from the regional aquifer by two on-site supply wells (Wells W-18 and W-20) into the distribution and storage system. Groundwater is chlorinated at the wellheads and may also be chlorinated, as needed, at the booster/transfer stations. Occasionally, discharges that may enter waters of the United States must be made from the drinking water system.

\subsection{Rationale and Design Criteria}

\subsubsection{Regulatory Drivers}

The Federal Water Pollution Control Act (Clean Water Act, 1972, 33 USC 1251) was enacted to restore and maintain the chemical, physical, and biological integrity of waters of the United States. To this end, Section 402 established the National Pollutant Discharge Elimination System (NPDES) to set the conditions under which pollutants could be discharged to navigable waters. The Central Valley Regional Water Quality Control Board (CVRWQCB) chose to regulate low-threat discharges to surface waters under a general NPDES permit, and in August 2000 the board issued a Notice of Applicability (CAG995001, WDR 5-00-175) for LLNL's occasional, large volume, low threat discharges from the Site 300 drinking water system. WDR 5-00-175 was rescinded in 2008, and effective February 2009, LLNL obtained coverage for these low threat discharges under a new Notice of Applicability (General Order WDR R5-2008-0081, CAG995001).

WDR R5-2008-0081 establishes monitoring requirements to verify compliance with established effluent limitations and to test for adverse impacts to the receiving waters. Effluent limits are established by the CVRWQCB for constituents of concern that could adversely affect waters of the state of California and of the United States. 


\subsubsection{Monitoring Objectives}

The objective of the Site 300 Drinking Water Discharges monitoring program is to demonstrate compliance with the effluent limitations of WDR R5-2008-0081 and to provide timely information to stop discharges if effluent limitations are not met.

\subsubsection{Sources and Analytes}

Anticipated pollutants from the drinking water system are residual chlorine and $\mathrm{pH}$. The residual chlorine in the drinking water system is maintained between 0.2 and 3.0 parts per million ( $\mathrm{ppm}$ ). The $\mathrm{pH}$ of the drinking water is 7.84 to 8.4. In addition, the General Order requires monitoring for specific conductance, temperature, flow, total suspended solids, settleable solids, and biochemical oxygen demand. Locations of drinking water sources and monitoring locations at Site 300 are shown in Figure 12-1.

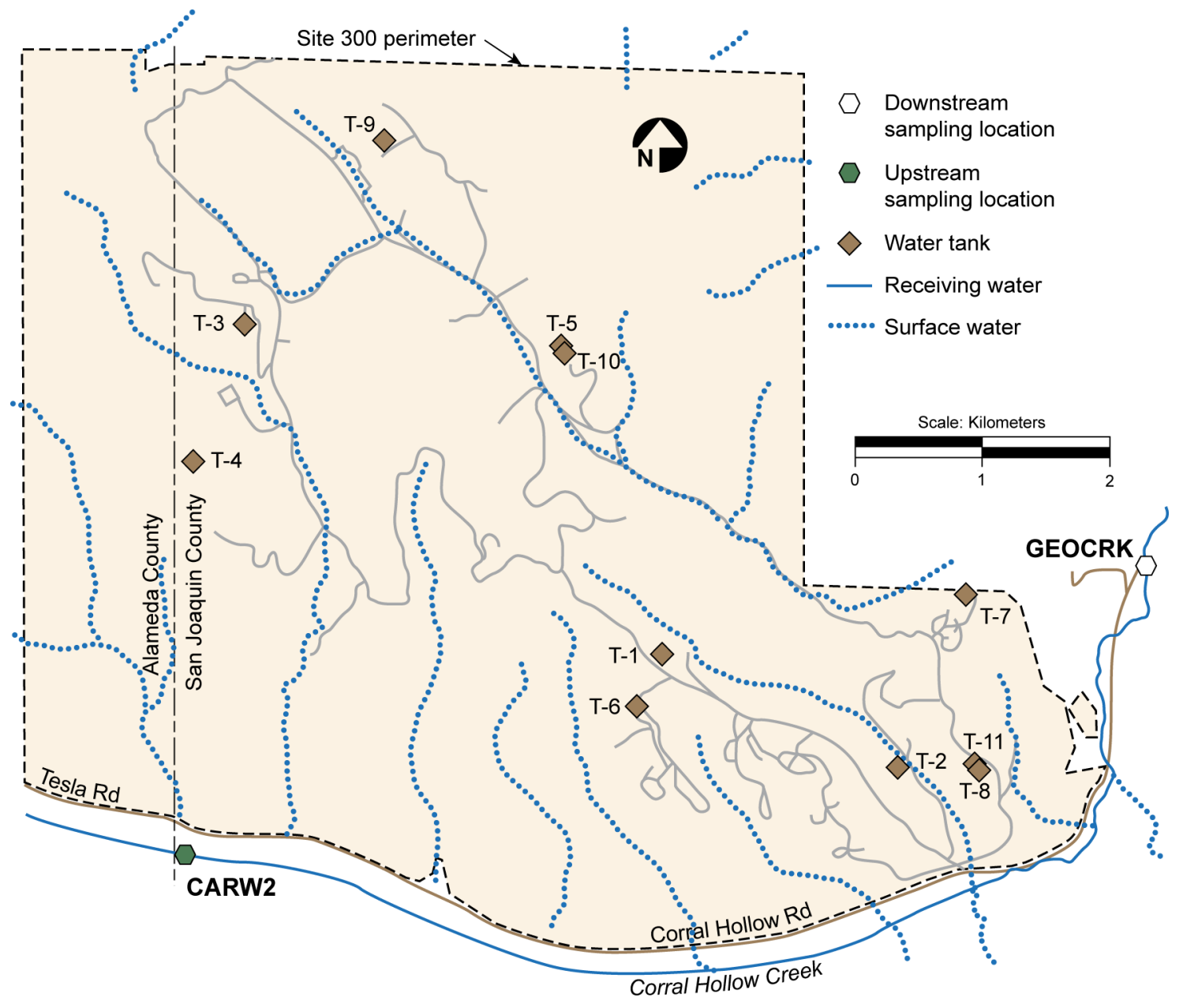

Figure 12-1. Site 300 surface waters, drinking water tanks, and receiving water monitoring locations. 


\subsubsection{Collection Methods}

Compliance monitoring of Site 300 drinking water discharges is done by both field and laboratory measurements. Grab samples are measured in the field for $\mathrm{pH}$, residual chlorine, specific conductance, and temperature because immediate measurements provide more representative information than laboratory analysis. Splits of these grab samples are sent to California-certified, off-site contract laboratories for analysis of total suspended solids, settleable solids, and biochemical oxygen demand. Sample handling and collection techniques used are similar to those for other environmental water sampling, as noted in procedure EMP-W-S, Water Sampling, and supplement EMPWSS-WSD, Site 300 Water System Discharges Monitoring and Sampling. Standard field tracking procedures as described in EMP-QA-DM, Sample and Data Management, are employed to document field conditions that may affect the samples.

\subsection{Extent and Frequency of Monitoring and Measurement}

The Pollution Prevention and Monitoring and Reporting Program (PPMRP) (Revelli and Campbell 2010) prepared by LLNL and submitted to the CVRWQCB establishes the following specific monitoring requirements for discharges:

- Drinking water storage tanks - monitor all discharges that have the potential to reach surface waters.

- System flushes - monitor one flush per pressure zone per quarter.

- Deadend flushes - monitor all flushes that have the potential to reach surface waters and, for any discharge that continues for more than three months, monitor quarterly.

- Well W-18 Discharges - monitor one of the intermittent operational discharges from well W-18 during any quarter in which discharges from that well can not be captured and have the potential to reach surface waters.

The releases identified above, which have the potential to reach surface waters, are monitored at up to three points, depending upon how far the water flows from the source of discharge. Grab samples are collected at the point of discharge, at the point the discharge enters the surface water (if applicable), and, if it reaches the receiving water, at the established downstream monitoring location in Corral Hollow Creek (GEOCRK). When a discharge reaches Corral Hollow Creek, the established upstream monitoring location in Corral Hollow Creek (CARW2) is also sampled in order to evaluate the impact of the discharge on the receiving water. See Figure 12-1 for the locations of the drinking water tanks, surface waters, and receiving water monitoring locations.

Observations of the discharges are also made. At the discharge point, the effluent is observed for evidence of other pollutants being carried with the discharge (such as oil and 
sediment), discoloration of water, and estimate of flow rate from the source. At the point that the effluent discharges into surface waters (if applicable), observations are made for the same parameters.

If the effluent reaches the receiving water, Corral Hollow Creek, observations are made at upstream and downstream locations for evidence of:

- $\quad$ Floating or suspended matter.

- Discoloration.

- Bottom deposits.

- Aquatic life.

- Visible films, sheens, or coatings.

- Potential nuisance conditions.

- Fungi, slimes, or objectionable growth.

\subsection{Procedures for Analysis}

Laboratory analyses are conducted by a laboratory currently under contract with LLNL that is accredited by the California Department of Public Health Environmental Laboratory Accreditation Program (ELAP). LLNL samples are analyzed according to conditions and methodology specified in an approved Statement of Work (SOW). A standard chain of custody form is used to track samples, double-check bottle labels, and exchange information with contract laboratories. Field analyses of Site 300 drinking water discharge samples are performed as described in EMP-WSS-WSD and EMP-W-S.

\subsection{Data Quality Assurance}

To ensure that all quality assurance (QA) and quality control (QC) objectives are met, all samples are collected in accordance with written procedures by trained sampling technologists. Field activities, such as instrument calibrations, observations, and monitoring records, are recorded on field tracking forms archived by the Data Management Team (DMT) per procedure EMP-QA-DM, Sample and Data Management. Laboratory sample tracking is maintained through the chain-of-custody process. Procedure EMP-QA-DM also ensures that all laboratory measurements are received, accurately recorded, and properly stored in a computer database for easy and fast retrieval. In addition, hard copies of the data are archived by the Environmental Functional Area (EFA) DMT. 


\subsubsection{Equipment Calibration for Field Measurements}

All field measurement samples collected in support of the Site 300 Drinking Water

Discharges Network Monitoring Program are analyzed at the time of collection, by trained individuals using calibrated equipment. All instruments used for field measurements (e.g., $\mathrm{pH}$, temperature, specific conductance, and residual chlorine) are calibrated prior to use following manufacturer instructions. The supplement EMP-WSSWSD, Site 300 Water System Discharges Monitoring and Sampling, describes the calibration and analysis requirements for these field measurements.

\subsubsection{Bias}

All quality check information provided by the analytical laboratories, including lab control standards, matrix spikes, matrix duplicates, and calibration standards are examined by the network analyst to identify any analytical bias. If calibration standards or matrix spikes are consistently high or low, the analyst will contact the laboratory for an explanation.

\subsubsection{Completeness}

The monitoring program, specified in the PPMRP, defines the sampling locations and frequency for the Site 300 Drinking Water Discharges Network. Completeness requires the successful collection of these PPMRP-specified samples. Controllable factors, such as time of day and planned entry restrictions, will be considered when scheduling routine discharges from the drinking water system to ensure that required samples are collected.

\subsection{Program Implementation Procedures}

The PPMRP identifies the approved monitoring and reporting program for Waste Discharge Requirement (WDR) R5-2008-0081. Sampling is conducted by LLNL technical staff according to procedure EMP-W-S, Water Sampling, and supplement EMP-WSS-WSD, Site 300 Water System Discharges Monitoring and Sampling. Sample and data management requirements, including documentation, are defined in EMP-QADM, Sample and Data Management. Supplements to EMP-QA-DM define processes that must be used for completing field tracking forms (FTFs) (EMP-QAS-FTF) and for controlling sample locations (EMP-QAS-LOC). Sample locations are tracked in a database.

\subsection{Action Levels}

Action levels for this network are the permitted effluent limits for the pollutants of concern. Two of these parameters are measured in the field. A residual chlorine 
concentration above $0.02 \mathrm{mg} / \mathrm{L}$ or a pH level outside the range of 6.5 to 8.5 requires immediate action.

If a field measurement indicates a discharge above the allowed residual chlorine concentration or outside the allowed $\mathrm{pH}$ range, the measurement is immediately repeated in the field. If the out-of-range measurement is confirmed, immediate corrective actions may include ceasing the discharge or redirecting effluents away from the surface water. Afterward, the procedures for discharges may be reviewed and modified, if necessary, to prevent future occurrences.

If observations indicate that other pollutants, such as eroded sediment, are carried in the effluent, immediate corrective actions may include:

- Ceasing the discharge.

- Reducing the flow rate of the discharge.

- Redirecting the effluent away from the surface water.

- Redirecting the effluent away from the area where the pollutants are being picked up by the effluent flow.

Maximum daily limitations for the permitted constituents requiring laboratory analyses are as follows:

- Biochemical oxygen demand: $30 \mathrm{mg} \mathrm{O} / \mathrm{L}$.

- Settleable solids: $0.1 \mathrm{ml} / \mathrm{L}$.

- Total suspended solids: $30 \mathrm{mg} / \mathrm{L}$.

If noncompliance with any prohibition, daily maximum effluent limit, or receiving water limitation contained in WDR R5-2008-0081 is identified, it must be reported to the CVRWQCB by phone within 24 hours, followed by a written report within 5 days (unless this requirement is waived by the CVRWQCB). The written confirmation must include the nature, time, duration, cause of the noncompliance, and a description of measures taken to remedy it and to prevent its recurrence.

\subsection{Preparation and Disposition of Reports}

Drinking water system discharge monitoring reports are prepared and submitted quarterly to the CVRWQCB. These reports are due on the first day of the second month following the end of the calendar quarter. Drinking water system discharge monitoring results are also summarized and discussed in the annual Environmental Report. 


\subsection{Future Plans}

In the future, LLNL anticipates the delivery of drinking water from the Hetch Hetchy system. The drinking water system discharge monitoring plan will be reevaluated at that time.

Hetch Hetchy water entering the LLNL pipeline at the Thomas Shaft will be chlorinated and will have an average chlorine residual range of $1.2-1.5$ parts per million (ppm) and an average $\mathrm{pH}$ range of $9.0-9.7$.

\subsection{References}

Environmental Report (annual), Lawrence Livermore National Laboratory, Livermore, CA. (UCRL-50027). Available at https://saer.1lnl.gov/

Revelli, M. A. and C. G. Campbell (2010), Pollution Prevention and Monitoring and Reporting Program for the Lawrence Livermore National Laboratory Experimental Test Site Drinking Water System, Revision 4.1, Lawrence Livermore National Laboratory, Livermore, CA (UCRL-AR-139704-Rev-4.1).

WDR 5-00-175. Central Valley Regional Water Quality Control Board, CAG995001.

WDR R5-2008-0081. Central Valley Regional Water Quality Control Board, CAG995001. 


\section{Other Waters}

Michael A. Revelli

\subsection{Introduction}

This chapter describes the program to monitor the Other Waters network of the environmental monitoring program at the Lawrence Livermore National Laboratory (LLNL). The Other Waters network comprises an on-site and an off-site sample location for drinking water sources and several off-site surface water sources in the Livermore Valley. The purpose of the Other Waters network is to determine the impact, if any, of airborne tritium or radionuclide particulates on surface water bodies and on drinking water derived from local groundwater sources in the Livermore Valley. Locations far from LLNL are sampled to serve as background values for comparison with sampling locations near and at LLNL. On-site and off-site locations are sampled to provide information on tritium, gross alpha, and gross beta levels. General information on the Environmental Monitoring Plan and the facilities at LLNL can be found in Chapter 1 .

\subsection{Rationale and Design Criteria for Other Waters Monitoring}

\subsubsection{Regulatory Drivers}

The regulatory drivers for monitoring the Other Waters network are the applicable portions of U.S. Department of Energy (DOE) Order 458.1.

\subsubsection{Monitoring Objectives}

The primary purpose of monitoring surface water locations and drinking water sources in the Livermore Valley is to characterize the impact, if any, of LLNL operations on these waters and to ensure that effluents from DOE activities not cause private or public drinking waters downstream of the facility discharges to exceed the drinking water radiological limits in 40 CFR Part 141.

DOE's Environmental Regulatory Guide for Radiological Effluent Monitoring and Environmental Surveillance (DOE 1991) describes the environmental monitoring objectives: 
The purpose of the surveillance program is to characterize the radiological conditions of the off-site environs and, if appropriate, estimate public doses related to these conditions, confirm predictions of public doses based on effluent monitoring data, and, where appropriate, to provide compliance data for all applicable regulations. The results of this evaluation should* be documented in the site Environmental Monitoring Plan.

\subsubsection{Sources and Analytes}

Samples are analyzed for tritium, gross alpha, and gross beta radiation. Surface water locations are positioned to monitor either tritium that is washed out of the air by rainfall or direct runoff of tritium. In addition, three locations upwind and not directly connected to LLNL runoff are used to determine background concentrations. Drinking water locations are selected to sample drinking water derived from local groundwater sources.

\subsubsection{Collection Methods}

Samples are collected by grab sampling from the surface waters or drinking water taps. If the water to be sampled is accessible to the technician, grab samples are collected by partially submerging sample bottles directly into the water and allowing them to fill with the sample water. Sampling is conducted away from the edge of the water, when possible, to minimize the collection of sediment with the sample matrix. If the water is not directly accessible, the sample may be collected in a large container and then transferred to sample bottles. After the bottles are filled, they are dried, labeled, packaged, and placed in an ice chest.

Sample bottle requirements, special sampling techniques, and preservation requirements for each analyte are specified in procedure EMP-W-S, Water Sampling, supplement EMP-WSS-VOW, Valley Other Waters Sampling, and the Sample Collect table of the Taurus Environmental Information Management System (TEIMS) database.

\subsection{Extent and Frequency of Monitoring and Measurement}

\subsubsection{Livermore Site}

Drinking waters are sampled at one location on the Livermore site and at one location in the Livermore Valley; surface waters are sampled at several locations in the

\footnotetext{
* The term should in this quotation identifies a DOE "high-priority element."
} 
Livermore Valley (Figure 13-1). On-site samples provide information about potential radioactive constituents in the LLNL drinking water supply; off-site samples provide information about potential radioactive constituents in the local supplies that could be related to LLNL activities.

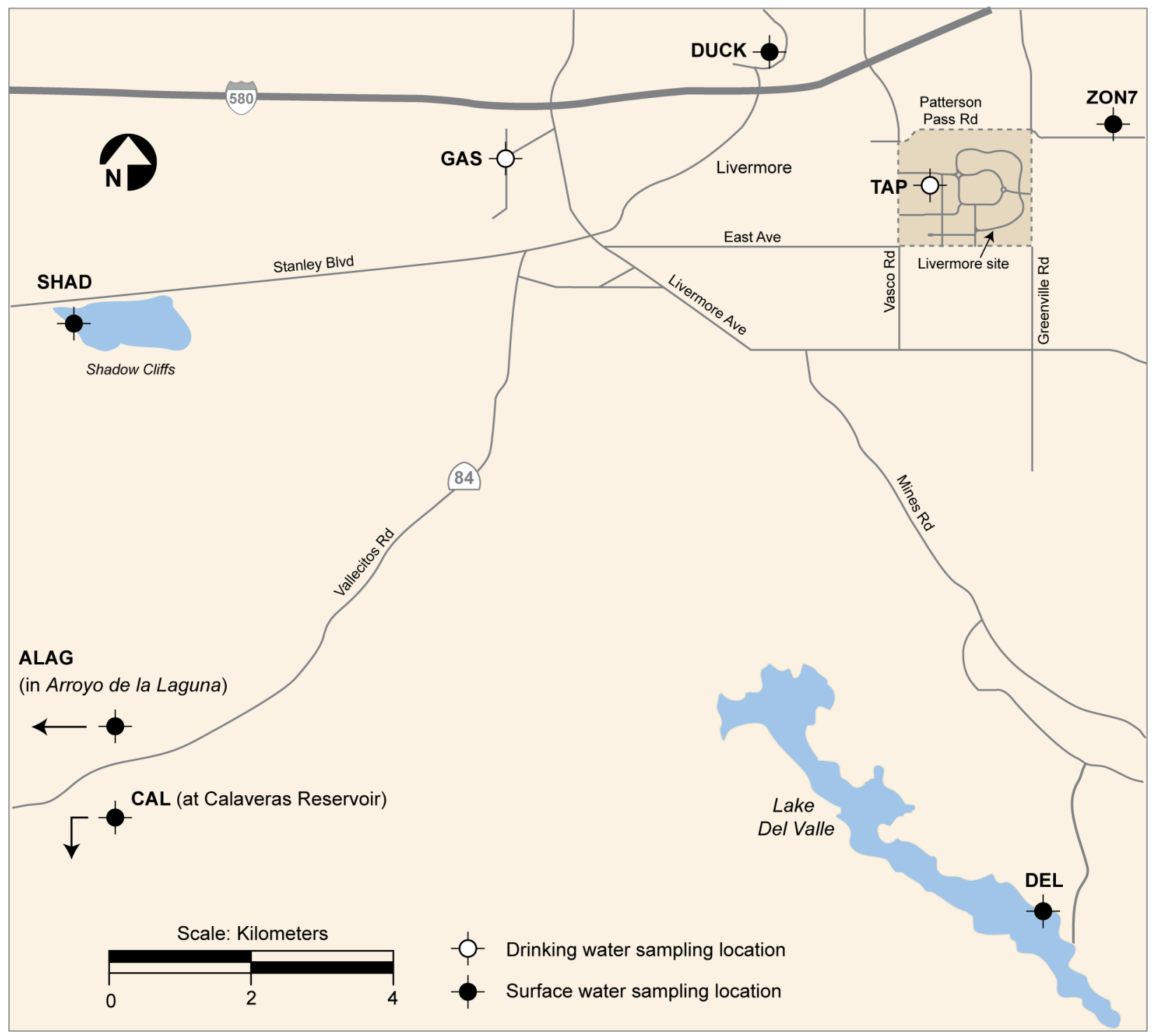

Figure 13-1. Surface and drinking water sampling locations, Livermore Valley.

At the Livermore site, sampling location TAP provides samples of on-site drinking water. (LLNL's primary on-site drinking water is Hetch Hetchy water; Zone 7 is the backup water supplier). One off-site location (GAS) provides additional samples of domestic drinking water, and six sites (ZON7, DUCK, ALAG, DEL, CAL, SHAD) 
provide samples from surface water bodies, some of which are potential drinking water sources.

Surface water bodies near the Livermore site include the treatment tanks and the reservoir at the Patterson Pass drinking water treatment facility (ZON7) $1.2 \mathrm{~km}$ east of the Livermore site, and the Springtown pond (DUCK), an artificial decorative pond maintained in a community recreation area $2.6 \mathrm{~km}$ northwest of the Livermore site. Sampling location ALAG is in the Arroyo de la Laguna, $13 \mathrm{~km}$ southwest of LLNL. Arroyo Seco and Arroyo Las Positas, to which LLNL discharges runoff, merge into Arroyo de la Laguna.

Lake Del Valle (DEL) and the Calaveras Reservoir (CAL) are drinking water storage reservoirs $9 \mathrm{~km}$ south of the Livermore site and $21 \mathrm{~km}$ southwest of the Livermore site, respectively. Lake Del Valle is also used for aquatic recreation (swimming, boating, and fishing), as is the Shadow Cliffs Regional Park (SHAD), a water storage reservoir $11 \mathrm{~km}$ west of the Livermore site. Locations DEL, CAL, and SHAD are used to evaluate background concentrations for environmental surface water monitoring. All three sites are generally upwind of LLNL and are not directly connected to LLNL runoff.

Drinking water is sampled semi-annually and surface water bodies are sampled annually based on the demonstrated history of minimal impact from LLNL.

\subsubsection{Site 300}

The requirements of DOE Order 458.1 are fully integrated in to storm water monitoring network discussed in Chapter 9 and the ground water monitoring networks discussed in Chapter 14.

\subsection{Procedures for Laboratory Analysis}

Laboratory analyses are conducted by a laboratory currently under contract with LLNL that is accredited by the California Department of Public Health Environmental Laboratory Accreditation Program (ELAP). LLNL samples are analyzed according to conditions and methodology specified in an approved Statement of Work (SOW). A standard chain-of-custody form is used to track samples, double-check bottle labels, and exchange information with contract laboratories.

\subsection{Data Quality Assurance}

Field activities are recorded on field tracking forms, and sample tracking is maintained through the chain-of-custody process. Procedure EMP-QA-DM, Sample and Data 
Management, ensures that all laboratory measurements are received, accurately recorded, and properly stored in a computer database for easy and fast retrieval. Hard copies of the data are also archived by the Environmental Functional Area Data Management Team.

\subsubsection{Precision}

Under the quality assurance program for this monitoring network, a duplicate sample is collected from a single location during each sampling event. The duplicate location is randomly chosen from the available locations.

The duplicate samples are collected for every analyte at that location and submitted to the lab for analysis, each with a unique sample identifier. The results for the duplicate location sample and actual location sample are compared by the network analyst upon the delivery of the analytical results from the laboratory.

\subsubsection{Bias}

All quality check information provided by the analytical laboratories, including lab control standards, matrix spikes, matrix duplicates, and calibration standards are examined by the network analyst to identify any analytical bias. If calibration standards or matrix spikes are consistently high or low, the analyst will contact the laboratory for an explanation.

\subsubsection{Completeness}

Samples from the Other Waters network are collected semi-annually or annually, as described in Section 13.3.1. Sampling would be considered 100 percent compete when each year's samples are collected in the Livermore Valley. Sample loss due to broken bottles is minimal and these locations can be readily resampled. The completeness target for this network is 100 percent.

\subsection{Program Implementation Procedures}

Sampling for the Other Waters network is conducted by LLNL technical staff according to procedure EMP-W-S, Water Sampling, and instruction EMP-WSS-VOW, Valley Other Waters Sampling. Methods used to prevent cross-contamination are similar throughout all sampling events.

Sample preservation and handling practices are performed according to the analytical method requirements and are specified in the SOW. Conditions identified during each sampling event are recorded on a field tracking form (FTF). This information, in conjunction with sampling results, provides a complete summary for each representative sampling location. The FTF may also provide information in the form of comments that may be useful to the analyst. Chain-of-custody forms document the 
sample from collection in the field through receipt of the data results from the analytical laboratories. Samples are submitted for analyses and resulting analytical results are managed using sample control and documentation procedure EMP-QA-DM, Sample and Data Management.

\subsection{Action Levels}

To evaluate the data from the Other Waters network, analysts compare the concentrations of tritium, gross alpha, and gross beta with their respective drinking water maximum contaminant levels (MCLs) of 740, 0.56, and $1.85 \mathrm{~Bq} / \mathrm{L}$, respectively, and to historical data. If concentrations were to increase dramatically or exceed an MCL, the cause of the result or results would be investigated. A detailed investigation may include elements such as:

- Management notification.

- Re-analysis of the samples.

- Additional sampling and analysis.

- Source investigation. (Results are compared with findings from other monitoring networks [e.g., air or rain], and LLNL activities that may have contributed to the result are investigated.)

- Expanded monitoring (more locations).

- Increased monitoring frequency.

\subsection{Preparation and Disposition of Reports}

Drinking water and surface water body monitoring results are summarized and discussed in the Water Monitoring Programs chapter of the annual Environmental Report. All data are summarized and trends are discussed. Each report includes a brief interpretation of the data.

\subsection{Future Plans}

There are no current plans to change the Other Waters network.

\subsection{References}

DOE (1991), Environmental Regulatory Guide for Radiological Effluent Monitoring and Environmental Surveillance, U. S. Department of Energy, Washington, D. C. (DOE/EH-0173T).

Environmental Report (annual), Lawrence Livermore National Laboratory, Livermore, CA. (UCRL-50027). Available at https://saer.llnl.gov/ 


\section{Ground Water}

Richard G. Blake • Michael A. Revelli

\subsection{Introduction}

This chapter describes environmental ground water monitoring programs conducted both at the Lawrence Livermore National Laboratory (LLNL) main site and in the surrounding Livermore Valley, and at the LLNL Experimental Test Site (Site 300) in the Altamont Hills that border the Livermore Valley on the east. The chapter is divided into surveillance monitoring (Section 14.2), which comprises four separate networks of ground water monitoring wells, and compliance monitoring (Section 14.3), which comprises five separate networks of ground water monitoring wells. The nine networks are:

1. Livermore site surveillance wells.

2. Livermore valley surveillance wells.

3. Site 300 surveillance wells.

4. Off-Site 300 surveillance wells.

5. Site 300 Pit 1 compliance wells.

6. Site 300 Pit 6 compliance wells.

7. Site 300 high explosives (HE) burn pit compliance wells.

8. Site 300 process water impoundments compliance wells.

9. Site 300 sewage ponds compliance wells.

Common to all nine monitoring well networks are the standard procedures used to obtain representative ground water samples, the standard methods used to analyze the samples, the management of the resulting data, and the data quality assurance methods.

Data and data analyses for the four surveillance well networks (1-4 above) are published only in the LLNL annual Environmental Report. Data and data analyses for the Pit 1 and for the Pit 6 compliance well networks ( 5 and 6 above) are presented in separate quarterly publications (e.g., Blake 2011a and Blake and Valett 2011, respectively). Data and data analyses for the HE burn pit compliance well network (7 above) are published annually (e.g., Revelli 2010). Data and data analyses for the process water and sewage compliance well networks ( 8 and 9 above) are combined in a semiannual monitoring report (e.g., Blake 
2011b). Compliance monitoring summaries (networks 5-9 above) are also published annually in the Environmental Report.

Section 14.2 describes in detail the environmental ground water surveillance monitoring that is conducted. Section 14-3 describes the five ground water compliance monitoring programs only briefly, because they are fully described in other readily available LLNL publications to which references are given. During the first quarter 2010, the Pit 7 was removed from the compliance monitoring network under the Central Valley Regional Water Quality Control Board Revised Pit 1 Monitoring and Reporting Program (MRP) for Permit 93-100, dated February 18, 2010. As part of the revised MRP, the Pit 7 was transferred to the Comprehensive Environmental Response, Compensation, and Liability Act (CERCLA). The Pit 7 network is now managed by the LLNL Environmental Restoration Department and is undergoing active remediation.

\subsection{Rationale and Design Criteria for Surveillance Ground Water Monitoring}

\subsubsection{Regulatory Drivers}

Environmental ground water surveillance monitoring is driven by U.S. Department of Energy (DOE) Order 458.1.

\subsubsection{Monitoring Objectives}

The primary objective of surveillance ground water monitoring is to determine the impact on local ground water resources, if any, of continuing LLNL operations. Surveillance monitoring is not a first-line defense against any inappropriate LLNL operation that might release hazardous material to the environment, because lag times of years are likely before such releases could be detected in the underlying ground water. Stringent administrative and operational controls of all hazardous materials are now in place at LLNL. These controls are designed either to prevent entirely or to minimize any release of hazardous material to the environment. The absence of such controls in the past caused some local contamination of ground water. Ground water contamination resulting from historical operations that have ceased is addressed by compliance monitoring and other LLNL ground water remediation programs that are conducted under Comprehensive Environmental Response, Compensation and Liability Act of 1980 (CERCLA) auspices.

Ground water that is or could be affected by DOE activities shall be monitored to determine and document the effects of those activities on ground water quality and quantity. LLNL's surveillance ground water monitoring program is designed to meet the following objectives: 
1. Obtain data for the purpose of determining baseline conditions of ground water quality and quantity.

2. Demonstrate compliance with and implementation of all applicable regulations and DOE orders.

3. Provide data to permit the early detection of ground water pollution or contamination.

4. Furnish a reporting mechanism for detected ground water pollution or contamination.

5. Identify existing and potential ground water contamination sources and maintain surveillance of these sources.

6. Supply data to inform the decisions that should be made concerning land disposal practices and the management and protection of ground water resources.

\subsubsection{Sources and Analytes}

Surveillance monitoring requirements are determined by site-specific characteristics, including areas where surficial materials (soil and sediment) are contaminated from past operations, but are at levels below the concern of CERCLA ground water remediation programs. LLNL CERCLA restoration programs extensively monitor ground water contamination that resulted from historical operations by LLNL and previous site owners, before stringent controls were implemented. Current surveillance monitoring includes those constituents of concern (COCs) addressed by the CERCLA restoration programs and many additional COCs that are not of concern to CERCLA restoration efforts, because they have never, or rarely, been detected, or are detected at concentrations below remedial action levels.

Ground water surveillance monitoring primarily concerns ground water quality beneath and adjacent to the LLNL Livermore site and Site 300. In total, it covers a wide range of elements, radioisotopes, inorganic and organic compounds, and general contaminant indicators.

\subsubsection{Site-specific Characteristics-Livermore Site and Livermore Valley}

For specifics of geology, see CERCLA Remedial Investigation Report for the LLNL Livermore Site (Thorpe et al. 1990).

Beneath the Livermore site, depth to the water table varies from about 8 to $40 \mathrm{~m}$. At the eastern edge of the Livermore site, ground water gradients are quite steep, but under most of the site and farther to the west, the contours flatten to a gradient of approximately 0.003 . Ground water flow under the northern and western portions of the site is generally westward. Aquifer tests on monitoring wells in the vicinity of the Livermore site indicate that the 
hydraulic conductivity of the permeable sediments ranges from 1 to $16 \mathrm{~m} /$ day. This, in combination with observed water-table gradients, yields ground water velocity estimates of 5 to $90 \mathrm{~m} /$ year. The range in these values reflects the heterogeneity typical of the alluvial sediments that underlie the area (Thorpe et al. 1990).

Figure 14-1 is an east-west cross-section along East Avenue showing the hydrostratigraphic units (HSUs) underlying the Livermore site. This cross section extends slightly past the western edge of LLNL at Vasco Road. The water table cuts across HSUs so that the shallowest watersaturated HSU (the uppermost aquifer) is HSU-6 at the southeastern corner of the site at Greenville Road and HSU-1B and HSU-2 along and toward the western site boundary (Vasco Road). Ground water from this area flows offsite toward the southwest (Hoffman et al. 1993; Macdonald et al. 1994).

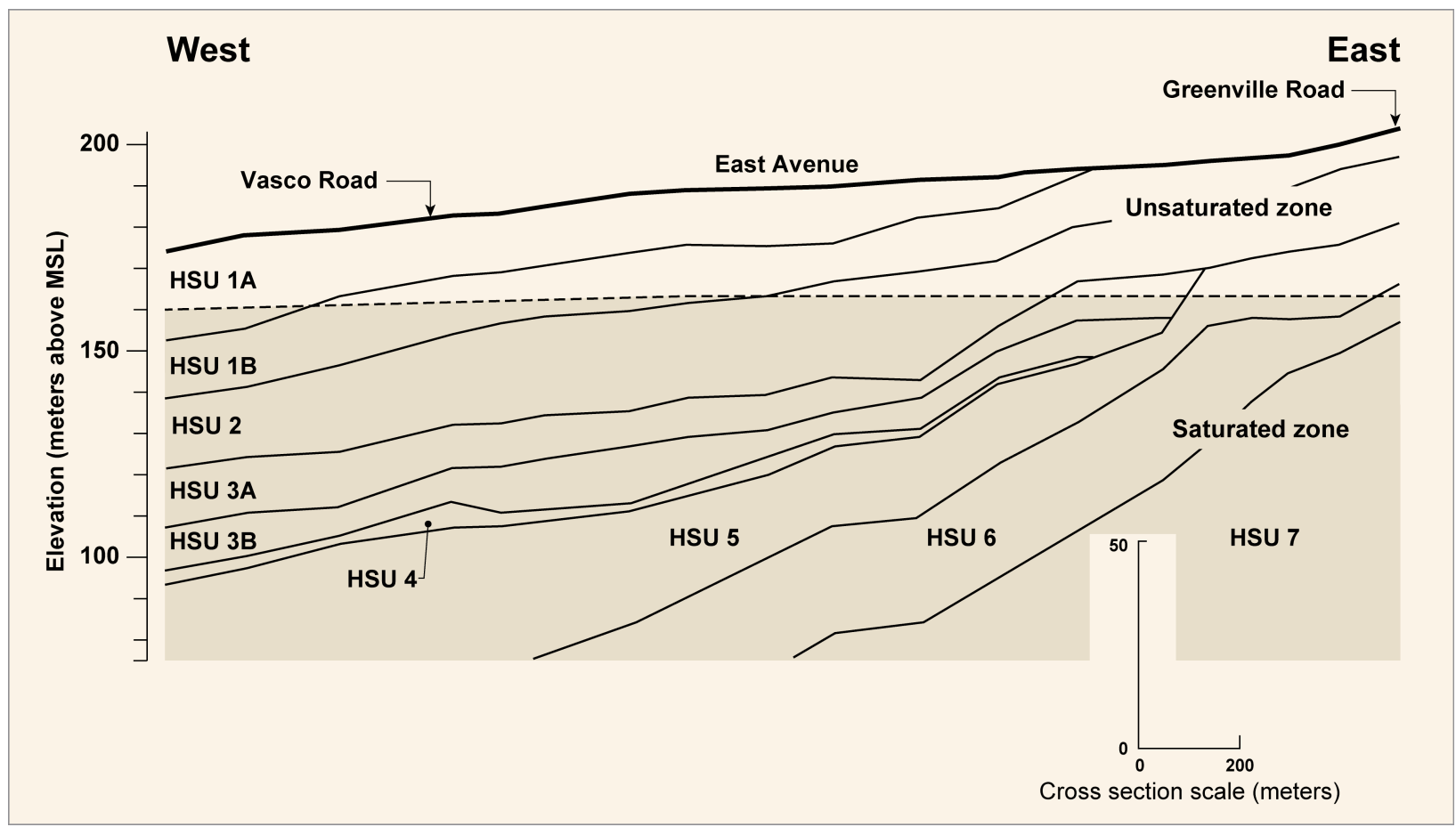

Figure 14-1. Livermore site hydrostratigraphic east-west cross section along East Avenue.

Ground water surveillance monitoring includes many potential COCs. Historically, wastes at the Livermore site that could potentially become pollutants to the ground water include metals, volatile organic compounds (VOCs), petroleum hydrocarbons, pesticides and herbicides, and radioactive wastes. Tritium is present in ground water near the East Taxi Strip Area, mostly in HSU-3A and HSU-3B (Figure 14-1). Tables 14-1 and 14-2 (at the end of this chapter) contain a comprehensive list of the elements, isotopes, and chemical compounds that are analyzed for the environmental ground water surveillance monitoring programs. Importantly, not all of the constituents shown in Tables 14-1 and 14-2 are monitored at each ground water sampling location. Rather, cost-effectiveness is achieved by limiting both the 
number of different analyses employed and the frequency of sampling. These decisions are made by the LLNL water analysts responsible for each surveillance monitoring network.

Two potential sources of ground water contamination that were initially evaluated prior to the LLNL sitewide remedial investigation - the Taxi Strip Area and the East Traffic Circle Landfill (Figure 14-2) — were further assessed for surveillance purposes through ground water monitoring during 1997 and 1998. Radioactively contaminated liquid wastes had been deposited in four disposal pits in the Taxi Strip Area from 1953 through about 1976, according to the remedial investigation (Thorpe et al. 1990). Contaminants detected in the soil were VOCs, metals, and various radionuclides. The radionuclides initially detected in the soils and other materials were transuranics (unspecified), americium-241, uranium-235, and cesium-137 (Buerer 1983). An earlier remedial action removed about 3000 cubic meters of contaminated soil and sediments.

At the East Traffic Circle Landfill, polychlorinated biphenyls (PCBs), metals, and various radionuclide contaminants were initially detected in the soil. The radionuclides detected in the soils and other materials were, in order of abundance: cesium-137, depleted uranium, radium226, thorium-232, uranium-238, americium-241, and some cobalt-60 (McConachie et al. 1986). Remediation there involved the excavation and removal of 11,000 cubic meters of debris and soil with metal shavings, broken bottles, and capacitors. About 6 cubic meters of the total material excavated contained radioactive material (Thorpe et al. 1990; McConachie et al. 1986).

Although contaminated sediments were removed from both of these waste management units (WMUs), and the depth to ground water is greater than $20 \mathrm{~m}$, LLNL continues surveillance monitoring to determine whether any hazardous materials have reached the ground water. Monitoring wells downgradient from these two areas (already used for restoration monitoring for VOCs and tritium) were added to the surveillance monitoring network during 1997.

During 1999, surveillance monitoring of the uppermost saturated aquifers (HSU-1B and HSU2) began, in monitoring wells both hydrologically upgradient and downgradient from the Plutonium and Tritium Facilities. Potential contaminants include plutonium and tritium from these facilities, respectively. Plutonium is much more likely to bind to the soils than migrate into the ground water. Tritium, as HTO, can migrate into ground water if spilled in sufficient quantities. Upgradient of these facilities, well W-305 is screened in HSU-2; downgradient wells W-101, W-147, and W-148 are screened in HSU-1B. 


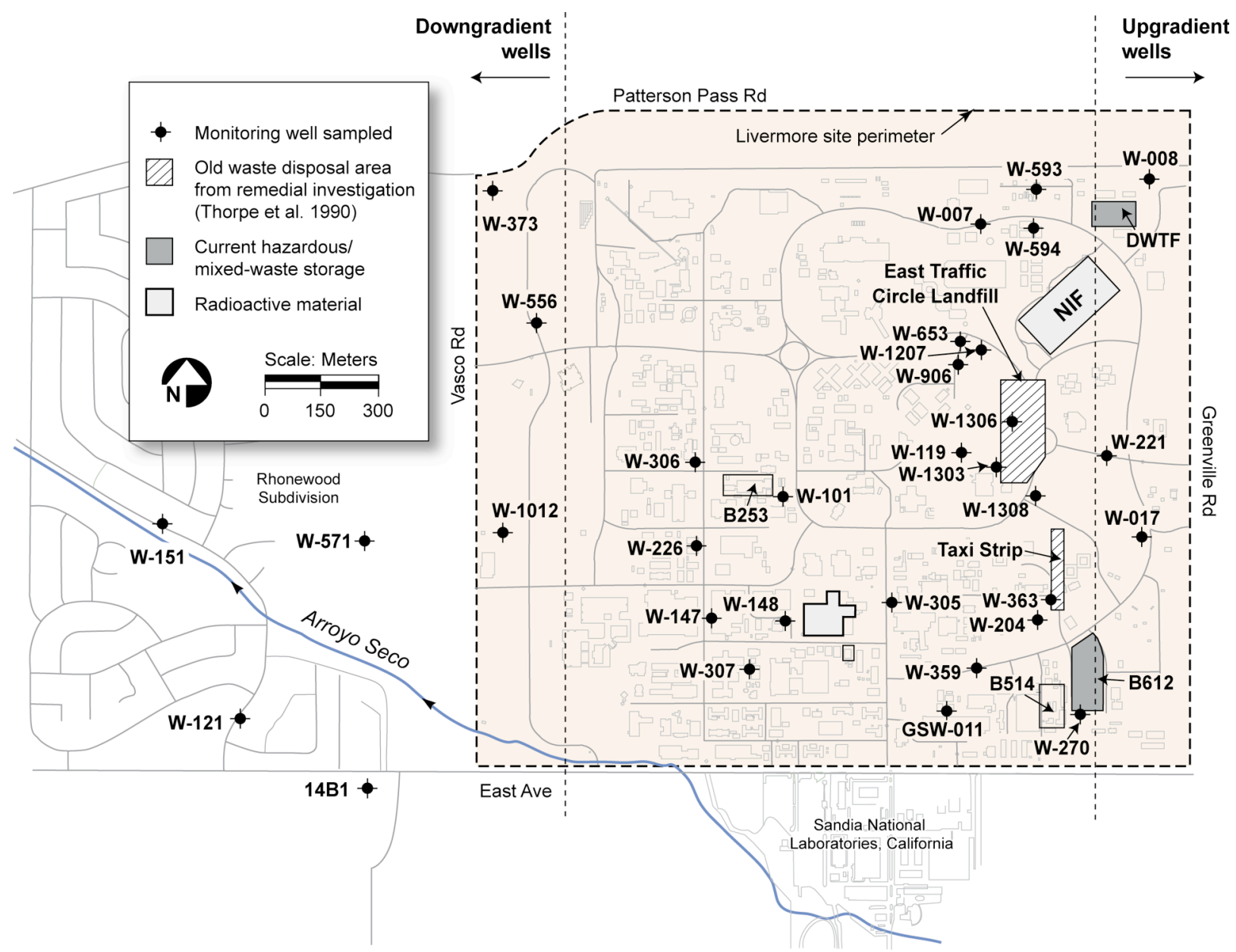

Figure 14-2. Livermore site and ground water surveillance monitoring well locations.

The former storage area around Building 514 and the hazardous waste/mixed waste storage facilities around Building 612 are also potential sources of contamination. The area and facilities are monitored by wells W-270 and W-359 (both screened in HSU-5), and well GSW-011 (screened in HSU-3A). Ground water from these wells is sampled and analyzed for gross alpha, gross beta, and tritium.

Ground water samples are obtained downgradient from areas where past releases of metals to the ground have occurred. Samples are obtained annually from monitoring well W-307 (screened in HSU 1B), downgradient from a fume hood vent on the roof of Building 322, a metal plating shop. Soil samples previously obtained from the area show elevated concentrations (in comparison with Livermore site background levels) of total chromium, copper, lead, nickel, zinc, and occasionally other metals. LLNL removed contaminated soils near Building 322 in 1999 and replaced them with clean fill. The area was then paved over, making it less likely that metals will migrate from the site. Ground water samples are also collected annually and analyzed for metals from monitoring wells W-226 and W-306. These 
wells are downgradient from sediments containing elevated metals that accumulated in a storm water catch basin (Figure 14-2).

A newer potential source of ground water contamination is the Decontamination and Waste Treatment Facility (DWTF) in the northeastern portion of the Livermore site. Ground water samples are obtained downgradient from this facility from wells W-007, W-593, and W-594 and are analyzed for tritium. Routine monitoring at well W-593 (screened in HSU 3A) was initiated in 1997; wells W-007 and W-594 (screened in HSUs 2/3A and 2, respectively) were added to this monitoring network in 2002.

Although the National Ignition Facility (NIF), which is also located in the northeastern portion of the Livermore site, has not yet begun full operations, it is prudent to obtain a baseline of ground water quality prior to start of full operations. NIF operations will use significant quantities of tritium. Analyses are conducted on ground water samples collected from wells W-653 and W-1207 (screened in HSUs 3A and 2, respectively) downgradient of NIF for tritium.

At the Livermore site, many utility vaults receive storm water runoff. These collected wastewaters are sampled and analyzed on a representative basis by other LLNL monitoring programs to determine proper disposal. The utility vaults may have contributed some amount of contaminants from surface runoff to the underlying sediments. Other potential sources of ground water contamination are investigated on a case-by-case basis as they are discovered, to determine if additional ground water monitoring is needed.

\subsection{Extent and Frequency of Monitoring and Measurements-Livermore Site and Livermore Valley}

LLNL has constructed more than 500 ground water monitoring wells on and in the vicinity of the Livermore site. Although the primary function of these wells is environmental restoration monitoring, data from a subset of these wells also fulfill the surveillance monitoring mandates of DOE Order 458.1.

LLNL's surveillance monitoring program employs three upgradient monitoring wells (W-008, $\mathrm{W}-017$, and $\mathrm{W}-221$ ) in the eastern and northeastern portions of the site to represent background ground water quality, and seven downgradient wells located near the western boundary of the site as shown in Figure 14-2 monitor ground water leaving the site. These wells are located downgradient from Treatment Facility B (W-571 and W-1012) and Treatment Facility C (W-373 and W-556); three of the downgradient wells (W-121, W-151, and W-14B1) are located downgradient from, but near the zone of influence of, Treatment Facility A. This configuration of monitoring wells was implemented in 1996 to monitor the uppermost aquifers (HSUs 1B and 2 [Figure 14-1]) for COCs that could be transported off site beneath Vasco Road by the predominant westward direction of ground water flow. 
In 1997, the ground water surveillance network was expanded to incorporate on-site monitoring wells downgradient from the Taxi Strip Area and the East Traffic Circle Landfill. Figure 14-2 shows the locations of the seven downgradient monitoring wells (W-119, W-204, W-363, W-906, W-1303, W-1306, and W-1308) that form the monitoring network for the Taxi Strip and the East Traffic Circle WMUs.

The network of 32 wells established for Livermore site surveillance (Figure 14-2) is sampled at least annually. Generally, the wells are sampled after the heaviest winter rains. Heavy winter rains tend to wash potential contaminants out of the vadose zone and into the ground water. Retest samples are obtained subsequent to analytical results that are elevated above background concentrations or above concentrations of concern for human health. All ground water sampling at the Livermore site is conducted by LLNL's Environmental Restoration Department (ERD) technical staff or contract staff.

COCs are reviewed annually by the responsible LLNL water analysts to determine whether they satisfy present surveillance needs. The COCs chosen for the surveillance sampling program are determined largely by knowledge of materials used at the Livermore site. All site perimeter surveillance monitoring wells are currently sampled at least annually and analyzed for general minerals, gross alpha and beta, and tritium. Selected metals (copper, lead, and zinc) and radioisotopes (tritium) are measured annually in the ground water in the vicinity of the Taxi Strip and the East Traffic Circle Landfill areas.

LLNL measures the tritium activity in ground water samples obtained annually from a network of 18 wells in the Livermore Valley. Tritium is potentially the most mobile ground water contaminant from LLNL operations. These Livermore Valley wells are located hydraulically downgradient (westward) of the LLNL site at distances ranging from 3.5 to $16 \mathrm{~km}$ and sample the ground water at depths ranging from less than 50 feet to more than 800 feet. The well locations and their identification codes are shown in Figure 14-3. Ground water samples are obtained in LLNL-supplied bottles by personnel employed at the following four facilities:

- California Water Service (four wells).

- City of Livermore (eight wells).

- City of Pleasanton (two wells).

- Zone 7 Water Agency (four wells)

Wells occasionally go out of service and other wells may be substituted by the facilities. Changes are made to the annual Environmental Report as this occurs. 


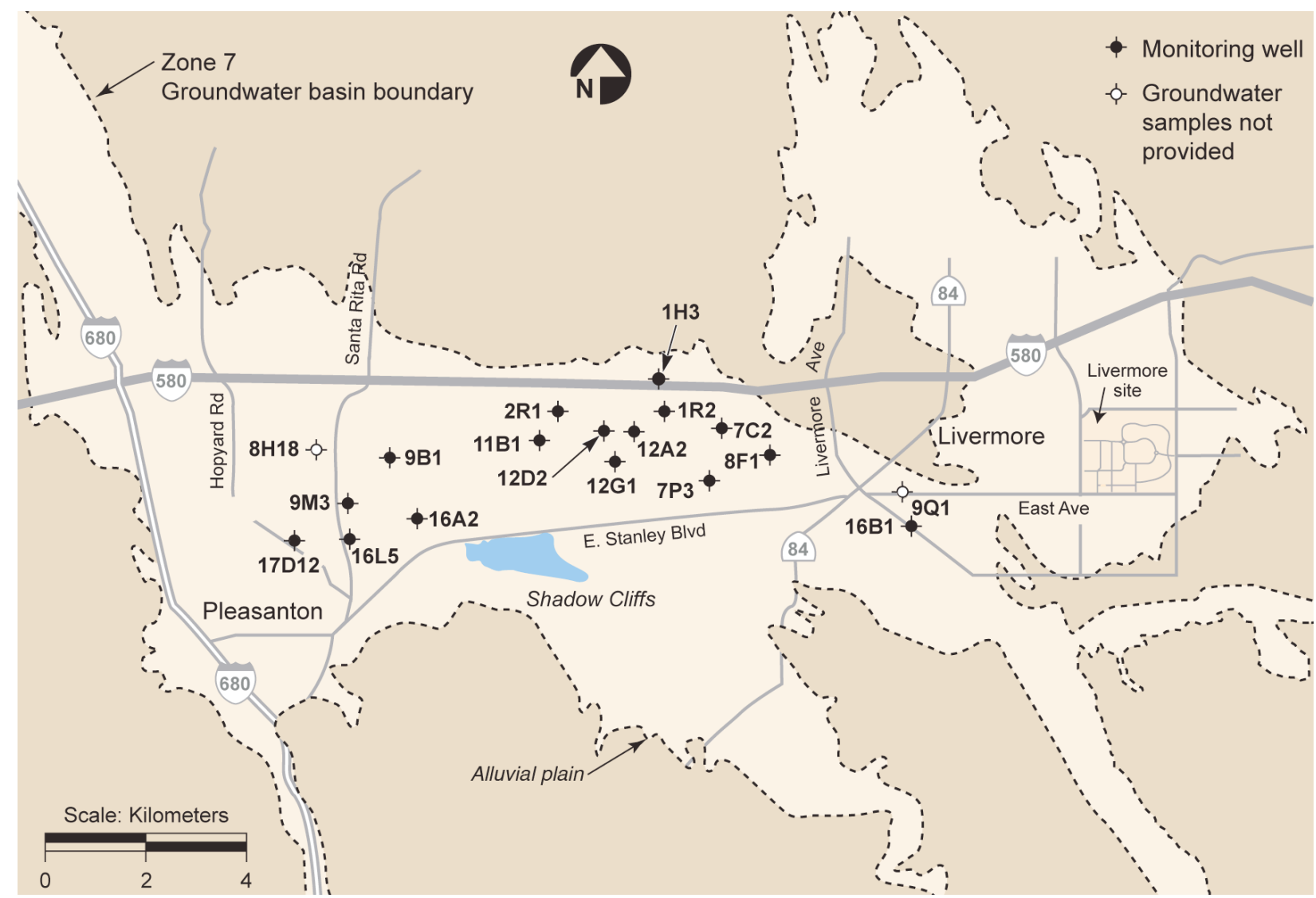

Figure 14-3. Livermore Valley ground water surveillance monitoring well locations.

\subsubsection{Site-specific Characteristics-Site 300}

Details of Site 300 geology and hydrogeology may be found in early studies (Raber and Carpenter 1983) and in subsequent CERCLA remedial investigations (Webster-Scholten 1994; Taffet et al. 1996; LLNL 2008). Site 300 is generally underlain by gently dipping sedimentary bedrock dissected by steep ravines. Topographic relief at the site is about $300 \mathrm{~m}$. Elevations range from about $200 \mathrm{~m}$ in the southeast to more than $500 \mathrm{~m}$ in the northwest. The bedrock is formed primarily of interbedded sandstone, siltstone, and claystone. The Neroly Formation is the principal hydrologic unit. The Neroly Formation is about $150 \mathrm{~m}$ thick and consists of distinctive blue-gray to brown weathering volcaniclastic sandstone and sandy siltstone, interbedded with light gray weathering tuffaceous claystone and conglomerate. It is exposed extensively within the northern half of Site 300. The Neroly Formation is also present in the subsurface underlying the southeastern portion of the Site. Figure 14-4 is a generalized stratigraphic diagram of Site 300 near-surface rocks and sediments. 


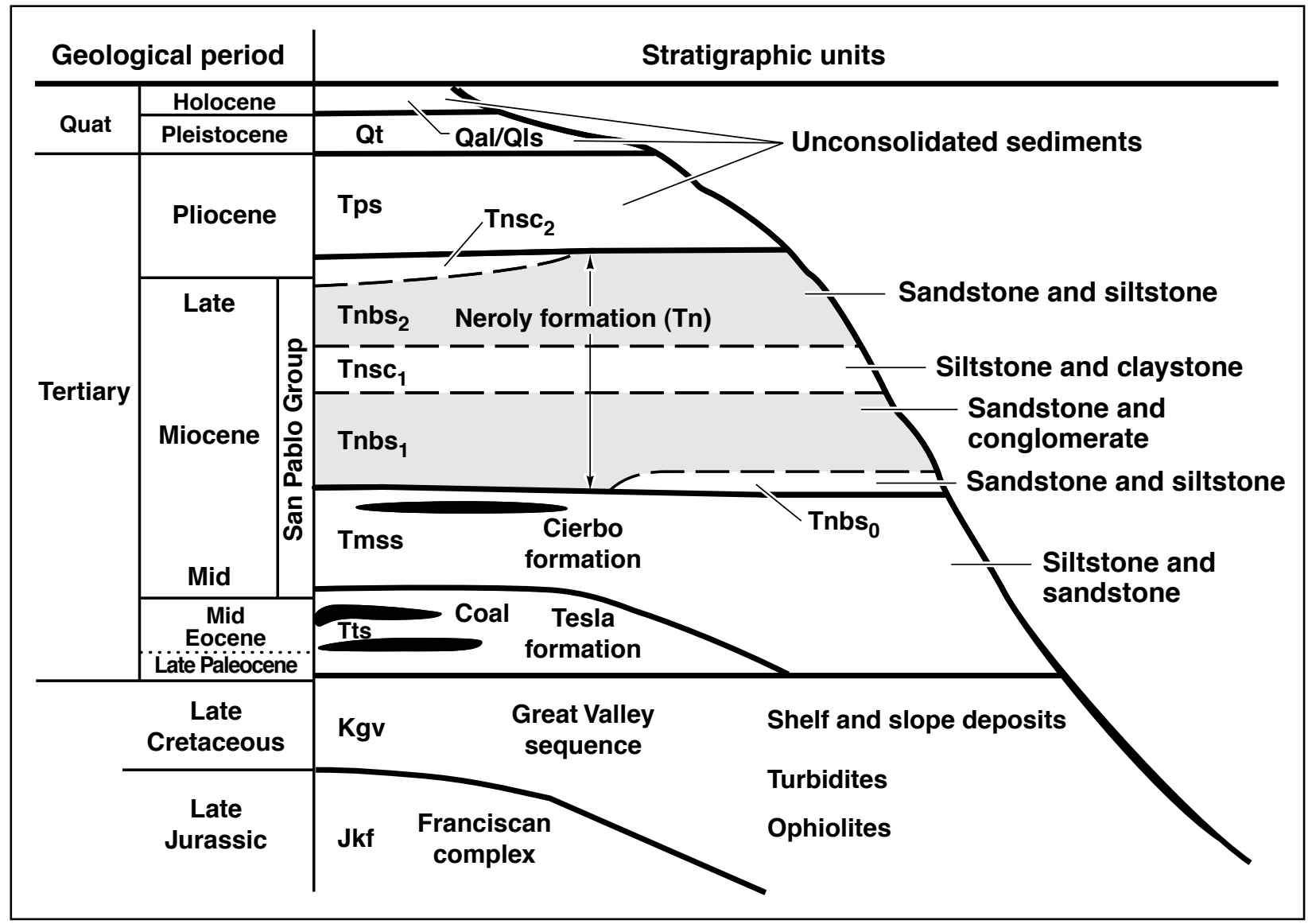

Figure 14-4. Site 300 generalized stratigraphy.

Hydraulic conductivities in the water-bearing strata at Site 300 vary over three orders of magnitude, from $10^{-3}$ to $10^{-6} \mathrm{~cm} / \mathrm{s}$. Ground water flow ranges from less than 1 to $40 \mathrm{~m} /$ year. Maximum flow rates occur in valley-fill deposits.

The uppermost, generally unconfined water-bearing zone is the primary target for ground water monitoring at Site 300 because it contains most of the existing contamination, and it would be the first zone to be influenced by any new release of contaminants at or near the ground surface.

\subsection{Extent and Frequency of Surveillance Monitoring and Measurements-Site 300}

Present LLNL operations at Site 300 are designed and managed to minimize contamination of soil and bedrock. Some soil and bedrock has been contaminated by historical LLNL

operations at the site and some of the contaminants have reached the ground water beneath the site. Much of the contaminated soil remains in place or is buried in closed landfills at the site. Removal actions, including the capping of landfill pits, have significantly reduced the rates of contaminant migration to ground water in those areas. However, under the unusual 
circumstance of excessive rainfall, rain infiltration, and water table rises, additional contaminants may be released to the underlying ground water.

Surveillance monitoring at Site 300 analyzes ground water samples from on-site DOE CERCLA wells and from private off-site production wells and springs. Although surveillance monitoring uses on-site wells that were placed for the purpose of site characterization under CERCLA, it is conducted independently of other monitoring. COCs of many types are monitored in ground water samples to accomplish several important goals. Surveillance monitoring provides independent checks of findings from site characterization studies and remediation efforts. It detects (down to detection limits) any slow-to-develop releases of COCs to ground water at the site. This program also detects any increases in existing contamination that could indicate accelerated COC releases from remaining buried sources. Chemical and radiological data from ground water monitoring at Site 300 are added continually to LLNL's database.

For surveillance monitoring purposes, the number and locations of sampling wells, the COCs, and frequency of sampling are prerogatives of LLNL, allowing the Laboratory to devise a comprehensive, cost-effective monitoring program. Because the flow rates of ground water beneath Site 300 rarely exceed $40 \mathrm{~m} /$ year, quarterly, semiannual, and annual sampling frequencies are deemed appropriate for data trending and to meet annual reporting requirements.

Ground water flow directions beneath Site 300 are known from area-wide measurements of water table elevations in the CERCLA wells and piezometers. Figure 14-5 shows the locations of closed landfills (formerly open pits), surface impoundments (process water), sewage ponds, and ground water surveillance wells and springs

The selected wells are typically screened in the uppermost water-bearing zone beneath the units in order to provide the earliest warning of COC releases to ground water. Other wells are screened in the regional aquifer and are used to detect any degradation of drinking water supplies. Some wells within Site 300 (Figure 14-5) were selected to follow surface water courses, such as Elk Ravine, where contaminant plumes caused by past operations have been detected by exhaustive remedial investigation studies (Webster-Scholten 1994; Taffet et al. 1996; LLNL 2008). These wells were installed to monitor the concentrations of COCs within contaminant plumes and to monitor the fate and transport of contaminant plumes. The surveyed locations and engineering specifications of the Site 300 ground water monitoring installations are maintained in the LLNL computer databases. 


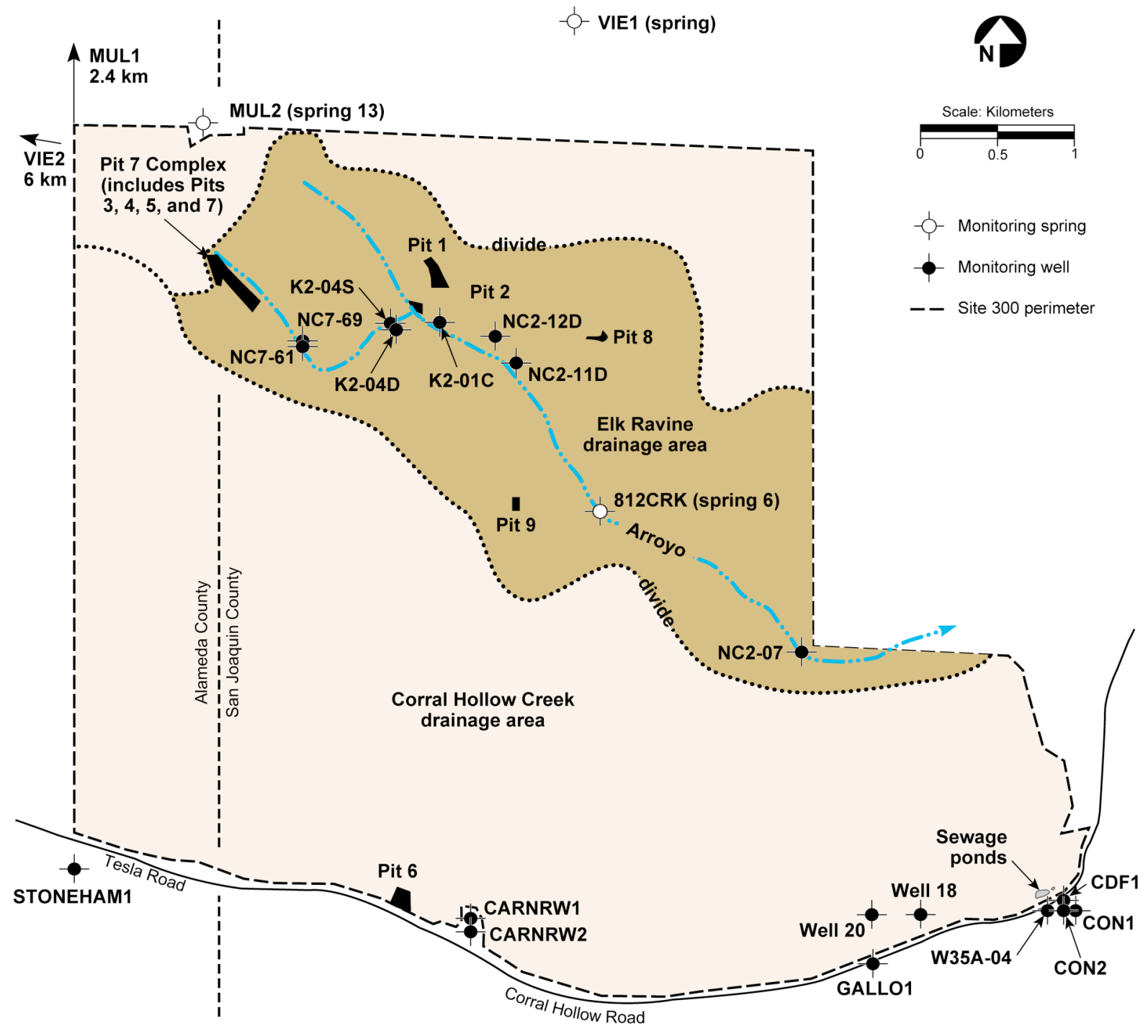

Figure 14-5. Site 300 locations of pits (closed landfills), former HE burn pit, surface impoundments (process water), sewage ponds, and ground water surveillance wells and springs.

EFA routinely monitors 68 ground water wells at Site 300 for surveillance and compliance. Twelve surveillance locations for ground water monitoring are off site. Four are to the north, and eight are to the south of Site 300 (Figure 14-5). Three locations, the MUL2 and VIE1 springs, and the cattle watering well, MUL1, are adjacent to Site 300 on the north, where the Altamont Hills slope down to the San Joaquin Valley. VIE2 represents a background well, typical of drinking water supplies in the Altamont Hills. It lies $6 \mathrm{~km}$ northwest of Site 300 in the upper reaches of the Livermore Valley watershed. Eight off-site surveillance locations are located immediately south of Site 300 in the Corral Hollow Creek drainage area and are monitored as guard wells to detect off-site migration of COCs. These are wells CARNRW1, CARNRW2, CDF1, CON1, CON2, GALLO1, STONEHAM1, and W35A-04. Of these southern wells, STONEHAM1 is monitored primarily to provide upgradient background data for water supply wells in Corral Hollow Creek. The remaining off-site surveillance wells, 
which are used to water cattle or suppress fires, monitor for VOCs beyond the southern boundary of Site 300 .

Of the 12 off-site ground water surveillance wells sampled, water samples are obtained at least quarterly from CARNRW1, CARNRW2, and GALLO1. Samples from the remaining six wells are obtained annually (MUL1, MUL2, VIE1, VIE2, STONEHAM1, and W35A-04). Those samples are analyzed for 17 elements (mostly metals), HE compounds, VOCs, extractable organic compounds, nitrate, perchlorate, general radioactivity (gross alpha and gross beta), tritium, and uranium isotopes.

Nine on-site surveillance wells and one spring (812CRK) are located along the system of fault-marked ravines and arroyos that constitute the Elk Ravine drainage area. Surveillance monitoring also includes two on-site water production wells, Well 18 and Well 20 (Figure 145). Well 20 provides potable water for use at Site 300 . Well 18 is a standby supply well.

Elk Ravine drains most of northern Site 300 in the area between the drainage divides shown in Figure 14-5. Surface runoff from firing tables and closed WMUs within the drainage area (Pits 1, 2, 3, 4, 5, 7, 8, and 9) is collected in arroyos. With sufficient seasonal rainfall, unconfined ground water can flow southeast on and within the valley-fill deposits that floor the Pit 7 Complex valley. Surface runoff from the Pit 7 Complex valley (containing the most elevated landfills) can flow southeast to Doall Road, where it is deflected northeastward into Doall Ravine by a landslide deposit. At the northeastern end of Doall Ravine, this runoff combines with channeled runoff from the ATA Building 865 area. From this confluence point, the arroyo trends southeasterly within Elk Ravine. Near Well NC2-07, channeled runoff turns easterly, away from the trend of the Elk Ravine Fault, and flows off site for approximately $2 \mathrm{~km}$ to its confluence with Corral Hollow Creek. Except for Doall Ravine, the arroyos and valley-fill deposits traverse and follow faults, especially the extensive Elk Ravine Fault, that may provide pathways to the underlying ground water. Thus, ground waters from wells that lie within the Elk Ravine drainage area are monitored. The monitored wells are (from highest to lowest elevation) NC7-61, NC7-69, K2-04D, K2-04S, K2-01C, NC2-12D, NC2-11D, and NC2-07. The 812CRK sampling location is a natural spring (also identified as Spring 6), located in the main Elk Ravine arroyo on the Elk Ravine Fault. Individual well locations are discussed below.

Wells NC7-61 and NC7-69 are screened in separate water-bearing zones beneath the upper reaches of Doall Ravine. Well NC7-61 is screened in Tnbs 1 (shallower zone), and Well NC769 is screened in Tmss (deeper zone). Wells K2-04D, K2-04S, and K2-01C are located near the junction of Elk Ravine and Doall Ravine. They are all screened in Tnbs 1 . Wells NC2-12D and NC2-11D are located in Elk Ravine below its juncture with Doall Ravine. Well NC2-11D is screened at the contact between Tnbs 1 and Tmss. Well NC2-07 is the farthest downstream surveillance well in the Elk Ravine drainage area and is screened in Tnbs 1 . 
Ground water samples are obtained annually at the seven upstream wells and one spring in Elk Ravine and semiannually at the downstream well NC2-07. These samples are analyzed for 17 elements (mostly metals), HE compounds, VOCs, nitrate, perchlorate, general radioactivity (gross alpha and gross beta), tritium, and uranium isotopes.

Well 20 supplies potable water for Site 300, and Well 18 serves as a standby water supply well. Both are located in the southeastern part of Site 300 (Figure 14-5). They are deep, highproduction water wells screened in Tnbs 1 . The Well 18 screen extends upward into a finegrained aquitard $\left(\mathrm{Tnsc}_{1}\right)$ in the Neroly Formation that separates $\mathrm{Tnbs}_{1}$ from the overlying Tnbs2. Each well can produce up to $1,500 \mathrm{~L} / \mathrm{min}$.

Ground water samples are obtained monthly from supply Well 20 and are analyzed for VOCs. Well 20 samples are analyzed quarterly for 17 elements (mostly metals), HE compounds, nitrate, general radioactivity (gross alpha and gross beta), tritium, and uranium isotopes. Since monitoring of Well 20 began in the 1980s, no contamination has appeared in ground water samples obtained from this production well. Ground water samples are obtained quarterly from the backup supply Well 18 and are analyzed for VOCs. For many years TCE was detected occasionally at Well 18 at very low concentrations $(<1.0 \mu \mathrm{g} / \mathrm{L})$. The long-term trend is less frequent TCE detections at lower concentrations.

\subsection{Rationale and Design Criteria for Compliance Ground Water Monitoring}

\subsubsection{Regulatory Drivers}

Environmental ground water compliance monitoring is conducted at Site 300 only and is driven by WMU post-closure plans and/or state-issued permits, such as:

- Permits and written agreements with the California Environmental Protection Agency (Cal EPA) Department of Toxic Substances Control (DTSC) issued under RCRA and CERCLA.

- Permits and other controlling documents issued under the Porter-Cologne Water Quality Control Act (California 1969) by the California Central Valley Regional Water Quality Control Board (CVRWQCB).

The specific documents governing ground water compliance monitoring at Site 300 are:

- For Pit 1:

Order No. 93-100, Waste Discharge Requirements Monitoring and Revised Monitoring and Reporting Plan (February 18, 2010) for University of California Lawrence 
Livermore National Laboratory Site 300 and U.S. Department of Energy, Landfill Pit 1, San Joaquin County (CVRWQCB 2010).

Order No. 93-100, Waste Discharge Requirements for University of California Lawrence Livermore National Laboratory Site 300 and U.S. Department of Energy, Landfill Pits 1 and 7, San Joaquin County (CVRWQCB 1993).

Revised Monitoring and Reporting Program No. 93-100 for Pits 1 and 7, Lawrence Livermore National Laboratory Site 300, San Joaquin County (CVRWQCB 1998).

Lawrence Livermore National Laboratory Site 300 Resource Conservation and Recovery Act Closure and Post-Closure Plans, Landfill Pits 1 and 7, Volumes I and II, (Cal EPA No. CA2890090002) (Rogers/Pacific Corporation 1990).

- For Pit 6:

Post-Closure Plan for the Pit 6 Landfill Operable Unit, Lawrence Livermore National Laboratory Site 300 (Ferry et al. 1998).

Compliance Monitoring Plan/Contingency Plan for Interim Remedies at Lawrence Livermore National Laboratory Site 300 (Ferry et al. 2002).

- For the Building 829 Closed High Explosives Burn Facility:

Final Closure Plan for the High-Explosives Open Burn Treatment Facility at Lawrence Livermore National Laboratory Experimental Test Site 300 (Mathews and Taffet 1997).

Post-Closure Permit Application for the Building 829 HE Open Burn Facility - Volume 1 (LLNL 2001).

Hazardous Waste Facility Post-Closure Permit (Permit Number: 02-BRK-04) (DTSC 2003).

Class 1 Modifications to Post-Closure Operation Plan, Building 829, Lawrence Livermore National Laboratory (LLNL) Site 300, Livermore, California, 94550. EPA ID No. CA2890090002 (DTSC 2005).

Class 1 Modifications to Post-Closure Operation Plan, Building 829, Lawrence Livermore National Laboratory (LLNL) Site 300, Livermore, California, 94550. EPA ID No. CA2890090002 (DTSC 2009).

- For Waste Discharge Monitoring Requirements for Site 300:

Order No. R5-2008-0148, Waste Discharge Requirements for the LLNL Experimental Test Site (Site 300) and the U.S. Department of Energy, is issued by the CVRWQCB. This permit replaced Waste Discharge Requirement (WDR) Order No. 96-248 in September 2008 that regulated the sewage evaporation pond and percolation pit monitoring at Site 300. In addition to this monitoring, the new permit requires monitoring of septic systems located through out the site, cooling tower blow down to percolation 
pits and septic systems, and mechanical equipment discharges located throughout the site. These networks are described in the fourth quarter/annual report (Blake et al. 2011).

\subsubsection{Monitoring Objectives}

The primary ground water compliance monitoring objective is to detect any release of COCs to ground water from the monitored facilities. The specific COCs monitored vary by facility.

\subsubsection{Sources and Analytes}

The sources of the COCs (analytes) typically lie within the monitored facilities themselves. Sources include wastes buried in closed landfills (Pits 1 and 6), residues remaining in soil beneath a covered former high explosives (HE) burn pit (Building 829 area) and active process and sewage water impoundments (HE area and General Services Area [GSA], respectively). Maps of facility (COC source) locations at Site 300, including the locations of their compliance monitoring wells are shown in Figures 14-6 through 14-15. 


\subsubsection{RCRA-closed Pit 1 Landfill.}

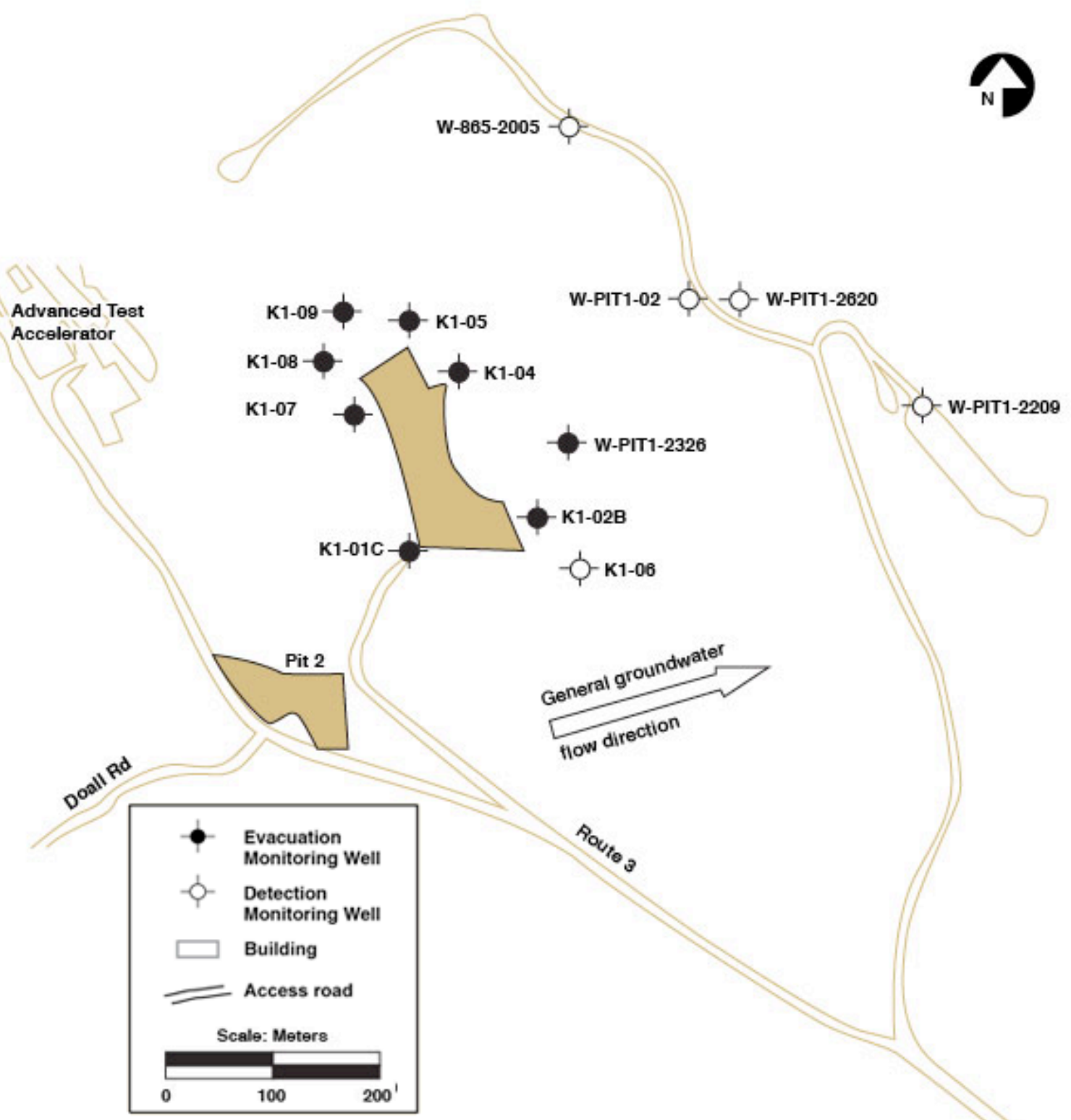

Figure 14-6. Location of Pit 1 and its eight compliance detection monitoring wells.

For specific details regarding the Pit 1 compliance monitoring program, including COCs and their permitted limits of concentration in ground water at each of the monitoring wells, see the regulatory documents listed for this monitoring network in Section 14.3.1. Ground water samples are obtained quarterly from the wells in this network. 


\subsubsection{CERCLA-closed Pit 6 Landfill.}

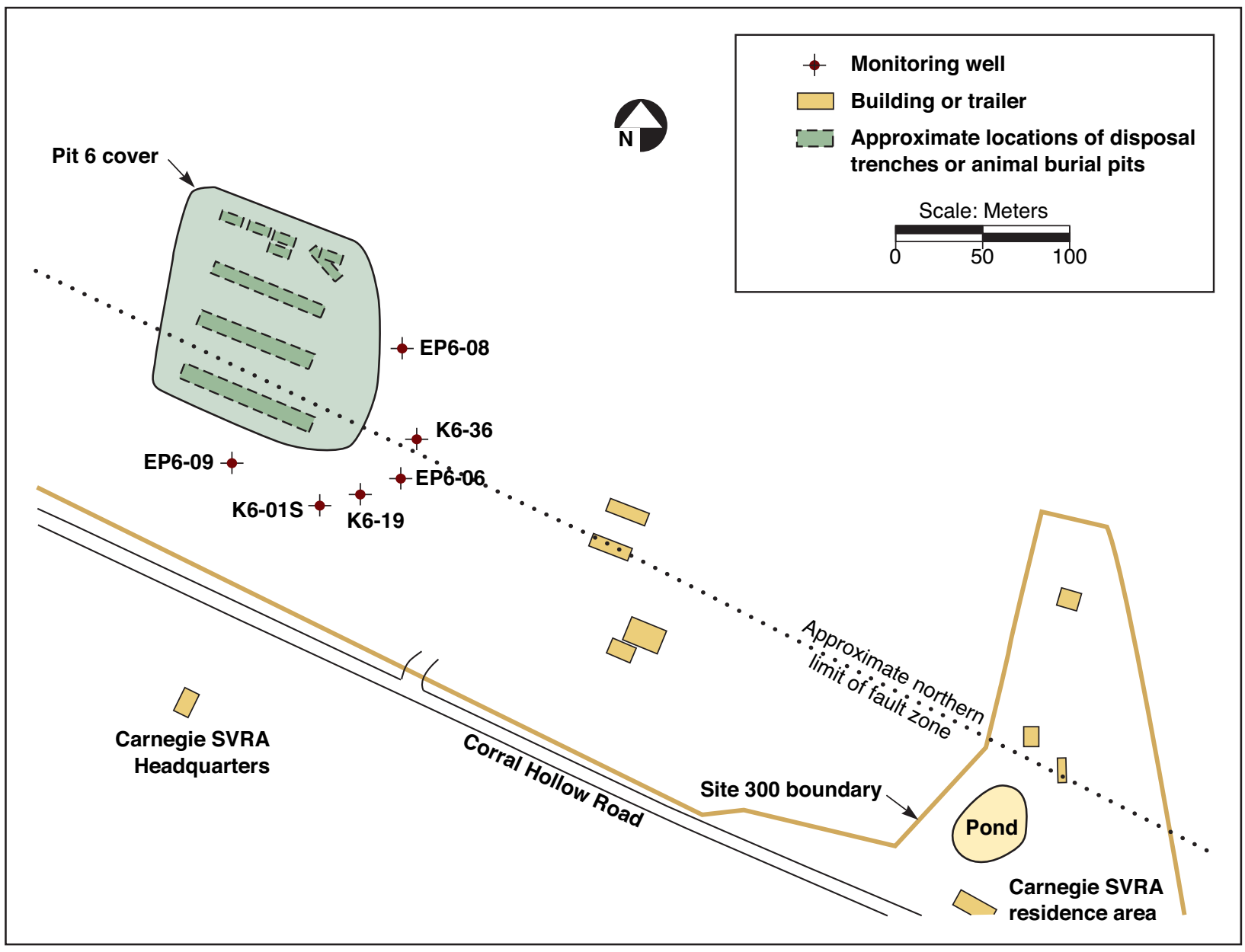

Figure 14-7. Location of Pit 6 and its six compliance detection monitoring wells.

For specific details regarding the Pit 6 compliance monitoring program, including COCs and their permitted limits of concentration in ground water at each of the monitoring wells, see the regulatory documents listed for this monitoring network in Section 14.3.1. Ground water samples are obtained quarterly from the wells in this network. 


\subsubsection{RCRA-closed Building 829 burn pit.}

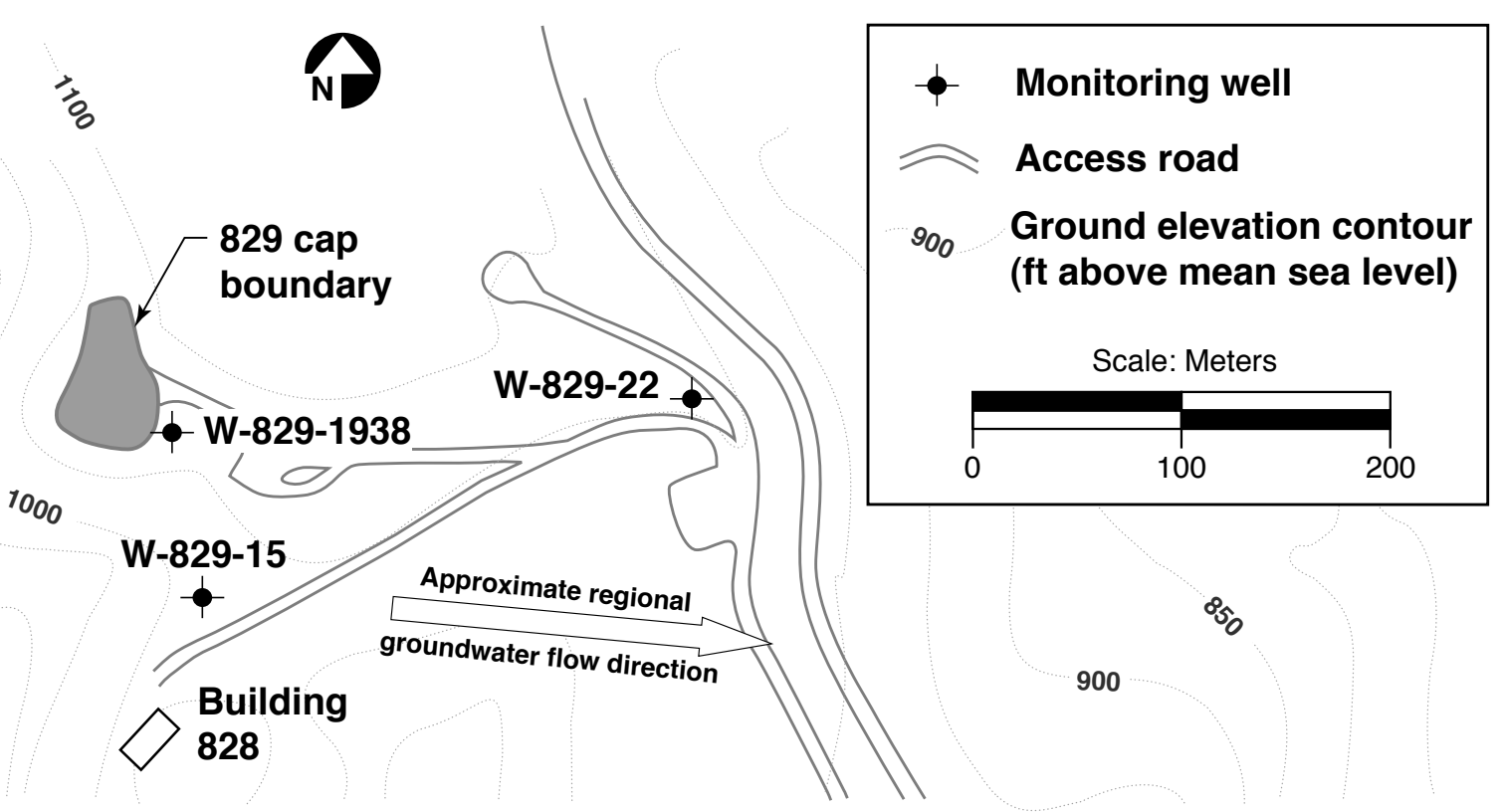

Figure 14-8. Location of the closed Building 829 burn pit at Site 300 and its three compliance detection monitoring wells.

For specific details regarding the HE burn pit compliance monitoring program, including COCs and their permitted limits of concentration in ground water at each of the monitoring wells, see the regulatory documents listed for this monitoring network in Section 14.3.1. Ground water samples are obtained quarterly from well W-829-1938, and annually from wells W-829-15 and W-829-22 in this network. 


\subsubsection{Active Sewage Water Impoundments (Ponds)}

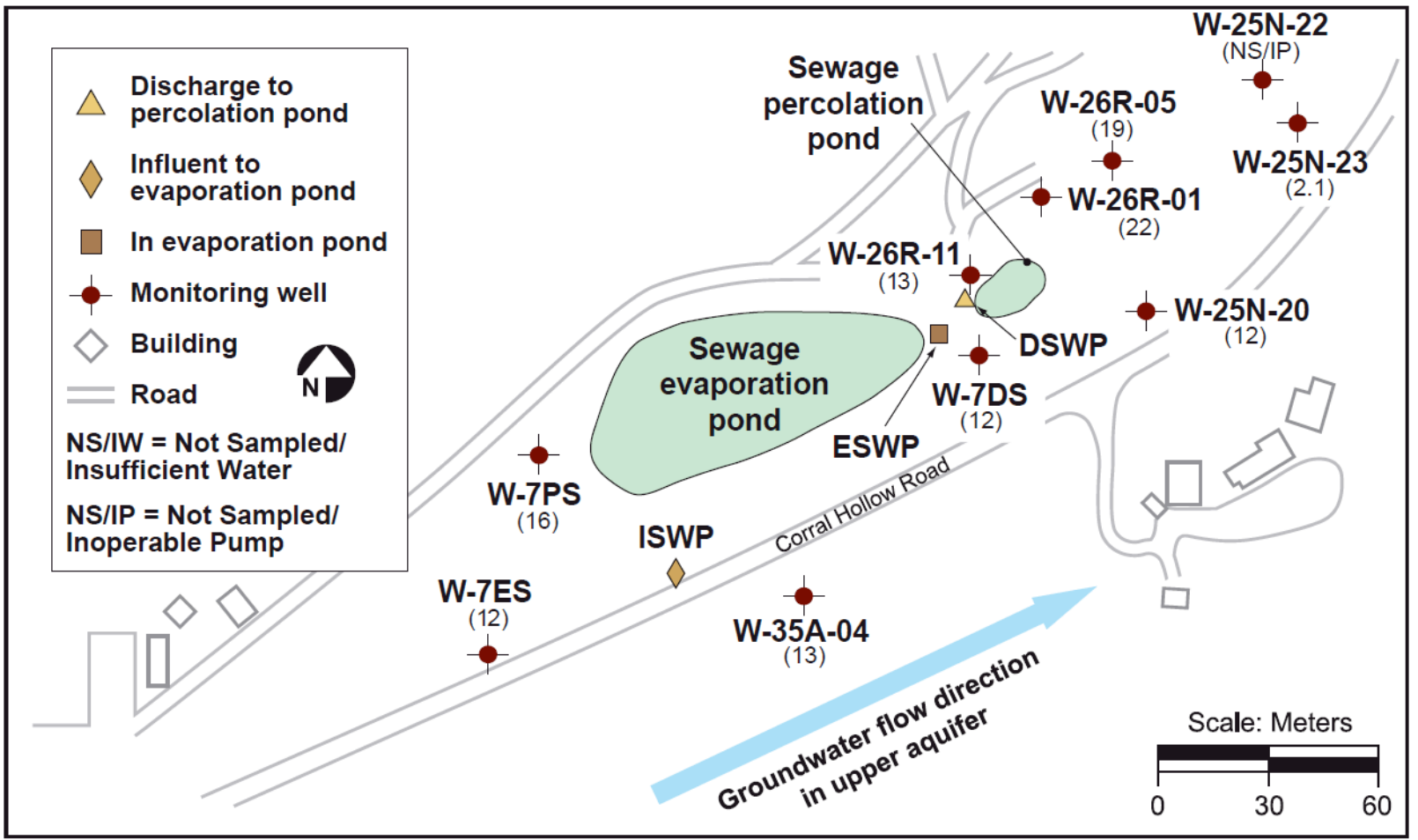

EDR_S3R_11_0103

Figure 14-9. Locations of the sewage ponds at Site 300 and their ten compliance detection monitoring wells.

For specific details regarding the sewage ponds compliance monitoring program, including COCs and their permitted limits of concentration in ground water at each of the monitoring wells, see the regulatory documents listed for this monitoring network in Section 14.3.1. Ground water samples are obtained semiannually from the wells in this network. 


\subsubsection{Septic Systems}

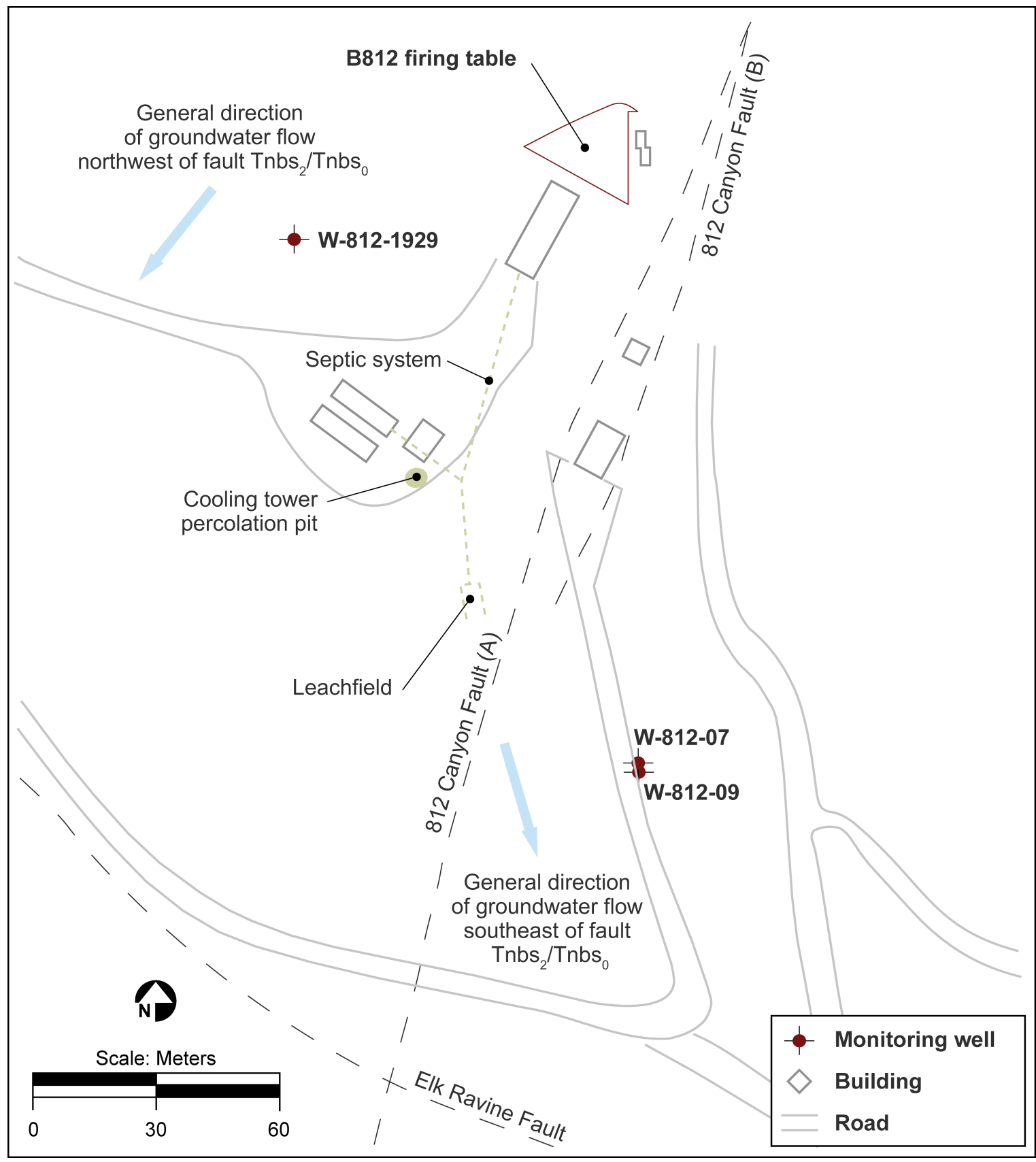

Figure 14-10. Building 812 Monitoring Network. 


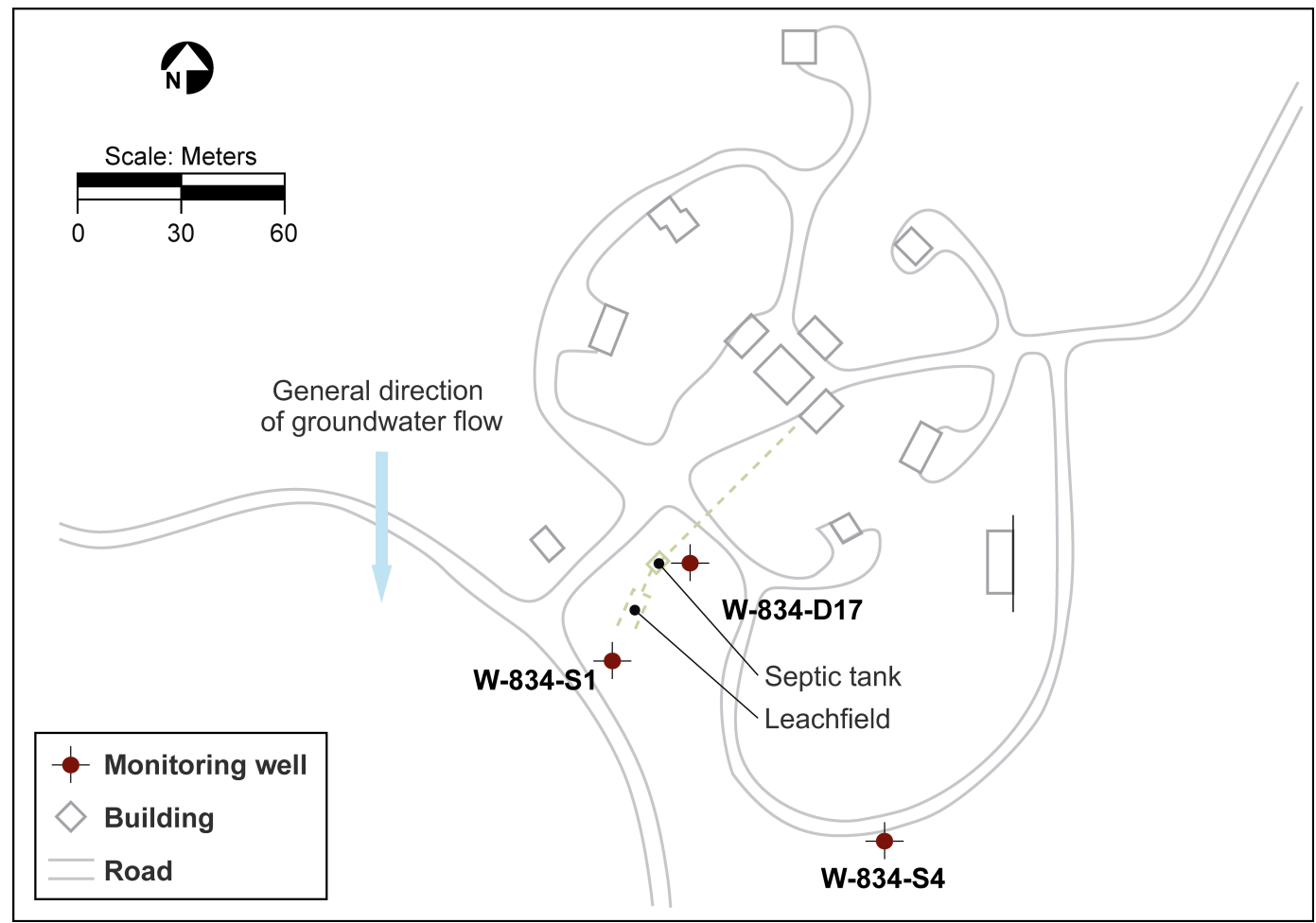

Figure 14-11. Building 834 Monitoring Network.

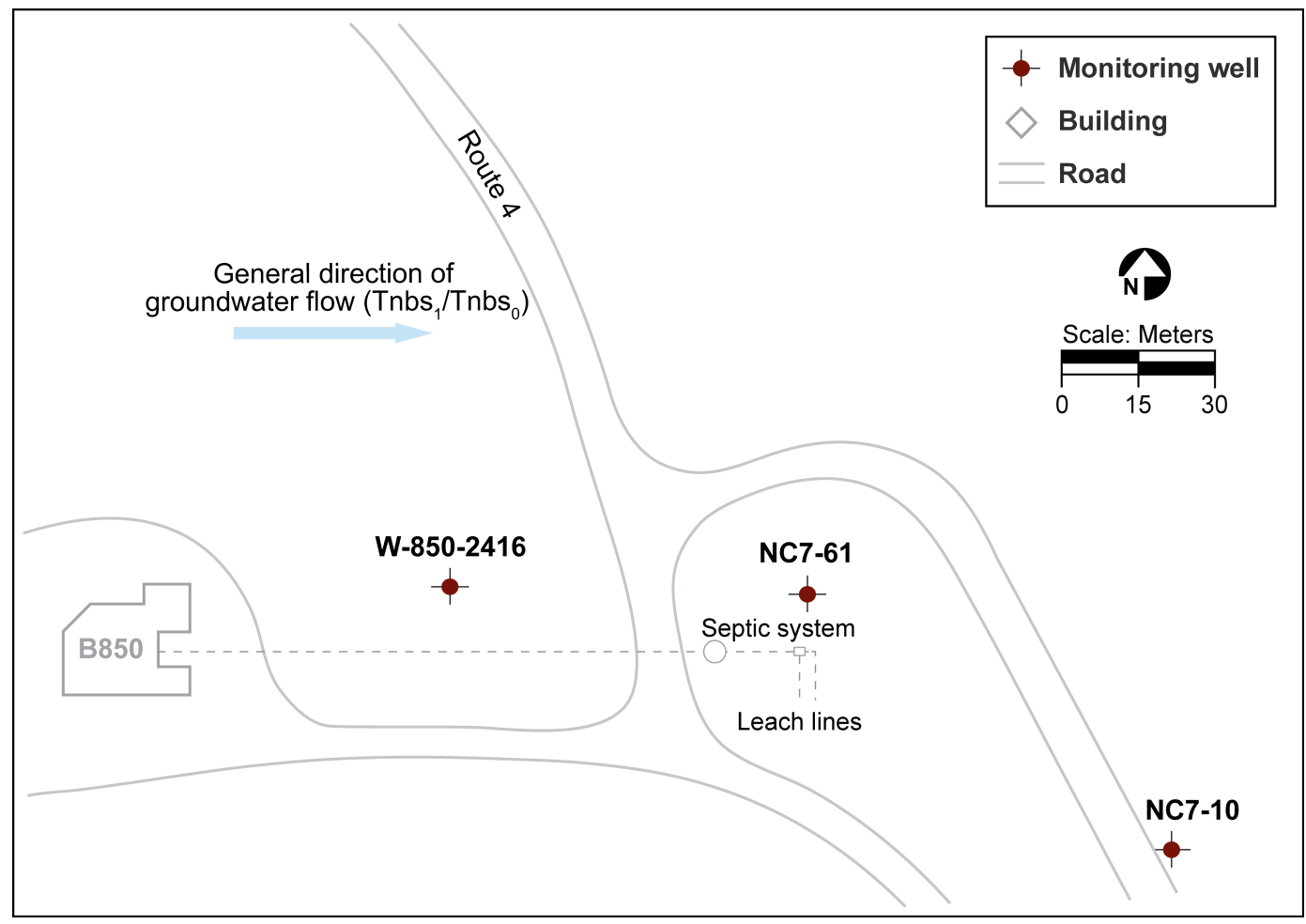

Figure 14-12. Building 850 Monitoring Network. 


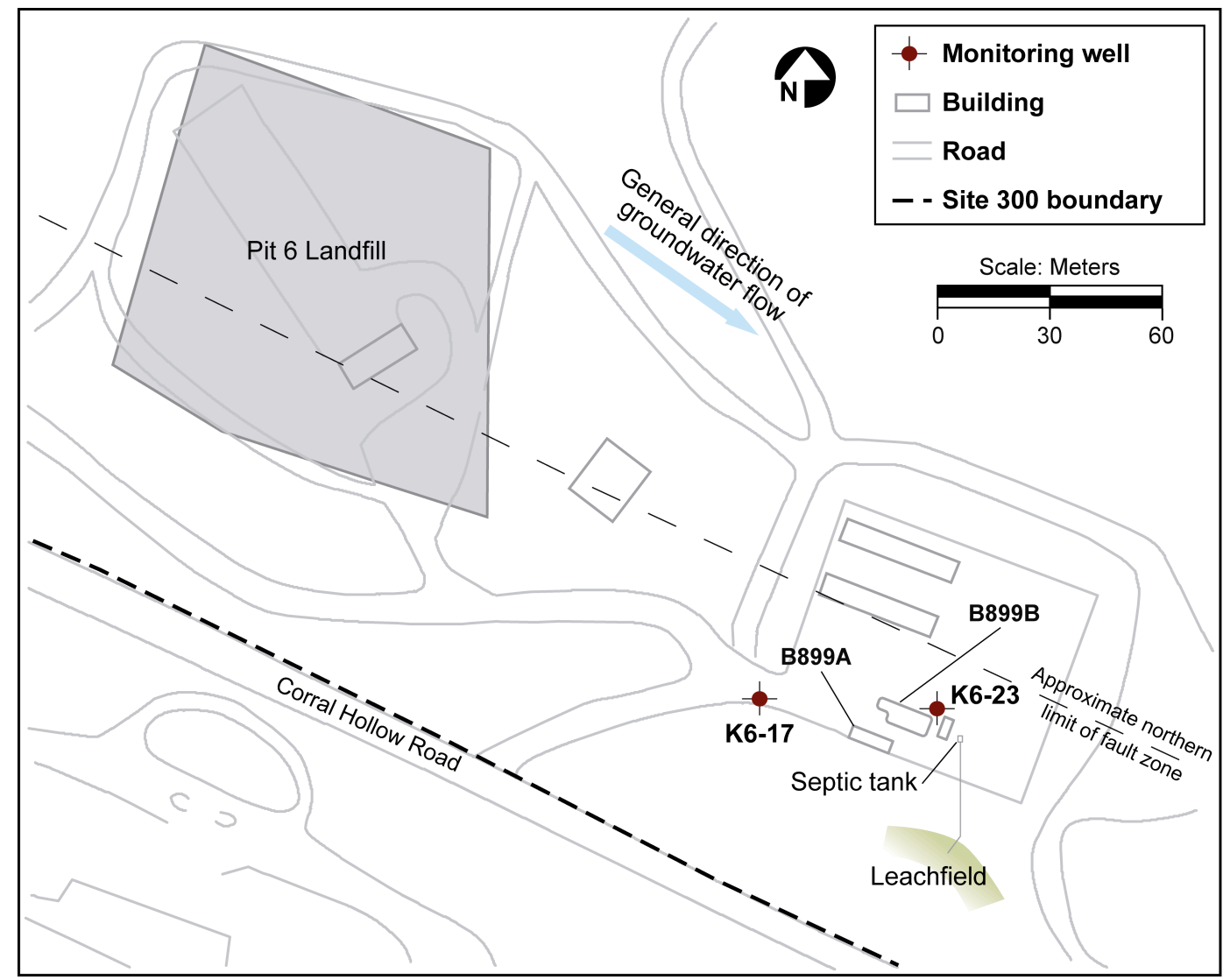

Figure 14-13. Building 899 Monitoring Network.

For specific details regarding the septic systems ground water monitoring for the Buildings $812,834,850$, and 899 compliance monitoring networks, including COCs and their permitted limits of concentration in ground water at each of the monitoring wells, see the regulatory documents listed for this monitoring network in Section 14.3.1. Ground water samples are obtained semiannually from the wells in this network. 


\subsubsection{Mechanical Equipment Percolation Pits}

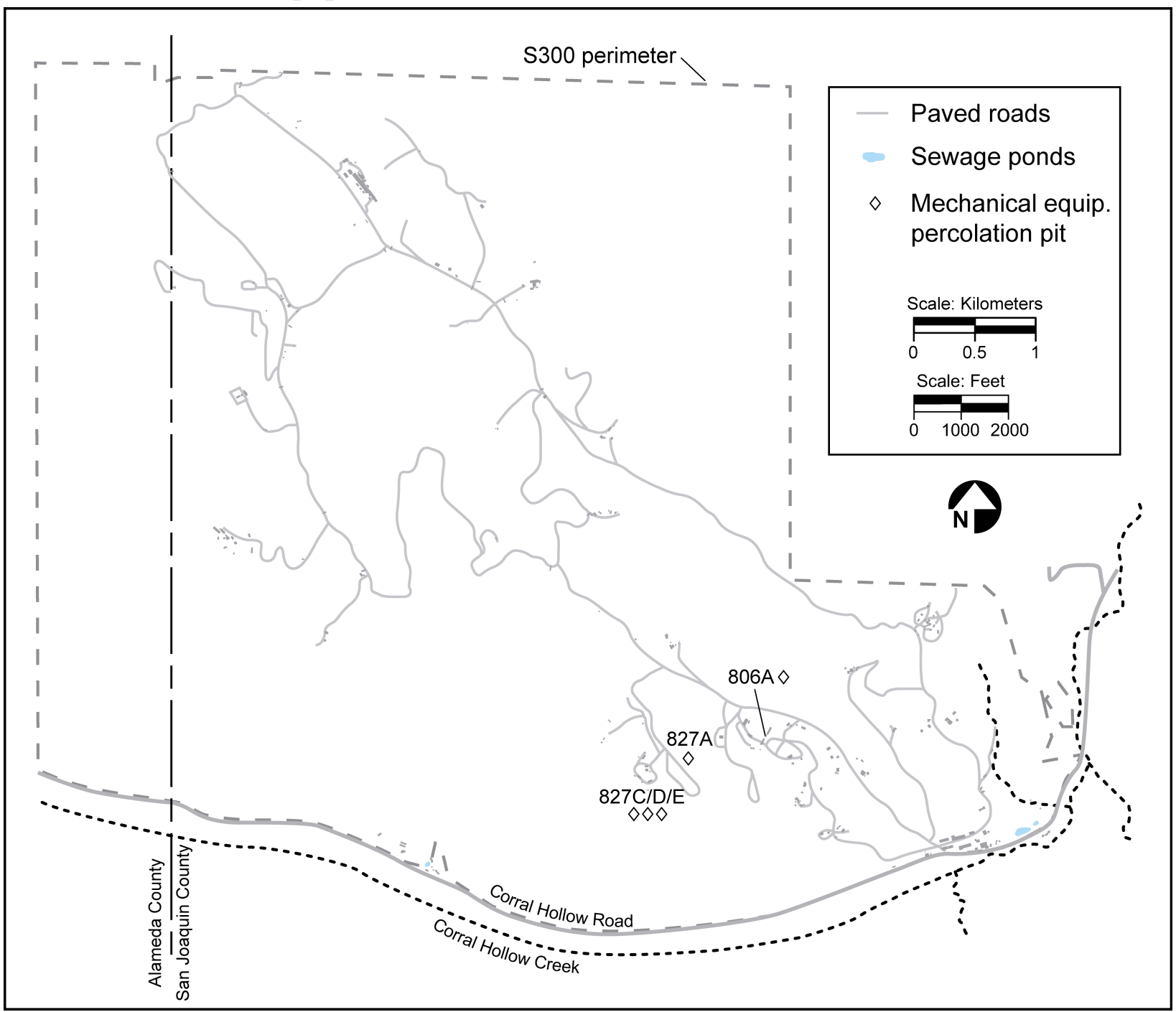

Figure 14-14. Location of mechanical equipment wastewater percolation pits.

For specific details regarding the mechanical equipment percolation pit water monitoring for the Buildings $806,827 \mathrm{~A}, 827 \mathrm{C}, 827 \mathrm{D}$, and $827 \mathrm{E}$ compliance monitoring networks, see the regulatory documents listed for this monitoring network in Section 14.3.1. The permit requires quarterly inspections of the five mechanical equipment percolation pits. If standing water is visible during the inspection, inspection frequency is increased to monthly until no water is visible. 


\subsubsection{Cooling Tower Percolation Pits}

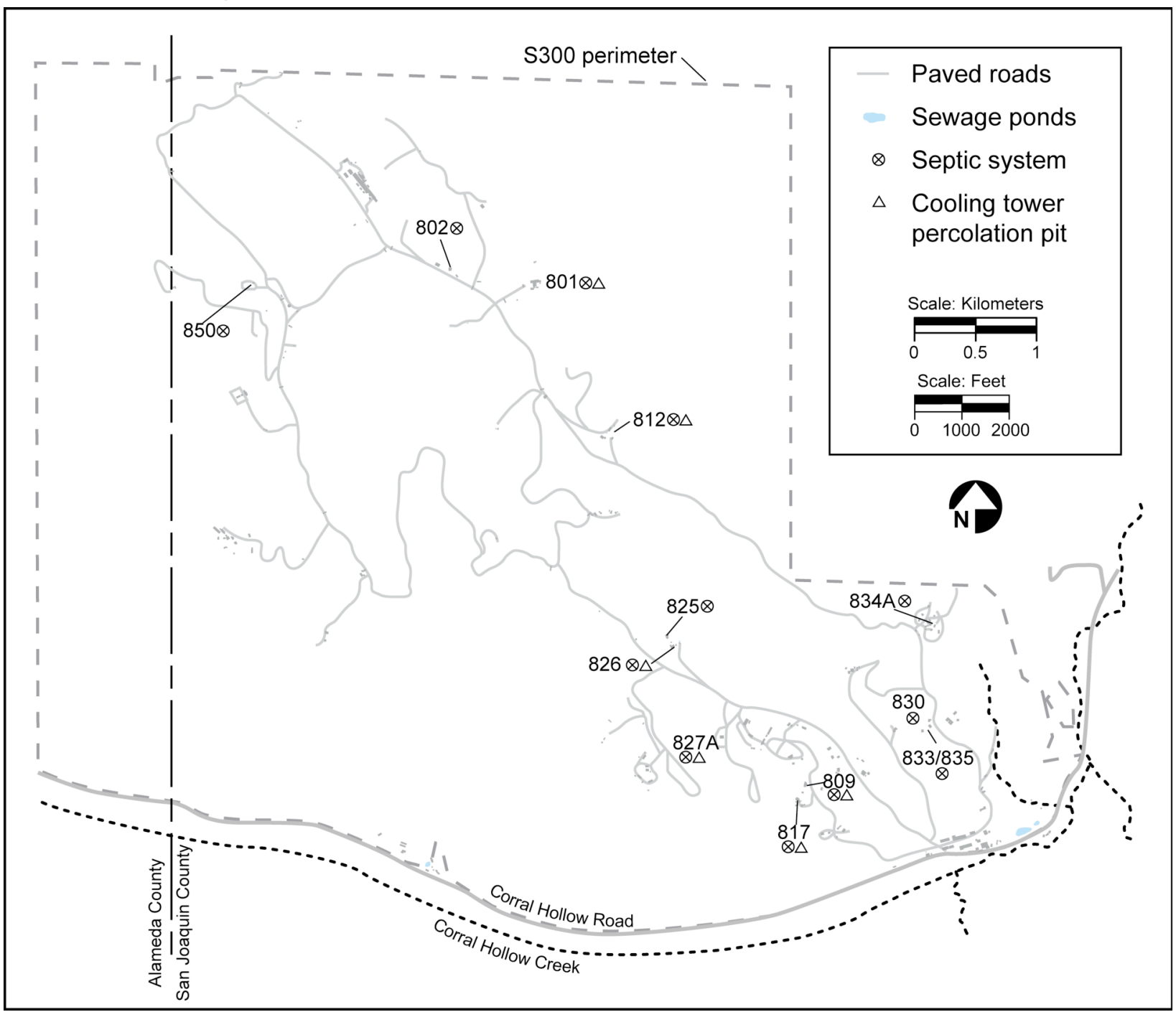

Figure 14-15. Location of cooling towers and percolation pits.

For specific details regarding the cooling tower percolation pit water monitoring for the Buildings $801,809,812,817 \mathrm{~A}, 825,826,827 \mathrm{~A}$, and 851 monitoring networks, see the regulatory documents listed for this monitoring network in Section 14.3.1. The permit requires quarterly inspections of the seven cooling tower percolation pits and one septic system for Building 825. If standing water is visible in the percolation pit during the inspection, inspection frequency is increased to monthly until no water is visible. The permit requires semi-annual sampling of cooling tower blowdown. 


\subsection{Ground Water Sample Collection Methods}

The standard operating procedures (SOPs) for ground water sample collection are fully described in the LLNL Livermore Site and Site 300 Environmental Restoration Project Standard Operating Procedures (Goodrich and Depue 2003). Ground water samples are collected by LLNL technicians who are trained in the appropriate SOPs. SOPs are followed to ensure consistent ground water monitoring results that accurately represent the ground water at all the monitoring locations.

\subsection{Procedures for Laboratory Analysis}

Chemical and radioactivity analyses are conducted by commercial laboratories under contract with LLNL. The analytical laboratories are certified by the California Department of Health Services Environmental Laboratory Accreditation Program (ELAP). Laboratories use EPA approved or other standard methods of analyses in accordance with 40 CFR Part 141. The analytical work is done in accordance with the conditions and methodology specified in an approved statement of work. Typically, COC concentrations in ground water are monitored down to their reporting limits (RLs). Analytical methods are selected to meet LLNL data quality objectives (DQOs). For compliance monitoring, RLs must be at or below permitted statistical limits of concentration (SLs) for the COCs. For surveillance monitoring, analytical methods are chosen whose RLs are at or below EPA or California maximum contaminant levels (MCLs) for the COCs in drinking water. MCLs are used by LLNL water analysts as reference standards. Tables 14-1 and 14-2 at the end of this chapter list LLNL COCs, the EPA or standard method used to measure them, and their contractual RLs.

\subsection{Quality Assurance Procedures}

\subsubsection{Precision}

Under the quality assurance program for this monitoring network, a duplicate or collocated sample is collected from at least $10 \%$ of sample locations, or at least one location, per sampling event. The duplicate location is randomly chosen from the available locations, if sufficient sample volume is present. An alternative location may be used if the required sample volume is not available at the pre-selected location. This duplicate sample is submitted to the lab for analysis with a unique sample identifier. The results for the duplicate location sample and actual location sample are compared by the network analyst upon the delivery of the analytical results from the laboratory. 


\subsubsection{Bias}

Field blanks may be submitted with some of the networks and analyzed by any compounds desired by the analyst. These analyses give some indication of field contamination, or combined field and laboratory contamination, which can lead to bias in analytical results. All quality check information provided by the analytical laboratories, including matrix spikes, matrix duplicates, and calibration standards are examined by the network analyst to identify any analytical bias. If calibration standards or matrix spikes are consistently high or low, the analyst will contact the laboratory for an explanation. Trip blanks are used with volatile organic compounds only to indicate which of those compounds may be contaminants.

\subsubsection{Completeness}

Ground water samples may not be collected as planned because of a well being dry, difficult field conditions (that sometimes occur during the rainy season), or for any other reason. For compliance monitoring, sampling of all locations for each compliance parameter is required; therefore, $100 \%$ completeness is necessary. Given the potential for sample loss for reasons described above, our target completeness would be $90 \%$ for each site (Livermore site and Site 300) for surveillance monitoring.

\subsection{Program Implementation Procedures}

The requirements for the implementation of the ground water compliance monitoring programs are specified in the post-closure and permit documents listed in Section 14.3.1. Each (new) surveillance or compliance monitoring program is assigned to an EFA water analyst who directs ground water monitoring on a day-to-day basis. The responsible water analyst begins by generating a quarterly sampling plan at least one month in advance of actual sampling. The sampling plan is then carried out by LLNL technicians who are trained in the appropriate SOPs (Goodrich and Lorega 2009). Technicians send samples to analytical laboratories where analyses are performed. Analytical data are returned to the responsible water analyst. The analyst apprises LLNL management regarding results from the monitoring program and writes any required reports.

\subsection{Action Levels}

Environmental action levels are COC concentration levels in ground water above which certain responses are automatic. For compliance ground water monitoring, the action levels are the permitted SLs for the monitored COCs. For surveillance ground water monitoring, the action levels may be the analytical RL for COCs that are not typically detected, or drinking water MCLs. Action level concentrations for ground water COCs at LLNL are listed in Tables 14-1 and 14-2 at the end of this chapter. Some constituents shown in Tables 14-1 and 14-2 do not 
have action level concentrations established because of a lack of sufficient data, because their concentration varies considerably from location to location, or because they are not actually COCs (that is, they are members of a group of constituents that are routinely measured and reported by a particular analytical method). These are listed as TBD (to be determined) in Table 14-1.

Automatic responses to exceedances of action level concentrations in routine ground water samples include the following actions:

1. Assess the accompanying quality assurance/quality control (QA/QC) data from the reporting analytical laboratory.

2. Notify LLNL management of the off-normal result.

3. Resample the monitoring location twice, with samples obtained at least one week apart to ensure independence. The samples are analyzed for the suspect COC using the same method as was used for the initial routine sample.

4. If either "retest" sample shows an exceedance of the COC, then the initial routine sample result is judged to be confirmed. If neither sample shows an exceedence, then the initial result is judged to be invalid. LLNL management is notified of the retest results.

5. For compliance monitoring (only), if retesting confirms the exceedance, a letter report regarding "statistical evidence of a release of (the COC) from (the monitored facility)" is made to the Site 300 Remedial Program Managers (RPMs) within seven days of the finding.

\subsection{Preparation and Disposition of Reports}

The following reports document monitoring results from both the compliance and the surveillance networks.

- The annual Environmental Report. Ground water surveillance monitoring data and significant results for a calendar year are summarized in the water chapter of the annual Environmental Report that is widely distributed to state and federal agencies and to the public. Summaries of the compliance monitoring at Site 300 are also included in the report. Surveillance ground water monitoring data are included with the Environmental Report.

- LLNL Experimental Test Site 300 Compliance Monitoring Program for RCRAClosed Landfill Pit 1 (e.g., Blake 2011). This report is submitted quarterly to the CVRWQCB. Required contents are tables of measurements made during a quarter or year, a summary of the measurement data with regard to compliance, 
and a short discussion of monitoring results, including any water quality violations.

- LLNL Experimental Test Site 300 Compliance Monitoring Program for the CERCLA-Closed Pit 6 Landfill (e.g., Blake and Valett 2011). This report is submitted quarterly to the Site 300 RPMs. Required contents are tables of measurements made during a quarter or year, a summary of the measurement data with regard to compliance, and a short discussion of monitoring results, including any water quality violations.

- LLNL Experimental Test Site 300 Compliance Monitoring Report for Waste Discharge Requirement Order No. R5-2008-0148 (e.g., Blake et al. 2011). This reports is submitted quarterly to the CVRWQCB. Contents of the reports are similar to the reports outlined above for closed landfills.

- LLNL Experimental Test Site 300 Compliance Monitoring Program for the Closed Building 829 Facility Annual Report (e.g., Revelli 2011). This report is submitted annually to DTSC. Report contents are similar to the reports outlined above for closed landfills.

- Occurrence Reports. An occurrence report may be required when a permitted COC concentration is exceeded, if it entails nonroutine reporting to a regulatory agency.

\subsection{Plans for the Future}

\subsubsection{Livermore Site and Livermore Valley Surveillance Monitoring}

Ongoing analyses will determine the need for long-term additions to the ground water surveillance monitoring programs and will determine sampling frequencies.

No changes to the surveillance monitoring programs are planned for the immediate future.

\subsubsection{Site 300 Surveillance Monitoring}

For onsite surveillance ground water monitoring at Site 300, LLNL uses DOE CERCLA wells and springs. Representative ground water samples are obtained at least once per year at every monitoring location; they are routinely measured for various elements (primarily metals), a wide range of organic compounds, general radioactivity (gross alpha and gross beta), uranium activity, and tritium activity. The onsite monitoring network consists primarily of nine monitoring points in the Elk Ravine Area. No changes to this network are proposed at this time. 
For offsite surveillance monitoring consists of collecting ground water samples from two offsite springs and ten off-site wells. With the exception of one well, all off-site monitoring locations are near Site 300 except for a private residence $6 \mathrm{~km}$ west of the site. All surveillance monitoring is conducted under DOE Order 458.1. No changes to the onsite or offsite surveillance monitoring networks are proposed at this time.

\subsubsection{Pit 1 Compliance Monitoring}

No changes are proposed for the Pit 1 compliance ground water monitoring network. The Pit 1 monitoring is currently conducted under the CVRWQCB Revised Permit 93-100 dated July 10, 2010.

\subsubsection{Pit 6 Compliance Monitoring}

No changes to ground water detection monitoring (EFA's tasks) are planned for the immediate future. Future changes may occur in corrective action monitoring program (ERD's tasks, Ferry et al. 2002).

\subsubsection{Pit 7 Compliance Monitoring}

The Pit 7 complex is currently undergoing active remediation by ERD. Because of the potential impact on the existing compliance monitoring network wells, this monitoring complex was removed from the compliance monitoring network during the first quarter 2010, where it was being monitored under the CVRWQCB. Pit 7 has been transferred to CERCLA and is now managed by ERD (See Section 14.1 for details).

\subsubsection{Building 829 Compliance Monitoring}

No changes to this compliance monitoring program are planned for the immediate future; however, the current permit expires in 2013 and must be renewed prior to that time.

\subsubsection{Sewage Ponds Compliance Monitoring}

Under authority of the State of California, and required by the Porter-Cologne Water Quality Control Act, the CVRWQCB issued Order No. R5-2008-0148 for the Experimental Test Site (Site 300), to Lawrence Livermore National Laboratory (LLNL). Monitoring and Reporting Program (MRP) Number R5-2008-0148 was adopted in September 2008. Under the terms of this MRP, LLNL submits semiannual and annual monitoring reports regarding its Experimental Test Site (Site 300) discharges of domestic and wastewater effluent to sewage evaporation and percolation ponds in the General Services Area, septic systems located throughout the Site, cooling tower blow down to percolation pits and septic systems and mechanical equipment discharges located throughout the Site. The monitoring data collected 
for this report documents compliance with all MRP and permit conditions and limits. Compliance certification accompanies this report, as required by federal and state regulations.

\subsection{References}

Blake, R. (2011a), LLNL Experimental Test Site 300 Compliance Monitoring Program for RCRA-Closed Landfill Pit 1, Third Quarter Report 2011, Lawrence Livermore National Laboratory, Livermore, CA (UCAR-10191-11-3).

Blake, R. (2011b), LLNL Experimental Test Site 300 Compliance Monitoring Report for Waste Discharge Requirement (WDR) Order No. R5-2008-0148 First Semester Report 2011 (LLNL-AR-411431-11-1).

Blake R. and J. Valett (2011), LLNL Experimental Test Site 300 Compliance Monitoring Program for the CERCLA-Closed Pit 6 Landfill, Third Quarter Report, 2011, Lawrence Livermore National Laboratory, Livermore, CA (UCRL-AR-132057-11-3).

Buerer, A. (1983), Assessment and Cleanup of the Taxi Strip Waste Storage Area at LLNL, Lawrence Livermore National Laboratory, Livermore, CA (UCID-20869).

CVRWQCB (1993), Monitoring and Reporting Program WDR Order 93-100, Lawrence Livermore National Laboratory Site 300 and U. S. Department of Energy, Landfill Pits 1 and 7, San Joaquin County, Central Valley Regional Water Quality Control Board, June 25, 1993.

CVRWQCB (1998), Revised Monitoring and Reporting Programs No. 93-100 and 96-248, Lawrence Livermore National Laboratory Site 300, San Joaquin County, Central Valley Regional Water Quality Control Board, September 25, 1998.

Environmental Report (annual), Lawrence Livermore National Laboratory, Livermore, CA. (UCRL-50027). Available at https://saer.llnl.gov/

Ferry, L., T. Berry and D. MacQueen (1998), Post-Closure Plan for the Pit 6 Landfill Operable Unit, Lawrence Livermore National Laboratory Site 300, Lawrence Livermore National Laboratory, Livermore, CA (UCRL-AR-128638).

Ferry, R., L. Ferry, M. Dresen, and T. Carlsen (2002), Compliance Monitoring Plan/Contingency Plan for Interim Remedies at Lawrence Livermore National Laboratory Site 300 (UCRL-AR-147570).

Goodrich, R. and G. Lorega (2009), LLNL Livermore Site and Site 300 Environmental Restoration Project Standard Operating Procedures (SOPs), Lawrence Livermore National Laboratory, Livermore, CA (UCRL-MA-109115, Rev. 12).

Hoffman, J., P. McKereghan, B. Qualheim, E. Folsom, M. Dresen, J. Ziagos, K. Anderson, R. Blake, L. Berg, K. Folks, B. Gelinas, G. Howard, V. Johnson, A. Kulshrestha, J. Macdonald, M. Maley, P. Ottesen, M. Ridley, E. Sorensen, A. Watts, R. Bainer (1993), LLNL Ground Water Project 1993 Annual Report, Lawrence Livermore National Laboratory, Livermore, CA (UCRL-AR-115640-93-4). 
LLNL (2001), Post-Closure Permit Application for the Building 829 HE Open Burn Facility Volume 1, Lawrence Livermore National Laboratory, Livermore, CA, (UCRL-AR139697).

LLNL (2008), CERCLA site-wide record of decision for Site 300 UCRL-AR-236665.

Macdonald, J., M. Dresen, R. Bainer, E. Folsom, B. Qualheim, and J. Ziagos (1994), LLNL Ground Water Project, Quarterly Progress Report, March 1994, Lawrence Livermore National Laboratory, Livermore, CA (UCRL-AR-115640-94-1).

Mathews, S. and M. Taffet (1997), Final Closure Plan for the High-Explosives Open Burn Treatment Facility at Lawrence Livermore National Laboratory Experimental Test Site 300, Lawrence Livermore National Laboratory, Livermore, CA (UCRL-ID-111753-REV-1).

McConachie, W. A., J. P. Como, D. W. Carpenter, and R. C. Ragaini (1986), East Traffic Circle Landfill Closure Report, Lawrence Livermore National Laboratory, Livermore, CA (UCID-20662).

Raber, E. (2004), Request for Analytical Method and Statistical Limit Changes to the Monitoring and Reporting Program (MRP) 96-248, Revision 1, (WGMG04-39:ER:SM:bld).

Raber, E. and D. W. Carpenter, eds. (1983), An Evaluation of the Hydrogeology and Ground Water Chemistry Associated with Landfills at LLNL's Site 300, Lawrence Livermore National Laboratory, Livermore, CA (UCRL-53416).

Revelli, M. A. (2011), LLNL Experimental Test Site 300 Compliance Monitoring Program for the Closed Building 829 Facility Annual Report 2010, Lawrence Livermore National Laboratory, Livermore, CA (UCRL-AR-143121-10).

Rogers/Pacific Corporation (1990), Lawrence Livermore National Laboratory Site 300 Resource Conservation and Recovery Act Closure and Post-Closure Plans-Landfill Pits 1 and 7, Pacific Corporation, Van Nuys, CA (California EPA Id. No. CA2890090002, Volumes I and II).

Taffet, M. J., L. Green-Horne, L. C. Hall, T. M. Carlsen, and J. A. Orberdorfer (1996), Addendum to Site-Wide Remedial Investigation Report, Building 850/Pit 7 Complex Operable Unit, Lawrence Livermore National Laboratory Site 300, Lawrence Livermore National Laboratory, Livermore, CA (UCRL-AR-108131, Add. 1).

Thorpe, R. K., W. F. Isherwood, M. D. Dresen, and C. P. Webster-Scholten (1990), CERCLA Remedial Investigation Report for the LLNL Livermore Site, Volumes 1-5, Lawrence Livermore National Laboratory, Livermore, CA (UCAR-10299).

Webster-Scholten, C. P., ed. (1994), Final Site-Wide Remedial Investigation Report, LLNL Site 300, Lawrence Livermore National Laboratory, Livermore, CA (UCRL-AR-108131). 
Table 14-1. Ground water monitoring, inorganic COCs, analytical methods, reporting limits, and action level concentrations.

\begin{tabular}{|c|c|c|c|}
\hline $\begin{array}{l}\text { Constituent of } \\
\text { concern (COC) }\end{array}$ & $\begin{array}{l}\text { Analytical } \\
\text { method }\end{array}$ & $\begin{array}{c}\text { Reporting } \\
\operatorname{limit}(a)\end{array}$ & $\begin{array}{c}\text { Action level } \\
\text { concentration }\end{array}$ \\
\hline \multicolumn{4}{|l|}{ Metals and minerals $(\mathrm{mg} / \mathrm{L})$} \\
\hline All alkalinities & SM $2310^{(b)}$ & 1 & TBD \\
\hline Aluminum & EPA 200.7 or 200.8 & 0.05 or 0.2 & MCL \\
\hline Ammonia nitrogen (as N) & EPA 350.1 or $\mathrm{SM} 4500-\mathrm{NH} 3$ & 0.03 or 0.1 & $\mathrm{RL}$ \\
\hline Antimony & EPA 204.2 or 200.8 & 0.005 & MCL \\
\hline Arsenic & EPA 206.2 or 200.8 & 0.002 & MCL \\
\hline Barium & EPA 200.7 or 200.8 & 0.025 or 0.01 & MCL \\
\hline Beryllium & EPA 210.2 or 200.8 & 0.0005 or 0.0002 & MCL \\
\hline Boron & EPA 200.7 & 0.05 & TBD \\
\hline Bromide & EPA 300.0 & 0.5 & TBD \\
\hline Cadmium & EPA 200.8 or SM $3113 \mathrm{~B}$ & 0.0005 & MCL \\
\hline Calcium & EPA 200.7 & 0.5 & TBD \\
\hline Chloride & EPA 300.0 & 0.5 & TBD \\
\hline Chlorine (residual) & SM 4500-CL & 0.1 & \\
\hline Chromium & EPA 218.2 or 200.8 & 0.01 or 0.001 & MCL \\
\hline Chromium(VI) & EPA 218.4 or 7196 & 0.002 or 0.05 & MCL \\
\hline Cobalt & EPA 200.7 or 200.8 & 0.025 & TBD \\
\hline Copper & EPA $200.7,220.2$, or 200.8 & $0.01,0.001$, or 0.05 & MCL \\
\hline Cyanide & EPA 335.2 or $4500-\mathrm{CN}$ & 0.02 & \\
\hline Fluoride & EPA 340.1 or 340.2 & 0.05 & MCL \\
\hline Hardness, total $\left(\mathrm{as} \mathrm{CaCO}_{3}\right)$ & SM2320B & 1 & TBD \\
\hline Iron & EPA 200.7 or 200.8 & 0.1 & TBD \\
\hline Lead & EPA 200.8 or SM $3113 \mathrm{~B}$ & 0.002 or 0.005 & MCL \\
\hline Magnesium & EPA 200.7 or 200.8 & 0.5 & TBD \\
\hline Manganese & EPA 200.7 or 200.8 & 0.03 & $\mathrm{RL}$ \\
\hline Mercury & EPA 245.1 or 245.2 & 0.0002 & MCL \\
\hline Molybdenum & EPA 200.7 or 200.8 & 0.025 & TBD \\
\hline Nickel & EPA $200.7,200.8$ or SM 3113B & $0.002,0.005$ or 0.1 & MCL \\
\hline Nitrate $\left(\right.$ as $\left.\mathrm{NO}_{3}\right)$ & EPA $353.2,300.0$, or SM $4500-\mathrm{NO} 2$ & 0.5 & MCL \\
\hline Nitrite (as NO2) & EPA $353.2,300.0$, or SM $4500-\mathrm{NO} 2$ & 0.5 & \\
\hline Orthophosphate & EPA $300.0,365.1$, or 365.2 & 0.05 & TBD \\
\hline Perchlorate & EPA 314.0 & 0.004 & TBD \\
\hline Potassium & EPA 200.7 & 1 & TBD \\
\hline Selenium & EPA 200.8 or SM $3113 \mathrm{~B}$ & 0.002 & MCL \\
\hline Silver & EPA 200.8 or SM $3113 B$ & 0.001 or 0.0005 & TBD \\
\hline Sodium & EPA 200.7 & 1 or 0.1 & TBD \\
\hline Sulfate & EPA 300.0 & 1 & TBD \\
\hline
\end{tabular}


Table 14-1. Ground water monitoring, inorganic COCs, analytical methods, reporting limits, and action level concentrations. (continued)

\begin{tabular}{|c|c|c|c|}
\hline $\begin{array}{l}\text { Constituent of } \\
\text { concern (COC) }\end{array}$ & $\begin{array}{l}\text { Analytical } \\
\text { method }\end{array}$ & $\begin{array}{l}\text { Reporting } \\
\operatorname{limit}(\mathbf{a})\end{array}$ & $\begin{array}{l}\text { Action level } \\
\text { concentration }\end{array}$ \\
\hline \multicolumn{4}{|l|}{$\begin{array}{l}\text { Metals and minerals (mg/L) } \\
\text { (cont.) }\end{array}$} \\
\hline Surfactants & EPA 425.1 or SM $5540 \mathrm{C}$ & 0.5 & TBD \\
\hline Thallium & EPA 279.2 or 200.8 & 0.001 & MCL \\
\hline Total dissolved solids & SM 2540C & 1 & TBD \\
\hline Total Kjeldahl nitrogen & EPA 351.2 or SM $4500-$ Norg & 0.2 & TBD \\
\hline Total phosphorus (as $\mathrm{P}$ ) & EPA 365.4 or SM 4500-P & 0.05 & \\
\hline Total suspended solids & SM 2540D & 1 & TBD \\
\hline Vanadium & EPA 200.7 or 200.8 & 0.02 or 0.025 & TBD \\
\hline Zinc & EPA 200.7 or 200.8 & 0.02 or 0.05 & TBD \\
\hline \multicolumn{4}{|l|}{ General indicator parameters } \\
\hline $\mathrm{pH}$ & EPA 150.1 & none & TBD \\
\hline $\begin{array}{l}\text { Biochemical oxygen demand } \\
(\mathrm{mg} / \mathrm{L})\end{array}$ & SM 5210B & 2 & \\
\hline Conductivity $(\mu \mathrm{S} / \mathrm{cm})$ & EPA 120.1 & none & TBD \\
\hline $\begin{array}{l}\text { Chemical oxygen demand } \\
(\mathrm{mg} / \mathrm{L})\end{array}$ & EPA 410.4 & 5 & \\
\hline Dissolved oxygen (mg/L) & SM 4500-O G & 0.05 & \\
\hline Total organic carbon $(\mathrm{mg} / \mathrm{L})$ & EPA 9060 or 415.1 & 1.0 & TBD \\
\hline Total organic halides (mg/L) & EPA 9020 & 0.01 & TBD \\
\hline Toxicity, acute (fathead minnow) & EPA 600/4-AB5-013 & NA & \\
\hline $\begin{array}{l}\text { Toxicity, chronic (fathead } \\
\text { minnow) }\end{array}$ & EPA 1000 & NA & \\
\hline Toxicity, chronic (daphnid) & EPA 1002 & NA & \\
\hline Toxicity, chronic (green algae) & EPA 1003 & NA & \\
\hline \multicolumn{4}{|l|}{ Radioactivity (Bq/L) } \\
\hline Gross alpha & EPA 900 & 0.074 & MCL \\
\hline Gross beta & EPA 900 & 0.111 & MCL \\
\hline \multicolumn{4}{|l|}{ Radioisotopes (Bq/L) } \\
\hline Americium 241 & U-NAS-NS-3050 & 0.0037 & RL \\
\hline Plutonium 238 & U-NAS-NS-3050 & 0.0037 & RL \\
\hline Plutonium $239+240$ & U-NAS-NS-3050 & 0.0037 & RL \\
\hline Radon-222 & EPA 913 & 3.7 & TBD \\
\hline Radium-226 & EPA 903 & 0.0093 & MCL \\
\hline Radium-228 & EPA 904 & 0.037 & MCL \\
\hline Thorium-228 & U-NAS-NS-3050 & 0.009 & TBD \\
\hline Thorium-230 & U-NAS-NS-3050 & 0.006 & \\
\hline Thorium-232 & U-NAS-NS-3050 & 0.006 & TBD \\
\hline
\end{tabular}


Table 14-1. Ground water monitoring, inorganic COCs, analytical methods, reporting limits, and action level concentrations. (concluded)

\begin{tabular}{|l|c|c|c|}
\hline $\begin{array}{c}\text { Constituent of } \\
\text { concern (COC) }\end{array}$ & $\begin{array}{c}\text { Analytical } \\
\text { method }\end{array}$ & $\begin{array}{c}\text { Reporting } \\
\text { limit (a) }\end{array}$ & $\begin{array}{c}\text { Action level } \\
\text { concentration }\end{array}$ \\
\hline Radioisotopes (Bq/L) (cont.) & EPA 906 & 3.7 & \\
Tritium & EPA 907 & 0.0037 & MCL \\
Uranium-234 & EPA 907 & 0.0037 & MCL \\
Uranium-235 & EPA 907, & 0.0037 & MCL \\
Uranium-238 & \\
\hline
\end{tabular}

(a) The significant figures displayed in this table vary by COC. These variations reflect regulatory agency permit stipulations, or the applicable analytical laboratory contract under which the work was performed, or both. Reporting limits listed are lowest possible limits as of November 2001.

$\mathrm{SM}=$ Standard Methods, rather than EPA Methods.

$\mathrm{TBD}=$ To be determined .

$\mathrm{MCL}=$ Maximum contaminant level.

$\mathrm{RL}=$ Reporting limit. 
Table 14-2. Ground water monitoring, organic COCs by EPA analytical method.

\begin{tabular}{|c|c|c|c|}
\hline Constituent of concern & $\begin{array}{l}\text { Reporting limit } \\
(\mu \mathrm{g} / \mathrm{L})^{(\mathrm{a}, \mathrm{b})}\end{array}$ & Constituent of concern & $\begin{array}{c}\text { Reporting limit } \\
(\mu \mathrm{g} / \mathrm{L}) \\
(\mathrm{a}, \mathrm{b})\end{array}$ \\
\hline EPA Method 1664 & & Dibromochloromethane & 0.2 \\
\hline Oil \& Grease & 1,000 & Dibromomethane & 0.2 \\
\hline EPA Method 420.1 & & Dichlorodifluoromethane & 0.2 \\
\hline Phenolics & 5 & Ethylbenzene & 0.2 \\
\hline EPA Method 502.2 & & Freon 113 & 0.2 \\
\hline 1,1,1,2-Tetrachloroethane & 0.2 & Hexachlorobutadiene & 0.2 \\
\hline 1,1,1-Trichloroethane & 0.2 & Isopropylbenzene & 0.2 \\
\hline $1,1,2,2$-Tetrachloroethane & 0.2 & $m$ - and $p$-Xylene isomers & 0.2 \\
\hline 1,1,2-Trichloroethane & 0.2 & Methylene chloride & 0.2 \\
\hline 1,1-Dichloroethane & 0.2 & $n$-Butylbenzene & 0.2 \\
\hline 1,1-Dichloroethene & 0.2 & $n$-Propylbenzene & 0.2 \\
\hline 1,1-Dichloropropene & 0.2 & Naphthalene & 0.2 \\
\hline 1,2,3-Trichlorobenzene & 0.2 & $o$-Xylene & 0.2 \\
\hline 1,2,3-Trichloropropane & 0.2 & Isopropyl toluene & 0.2 \\
\hline 1,2,4-Trichlorobenzene & 0.2 & sec-Butylbenzene & 0.2 \\
\hline 1,2,4-Trimethylbenzene & 0.2 & Styrene & 0.2 \\
\hline 1,2-Dichlorobenzene & 0.2 & tert-Butylbenzene & 0.2 \\
\hline 1,2-Dichloroethane & 0.2 & Tetrachloroethene & 0.2 \\
\hline 1,2-Dichloropropane & 0.2 & Toluene & 0.2 \\
\hline 1,3,5-Trimethylbenzene & 0.2 & trans-1,2-Dichloroethene & 0.2 \\
\hline 1,3-Dichlorobenzene & 0.2 & trans-1,3-Dichloropropene & 0.2 \\
\hline 1,3-Dichloropropane & 0.2 & Trichloroethene & 0.2 \\
\hline 1,4-Dichlorobenzene & 0.2 & Trichlorofluoromethane & 0.2 \\
\hline 2,2-Dichloropropane & 0.2 & Vinyl chloride & 0.2 \\
\hline 2-Chlorotoluene & 0.2 & EPA Method 507 & \\
\hline 4-Chlorotoluene & 0.2 & Alachlor & 0.5 \\
\hline Benzene & 0.2 & Atraton & 0.5 \\
\hline Bromobenzene & 0.2 & Atrazine & 0.5 \\
\hline Bromochloromethane & 0.2 & Bromacil & 0.5 \\
\hline Bromodichloromethane & 0.2 & Butachlor & 0.5 \\
\hline Bromoform & 0.2 & Diazinon & 0.5 \\
\hline Bromomethane & 0.2 & Dichlorvos & 0.5 \\
\hline Carbon tetrachloride & 0.2 & Ethoprop & 0.5 \\
\hline Chlorobenzene & 0.2 & Merphos & 0.5 \\
\hline Chloroethane & 0.2 & Metolachlor & 0.5 \\
\hline Chloroform & 0.2 & Metribuzin & 0.5 \\
\hline Chloromethane & 0.2 & Mevinphos & 0.5 \\
\hline cis-1,2-Dichloroethene & 0.2 & Molinate & 0.5 \\
\hline cis-1,3-Dichloropropene & 0.5 & Prometon & 0.5 \\
\hline
\end{tabular}


Table 14-2. Ground water monitoring, organic COCs by EPA analytical method (cont.)

\begin{tabular}{|c|c|c|c|}
\hline $\begin{array}{l}\text { Constituent } \\
\text { of concern }\end{array}$ & $\underset{(\mu \mathrm{g} / \mathrm{L})^{(\mathrm{a}, \mathrm{b})}}{\text { Reporting limit }}$ & $\begin{array}{l}\text { Constituent } \\
\text { of concern }\end{array}$ & $\begin{array}{l}\text { Reporting limit } \\
(\mu \mathrm{g} / \mathrm{L})^{(\mathrm{a}, \mathrm{b})}\end{array}$ \\
\hline EPA Method 507 (cont.) & & Dibromomethane & 1 \\
\hline Prometryn & 0.5 & Dichlorodifluoromethane & 2 \\
\hline Simazine & 0.5 & Ethylbenzene & 1 \\
\hline Terbutryn & 0.5 & Ethylene dibromide & 1 \\
\hline EPA Method 524.2 & & Freon-113 & 1 \\
\hline 1,1,1,2-Tetrachloroethane & 1 & Hexachlorobutadiene & 1 \\
\hline 1,1,1-Trichloroethane & 1 & Isopropylbenzene & 1 \\
\hline 1,1,2,2-Tetrachloroethane & 1 & $m$ - and $p$-Xylene isomers & 1 \\
\hline 1,1,2-Trichloroethane & 1 & Methylene chloride & 1 \\
\hline 1,1-Dichloroethane & 1 & $n$-Butylbenzene & 1 \\
\hline 1,1-Dichloroethene & 1 & $n$-Propylbenzene & 1 \\
\hline 1,1-Dichloropropene & 1 & Naphthalene & 1 \\
\hline 1,2,3-Trichlorobenzene & 1 & $o$-Xylene & 1 \\
\hline 1,2,3-Trichloropropane & 1 & Isopropyl toluene & 1 \\
\hline 1,2,4-Trichlorobenzene & 1 & sec-Butylbenzene & 1 \\
\hline 1,2,4-Trimethylbenzene & 1 & Styrene & 1 \\
\hline 1,2-Dibromo-3-chloropropane & 2 & tert-Butylbenzene & 1 \\
\hline 1,2-Dichlorobenzene & 1 & Tetrachloroethene & 1 \\
\hline 1,2-Dichloroethane & 1 & Toluene & 1 \\
\hline 1,2-Dichloropropane & 1 & trans-1,2-Dichloroethene & 1 \\
\hline 1,3,5-Trimethylbenzene & 1 & trans-1,3-Dichloropropene & 1 \\
\hline 1,3-Dichlorobenzene & 1 & Trichloroethene & 0.5 \\
\hline 1,3-Dichloropropane & 1 & Trichlorofluoromethane & 1 \\
\hline 1,4-Dichlorobenzene & 1 & Vinyl chloride & 2 \\
\hline 2-Chlorotoluene & 1 & EPA Method 525 & \\
\hline 4-Chlorotoluene & 1 & 2,4-Dinitrotoluene & 0.5 \\
\hline Benzene & 1 & 2,6-Dinitrotoluene & 0.5 \\
\hline Bromobenzene & 1 & 4,4'-DDD & 0.5 \\
\hline Bromodichloromethane & 1 & 4,4'-DDE & 0.5 \\
\hline Bromoform & 1 & $4,4^{\prime}-\mathrm{DDT}$ & 0.5 \\
\hline Bromomethane & 2 & Acenaphthylene & 0.5 \\
\hline Carbon tetrachloride & 1 & Alachlor & 0.5 \\
\hline Chlorobenzene & 1 & Aldrin & 0.5 \\
\hline Chloroethane & 2 & Anthracene & 0.5 \\
\hline Chloroform & 1 & Aroclor 1016 (PCB) & 0.5 \\
\hline Chloromethane & 2 & Aroclor 1221 (PCB) & 0.5 \\
\hline cis-1,2-Dichloroethene & 1 & Aroclor 1232 (PCB) & 0.5 \\
\hline cis-1,3-Dichloropropene & 1 & Aroclor 1242 (PCB) & 0.5 \\
\hline Dibromochloromethane & 1 & Aroclor 1248 (PCB) & 0.5 \\
\hline
\end{tabular}


Table 14-2. Ground water monitoring, organic COCs by EPA analytical method. (cont.)

\begin{tabular}{|c|c|c|c|}
\hline Constituent of concern & $\begin{array}{l}\text { Reporting limit } \\
(\mu \mathrm{g} / \mathrm{L})^{(\mathrm{a}, \mathrm{b})}\end{array}$ & Constituent of concern & $\begin{array}{c}\text { Reporting limit } \\
(\mu \mathrm{g} / \mathrm{L})(\mathrm{a}, \mathrm{b})\end{array}$ \\
\hline EPA Method 525 (cont.) & & Lindane & 0.5 \\
\hline Aroclor 1254 (PCB) & 0.5 & Merphos & 0.5 \\
\hline Aroclor 1260 (PCB) & 0.5 & Methoxychlor & 0.5 \\
\hline Atraton & 0.5 & Metolachlor & 0.5 \\
\hline Atrazine & 0.5 & Metribuzin & 0.5 \\
\hline Benzo(a)anthracene & 0.5 & Mevinphos & 0.5 \\
\hline Benzo(a)pyrene & 0.5 & Pentachlorobenzene & 0.5 \\
\hline Benzo(b)fluoranthene & 0.5 & Pentachlorophenol & 0.5 \\
\hline Benzo(g,h,i)perylene & 0.5 & Phenanthrene & 0.5 \\
\hline Benzo(k)fluoranthene & 0.5 & Prometon & 0.5 \\
\hline Bis(2-ethylhexyl)phthalate & 0.5 & Prometryne & 0.5 \\
\hline Bromacil & 0.5 & Propachlor & 0.5 \\
\hline Butachlor & 0.5 & Pyrene & 0.5 \\
\hline Butylbenzylphthalate & 0.5 & Simazine & 0.5 \\
\hline Chlordane & 0.5 & Stirophos & 0.5 \\
\hline Chloropropham & 0.5 & Terbutryn & 0.5 \\
\hline Chlorpyrifos & 0.5 & Toxaphene & 0.5 \\
\hline Chrysene & 0.5 & EPA Method 547 & \\
\hline Di (2-ethylhexyl) adipate & 0.5 & Glyphosate & 20 \\
\hline Di-n-butylphthalate & 0.5 & EPA Method 601 & \\
\hline Diazinon & 0.5 & 1,1,1-Trichloroethane & 0.5 \\
\hline Dibenzo(a,h)anthracene & 0.5 & 1,1,2,2-Tetrachloroethane & 0.5 \\
\hline Dichlorvos & 0.5 & 1,1,2-Trichloroethane & 0.5 \\
\hline Dieldrin & 0.5 & 1,1-Dichloroethane & 0.5 \\
\hline Diethylphthalate & 0.5 & 1,1-Dichloroethene & 0.5 \\
\hline Dimethylphthalate & 0.5 & 1,2-Dichlorobenzene & 0.5 \\
\hline Disulfoton & 0.5 & 1,2-Dichloroethane & 0.5 \\
\hline Endosulfan I & 0.5 & 1,2-Dichloroethene (total) & 0.5 \\
\hline Endosulfan II & 0.5 & 1,2-Dichloropropane & 0.5 \\
\hline Endosulfan sulfate & 0.5 & 1,3-Dichlorobenzene & 0.5 \\
\hline Endrin & 0.5 & 1,4-Dichlorobenzene & 0.5 \\
\hline Endrin aldehyde & 0.5 & 2-Chloroethylvinylether & 0.5 \\
\hline Ethoprop & 0.5 & Bromodichloromethane & 0.5 \\
\hline Fluorene & 0.5 & Bromoform & 0.5 \\
\hline Heptachlor & 0.5 & Bromomethane & 0.5 \\
\hline Heptachlor epoxide & 0.5 & Carbon tetrachloride & 0.5 \\
\hline Hexachlorobenzene & 0.5 & Chlorobenzene & 0.5 \\
\hline Hexachlorocyclopentadiene & 0.5 & Chloroethane & 0.5 \\
\hline Indeno(1,2,3-c,d)pyrene & 0.5 & Chloroform & 0.5 \\
\hline Isophorone & 0.5 & Chloromethane & 0.5 \\
\hline
\end{tabular}


Table 14-2. Ground water monitoring, organic COCs by EPA analytical method. (cont.)

\begin{tabular}{|c|c|c|c|}
\hline Constituent of concern & $\begin{array}{l}\text { Reporting limit } \\
(\mu \mathrm{g} / \mathrm{L})^{(\mathrm{a}, \mathrm{b})}\end{array}$ & Constituent of concern & $\begin{array}{c}\text { Reporting limit } \\
(\mu \mathrm{g} / \mathrm{L})(\mathbf{a}, \mathbf{b})\end{array}$ \\
\hline EPA Method 601 (cont.) & & Dinoseb & 1 \\
\hline cis-1,2-Dichloroethene & 0.5 & MCPA & 250 \\
\hline cis-1,3-Dichloropropene & 0.5 & МСРP & 250 \\
\hline Dibromochloromethane & 0.5 & EPA Method 624 & \\
\hline Dichlorodifluoromethane & 0.5 & 1,1,1-Trichloroethane & 1 \\
\hline Freon-113 & 0.5 & 1,1,2,2-Tetrachloroethane & 1 \\
\hline Methylene chloride & 0.5 & 1,1,2-Trichloroethane & 1 \\
\hline Tetrachloroethene trans-1,2- & 0.5 & 1,1-Dichloroethane & 1 \\
\hline Dichloroethene trans-1,3- & 0.5 & 1,1-Dichloroethene & 1 \\
\hline Dichloropropene & 0.5 & 1,2-Dichlorobenzene & 1 \\
\hline Trichloroethene & 0.5 & 1,2-Dichloroethane & 1 \\
\hline Trichlorofluoromethane & 0.5 & 1,2-Dichloroethene (total) & 1 \\
\hline Vinyl chloride & 0.5 & 1,2-Dichloropropane & 1 \\
\hline EPA Method 608 & & 1,3-Dichlorobenzene & 1 \\
\hline Aldrin & 0.05 & 1,4-Dichlorobenzene & 1 \\
\hline $\mathrm{BHC}$, alpha isomer & 0.05 & 2-Butanone & 20 \\
\hline $\mathrm{BHC}$, beta isomer & 0.05 & 2-Chloroethylvinylether & 20 \\
\hline $\mathrm{BHC}$, delta isomer & 0.05 & 2-Hexanone & 20 \\
\hline $\begin{array}{l}\text { BHC, gamma isomer } \\
\text { (Lindane) }\end{array}$ & 0.05 & 4-Methyl-2-pentanone & 20 \\
\hline Chlordane & 0.2 & Acetone & 10 \\
\hline Dieldrin & 0.1 & Benzene & 1 \\
\hline Endosulfan I & 0.05 & Bromodichloromethane & 1 \\
\hline Endosulfan II & 0.1 & Bromoform & 1 \\
\hline Endosulfan sulfate & 0.1 & Bromomethane & 2 \\
\hline Endrin & 0.1 & Carbon disulfide & 1 \\
\hline Endrin aldehyde & 0.1 & Carbon tetrachloride & 1 \\
\hline Heptachlor & 0.05 & Chlorobenzene & 1 \\
\hline Heptachlor epoxide & 0.05 & Chloroethane & 2 \\
\hline Methoxychlor & 0.5 & Chloroform & 1 \\
\hline 4,4'-DDD & 0.1 & Chloromethane & 2 \\
\hline $4,4^{\prime}-\mathrm{DDE}$ & 0.1 & cis-1,2-Dichloroethene & 1 \\
\hline 4,4’-DDT & 0.1 & cis-1,3-Dichloropropene & 1 \\
\hline Toxaphene & 1 & Dibromochloromethane & 1 \\
\hline EPA Method 615 & & Dibromomethane & 1 \\
\hline $2,4,5-\mathrm{T}$ & 0.5 & Dichlorodifluoromethane & 2 \\
\hline 2,4,5-TP (Silvex) & 0.2 & Ethylbenzene & 1 \\
\hline $2,4-\mathrm{D}$ & 1 & Freon 113 & 1 \\
\hline $\begin{array}{l}\text { 2,4-Dichlorophenoxy acetic } \\
\text { acid }\end{array}$ & 2 & Methylene chloride & 1 \\
\hline Dalapon & 10 & Styrene & 1 \\
\hline Dicamba & 1 & Tetrachloroethene & 1 \\
\hline Dichloroprop & 2 & Toluene & 1 \\
\hline
\end{tabular}


Table 14-2. Ground water monitoring, organic COCs by EPA analytical method (cont.)

\begin{tabular}{|c|c|c|c|}
\hline $\begin{array}{l}\text { Constituent } \\
\text { of concern }\end{array}$ & $\begin{array}{l}\text { Reporting limit } \\
(\mu \mathrm{g} / \mathrm{L}) \\
(\mathbf{a}, \mathrm{b})\end{array}$ & $\begin{array}{c}\text { Constituent } \\
\text { of concern }\end{array}$ & $\begin{array}{l}\text { Reporting limit } \\
(\mu \mathrm{g} / \mathrm{L})(\mathrm{a}, \mathrm{b})\end{array}$ \\
\hline EPA Method 624 (cont.) & & Benzoic acid & 25 \\
\hline Total xylene isomers & 2 & Benzyl alcohol & 10 \\
\hline trans-1,2-Dichloroethene & 1 & $\begin{array}{l}\text { Bis }(2- \\
\text { chloroethoxy)methane }\end{array}$ & 5 \\
\hline trans-1,3-Dichloropropene & 1 & Bis(2-chloroisopropyl)ether & 5 \\
\hline Trichloroethene & 0.5 & Bis(2-ethylhexyl)phthalate & 5 \\
\hline Trichlorofluoromethane & 1 & Butylbenzylphthalate & 5 \\
\hline Vinyl acetate & 1 & Chrysene & 5 \\
\hline Vinyl chloride & 1 & Di- $n$-butylphthalate & 5 \\
\hline EPA Method 625 & & Di- $n$-octylphthalate & 5 \\
\hline 1,2,4-Trichlorobenzene & 5 & $\operatorname{Dibenzo}[a, h]$ a nthracene & 5 \\
\hline 1,2-Dichlorobenzene & 5 & Dibenzofuran & 5 \\
\hline 1,3-Dichlorobenzene & 5 & Diethylphthalate & 5 \\
\hline 1,4-Dichlorobenzene & 5 & Dimethylphthalate & 5 \\
\hline 2,4,5-Trichlorophenol & 5 & Fluoranthene & 5 \\
\hline 2,4,6-Trichlorophenol & 5 & Fluorene & 5 \\
\hline 2,4-Dichlorophenol & 5 & Hexachlorobenzene & 5 \\
\hline 2,4-Dimethylphenol & 5 & Hexachlorobutadiene & 5 \\
\hline 2,4-Dinitrophenol & 25 & Hexachlorocyclopentadiene & 5 \\
\hline 2,4-Dinitrotoluene & 5 & Hexachloroethane & 5 \\
\hline 2,6-Dinitrotoluene & 5 & Indeno $[1,2,3-c, d] \mathrm{p}$ yrene & 5 \\
\hline 2-Chloronaphthalene & 5 & Isophorone & 5 \\
\hline 2-Chlorophenol & 5 & $m$ - and $p$-Cresol & 5 \\
\hline 2-Methylphenol & 5 & $\begin{array}{l}N \text {-Nitroso-di- } n \text { - } \\
\text { propylamine }\end{array}$ & 5 \\
\hline 2-Methyl-4,6-dinitrophenol & 25 & Naphthalene & 5 \\
\hline 2-Methylnaphthalene & 5 & Nitrobenzene & 5 \\
\hline 2-Nitroaniline & 25 & Pentachlorophenol & 5 \\
\hline 3,3'-Dichlorobenzidine & 10 & Phenanthrene & 5 \\
\hline 3-Nitroaniline & 25 & Phenol & 5 \\
\hline 4-Bromophenylphenylether & 5 & Pyrene & 5 \\
\hline 4-Chloro-3-methylphenol & 10 & EPA Method 632 & \\
\hline 4-Chloroaniline & 10 & Diuron & 0.1 \\
\hline 4-Chlorophenylphenylether & 5 & EPA Method 8082 & \\
\hline 4-Nitroaniline & 25 & $\begin{array}{l}\text { Polychlorinated biphenyls } \\
\text { (PCBs) }\end{array}$ & 0.5 \\
\hline 4-Nitrophenol & 25 & EPA Method 8140 & \\
\hline Acenaphthene & 25 & Bolstar & 1 \\
\hline Acenaphthylene & 5 & Chlorpyrifos & 1 \\
\hline Anthracene & 5 & Coumaphos & 1 \\
\hline Benzo $[a]$ anthracene & 5 & Demeton & 1 \\
\hline Benzo $[a]$ pyrene & 5 & Diazinon & 1 \\
\hline Benzo $[g, h, i]$ perylene & 5 & Benzo $[b]$ fluoranthene & 5 \\
\hline Benzo $[k]$ fluoranthene & 5 & Dichlorvos & 1 \\
\hline
\end{tabular}


Table 14-2. Ground water monitoring, organic COCs by EPA analytical method (cont.)

\begin{tabular}{|c|c|c|c|}
\hline $\begin{array}{l}\text { Constituent } \\
\text { of concern }\end{array}$ & $\begin{array}{c}\text { Reporting limit } \\
(\mu \mathrm{g} / \mathrm{L})(\mathrm{a}, \mathrm{b})\end{array}$ & $\begin{array}{l}\text { Constituent } \\
\text { of concern }\end{array}$ & $\begin{array}{l}\text { Reporting limit } \\
(\mu \mathrm{g} / \mathrm{L})(\mathrm{a}, \mathrm{b})\end{array}$ \\
\hline EPA Method 8140 (cont.) & & Chlorobenzene & 0.5 \\
\hline Disulfoton & 1 & Chloroethane & 0.5 \\
\hline Ethoprop & 1 & Chloroform & 0.5 \\
\hline Fensulfothion & 1 & Chloromethane & 0.5 \\
\hline Fenthion & 1 & Chloroprene & 5 \\
\hline Merphos & 1 & Dibromochloromethane & 0.5 \\
\hline Methyl Parathion & 1 & Dichlorodifluoromethane & 0.5 \\
\hline Mevinphos & 1 & Ethanol & 1,000 \\
\hline Naled & 1 & Ethylbenzene & 0.5 \\
\hline Phorate & 1 & Freon-113 & 0.5 \\
\hline Prothiophos & 1 & Methylene chloride & 0.5 \\
\hline Ronnel & 1 & Styrene & 0.5 \\
\hline Stirophos & 1 & Tetrachloroethene & 0.5 \\
\hline Trichloronate & 1 & Toluene & 0.5 \\
\hline EPA Method 8260 & & Total xylene isomers & 0.5 \\
\hline $1,1,1,2$-Tetrachloroethane & 0.5 & Trichloroethene & 0.5 \\
\hline 1,1,1-Trichloroethane & 0.5 & Trichlorofluoromethane & 0.5 \\
\hline 1,1,2,2-Tetrachloroethane & 0.5 & Vinyl acetate & 20 \\
\hline 1,1,2-Trichloroethane & 0.5 & Vinyl chloride & 0.5 \\
\hline 1,1-Dichloroethane & 0.5 & cis-1,2-Dichloroethene & 0.5 \\
\hline 1,1-Dichloroethene & 0.5 & cis-1,3-Dichloropropene & 0.5 \\
\hline 1,2,3-Trichloropropane & 0.5 & trans-1,2-Dichloroethene & 0.5 \\
\hline 1,2-Dibromo-3-chloropropane & 0.5 & trans-1,3-Dichloropropene & 0.5 \\
\hline 1,2-Dichloroethane & 0.5 & EPA Method 8290 & \\
\hline 1,2-Dichloroethene (total) & 0.5 & 1,2,3,4,6,7,8-HpCDD & 0.00025 \\
\hline 1,2-Dichloropropane & 0.5 & $1,2,3,4,6,7,8-\mathrm{HpCDF}$ & 0.00025 \\
\hline 2-Butanone & 0.5 & $1,2,3,4,7,8,9-\mathrm{HpCDF}$ & 0.00025 \\
\hline 2-Chloroethylvinylether & 0.5 & $1,2,3,4,7,8-\mathrm{HxCDF}$ & 0.00025 \\
\hline 2-Hexanone & 0.5 & 1,2,3,6,7,8-HxCDD & 0.00025 \\
\hline 4-Methyl-2-pentanone & 0.5 & $1,2,3,6,7,8-\mathrm{HxCDF}$ & 0.00025 \\
\hline Acetone & 10 & $1,2,3,7,8,9-\mathrm{HxCDD}$ & 0.00025 \\
\hline Acetonitrile & 100 & $1,2,3,7,8,9-\mathrm{HxCDF}$ & 0.00025 \\
\hline Acrolein & 50 & $1,2,3,7,8-\mathrm{PeCDD}$ & 0.0001 \\
\hline Acrylonitrile & 50 & $1,2,3,7,8-\mathrm{PeCDF}$ & 0.0001 \\
\hline Benzene & 0.5 & $2,3,4,6,7,8-\mathrm{HxCDF}$ & 0.00025 \\
\hline Bromodichloromethane & 0.5 & 2,3,4,7,8-PeCDF & 0.0001 \\
\hline Bromoform & 0.5 & $2,3,7,8-\mathrm{TCDD}$ & 0.0001 \\
\hline Bromomethane & 0.5 & $2,3,7,8-\mathrm{TCDF}$ & 0.0001 \\
\hline Carbon disulfide & 5 & OCDD & 0.0005 \\
\hline Carbon tetrachloride & 0.5 & OCDF & 0.0005 \\
\hline
\end{tabular}


Table 14-2. Ground water monitoring, organic COCs by EPA analytical method. (Concluded)

\begin{tabular}{|l|c|}
\hline \multicolumn{1}{|c|}{ Constituent of concern } & $\begin{array}{c}\text { Reporting limit } \\
(\boldsymbol{\mu g} / \mathbf{L})\end{array}$ \\
\hline EPA Method 8330B
\end{tabular}

(a) The number of decimal places displayed in this table vary by constituent. These variations reflect regulatory agency permit stipulations, the applicable analytical laboratory contract under which the work

(b) was performed, or both.

These reporting limits are for water samples with low concentrations of dissolved solids. If higher concentrations are present, limits are likely to be higher.

HMX = octahydro-1,3,5,7-tetranitro-1,3,5,7-tetrazocine.

RDX = hexahydro-1,3,5-trinitro-1,3,5-triazine.

$\mathrm{TNT}=2,4,6$-trinitrotoluene.

MPN $=$ most probable number (of organisms). 


\section{Soil}

Jennifer C. Nelson

\subsection{Introduction}

Soil is an integrating medium that can contain pollutants originally released directly to the ground, to the air, or through liquid effluents. For the purpose of surveillance monitoring, "soil" is defined as the top layer of earth, suitable for the growth of plants.

Lawrence Livermore National Laboratory (LLNL) monitors and measures the radioactivity present in several aspects of the environment, including the soil. Monitoring of the soil is designed to detect any changes in environmental levels of radioactivity released from LLNL that may contribute to radiological dose to the public and environment. By monitoring distant locations not impacted by operations at LLNL, naturally occurring background radiation can be measured and used for comparison.

\subsection{Rationale and Design Criteria}

\subsubsection{Regulatory Drivers}

Soil monitoring efforts are driven by the applicable portions of Department of Energy (DOE) Order 458.1, which requires environmental surveillance be conducted to monitor the effects, if any, of DOE activities on environmental and natural resources both onsite and offsite. One major objective of DOE Order 458.1 is for DOE to operate its facilities and conduct its activities so that radiation exposures to members of the public are maintained within the limits established by the order. It is also a DOE objective that potential exposure to members of the public be as far below limits as is reasonably achievable (ALARA) and that DOE facilities have the capabilities to monitor for such releases.

Soil is specifically mentioned in the DOE guidance for environmental monitoring, Environmental Regulatory Guide for Radiological Effluent Monitoring and Environmental Surveillance (DOE 1991), as an environmental medium that should be analyzed to determine the impacts of facility operations. DOE states that "periodic sampling and analysis of indicator materials, such as soil ... should be performed to determine if there is measurable long-term buildup of radionuclides in the terrestrial environment. . . Soil sampling and analysis should be used to evaluate the long-term 
accumulation trends and to estimate environmental radionuclide inventories" (DOE 1991).

No specific guidance or regulations requiring or recommending soil monitoring for surveillance of the nonradiological environmental effects of ongoing operations have been identified. However, explicit regulatory requirements are not the sole basis for monitoring. Monitoring is carried out where there is a high level of public interest or concern, or where best management practices indicate monitoring is appropriate. Best management practice evaluations have indicated that soil samples from both sites should be evaluated for known contaminants, and that soil samples taken from location(s) at Site 300 should also be evaluated for beryllium.

\subsubsection{Monitoring Objectives}

LLNL conducts soil surveillance monitoring to evaluate long-term accumulation trends and to estimate environmental radionuclide inventories. DOE monitoring guidance specifies that nuclides in use at a facility, as well as naturally occurring nuclides, should be monitored. In particular, the guidance states: "it is desirable to assess, document, and periodically reassess the distribution and fate of radionuclides in the environment, especially plutonium in soil samples" (DOE 1991).

The most significant pathway of soil contamination, barring direct contamination by dumping (which is prevented by LLNL administrative and management controls) is a combination of deposition of materials from the air and from water. Consequently, the surveillance soils monitoring program addresses the surface of the soil on which materials can be deposited or from which materials can be resuspended. However, when air monitoring is carried out routinely, as at LLNL, soil sampling plays a supplementary role in the monitoring program (Hardy and Krey 1971).

The two primary objectives of the soil monitoring program are (1) to establish background levels of radioactive fallout radionuclides, naturally occurring radionuclides, and naturally occurring metals and (2) to assess the effects, if any, of LLNL operations on soils.

\subsubsection{Sources and Analytes}

Soil contaminants can be present in any of the three phases: solid, liquid, or gas. Various types of materials can be scoured from or settle out of the atmosphere and transported by rainfall.

At the LLNL Livermore site, the major potential sources of radionuclides are the Building 332 Plutonium Facility; the Building 331 Tritium Facility; the southeast 
quadrant, from which low levels of plutonium can be resuspended; and the Decontamination and Waste Treatment Facility (DWTF) and other waste management treatment and storage areas, from which materials can be emitted or resuspended. All soil samples are analyzed for plutonium and gamma-emitting nuclides. However, only some soil samples that are located around the perimeter of the Livermore site and a soil sample taken from the settling basin are analyzed for tritium. The tritium results are used in dose to biota calculations set forth by DOE in the guidance document, "DOE Standard: A Graded Approach for Evaluating Radiation Doses to Aquatic and Terrestrial Biota" (DOE 2002), and the RAD-BCG (Biota Concentration Guides) Calculator (Version 2). DOE sites are requested to calculate dose to biota based upon this guidance, and tritium measured in soil is one of the primary contributors to dose by this calculation. In addition, soil at these selected perimeter and settling basin locations are analyzed for gross alpha and gross beta to provide a comparison point for the data obtained from measurements in surface water. Additionally, tests for PCBs are conducted because of particular interest at a known site of contamination. There is the possibility that these materials could be transported through the vadose zone to the groundwater. (For information about PCBs, see the Environmental Protection Agency (EPA) web page http://www.epa.gov/ebtpages/pollsoilcontaminanpolychlorinatedbiphenylspcbs.html.)

The radiological analytes of interest at Site 300 are the isotopes of uranium, especially uranium-238 and uranium-235, and the ratio of these values in a given sample.

Depleted uranium (i.e., natural uranium depleted of much of the uranium-235) has historically been and is currently used in experimental tests at Site 300 . The variation of the sample ratio of uranium-235/uranium-238 from the natural ratio of 0.726 percent gives an indication of the impact of LLNL operations on the site.

Beryllium has also been used in outdoor explosive tests at Site 300. Results of dispersion measurements and modeling of beryllium from high explosive tests at Site 300 during 1991 show that these tests have a very small "footprint" and that soils testing would only show elevated levels of beryllium if the soil samples are obtained within that footprint. In addition, not all beryllium in the test shot becomes part of the explosive cloud (Baskett 1994). However, in view of the fact that some samples at locations near firing tables show increased beryllium levels, samples representing background and soils near firing table operations at Site 300 continue to be analyzed for beryllium.

\subsubsection{Collection Methods}

There are three generally accepted methods for collecting soils samples: coring, template, and trench. The coring method uses a coring tool to take samples of a 
standard volume and depth; it usually involves taking a number of samples to a depth of $5 \mathrm{~cm}$ to represent one sampling location. The template method is used in locations where the presence of rocks makes it impossible to collect samples using the coring method. The template method employs a square, cold-rolled steel template, 20 or $30 \mathrm{~cm}$ on the inner edge, to mark an area; the area is then excavated to the appropriate depth using chisels and scoops. The trench method is used to establish a depth profile. It requires digging a trench about $60 \mathrm{~cm}$ wide by $90 \mathrm{~cm}$ long by $60 \mathrm{~cm}$ deep and taking samples by pressing a flat-bottomed, three-sided pan with cutting edges on the open side into the face of the trench.

The coring method is preferred for collecting surface samples from soil. LLNL follows the coring method set out by the American Society for Testing and Materials, Standard Practice for Sampling Surface Soils for Radionuclides (ASTM 1990). The sampling technologist chooses two $1-\mathrm{m}^{2}$ areas from which to collect the sample. Surface vegetation is cleared away from the sampling area, and an LLNL-designed, stainless steel core sampler $(8.25 \mathrm{~cm}$ in diameter) is driven into the ground to a depth of $5 \mathrm{~cm}$ for each subsample. The sample is a composite consisting of ten subsamples collected individually at the four corners and the center of each square (procedure EMP-S-S, Soil and Arroyo Sediment Sampling). As previously determined by soil profiles to $30 \mathrm{~cm}$ deep, a surface sample from a depth of $5 \mathrm{~cm}$ is sufficiently deep to obtain 90 to 95 percent of airborne material, and the results are reproducible (EML 1997).

Historically, the coring method was also used to collect sediment samples. As determined by a comparison of samples taken $30-45 \mathrm{~cm}$ deep and 0-5 cm deep, a sediment sample taken $0-5 \mathrm{~cm}$ deep was sufficient to obtain materials deposited in the sediment sampling locations (Gallegos et al. 1993). For particulate radionuclide and metals analysis, the sediment coring samples were collected the same way as soil samples, except the ten subsamples were taken at 1-m intervals along a linear transect that approximates the center line of the arroyo or channel.

At location ESB, the transect is plotted to get a sample that is representative of the flow of water and resultant deposition from what is known to be a spatially heterogeneous deposition process. For tritium analysis, a soil sample is taken $5-15 \mathrm{~cm}$ deep from one core. However, because the concern being addressed by sampling for PCBs is the potential effect of sediment contamination on groundwater, and because PCBs are not present in as great a concentration at the surface as at depth, these samples are collected at $45-65 \mathrm{~cm}$ deep. 


\subsection{Extent and Frequency of Monitoring and Measurement}

\subsubsection{Sampling Locations}

No set number of soil sampling locations is required. Soil sampling locations are selected based on the following criteria:

- Proximity to LLNL and the potential for being affected by LLNL operations from wind deposition of contaminants,

- Background locations with geologically similar substrates as those near LLNL, but unlikely to be affected by LLNL operations,

- Areas of known or suspected LLNL-induced contamination, and

- Proximity to an air sampling location to enable analysis of resuspension.

Specific sampling locations should represent the geographical areas in which they are located. Some areas - such as frequently tilled or disturbed areas, locations near buildings or other obstructions, or areas with unusual wind or precipitation influences - are avoided because samples are intended to be representative of the geographical area. Practical considerations also influence the selection of sampling locations. The use of private property is discouraged because private ownership may change, and attitudes toward sampling may also change. Also, private property may be developed, rendering the location no longer useful. If a location on private property is chosen, a written access agreement is required. Government installations (federal, state, city, or regional) can be good sources of sampling locations as long as appropriate arrangements are made and development does not occur on the property. Other considerations for sampling locations include locations of underground utilities, access during inclement weather, and the safety of personnel in vehicle operation or sample collection.

Consistent sampling locations enable the evaluation of long-term trends. The LLNL environmental monitoring program soil sampling locations are shown in Figure 15-1 and Figure 15-2. Descriptions of these sampling locations have been created and are stored in the Taurus Environmental Information Management System (TEIMS). 


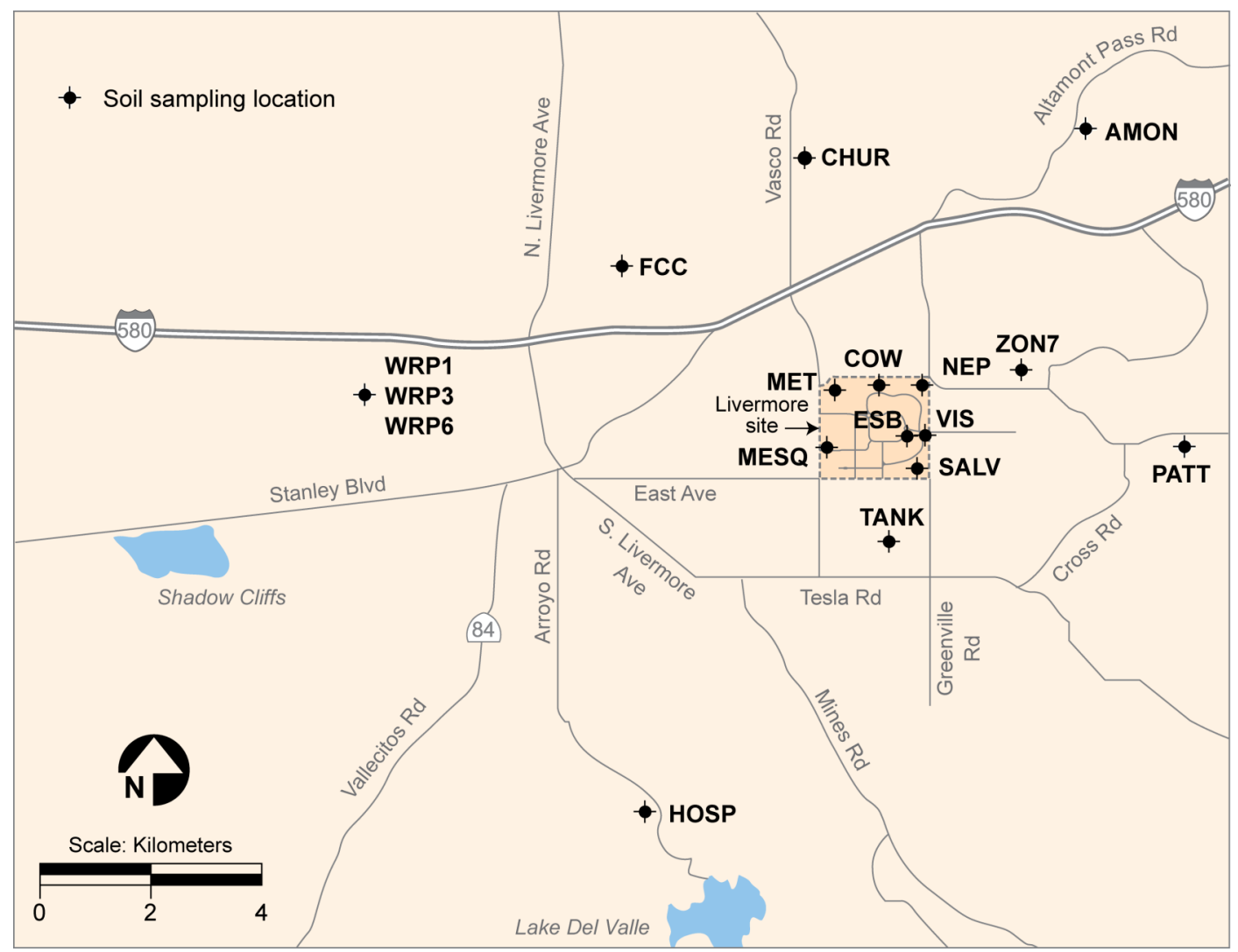

Figure 15-1. Soil sampling locations, Livermore site and Livermore Valley.

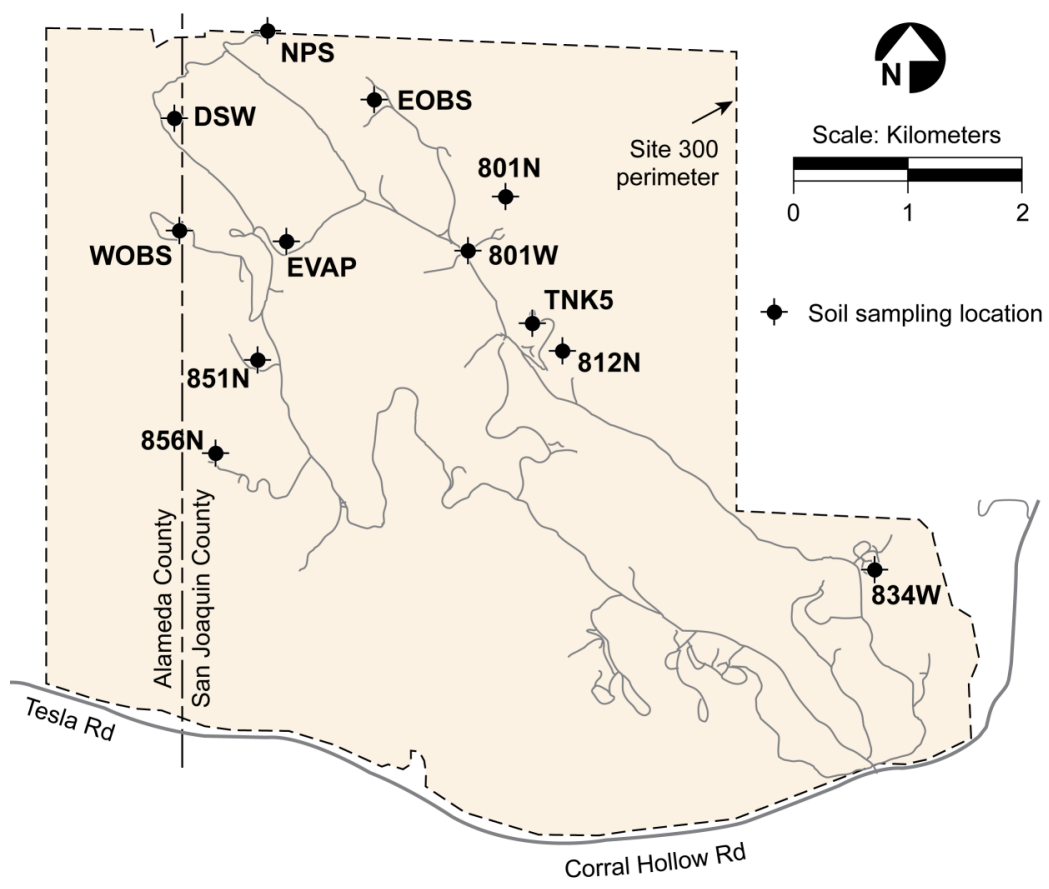

Figure 15-2. Site 300 soil sampling locations. 
Seven soil sampling locations are positioned around the Livermore site; three sampling locations are offsite in generally downwind directions; and four sampling locations are offsite in generally upwind directions, representing background locations. Two of the perimeter locations, MET and MESQ (Figure 15-1), may not both be necessary, but both are air particulate monitoring locations, and both are near offsite areas that have been developed for residential use. Location ESB was selected because it is a location where sediment collects in large volume. In addition, samples are collected at the Livermore Water Reclamation Plant (LWRP); historic releases, including an estimated 32-mCi plutonium release to the sewer in 1967, resulted in local contamination of soils in the area around the LWRP. Three locations are sampled at the LWRP to monitor the area. Construction at the LWRP site in recent years has reduced the surface area of concern; continued construction or paving the surface may remove some of these locations. Another 12 sampling locations are at Site 300 near active or historic experimental test sites and at background locations.

\subsubsection{Sampling Frequency}

Soil sampling is conducted annually, as recommended by DOE/EH-0173T (DOE 1991) for sampling that is conducted to determine trends. Soil sampling is generally conducted in the second or third quarter of each year. In these quarters, the soils are no longer extremely wet from the rainy season and new soil has been deposited. An important constraint on soil sampling is that it should not be conducted when the ambient air temperature is so high that sampling technologists will suffer heat-related stress due the physically demanding effort required to collect the samples.

\subsection{Procedures for Laboratory Analysis}

Preservation is not required for soil samples that are analyzed for particulate radionuclides. However, soil samples that are analyzed for tritium are chilled in the field and frozen until analyzed. Samples collected for PCB analysis are kept cool until analyzed; they are kept on dry ice while in the field. These samples are still refrigerated or frozen when delivered to analytical laboratories.

Soil samples to be analyzed for plutonium and gamma-emitting radionuclides have defined sample preparation requirements. These samples are dried at $100{ }^{\circ} \mathrm{C}$ for at least two days, pulverized in a grinding mill, sieved through a 32-mesh sieve, and blended. Samples for gamma analysis are packed in a tared, steel can and allowed to equilibrate for at least 30 days before counting.

Radiological analyses for soil samples are completed by LLNL's Physical and Life Sciences Environmental Monitoring Radioanalytical Laboratory (EMRL). EMRL 
follows verified analytical methods in its radiological analyses. The methods used include the following:

- Plutonium-238 and plutonium-239+240 by alpha spectroscopy following acid leaching.

- Tritium by liquid scintillation following freeze-dry extraction of the soil moisture.

- Gamma scan by EPA Method 901.1 using a high purity germanium detector. The library for the gamma scan includes 47 radionuclides and over 350 gamma rays. The radionuclides include fission products (zirconium-95, niobium-95, antimony-125, iodine-131, cesium-137, cesium-134, cerium141, cerium-144, europium-152, europium-154, and europium-155), activation products from neutron interactions on steel (manganese-54, cobalt-57, zinc-65, silver-108m, and silver-110m), actinides (plutonium239, plutonium-241, and americium-24), and naturally occurring radionuclides (beryllium-7, potassium-40, uranium-235, uranium-238, thorium-232, radium-226, and radium-228). In addition, any peaks not identified in the standard library are manually identified from other references. So effectively all radioisotopes that emit gammas above minimum detectable limits are being scanned, regardless of the gamma library used.

Nonradiological analyses are performed by off-site laboratories using standard EPA methods. Analysis of polychlorinated biphenyls is by EPA Method 8082. Beryllium content is determined by atomic emission spectrometry (EPA Method 6010B). Chainof-custody procedures are followed throughout the sampling, delivery, and analytical processes.

\subsection{Data Quality Assurance}

\subsubsection{Precision}

The detection limits for radionuclides in soils are shown in Table 15-1.

A lower detection limit for uranium-238 would be advantageous because it would be useful to have well-characterized background values. However, the current detection limit is sufficient to determine impacts on areas affected by LLNL operations, and the expense of analytical methods with more sensitive detection limits is not justified. 
The detection limit for beryllium in soils is $0.5 \mathrm{mg} / \mathrm{kg}$. The detection limit for PCBs is $0.1 \mathrm{mg} / \mathrm{kg}$. If there were a need for sampling for metals, the detection limits would be specified by analytical contract.

Table 15-1. Detection limits for radionuclides in soil.

\begin{tabular}{|l|c|}
\hline Radionuclide & Detection Limit (Bq/g) \\
\hline${ }^{239+240} \mathrm{Pu}$ & $1.0 \times 10^{-6}$ \\
${ }^{137} \mathrm{Cs}$ & $1.0 \times 10^{-4}$ \\
${ }^{238} \mathrm{U}$ & $2.0 \times 10^{-2}$ \\
${ }^{235} \mathrm{U}$ & $2.0 \times 10^{-4}$ \\
${ }^{232} \mathrm{Th}$ & $1.0 \times 10^{-3}$ \\
${ }^{40} \mathrm{~K}$ & $1.0 \times 10^{-2}$ \\
${ }^{3} \mathrm{H}$ & $1.7(\mathrm{~Bq} / \mathrm{L}$ of extracted moisture $)$ \\
\hline
\end{tabular}

In accordance with LLNL procedure EMP-S-S, Soil Sampling, field duplicate samples are submitted with each batch of soil samples. At locations chosen for duplicate samples, two identical samples are collected. Adjacent cores are collected from the corners and the center of the sampling square. Separate composites of ten cores each are made, and the two samples are identified with unique sample identifier codes. Similarly, duplicate 10-g aliquots for beryllium analyses are produced. The sampling locations of field duplicate samples are not identified on the sample bags, the sample identification tags, or vial labels, so that the analytical laboratory does not know where the samples originated (procedure EMP-QA-DM, Sample and Data Management). However, this information is recorded on field tracking forms (FTFs), which are filled out in the field by the sampling technologist and which contain detailed information about actual sampling locations and other conditions affecting sampling. Approximately 10 percent of samples are field duplicates. After the results are obtained, the ratios of the individual sample pairs (of greater-than-detection-limit results) are averaged; the average ratio should be between 0.7 and 1.3 . If the average is not within this range, the data are first examined for transcription errors; and then the analytical laboratory is contacted to discuss any problems that may have occurred during analysis. Continued ratios outside the range may indicate problems with the analytical method and require further investigation.

The analytical laboratory creates laboratory duplicates (also called splits) in accordance with the laboratory standard operating procedures. Laboratory duplicates are introduced blind into the sample processing at a rate of about 10 percent of samples. Results from duplicate samples are compared according to procedure CES-SOP-P500, CES Control Charts. 


\subsubsection{Accuracy}

Soil is not very amenable to the creation of field blank and spike samples. It is virtually impossible to create a blind field blank that would not be immediately obvious to the analytical staff. In addition, blank soil samples from the National Institute for Standards and Technology (NIST) are very expensive (on the order of $\$ 10-\$ 15$ per gram). Because about $300 \mathrm{~g}$ per sample are needed, the use of blank soil samples gets very expensive and, furthermore, is of little value because the blank soil is physically different from the soils collected in the Livermore Valley and Site 300.

Field spikes are also very difficult to prepare due to the heterogeneity of soils and the difficulty of evenly dispersing any known amount of material in soil.

The radioanalytical laboratory does run blank and standard reference NIST-traceable samples, as do the nonradiological laboratories. For example, NIST "Environmental Radioactivity River Sand" is used as a primary standard for gamma soils analysis.

The radioanalytical laboratory also participates in the DOE Environmental Measurements Laboratory Quality Assurance Program. In these studies, the DOE sends samples with known amounts of radionuclides to the participating laboratories, compares the analytical results (thereby determining the accuracy of the various participating laboratories), and publishes reports of the results so that analytical laboratory personnel, and their customers, can evaluate the analytical laboratory's relative performance.

\subsubsection{Completeness}

In general, all soil samples that are planned to be collected are actually collected. Exceptions can occur where the location has been developed (and is no longer undisturbed) or is inundated with water. With respect to laboratory analyses, the Environmental Functional Area (EFA) requires that 90 percent of the samples submitted to, and analyzed by, EMRL yield valid data.

\subsubsection{Calibration}

Equipment in the EMRL is calibrated with sources that are traceable to NIST. Calibration follows a variety of methods, from calibration by a certified third party, to calibration with known standards that are made from traceable materials. Calibration practices are in accordance with standard procedures, and records are maintained for each piece of calibrated equipment. 


\subsection{Program Implementation Procedures}

The primary responsibility for activities related to the soil and sediment monitoring network is assigned to a Water, Air, Monitoring and Analysis (WAMA) environmental analyst. The analyst is responsible for the design, implementation, and correct operation of the network; the analysis and evaluation of all monitoring results; data trending; documentation; and reporting. The following is a list of the procedures associated with the sampling network:

- EMP-S-S, Soil Sampling: Details of sampling, processing, and documentation for radiological and beryllium air particulates.

- EMP-QA-DM, Sample and Data Management: Details how samples are handled, stored, and delivered.

In conjunction with the sampling procedures, the handling and validity of soil samples are documented using field tracking forms and chain of custody forms.

\subsection{Action Levels}

Sample results are compared to the running historic geometric means for the Livermore site and Site 300 locations for lognormally distributed materials such as plutonium-239, cesium-137, uranium-235, thorium-232, and beryllium. Separate uranium and thorium values are stated for the Livermore site and Site 300 because the underlying geology is different and these differences are reflected in the amounts of naturally occurring uranium and thorium that are present. The 5-year running mean and standard deviation for radionuclides in soils for the years 2000 through 2004 are shown in Table 15-2. (Results for naturally occurring and fallout materials are consistent from year to year and can be used as an indicator of sampling or analytical problems.)

The 5-year running historic geometric mean and standard deviation for beryllium at most Site 300 sampling locations are 0.56 and 1.6, respectively, and for the Building 812 area (an area of known contamination) are 4.2 and 9.2, respectively.

Any results for lognormally distributed analytes outside two geometric standard deviations of the mean (a warning level) are examined for data transcription errors, and the analytical lab is contacted to discuss any problems that may have occurred during analysis. Any results outside three geometric standard deviations (the action level) are also subject to examination for transcription errors and analytical problems. In addition, the location is resampled, perhaps in duplicate or triplicate, depending on the nature of the problem. For normally distributed materials, such as potassium-40, the results are compared to a running arithmetic mean and standard deviation, with the same warning and action levels. If no transcription, analytical, or other error is found to explain an 
out-of-limit value, the environmental analyst notifies EFA management and further action, such as a special study in the area of the problematic sample, may be taken with concurrence by EFA management.

Table 15-2. Geometric mean and standard deviation for radionuclides, 2000-2004

\begin{tabular}{|l|c|c|}
\hline \multicolumn{1}{|c|}{ Radionuclide } & Geometric Mean (Bq/g) & Standard deviation \\
\hline${ }^{239}+240 \mathrm{Pu}$ & $5.95 \times 10^{-5}$ & 3.8 \\
${ }^{239+240} \mathrm{Pu}(\mathrm{LWRP}){ }^{(a)}$ & $1.72 \times 10^{-3}$ & 3.1 \\
${ }^{137} \mathrm{Cs}$ & $1.10 \times 10^{-3}$ & 3.1 \\
${ }^{238} \mathrm{U}$ (Livermore site) & $2.02 \times 10^{-2}$ & 1.4 \\
${ }^{238} \mathrm{U}$ (Site 300) & $3.19 \times 10^{-2}$ & 1.7 \\
${ }^{238} \mathrm{U}$ (B812) & $5.60 \times 10^{-1}$ & 2.3 \\
${ }^{235} \mathrm{U}$ (Livermore site) & $1.34 \times 10^{-3}$ & 1.3 \\
${ }^{235} \mathrm{U}$ (Site 300) & $1.99 \times 10^{-3}$ & 1.5 \\
${ }^{235} \mathrm{U}$ (B812) & $8.01 \times 10^{-2}$ & 2.2 \\
${ }^{232} \mathrm{Th}$ (Livermore site) & $2.55 \times 10^{-2}$ & 1.3 \\
${ }^{232} \mathrm{Th}$ (Site 300) & $3.88 \times 10^{-2}$ & 1.2 \\
${ }^{3} \mathrm{H}$ & $5.90 \times 10^{0}(\mathrm{~Bq} / \mathrm{L})$ & 2.7 \\
${ }^{40} \mathrm{~K}$ (a) & $4.27 \times 10^{-1}$ & 0.077 \\
\hline
\end{tabular}

(a) The arithmetic mean and standard deviation are shown for ${ }^{40} \mathrm{~K}$.

(a) LWRP = Livermore Water Reclamation Plant.

\subsection{Preparation and Disposition of Reports}

The environmental analyst analyzes the monitoring results after all the results for the calendar year are obtained. The results are reported in annual Environmental Report. No other reporting for soil data is required.

\subsection{Future Plans}

The short-term plan for soil sampling is to continue monitoring soil in the manner described in this chapter.

Long-term plans include following the development of federal and regional soil policies to ensure that soil monitoring is conducted in an appropriate manner. An additional long-term plan is to keep up-to-date with changes in LLNL operations and to add and remove sampling locations as indicated by operational impacts or changes in sampling conditions. 


\subsection{References}

ASTM (1990), Standard Practice for Sampling Surface Soils for Radionuclides, American Society for Testing and Materials, Philadelphia, PA (C 998-90).

Baskett, R. L. (1994), Atmospheric and Geological Sciences Division, Lawrence Livermore National Laboratory, Livermore, CA, private communication, September 8, 1994.

DOE (1991), Environmental Regulatory Guide for Radiological Effluent Monitoring and Environmental Surveillance, U. S. Department of Energy, Washington, D. C. (DOE/EH-0173T).

DOE (2002), "A Graded Approach for Evaluating Radiation Doses to Aquatic and Terrestrial Biota, " U. S. Department of Energy, Washington, D. C. (DOE-STD1153-2002). Available at http://www.hss.doe.gov/nuclearsafety/ns/techstds/standard/std1153/1153.htm

EML (1997), Procedures Manual, 28th ed., Vol. 1, Environmental Measurements Laboratory, New York, NY (HASL-300). Available at http://www.eml.st.dhs.gov/publications/procman.cfm

Hardy, E. P., and P. W. Krey (1971), "Determining the Accumulated Deposit of Radionuclides by Soil Sampling and Analysis," Proceedings of Environmental Plutonium Symposium, Los Alamos National Laboratory, Los Alamos, NM (LA-4756), U.S. Department of Energy, Oak Ridge, TN (DOE/TIC-11223).

Gallegos, G. M., S. M. Wander, B. K. Balke, E. Christofferson, P. J. Tate, K. A. Surano, R. J. Harrach, L. M. Garcia, B. C. Fields, W. G. Hoppes, R. A Failor (1993), Environmental Report 1992, Lawrence Livermore National Laboratory, Livermore, CA (UCRL-50027-92). 


\section{Vegetation and Foodstuff}

Tony Wegrecki

\subsection{Introduction}

Vegetation and foodstuff monitoring is part of a comprehensive and ongoing environmental monitoring program for Lawrence Livermore National Laboratory (LLNL) (see Chapter 1). Data from the vegetation and foodstuff network are used to demonstrate compliance with regulatory requirements and to calculate doses that evaluate the effect of LLNL operations on human health and the environment.

Sampling and analysis of vegetation and foodstuff can provide information about the presence and movement of radionuclides released to the environment. At LLNL, vegetation and wine are part of the environmental pathway from atmospheric releases of radionuclides to ingestion dose. Concentrations of radionuclides in vegetation can be used to estimate concentrations in edible plant and animal products and consequent potential dose to humans from ingestion of a normal diet. Although the ingestion of wine may be just a small fraction of the total diet, wine is the most important agricultural product in the Livermore Valley. Since monitoring of wine began in 1977, data have indicated that, although tritium concentrations in all wines are low, Livermore Valley wines contain statistically more tritium than do their California counterparts. Therefore, local wines are monitored to demonstrate the small but measurable effect of LLNL operations on wine.

In the past, other foodstuffs (cow milk, goat milk, and honey) leading to potential dose were also monitored for tritium. At present, however, honey and milk are not commercially produced in the vicinity of LLNL, so only tritium concentrations in vegetation and wine are used to assess potential ingestion dose from tritium emitted during LLNL operations.

\subsection{Vegetation Monitoring Program}

\subsubsection{Rationale and Design Criteria for Vegetation Monitoring}

\subsubsection{Regulatory Drivers}

The regulatory driver for vegetation and foodstuff monitoring is the applicable portions of Department of Energy (DOE) Order 458.1 (Change 2). Guidance for monitoring specific terrestrial foods appropriate for surveillance sampling and analysis is provided in the DOE's Environmental Regulatory Guide for Radiological Effluent Monitoring and Environmental Surveillance (DOE 1991). The DOE guidance calls for pathway analyses of important 
agricultural products grown within $16 \mathrm{~km}$ of the site. Although milk is considered the most important pathway-significant agricultural product, it is no longer included in the LLNL monitoring program because no dairy cows are found within $16 \mathrm{~km}$ of the Livermore site. LLNL thus samples vegetation, the second most important agricultural product within $16 \mathrm{~km}$. When locally grown vegetables, grains or fruit do not contribute significantly to diet, as is the case with LLNL, DOE guidance states that native (or, more correctly, non-cultivated) vegetation can be used as an indicator species.

\subsubsection{Monitoring Objectives}

The primary purpose of vegetation monitoring is to evaluate the potential ingestion dose to people from radionuclides that enter the food chain through vegetation. Secondary purposes are to determine if the radionuclide is behaving as expected in the environment, to evaluate longterm accumulation trends, and to estimate environmental radionuclide inventories.

\subsubsection{Sources and Analytes}

Tritium is the only nuclide released from LLNL that can be detected in vegetation. Most uptake is from tritium released to the atmosphere from LLNL's ongoing operations, but in a few locations uptake is from tritium-contaminated groundwater. Tritium moves through the environment as tritiated water (HTO). As such, it is easily assimilated into plant water. Through photosynthesis, tritium is incorporated into the organic matter of plants. Tritiated water and organically bound tritium (OBT) are readily transferred to animals that eat vegetation exposed to tritium in air or soil water. A fraction of the radiation dose to human beings results from ingestion of contaminated plant or animal products.

Organically bound tritium in vegetation is not measured by LLNL. Analyzing for OBT is more time-consuming and labor-intensive than analyzing for HTO, and, given the minimal risk to the public from LLNL's low levels of tritium, models can be used to estimate OBT concentrations. Although the dose per unit intake of OBT is about 2.3 times higher than dose per unit intake of HTO (ICRP 1996), the OBT contribution from the diet is unlikely to increase the tritium dose to the public by more than a factor of two (ATSDR 2002).

At LLNL's Livermore site, the major contributors to airborne tritium emissions are routine emissions from the Tritium Facility (Building 331 and its associated operations) and the Building 612 Radioactive and Hazardous Waste Management Yard. Tritium is also present at Site 300. The planned activities at the National Ignition Facility are anticipated to have emissions of tritium of about $30 \mathrm{Ci} / \mathrm{y}$, which will be of similar magnitude to past emissions from the Tritium Facility.

There are no measureable particulate radionuclide emissions from LLNL operations at the Livermore site, but there is some resuspension of plutonium-contaminated soils in the southeast quadrant. At Site 300, the primary radionuclide of concern for surveillance 
of ongoing activities is uranium, which is used in tests at the site. Plutonium and uranium are not of concern in vegetation surveillance monitoring because they are only slightly soluble, leading to minimal plant uptake. In addition, their low solubility also results in a low ingestion dose. For dose calculations, the fractional uptake from the small intestine to blood for common chemical forms ranges from 0.002 to 0.05 for uranium and 0.00005 to 0.003 for plutonium (EPA 1988). Inhalation of these radionuclides is a much more significant environmental pathway, and the air is monitored for these radionuclides. (See Chapters 3, 4, and 5)

Emission levels of nonradiological materials at LLNL do not warrant routine monitoring. An evaluation of air deposition to vegetation for a variety of volatile organic compounds was conducted for the Health Risk Assessment for Hazardous and Mixed Waste Management Units at Lawrence Livermore National Laboratory (McDowell-Boyer et al. 1995). The evaluation, based on an assumed $1 \mathrm{mg} / \mathrm{m}^{3}$ concentration in air, showed that the ingestion pathway accounts for less than 1 percent of the overall risk calculated for these compounds. Furthermore, the AB2588 Air Toxics Risk Screening Document for Lawrence Livermore Laboratory, Plant 255 (LLNL 1991) indicates that LLNL's actual concentrations of volatile organic chemicals in air at the point of maximum impact would be three orders of magnitude to several times lower than $1 \mathrm{mg} / \mathrm{m}^{3}$.

\subsubsection{Collection Methods}

Preferentially, the green, leafy material of grass and other vegetation is collected. Leaves of different types of plants will exhibit similar tritium concentrations in their plant water, so the vegetation sampled does not have to be edible. Since water is easily extracted from plants, it is the tritium in the free water of plants that is measured. Tritium concentrations in plant water rapidly reach equilibrium with tritium in air moisture. Therefore, collection methods used by the sampling technologists are designed to avoid contamination of the sample and ensure that the sample is sealed in a plastic bag so that no exchange can occur between the tritium in the plant water (at time of sampling) and air after leaving the sampling location. The sample is also placed on dry ice in the field to freeze it as quickly as possible to prevent the loss of tritiated water to the sample container.

Because the concentrations of HTO found in leaves are normally higher than those observed in fruits, vegetables, root crops and grain for the same tritium concentration in air moisture (Peterson and Davis 2002), dose estimates based on HTO concentrations in leaves will be more health protective than those based on measured HTO in other edible plant parts.

\subsubsection{Extent and Frequency of Vegetation Monitoring and Measurement}

To assess doses from ingestion of tritium in vegetation, LLNL primarily monitors annual grasses, the occasional forb, and a few leafy vegetables. Noxious plants (e.g., poison oak, stinging nettles) are not sampled to avoid injury to the sampling technologists. The potential for seasonal variability for vegetation is addressed through quarterly sampling. Only plants that 
are green (i.e., living) are sampled. In dry summer months, mostly deep-rooted plants are sampled, because most grasses are dried. Duplicate samples are collected from each location. In addition, sets of quality assurance (QA) duplicates are collected each quarter from one onsite, one Livermore Valley, and one Site 300 location.

The vegetation locations for the area in and around the Livermore site comprise three groups (see Figure 16-1). The first group, "Near," includes locations onsite or within $1 \mathrm{~km}$ of the Livermore-site perimeter (AQUE, GARD, NPER, MESQ, MET, and VIS). The "Intermediate" group consists of locations in the Livermore Valley that are removed from the site (1 to less than $5 \mathrm{~km}$ from the Livermore site perimeter), but close enough and often downwind so that they are still potentially under the influence of tritium releases at the site. The "Intermediate" locations are I580, TESW, ZON7, and PATT. The third group, "Far," represents locations highly unlikely to be affected by LLNL operations. One background location (CAL) is more than $25 \mathrm{~km}$ away, while the other (FCC) is about $5 \mathrm{~km}$ upwind of the Livermore site perimeter.

From December 1996 through the last quarter of 2004, two pine trees on the Livermore site were monitored for tritium. PIN1 is rooted in a location of known elevated tritium concentrations in soil and groundwater near Building 292 and is a small diffuse source of tritium; PIN2, at the VIS location, was sampled for direct comparison. Through 2002, miniscule doses at the perimeter fence were estimated based on potential ingestion of hypothetical foodstuffs contaminated by tritium released from PIN1. In 2003, dose calculations using PIN1 as a source were discontinued because LLNL obtained permission from the Environmental Protection Agency to demonstrate compliance by using air monitoring data in place of modeling dose from releases from small sources. Sampling of both pine trees was discontinued accordingly. 


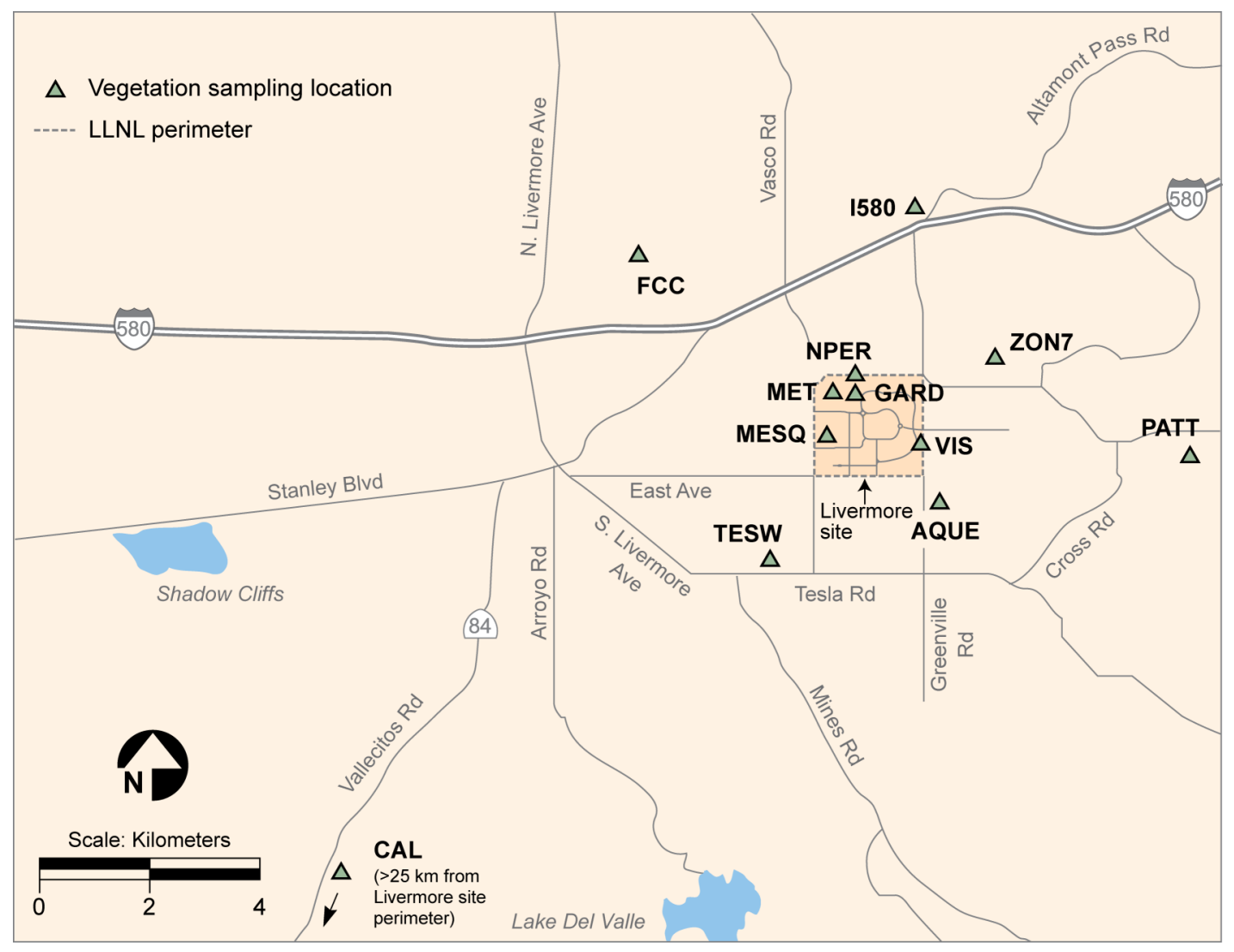

Figure 16-1. Vegetation sampling locations, Livermore site and surroundings.

At Site 300, most sampling locations historically have exhibited natural background tritium levels in vegetation. At present, background tritium concentrations are monitored at locations TNK5 and PSTL (Figure 16-2), and any changes in operations should be detected at these locations. The vegetation at locations DSW and EVAP (Figure 16-2) may have elevated tritium concentrations due to root uptake from contaminated groundwater. From 1971 until 1994, vegetation samples from location DSW consistently exhibited much higher than background concentrations of tritium. Location DSW is adjacent to a landfill that contains debris contaminated with tritium from past experiments and is included in the investigation for contaminated groundwater under the Comprehensive Environmental Response, Compensation, and Liability Act (CERCLA) (see annual Environmental Report, Compliance Summary chapter). More recently, vegetation samples from location DSW have exhibited variable concentrations, ranging from relatively high to not detectable. Similarly, since sampling began in 1993, samples from the location EVAP have shown both higherthan-background tritium values as well as non-detects. The highest concentrations apparently occur when plants with roots that reach the water table are sampled randomly. 


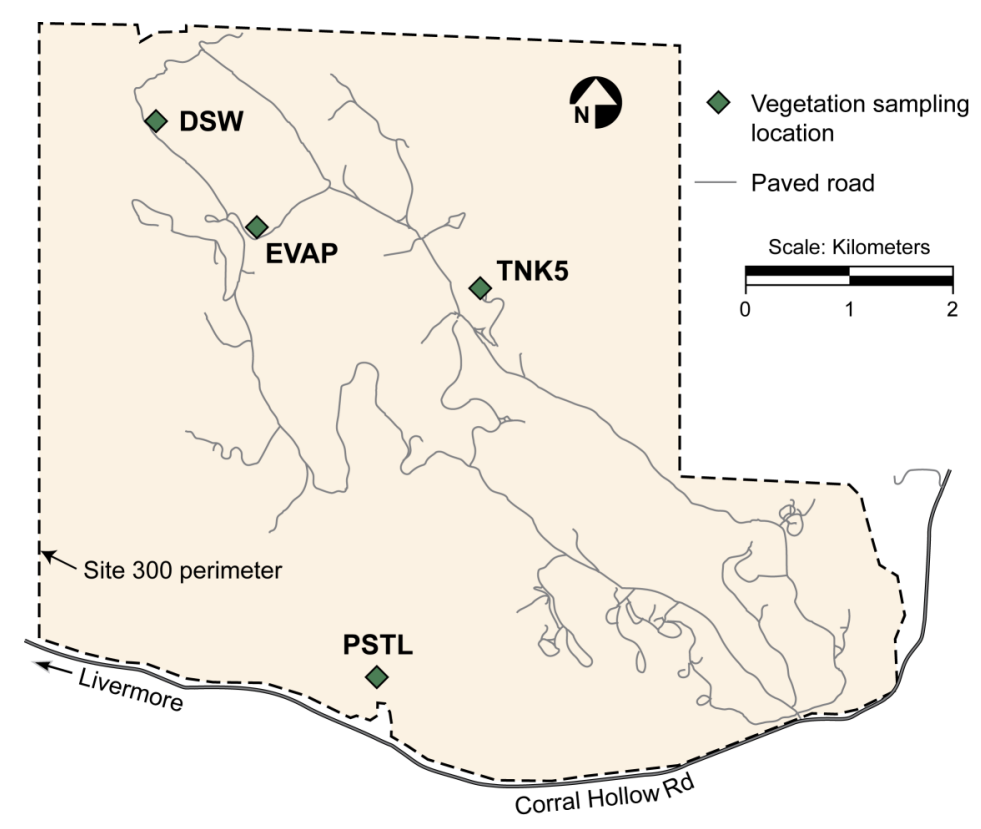

Figure 16-2. Site 300 vegetation sampling locations.

Consistent use of the same sampling locations allows for better trending of data and closer monitoring of areas of concern. A detailed description of all past and present sampling locations is maintained in a database. The EMP-QAS-LOC, Locations Database SOP Supplement, describes the process to be used for defining, documenting, and approving sampling locations. All vegetation sampling locations are marked with permanent location markers. The requirements for a good sampling location are described in the procedure EMPVG-S, Vegetation and Foodstuff Sampling.

\subsubsection{Procedures for Laboratory Analysis}

Two bags of frozen, labeled samples of vegetation from each sampling location are delivered to the onsite Environmental Monitoring Radioanalytical Laboratory (EMRL). The vegetation is stored in a non-frost-free freezer until analysis. One bag of vegetation is analyzed, and the other is archived by the analytical laboratory. Vegetation samples are weighed on properly maintained and calibrated balances (SOP-CES-P542, CES Balances). Tritiated water is extracted from the samples by freeze-drying samples (CES-EM-P542, Low Level Tritium Analysis -Freeze Dry) in the laboratory. The samples are then analyzed for tritium by liquid scintillation counting (SOPEM-P552, Operation of Packard Tri-Carb LSC for Environmental Samples). Concentrations are reported in $\mathrm{pCi} / \mathrm{L}$ extracted plant water and in $\mathrm{pCi} / \mathrm{g}$ dry weight vegetation both in hard copy and electronically to the Environmental Functional Area (EFA) Data Management Team (DMT). 


\subsubsection{Data Quality Assurance}

\subsubsection{Precision}

The reporting limit for tritium in vegetation is about $2.2 \mathrm{~Bq} / \mathrm{L}(59 \mathrm{pCi} / \mathrm{L})$. In accordance with LLNL procedure EMP-VG-S, Vegetation and Foodstuff Sampling, field duplicate samples are submitted with each batch of vegetation samples. Approximately 10 percent of samples are field duplicates. Two "identical" samples are collected at locations chosen for duplicate samples. The sampling locations of field duplicate samples are not identified so the analytical laboratory does not know where the samples originated (EMP-QA-DM, Sample and Data Management). However, this information is recorded on field tracking forms (FTFs), which are filled out in the field by the sampling technologist and which contain detailed information about actual sampling locations and other conditions affecting sampling. After the results are obtained, the concentrations of duplicates are compared. Either analytical error or natural variability is the most likely cause of different concentrations, because sampling vegetation is simple and straightforward. When the source of the tritium is atmospheric, the difference between duplicate samples usually can be explained by analytical error. This is invariably true when concentrations are near the detection limits, which occurs much of the time in the vegetation network. When one of the results in a pair is a nondetection, the other result should be less than two times the detection limit (see annual Environmental Report, Quality Assurance chapter). When the source of the tritium is soil water, as at locations DSW and EVAP, natural variability will be the cause of any large differences in the concentrations of the duplicates (up to a factor of three, historically, although usually less than a factor of two). These differences are to be expected because the roots of even adjacent plants may reach water of different concentrations. Given the variability in the field from a groundwater source and the rapid exchange of HTO between air and vegetation when the tritium source is atmospheric, resampling cannot resolve any differences. If the magnitude of the differences cannot be explained, the analytical laboratory is contacted to discuss any problems that may have occurred during analysis.

The analytical laboratory creates laboratory duplicates (also called splits) in accordance with SOP-EM-P542, Low Level Tritium Analysis - Freeze Dry. Laboratory duplicates are introduced blind into sample processing at a rate of about 10 percent of samples. The relative error ratio is calculated and reported for each split sample. If the control limit of 3.0 for the Relative Error Ratio is exceeded, the source of the problem is investigated and corrected (SOPCES-P810, Data Validation and SOP-CES-P811, Data Verification).

\subsubsection{Accuracy}

The radioanalytical laboratory runs blank and control samples traceable to standards of the National Institute of Standards and Technology (NIST). There are no field or laboratory blanks for vegetation, but, to compensate for this, the laboratory analyzes vegetation samples concurrently with air monitoring samples, with a silica gel blank serving as the laboratory 
blank for both media (see Chapter 5). Currently, no field spikes are prepared due to the difficulty of evenly dispersing any known amount of tritium in vegetation, but laboratory spikes made from blanks with standards added are counted.

The radioanalytical laboratory also participated in the DOE Environmental Measurements Laboratory (EML) Quality Assurance Program (SOP-CES-P820, CES Performance Evaluation Program), which ran from 1976 to 2004. For tritium, the DOE sent water samples with known concentrations to the participating laboratories, compared the analytical results (thereby determining the accuracy of the various participating laboratories), and published reports of the results so that analytical laboratory personnel and their customers could evaluate their analytical laboratory's relative performance. The results of the study were published on the EML web site http://www.eml.st.dhs.gov/qap/.

\subsubsection{Completeness}

$100 \%$ of all vegetation samples are collected routinely. However, it may be time-consuming to sample during the driest periods of the year when a large area must be covered to collect an adequate mass of growing vegetation. With respect to laboratory analyses, the Water, Air, Monitoring and Analysis (WAMA) group of EFA requires that ninety percent of the samples submitted to and analyzed by EMRL yield valid data.

\subsubsection{Calibration}

Equipment in the EMRL is calibrated with sources that are traceable to NIST. Calibration follows a variety of methods, from calibration by a certified third party, to calibration with known standards that are made from traceable materials. Calibration practices are in accordance with standard procedures, and records are maintained for each piece of calibrated equipment.

\subsubsection{Program Implementation Procedures}

The primary responsibility for activities related to vegetation monitoring is assigned to an environmental analyst in WAMA. The analyst is responsible for the following:

- Designing, implementing, and maintaining the sampling network.

- Determining analytes, collection methods, and analytical methods.

- Coordinating network activities with sampling technologists and analytical laboratory personnel.

- Reviewing and analyzing the data.

- Performing dose assessments.

- Following trends in data.

- Reporting results. 
Vegetation is collected according to LLNL procedure EMP-VG-S, Vegetation and Foodstuff Sampling, which is reviewed annually, and revised at least once every three years. Vegetation is submitted for analyses using sample control, chain-of-custody (COC), and documentation procedures (EMP-QA-DM, Sample and Data Management). The written procedures include requirements for sample collection and submittal for chemical analysis, keeping a log, and filling out FTFs and COC forms. The procedures also require the sampling technologist to alert the environmental analyst about difficulties encountered during any sampling.

\subsubsection{Action Levels}

Sample results are compared to the 5-year historic geometric mean for each sampling group in the vegetation monitoring networks ("Near," "Intermediate," or "Far" for Livermore site vegetation; "General," EVAP, or DSW for Site 300 vegetation). As discussed in Section 16.2.2, plants at DSW and EVAP are growing in locations of known groundwater contamination. Thus their action levels need to be calculated separately. Geometric means, standard deviations, warning limits, and action levels for 1999 through 2003 are provided in Table 16-1.

Table 16-1. Geometric means, geometric standard deviations, and upper warning and action limits for vegetation sampling groups (1999-2003).(a)

\begin{tabular}{|l|c|c|c|c|}
\hline \multicolumn{1}{|c|}{ Group } & $\begin{array}{c}\text { Geometric Mean } \\
\text { (Bq/L) }\end{array}$ & $\begin{array}{c}\text { Geometric } \\
\text { Standard } \\
\text { Deviation }\end{array}$ & $\begin{array}{c}\text { Warning Limit } \\
\text { (upper) }\end{array}$ & $\begin{array}{c}\text { Action } \\
\text { Limit (upper) }\end{array}$ \\
\hline LLNL vegetation & & & 34 & 120 \\
Near & 2.6 & 3.5 & 14 & 41 \\
Intermediate & 1.6 & 2.8 & 22 & 130 \\
Far & 0.66 & 5.5 & & 63 \\
Site 300 vegetation & & & 15 & 110,000 \\
General & 0.86 & 4.0 & 6,700 & 23,000 \\
DSW & 26 & 15 & 2,300 & \\
EVAP & 24 & 9.2 & & \\
\hline
\end{tabular}

(a) The 1999 to 2003 data are representative of anticipated future conditions.

Any results outside two geometric standard deviations (a warning level) are examined for data transcription errors, and the analytical lab is contacted to discuss any problems that may have occurred during analysis. In addition, an attempt is made to determine if the result could have been caused by an unusual release or wind patterns. If a release occurred, other locations may have been affected to some degree; as well, the release will probably have been detected by another sampling network (e.g., air tritium). No further action need be taken unless the warning limit is exceeded at the next quarterly sampling. In this case, a special study to determine the source of the tritium is warranted. Any results outside three geometric standard deviations (the action level) are also subject to examination for transcription errors, analytical problems, and unusual releases and/or wind patterns. In addition, the location is resampled, perhaps in 
duplicate or triplicate depending on the nature of the problem. If no explanation is found for the out-of-limit value, the environmental analyst notifies EFA management, and further action, such as a special sampling study, may be taken.

\subsubsection{Preparation and Disposition of Reports}

The environmental analyst conducts ingestion dose assessments, based on the monitoring data and using methods detailed in guidance document EMP-R-DA, Radiological Dose Assessment Guidance Document, for vegetation once all data for a calendar year are obtained. Data are analyzed based on EMP-QA-D, Data Analysis. The monitoring and dose assessment results are reported in the annual Environmental Report.

No other reporting is required for vegetation.

\subsubsection{Future Plans}

The short-term plan for vegetation sampling is to continue monitoring in the manner described in this document.

\subsection{Wine Monitoring Program}

\subsubsection{Rationale and Design Criteria for Wine Monitoring}

\subsubsection{Regulatory Drivers}

The regulatory driver for foodstuff monitoring is the applicable sections of DOE Order 458.1

(Change 2). Guidance in monitoring specific terrestrial foods appropriate for surveillance sampling and analysis is provided in the DOE's Environmental Regulatory Guide for Radiological Effluent Monitoring and Environmental Surveillance (DOE 1991).

It is not necessary to monitor fruit unless pathway analysis indicates that unusual circumstances are present (DOE 1991); therefore, there is no regulatory requirement to monitor wine, which is made from fruit (grapes). Explicit regulatory requirements are not the sole basis for monitoring, however. Monitoring is also carried out when there is a high level of public interest or concern, or where best management practices indicate monitoring is appropriate. In the past, tritium concentrations in Livermore Valley wines have attracted much public interest, as evidenced by newspaper and television coverage. Because of that interest, and because wines can contribute to radiological doses, however small, LLNL has analyzed more wine samples at more sensitive detection levels than might otherwise be required.

\subsubsection{Monitoring Objectives for Wine}

The primary purpose of wine monitoring is to evaluate the dose to the public from tritium found in wines purchased during the reporting (calendar) year. Secondarily, because wine samples integrate their tritium exposure over the growing season, the tiny impact of LLNL 
operations on tritium concentrations in Livermore Valley wines can be tracked based on concentrations decay-corrected to vintage year. Furthermore, measuring concentrations in California wines (other than Livermore Valley) provides the background concentrations against which to compare the low concentrations found in local wines; measuring concentrations in wines from Europe demonstrates that wines other than those from the Livermore Valley may have slightly elevated tritium concentrations that may exceed those of Livermore wines.

\subsubsection{Sources and Analytes}

Tritium is the only nuclide released from LLNL that can be detected in wine. At LLNL's Livermore site, the major contributors to airborne tritium emissions are routine emissions from the Tritium Facility (Building 331 and its associated operations) and the Radioactive and Hazardous Waste Management Yard of Building 612. The planned activities at the National Ignition Facility are anticipated to have emissions of tritium of about $30 \mathrm{Ci} / \mathrm{y}$, which will be of similar magnitude to past emissions from the Tritium Facility. Tritium is released from the Building 331 stacks as either tritiated gas (HT) or as tritiated water vapor (HTO). Tritium moves through the environment as tritiated water. As such, it is easily assimilated into plant water and incorporated into developing grapes. Through photosynthesis, tritium also is incorporated into the organic matter of grapes. The HTO and OBT in grapes made into wine can contribute to a radiation dose to human beings from drinking wine.

\subsubsection{Collection Methods}

Wine for annual analysis is purchased at local retail stores in $750 \mathrm{~mL}$ or $1 \mathrm{~L}$ bottles. The wine represents what a customer might purchase and take home to drink during the calendar year. It represents more than one vintage year.

\subsubsection{Extent and Frequency of Wine Monitoring and Measurements}

Wine is sampled annually at the end of the calendar year. The annual wine sampling is an extremely sensitive issue because of the potential economic, political, and public relations impacts of the data, and because it involves the purchase of alcoholic beverages and their possession onsite at LLNL. As a controlled item, the purchase of wine samples requires special approval by DOE and both the LLNL Procurement and Materiel Department and the Safeguards and Security Department (see EMP-VG-S, Vegetation and Foodstuff Sampling).

Each year from 1993 to 2003, twelve bottles (plus two duplicates) from the Livermore Valley, six bottles (plus one duplicate) from California (outside the Livermore Valley), and four bottles from Europe (France, Germany, and Italy) have been sampled. In 2004, the sampling effort was reduced to six bottles (plus two duplicates) from the Livermore Valley, two bottles from California, and two bottles from the Rhone Valley in France. Wine sampling locations are listed in the locations electronic database (EMP-QAS-LOC, Locations Database SOP Supplement). Since 1996, an equal number of red and white wines from each geographic area 
have been sampled. Any wine from a designated area is considered representative of that area, and the selection is random. Every effort is made to purchase estate wines (27 CFR 4.26), especially for the Livermore Valley sample. If an appropriate estate wine cannot be found, then the California wine must at least be labeled as being from an American Viticultural Areas (27 CFR 9 Subpart C).

European wines were initially chosen for evaluation because Europe is a significant winegrowing region with historically or potentially high tritium content in wine from locations, such as the Rhone Valley, near nuclear power plants. California wines from regions other than the Livermore Valley serve as natural background samples for comparative purposes.

\subsubsection{Procedures for Laboratory Analysis}

To avoid airborne tritium contamination, wine samples are submitted unopened to the onsite EMRL. Samples are analyzed for HTO using liquid scintillation counting. If necessary, samples can also be analyzed for tritium content (both HTO and OBT) by helium-3 mass spectrometry (Surano et al. 1992). Reports are issued to the environmental analyst.

\subsubsection{Data Quality Assurance}

\subsubsection{Precision}

The detection limit for wine using liquid scintillation counting is approximately $1.5 \mathrm{~Bq} / \mathrm{L}$ $(40 \mathrm{pCi} / \mathrm{L})$. The detection limit for wine using helium-3 mass spectrometry is $5.6 \times 10^{-2} \mathrm{~Bq} / \mathrm{L}$ $(1.3 \mathrm{pCi} / \mathrm{L})$. In accordance with LLNL procedure EMP-VG-S, Vegetation and Foodstuff Sampling, two QA duplicates, both from the Livermore Valley, are purchased each year. The identity of each wine is listed on the FTF, but, on the COC, each is referred to only as a QA sample. The labels are removed from the bottles before submission to the laboratory to disguise the identities of the vineyards. The bottles are relabeled as QA samples. Once the identity of the QA duplicates has been revealed, the likelihood that the samples are identical is calculated by the laboratory.

Laboratory duplicates (also called splits) are analyzed each year. Results are expected to be very close because wines are well-mixed. Paired duplicates are compared, and the magnitude and distribution of deviations relative to stated errors are examined. In general, the duplicate analyses agree slightly better than those predicted by their stated uncertainties.

\subsubsection{Accuracy}

For wine, an empty sample bottle serves as a blank. A controlled $18 \mathrm{~L}$ cask of wine, purchased in 1990, serves as a secondary standard. Samples of this cask wine have been measured yearly, and the measurements serve as a good test of long-term reproducibility. The primary standard is produced by mixing a low-level NIST standard with either "dead" water or the cask wine. A number of years ago, there was a laboratory intercomparison (unpublished) for low-level 
tritium concentrations in water. Five laboratories participated, analyzing 45 blind samples over a two-year period. All laboratories measured the samples accurately. Based on these results, the LLNL helium-3 mass spectrometry laboratory adopted an uncertainty relation of $10 \%+$ $0.185 \mathrm{~Bq} / \mathrm{L}$ (quadratic sum). In 2003, the laboratory ran approximately 50 samples in duplicate with the United States Geological Survey and had excellent agreement (unpublished).

\subsubsection{Completeness}

$100 \%$ of all wine samples are collected routinely. When twelve bottles of Livermore Valley wine had to be collected, it was sometimes difficult to select estate bottled wines exclusively, but this criterion is much more easily met when just six bottles are required. With respect to laboratory analyses, WAMA requires that ninety percent of the samples submitted to and analyzed by the laboratory yield valid data

\subsubsection{Calibration}

Equipment in the EMRL is calibrated with sources that are traceable to NIST. Calibration follows a variety of methods, from calibration by a certified third party, to calibration with known standards that are made from traceable materials. Calibration practices are in accordance with standard procedures, and records are maintained for each piece of calibrated equipment.

\subsubsection{Program Implementation Procedures}

The primary responsibility for activities related to wine monitoring is assigned to an environmental analyst in the WAMA group of EFA. The analyst is responsible for the following:

- Designing, implementing, and maintaining the sampling network.

- Determining analytes, collection methods, and analytical methods.

- Coordinating network activities with sampling technologists and analytical laboratory personnel.

- Reviewing and analyzing the data.

- Performing dose assessments.

- Following trends in data.

- Reporting results.

Wine samples are collected according to LLNL procedure EMP-VG-S, Vegetation and Foodstuff Sampling, and are submitted for analyses using sample control, chain-of-custody, and documentation procedures (EMP-QA-DM, Sample and Data Management). The written procedures include requirements for sample collection and submittal for chemical analysis, keeping a log, and filling out FTFs and COC forms. 


\subsubsection{Action Levels}

Sample results are compared to the 5-year historic geometric mean for each sampling group in the wine monitoring networks (Livermore, California, and Europe). These geometric means and standard deviations are provided in Table 16-2.

Table 16-2. Geometric means, geometric standard deviations, and upper warning and action limits for wine sampling groups (1999-2003).(a)

\begin{tabular}{|l|c|c|c|c|}
\hline \multicolumn{1}{|c|}{ Group } & $\begin{array}{c}\text { Geometric Mean } \\
\text { (Bq/L) }\end{array}$ & $\begin{array}{c}\text { Geometric } \\
\text { Standard Deviation }\end{array}$ & $\begin{array}{c}\text { Warning Limit } \\
\text { (upper) }\end{array}$ & $\begin{array}{c}\text { Action Limit } \\
\text { (upper) }\end{array}$ \\
\hline Livermore & 1.7 & 1.6 & 4.6 & 7.6 \\
California & 0.44 & 1.2 & 0.69 & 0.86 \\
Europe & 1.2 & 1.7 & 3.6 & 6.1 \\
\hline
\end{tabular}

(a) The 1999 to 2003 data are representative of anticipated future conditions.

Any results outside two geometric standard deviations (a warning level) are examined for data transcription errors, and the analytical lab is contacted to discuss any problems that may have occurred during analysis. Any results outside three geometric standard deviations (the action level) are also subject to examination for transcription errors and analytical problems. In addition, an attempt will be made to purchase the same wine, perhaps in duplicate or triplicate, for reanalysis. If no transcription, analytical, or other error is found to explain an out-of-limit value, the environmental analyst notifies EFA management, and further action, such as a special study, may be taken with EFA management concurrence.

\subsubsection{Preparation and Disposition of Reports}

The environmental analyst conducts dose assessments, based on the monitoring data and using methods detailed in guidance document EMP-R-DA, Radiological Dose Assessment Guidance Document, for wine once all data for a calendar year are obtained. The monitoring and dose assessment results are reported in the annual Environmental Report. In addition, tritium concentrations in wine decay-corrected to the harvest year are reported for all wines sampled. No other reporting is required for wine.

\subsubsection{Future Plans}

The short-term plan for wine sampling is to continue monitoring in the manner described in this chapter.

\subsection{References}

ATSDR (2002), Health Consultation, Tritium Releases and Potential Offsite Exposures. Agency for Toxic Substances and Disease Registry. U.S. Department of Health and Human Services, Atlanta, GA: 99 pp; March 11, 2002. 
DOE (1991), Environmental Regulatory Guide for Radiological Effluent Monitoring and Environmental Surveillance, U. S. Department of Energy, Washington, D. C. (DOE/EH-0173T).

Environmental Report (annual), Lawrence Livermore National Laboratory, Livermore, CA. (UCRL-50027). Available at https:saer.1lnl.gov

EPA (1988), Limiting Values of Radionuclide Intake and Air Concentration and Dose Conversion Factors for Inhalation, Submersion, and Ingestion. Federal Guidance Report No. 11. Office of Radiation and Indoor Air, United States Environmental Protection Agency, Washington, D.C. September 1988.

ICRP (1996), Age dependent doses to members of the public from intake of radionuclides, Part 5, Compilation of Ingestion and Inhalation Dose Coefficients from Parts 1-4. International Commission on Radiological Protection. Oxford: Pergamon Press; ICRP Publication 72; Ann. ICRP 26(1).

LLNL (1991), AB2588 Air Toxics Risk Screening Document for Lawrence Livermore Laboratory, Plant 255, Lawrence Livermore National Laboratory, Livermore, CA.

McDowell-Boyer, L., J. Daniels, G. Gallegos, F. Gouveia, and L. Hall (1995), Health Risk Assessment for Hazardous and Mixed Waste Management Units at Lawrence Livermore National Laboratory, Lawrence Livermore National Laboratory, Livermore, CA (UCRL-AR-119482).

Peterson, S-R., and P.A. Davis. (2002), Tritium Doses from Chronic Atmospheric Releases: A New Approach Proposed for Regulatory Compliance." Health Physics 82(2):213-225. UCRL-JC-141535.

Surano, K. A., G. B. Hudson, R. A. Failor, J. M. Sims, R. C. Holland, S. C. MacLean, and J. C. Garrison (1992), "Helium-3 Mass Spectrometry for Low-Level Tritium Analysis of Environmental Samples,” J. Radioanal. Nucl. Chem. 6:443-453. 


\section{Ambient Radiation}

Nicholas A. Bertoldo

\subsection{Introduction}

A wide variety of radiological operations with the potential for radiological impacts to the public and environment take place at Lawrence Livermore National Laboratory (LLNL). Dose assessments based on a comprehensive environmental surveillance and effluent monitoring program (see Chapter 1) are used to determine LLNL radiological impacts. For completeness, ambient radiation (i.e., direct radiation impacts) must also be evaluated. At LLNL this means evaluating ambient gamma and neutron induced radiation doses as needed.

\subsection{Rationale and Design Criteria}

\subsubsection{Regulatory Drivers}

In accordance with the applicable U.S. Department of Energy (DOE) orders (see Chapter 1), LLNL monitors ambient radiation to establish background levels and to determine public doses resulting from its operations. To measure potential doses from DOE operations, the Environmental Regulatory Guide for Radiological Effluent Monitoring and Environmental Surveillance (DOE 1991) recommends instruments for application to DOE environmental surveillance programs, including Geiger-Müller (GM) and gamma scintillation systems, Pressurized Ion Chambers (PICs), thermoluminescent dosimeters (TLDs) and moderated $\mathrm{BF}_{3}$ counters (rem) counters to monitor gamma and neutron-induced gamma radiation at the site perimeter.

LLNL's routine surveillance program uses environmental TLDs for determining the ambient radiation dose at the perimeter. As the National Ignition Facility (NIF) continues to operate, additional instruments may be incorporated, such as $\mathrm{BF}_{3}$ counters for neutron monitoring and gamma detectors for sky shine, in addition to the routine surveillance network. The specific TLD-related activities (e.g., annealing, calibration, readout, storage, and exposure periods) are consistent with the recommendations of the American National Standards Institute (ANSI 1975). LLNL's use of TLDs meets the specifications of the above-mentioned orders, regulations, and guidance.

The public dose limit specified in DOE 458.1 does not include dose received from occupational exposures, naturally occurring "background" radiation, doses received as a patient from medical practices, or doses received from consumer products. Consequently, LLNL measures and characterizes ambient radiation to understand background radiation 
levels and to understand LLNL's operational impacts on the environment and dose to the public relative to the natural background and its associated variance.

\subsubsection{Monitoring Objectives}

The primary objective of ambient radiation monitoring is to measure radiation in the environment and evaluate any public dose that may be received as a result of ambient radiation from LLNL operations. This is accomplished by the deployment of perimetermonitoring networks at each site boundary (one at the Livermore site and one at Site 300). Environmental TLDs are deployed at locations on or near the perimeter of the Livermore site, in the Livermore Valley, on or near the perimeter of Site 300, near Site 300, and in the city of Tracy. Deploying a sufficient number of TLDs ensures that the monitoring networks are capable of detecting radiation from LLNL operations and that the natural background radiation field is sufficiently characterized. The objective is to make measurements in areas where members of the public may potentially be exposed.

\subsubsection{Sources and Analytes}

There are many radiological operations throughout LLNL in a variety of research and development programs that use gamma radiation sources. For example, various sources of gamma radiation at the Livermore site are found in waste management activities and laser and biomedical research.

\subsubsection{Collection Methods}

LLNL's primary ambient radiation monitoring method uses Panasonic UD 814-AS1 environmental TLDs to passively detect penetrating radiation at the site of TLD deployment in a gamma or neutron radiation field. Penetrating radiation cannot be measured directly unless radioactive material is collected directly on filters. Thermoluminescence is a method utilizing the principles of solid-state physics to trap penetrating gamma radiation in the crystal lattice of these solid-state crystal devices known as TLDs. These dosimeters absorb the gamma radiation energy that is imparted to the dosimeter as a result of its exposure to natural background radiation in the environment and any anthropogenic radiation sources. The absorbed dose of radiation is interpreted by heating the TLD crystals to a pre-defined temperature that allows the integrated trapped energy to be re-emitted in the form of light as a corresponding "glow curve." By calibration of the TLD to known standards such as cesium-137 with a $0.662 \mathrm{MeV}$ energy, the energy output of the glow curve is proportional to the absorbed dose. The TLD inherently becomes an "integrator" of both background energy and any additional contribution during the time of the deployment cycle. 


\subsubsection{Energy Absorption}

As the physical matrix of the TLD is exposed to gamma radiation, impurities in the crystals form low temperature trapping sites for electrons excited to higher energy states. The electrons remain in an exited energy state at normal ambient temperatures. In the analytical laboratory, the TLD is processed in a three-phase process. First, the TLD is heated, causing the electrons to be released from the trapping sites; when they drop to a lower energy state, photons are emitted. Second, the photons are measured with a photomultiplier tube with the light intensity being proportional to the original absorbed dose of radiation; the light intensity measurement is recorded. Third, after the TLD is read, it is heated and read again. The second reading should be near zero, indicating that all of the gamma-radiation-induced stored energy has been released (and therefore measured). This second heat treatment is referred to as annealing and verifies that the TLD is ready for reuse in the field.

TLDs measure exposure as absorbed dose (milli-roentgen; $\mathrm{mR}$ ). The absorbed dose is the quantity of energy deposited by radiation in a given amount of material. This is converted to radiation dose (mrem or $\mathrm{mSv}$ ) by calibrating the dosimeter reader to read the absorbed dose and then applying a quality factor for a gamma radiation field (Graham and Trombino 1997). The accuracy of radiation measurements made with TLDs may be evaluated by charting the performance of dosimeters exposed to known Cs-137 radiation exposures. LLNL's Environment, Safety, and Health (ES\&H) Calibration and Standards Laboratory irradiates these quality control TLDs using National Institute of Standards and Technology (NIST)-traceable cesium-137 standards.

LLNL uses the Panasonic Model UD-814AS1 TLD, which contains one element of lithium borate $\left(\mathrm{Li}_{2} \mathrm{~B}_{4} \mathrm{O}_{7}\right)$ and three components of activated calcium sulfate $\left(\mathrm{CaSO}_{4}\right)$. Only the $\mathrm{CaSO}_{4}$ elements are used to measure LLNL environmental gamma radiation because of the crystal's sensitivity to these radiation levels. The luminescence of the $\mathrm{CaSO}_{4}$ element is 30 times greater than other TLD crystals considered for use. This makes the UD-814AS1 TLD an obvious choice for measurements in the milli-roentgen absorbed dose range (converted to the single-digit milli-rem range).

\subsection{Extent and Frequency of Monitoring and Measurement}

TLDs are deployed at locations around the Laboratory perimeter and off-site at both the Livermore site and Site 300 to ensure that any measurable gamma radiation dose from LLNL operations would be detected and to characterize the ambient average level from terrestrial and cosmic background radiation.

The Livermore site perimeter locations have been chosen based on proximity to LLNL gamma emitting operations, potential public exposure, and accessibility of the monitoring location. The off-site dosimeters are located to provide information about background 
radiation and LLNL impact on radiation levels in nearby residential areas. All radiationmonitoring locations are chosen to ensure that the exposures measured will be representative of those that could potentially result from LLNL operations.

In addition, the following network design criteria were considered before deciding on permanent TLD sampling locations:

- TLDs are placed as far as possible from large or dense objects and that proximity of a structure will not alter the measurement.

- Locations are not likely to be temporarily obstructed to minimize distortion of the radiation field.

- TLD hanging location including consistency in TLD height from the ground (approximately one meter).

- Population distributions.

- Local geology.

Sampling is done quarterly as directed in the guidance document DOE/EH-0173T (DOE 1991) to establish a detectable background dose.

TLD sampling locations have undergone adjustments as a result of geographical changes, safety concerns, and overall reduction in sampling locations. A description of sampling locations is maintained in the TEIMS database. The supplement also describes the process to be used for defining, documenting, and approving sampling locations.

\subsubsection{Livermore Site and Livermore Valley}

External exposures from gamma radiation are measured quarterly, using TLDs, at 14 Livermore-site perimeter locations and 22 off-site locations in the Livermore Valley (Figures 17-1 and 17-2). Quarterly sampling periods produce a readily detectable dose, following guidance in DOE/EH-0173T (DOE 1991). For TLDs in the LLNL vicinity, this nominally represents a quarterly background ambient radiation dose on the order of 0.1 to $0.2 \mathrm{mSv}$ (10 to $20 \mathrm{mrem}$ ) per 90-day exposure. Furthermore, quarterly sampling allows evaluation of seasonal variation and increases the probability that data are obtained from all locations for at least a portion of the year. That is, if a TLD is lost or damaged at a given location, data from only a single quarter are lost, thus allowing an estimate of annual exposure to be made from data acquired during the other three quarters. 


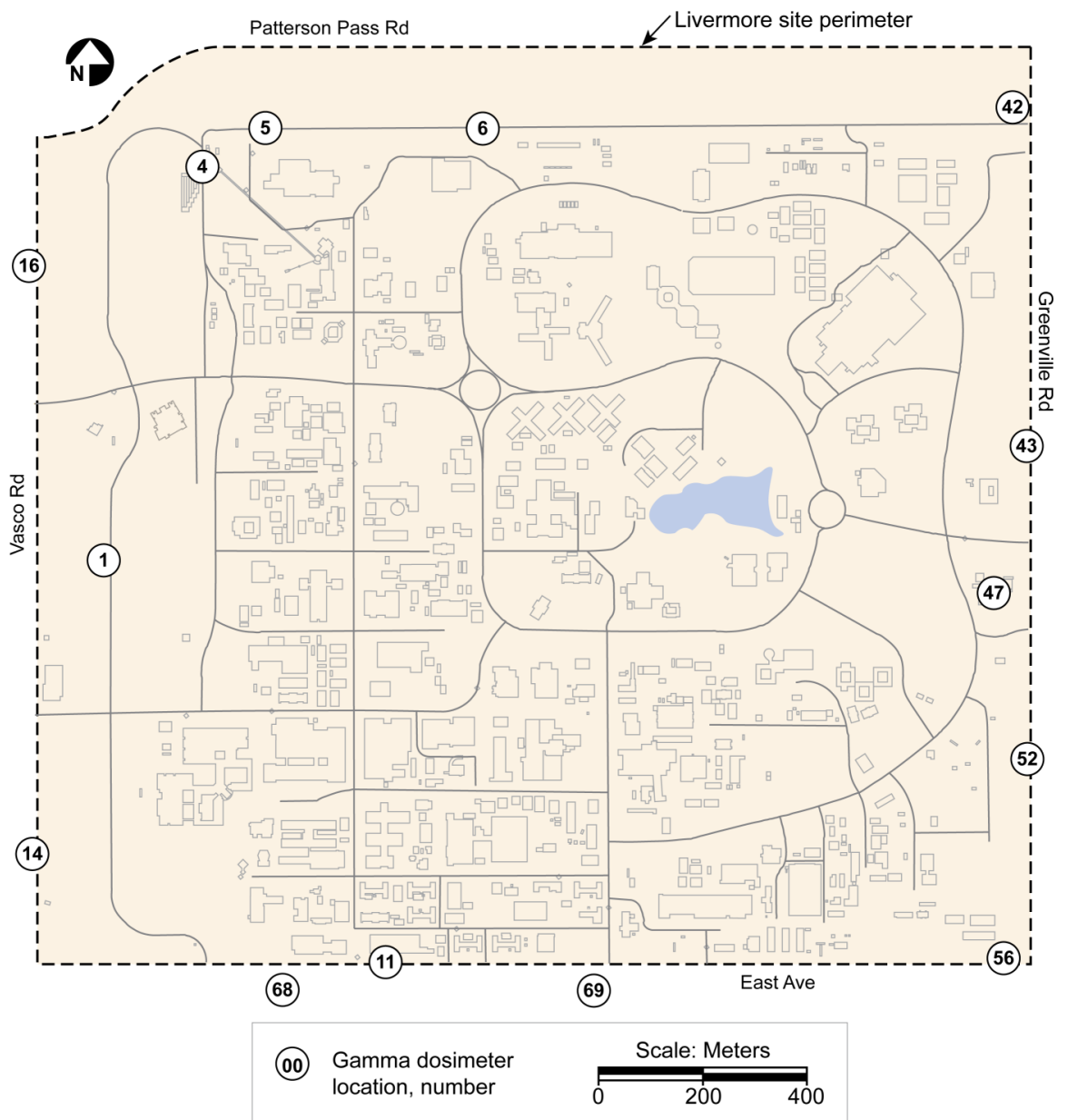

Figure 17-1. Gamma dosimeter locations, Livermore site.

Contributions to ambient radiation doses from LLNL operations have neither been historically above the natural background radiation environment levels at or beyond the Livermore-site perimeter, nor have they changed significantly over the last twenty years. Exposures measured at the LLNL perimeter typically are statistically identical to the offsite doses, which are considered to be natural ambient radiation background levels. This indicates that LLNL operations do not contribute to the external dose at or beyond the Livermore-site perimeter. 


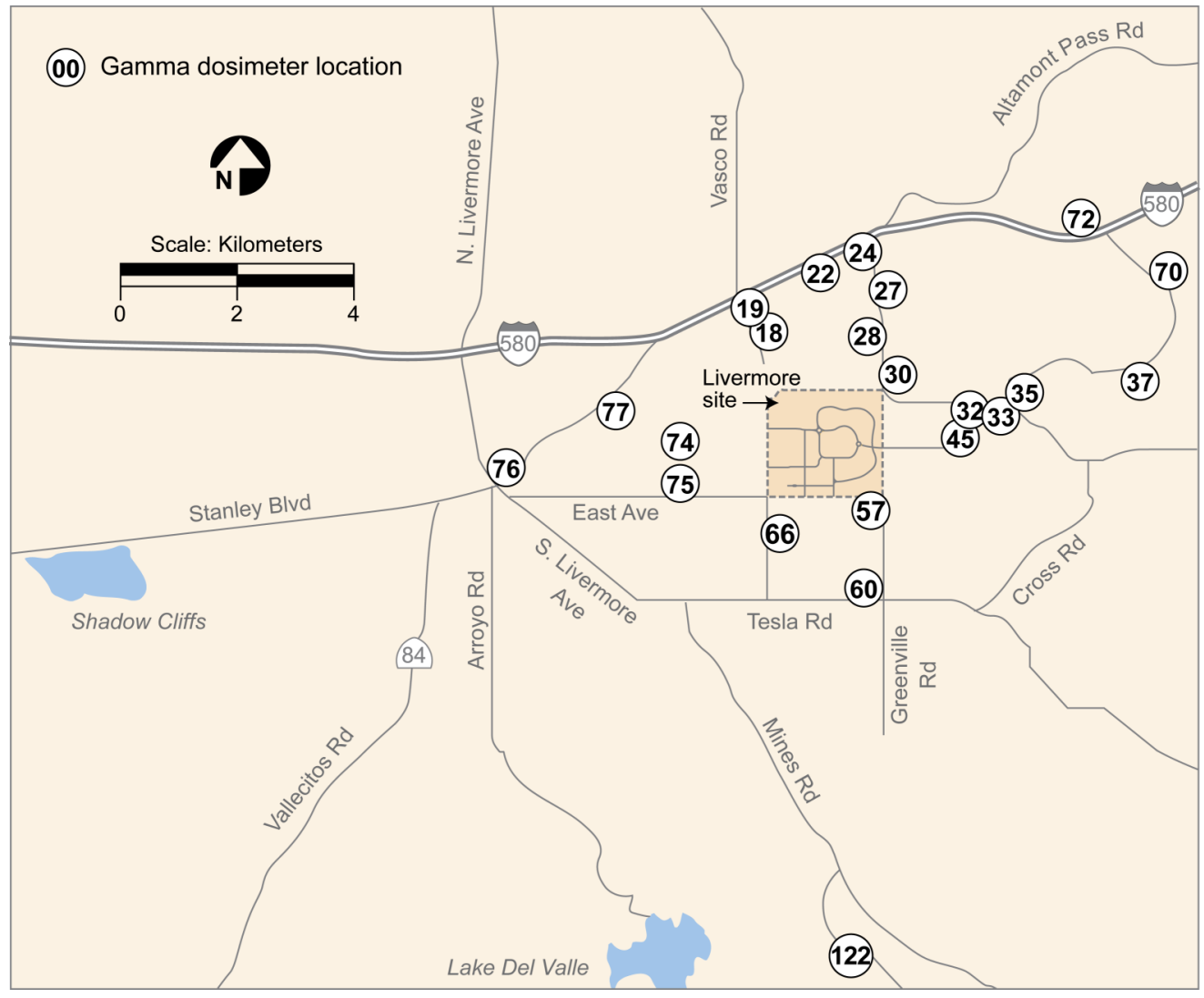

Figure 17-2. Gamma dosimeter locations, Livermore Valley.

\subsubsection{Site 300}

There are nine on-site perimeter and two off-site TLD monitoring locations at Site 300 plus two locations in Tracy, California. These locations are illustrated in Figure 17-3. Offsite dosimeters are located in areas accessible to the public, including locations on Corral Hollow Road, and in the city of Tracy.

The initial TLD network design for Site 300 limited monitoring to the site perimeter and three locations in the San Joaquin Valley near the city of Tracy. These original off-site locations were chosen to provide exposure information about nearby population centers, as well as background radiation levels, and they continue to serve those purposes. However, the terrain and geological composition of Site 300 is different from that of the city of Tracy and the surrounding San Joaquin Valley; Site 300 has outcroppings of igneous rocks, whereas the city of Tracy and the surrounding area is located on sedimentary soils. The region around Site 300 has elevated levels of naturally occurring thorium and uranium that accounts for the difference between historically measured external gamma radiation between Site 300 and the city of Tracy. The more recently selected off-site monitoring locations, found on a geological substrate more comparable to that at Site 300, are used to evaluate the potential for local, LLNL-induced exposures. 


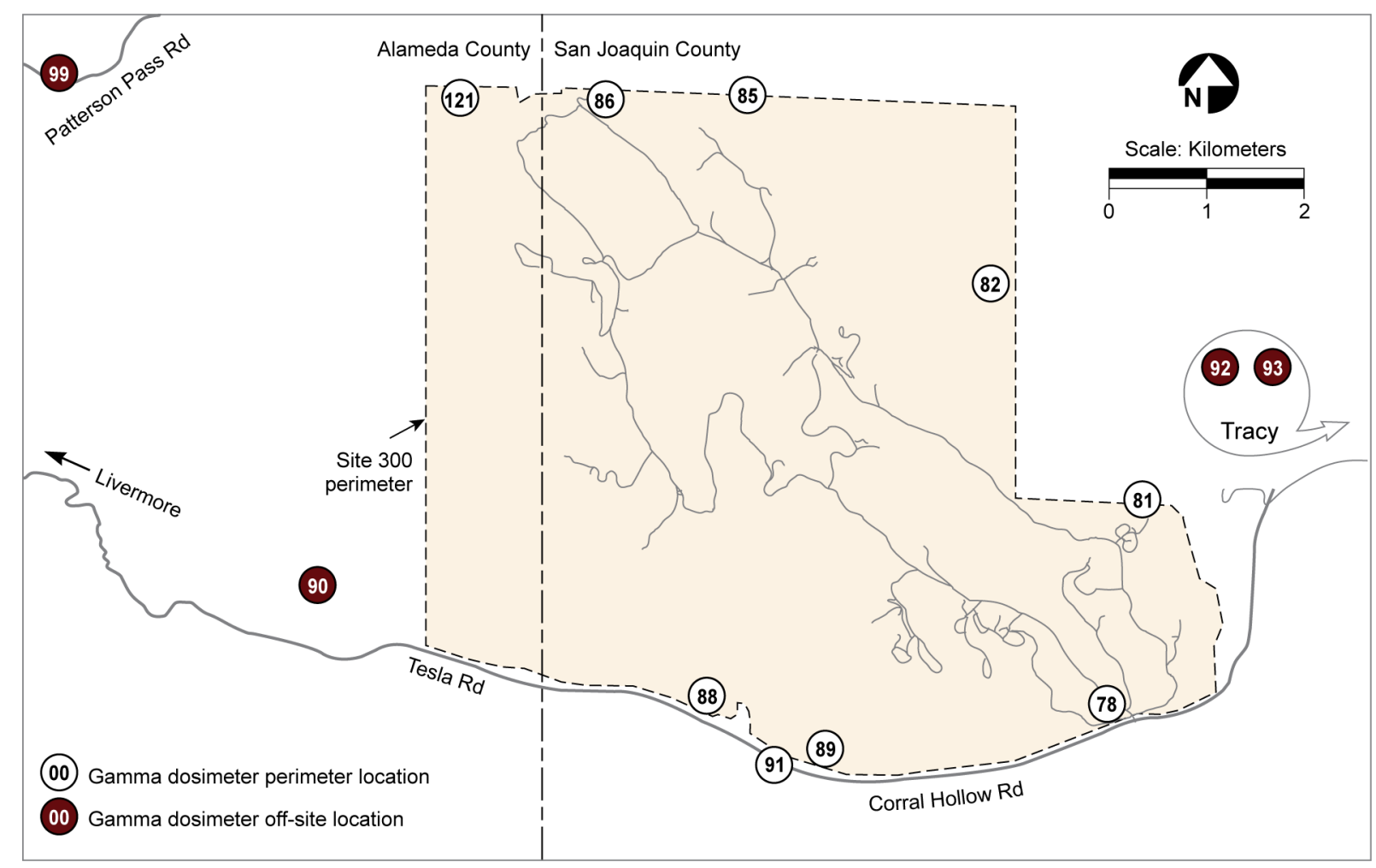

Figure 17-3. Gamma dosimeter locations, Site 300 and vicinity.

\subsubsection{State of California Co-Monitoring}

Currently, the California Department of Public Health (CDPH), Radiological Health Branch, co-monitors ambient gamma radiation using their own TLDs at nine LLNL monitoring locations; this co-monitoring effort began in 1987. These radiation dosimeters are also collected by the state and read on a quarterly basis. Historically, data from the State dosimeters have been in good agreement with data from LLNL TLDs.

\subsection{Procedures for Laboratory Analysis}

LLNL's TLDs are prepared for deployment by annealing and read by the LLNL ES\&H External Dosimetry Lab. The ES\&H Radiation Calibration Laboratory using standards traceable to NIST performs calibration of the TLD reader. Data are electronically reported to the Water, Air, Monitoring and Analysis (WAMA) environmental analyst. The environmental analyst is responsible for calculating the gamma exposure on the TLDs, ensuring that the data are corrected to a 90-day standard quarter for comparison, performing quality control checks, and reporting the data in the annual Environmental Report. 


\subsubsection{Calibration}

Each quarter, when environmental TLDs are read, the Panasonic TLD reader used by the External Dosimetry Lab is calibrated with exposed standards. A batch of annealed TLD standards for calibration is stored for the first half of the quarter in a zip-locked plastic bag in a lead container, on-site and outdoors. The lead container shields the calibration TLDs from exposure to natural terrestrial and cosmic background radiation while allowing them to be subjected to the same environmental conditions as those TLDs used for monitoring. At mid-quarter, of the 12 calibration TLDs, 6 are irradiated to $100 \mathrm{mR}$ exposures while 6 of the "zero" or "background" TLDs are exposed only to "natural" dose. The calibration TLDs are then returned to the lead container until the quarter's end when all TLDs recovered from the field plus the calibration TLDs in the lead shielded container are returned to LLNL's External Dosimetry Lab for reading. See procedure EMP-R-SCA, External Environmental Radiation Monitoring and Calibration, for details on the calibration of the Panasonic reader and the reading of the TLDs.

\subsubsection{TLD Data Analysis}

The TLDs measure environmental gamma radiation exposure in milliroentgens. The measured exposure is converted to dose by using a correction factor. All measured doses at the Livermore site boundary are compared to both recent and historical background measurements to determine the contribution, if any, from LLNL operations. All data are reported as total doses (EDE in mrem), including those from both background and LLNL sources.

When a TLD is missing, the annual dose is calculated as four times the average quarterly dose determined from available data. TLDs that are wet, damaged, or found on the ground are not accepted for use in monitoring and are noted. The analyst indicates which TLDs were reported as missing or damaged in the data tables for the Site Annual Environmental Report.

\subsection{Data Quality Assurance}

Summary statistics, accuracy and precision of analytical results are reported using means, range, variance, standard deviation and/or confidence intervals as stated in guidance document EMP-QA-D, Data Analysis.

\subsubsection{Precision and Accuracy}

In an effort to maintain the highest quality standards, TLD results are rigorously examined and statistically compared to long-term background averages, and the procedures for calibration, sample preparation, and field deployment are strictly adhered to. This effort ensures that appropriate analytical methods and TLD holding times are being used to 
attain the level of precision and accuracy sought in measuring the ambient radiation field at LLNL and the nearby community.

The WAMA analyst examines results from blanks and spikes of known exposures by comparing the reported data to the known exposures. Each quarter, a set of quality control (QC) TLDs are irradiated with known exposures ("spikes"); some of the QC TLDs remain unexposed and therefore serve as "blanks." Although handled in a similar manner, these QC TLDs should not be confused with the calibration TLDs described in Section 17.4.1. Like the calibration TLDs, the QC TLDs are stored in a lead container, subjected at midquarter to known exposures, returned to the lead container, and submitted for analysis at the end of quarter along with the environmental monitoring and calibration TLDs. However, unlike the calibration TLDs, members of the External Dosimetry Lab do not know which of the submitted TLDs are the QC TLDs nor do they know the exposures. The average value of the QC TLD readings must fall within $\pm 20 \%$ of the "true" TLD exposure value (Graham and Trombino 1997).

The External Dosimetry Lab participates in the DOE Laboratory Accreditation Program (DOELAP) every two years and must meet specified inter-laboratory comparison performance goals and pass a two-day on-site audit. WAMA participates in the DOE Environmental Measurements Laboratory (EML) inter-comparison study program whenever inter-comparison tests are offered. TLDs with known exposures are sent to EML for analysis. The analytical results are published, allowing WAMA to evaluate the performance of the External Dosimetry Lab in an independent quality check. Sampling and analysis procedures are reviewed annually to determine whether the procedures are up-todate and being performed correctly.

As stated in Section 17.3.3, the CDPH co-monitors at nine of the LLNL TLD monitoring locations. According to the $\mathrm{CDPH}$ personnel, the $\mathrm{CDPH}$ dosimeters consist of four individual elements of calcium sulfate dysprosium-doped powder, wrapped with a cadmium foil to provide linear energy response, and assembled into a single package. The material is annealed together and subsequently read simultaneously. Control packets are used to determine transit exposure. Selected packages are exposed within the NIST calibration range in Sacramento, California, for quality control purposes. The gross exposures received by the dosimeters are determined by the Radiation Detection Company, Sunnyvale, California, and are reported to CDPH Radiological Health Branch. LLNL is in contact with CDPH regarding the co-monitoring program and its data.

\subsubsection{Completeness}

In addition to the comparison of co-located TLD data as stated in Section 17.5.1, LLNL deploys a significant number of TLDs to obtain a reasonable representation of the natural background in the surrounding areas of the Livermore site, Livermore Valley, Site 300, 
and off-site Site 300 locations including the city of Tracy. Although some samples may be lost due to either uncontrollable damage or vandalism, every effort is made to ensure the media completeness is maintained to the highest quality objective by the frequency of sampling and number of locations used for sampling. Missing samples are reported on the field tracking forms at the time of collection on a quarterly basis. Summary statistics that represent these data losses are generated and reviewed as needed in order to take action (such as moving a particular sample location to ensure sample survivability) should any trend develop. On average, the statistical number of data lost each year is less than $10 \%$ for Site 300, Livermore site, and the Livermore Valley sample locations.

\subsection{Program Implementation Procedures}

The primary responsibility for activities related to the environmental radiation-monitoring network is assigned to a WAMA environmental analyst. The analyst is responsible for the network design, implementation, and correct operation of the network; the analysis and evaluation of all monitoring results; data trending; documentation; and reporting. The following is a list of the procedures associated with the sampling network:

- EMP-R-SCA, External Environmental Radiation Monitoring and Calibration: Details of sampling, processing, and calibration for the TLDs.

- EMP-TLD-CALC, TLD Calculation: Methodology used to calculate the gamma radiation dose from the TLDs.

- EMP-QA-D, Data Analysis: Guidance on the statistical analyses of monitoring results.

- EMP-QA-DM, Sample and Data Management: Details methods used for sample and data management and the documentation required for environmental samples.

\subsection{Action Levels}

Action levels for environmental TLDs are now derived by calculating a five-year average with the error limited to plus or minus three standard deviations of all combined locations on a quarterly basis. Measurements that fall outside the action level range are investigated. LLNL management is notified if the unusual measurement cannot be attributed to sampling variability or errors in analytical methodology. The annual mean action level for all TLD locations is set to the quarterly 5 -yr mean $\pm 3 \sigma$. These calculated quarterly ranges for the years 2006-2010 are as follows:

- Livermore site: $0.143 \pm 0.030 \mathrm{mSv}$.

- Livermore Valley (background): $0.143 \pm 0.039 \mathrm{mSv}$.

- Site 300: $0.170 \pm 0.039 \mathrm{mSv}$.

- Site 300 Environs (background): $0.163 \pm 0.183 \mathrm{mSv}$. 
Due to seasonal effects, the measured data tends to be higher in dry quarters. The annual mean of the Livermore Valley is approximately $0.55 \mathrm{mSv}$. Although the data may be seen to vary terrestrially by soil moisture content and geological constituents that produce higher natural background at some locations, the mean +3 sigma upper bound tends to account for both terrestrial and cosmic variability, measurement error and missing data.

\subsection{Preparation and Disposition of Reports}

The data from the environmental gamma radiation network are processed, analyzed, and reported in the annual Environmental Report. No other reporting is required for the ambient radiation data. Sampling location maps, descriptions of collection and analytical methods, all data from all monitoring locations, summary statistics, statistical evaluations, comparisons with background radiation levels, trending of data, and discussion of overall environmental impacts are included in the annual Environmental Report.

\subsection{Future Plans}

Ambient radiation monitoring as described here will continue to be a part of LLNL's environmental monitoring effort. The monitoring locations will continue to be evaluated to ensure that suitable coverage and compliance with regulations are sustained.

\subsection{References}

ANSI (1975), N545: Performance, Testing, and Procedural Specifications for Thermoluminescent Dosimetry: Environmental Applications, American National Standards Institute, Philadelphia, PA.

DOE (1991), Environmental Regulatory Guide for Radiological Effluent Monitoring and Environmental Surveillance, U. S. Department of Energy, Washington, D. C. (DOE/EH-0173T).

Site Annual Environmental Report, Lawrence Livermore National Laboratory, Livermore, CA. (UCRL-TR-50027-yr, where "yr." = current year) available at https://saer.llnl.gov/

Graham, C. L., and D. G. Trombino (1997) Personnel Dosimetry Procedures: Chapter 6, Environmental Dosimetry, Hazards Control Department, Lawrence Livermore National Laboratory, Livermore, CA. 


\section{Appendix A. Acronyms}

ACG

ALAB

ALARA

ANSI

ATA

AWQC

BAAQMD

BMP

BOD

$\mathrm{CDPH}$

CEQA

CERCLA

CFF

CFR

COC

COD

CRWQCB

CVRWQCB

DAM

DAP

DCTS

DMT

DOE

DOELAP

DQO

DTSC

DWTF ambient concentration guide

Worker Safety and Health Analytical Lab

as low as reasonably achievable

American National Standards Institute

Advanced Test Accelerator

Ambient Water Quality Criteria

Bay Area Air Quality Management District

best management practice

biological oxygen demand

California Department of Public Health

California Environmental Quality Act

Comprehensive Environmental Response, Compensation, and Liability Act

Contained Firing Facility

Code of Federal Regulations

Chain-of-custody

constituent of concern

chemical oxygen demand

California Regional Water Quality Control Board

Central Valley Regional Water Quality Control Board

Discharge Authorization Manager

discipline action plan

derived concentration technical standard

Data Management Team

U.S. Department of Energy

Department of Energy Laboratory Accreditation Program

data quality objective

Department of Toxic Substances Control

Decontamination and Waste Treatment Facility 


\begin{tabular}{|c|c|}
\hline EA & environmental analyst \\
\hline EDE & effective dose equivalent \\
\hline EDO & Environmental Duty Officer \\
\hline EFA & Environmental Functional Area \\
\hline ELAP & Environmental Laboratory Accreditation Program \\
\hline EMP & Environmental Monitoring Plan \\
\hline EMRL & Environmental Monitoring Radioanalytical Laboratory \\
\hline EMT & Emergency Management Team \\
\hline EOC & Emergency Operations Center \\
\hline EPA & (U.S.) Environmental Protection Agency \\
\hline ERD & Environmental Restoration Department \\
\hline ES\&H & environment, safety, and health \\
\hline ESPM & Environmental Stewardship Planning \& Monitoring \\
\hline ESPO & Environmental Support and Programmatic Outreach \\
\hline EST & Environmental Support Team \\
\hline FTF & field tracking form \\
\hline GM & Geiger-Müller \\
\hline GSA & General Services Area (Site 300) \\
\hline $\mathrm{HE}$ & high explosive \\
\hline HSU & hydrostratrigraphic units \\
\hline HT & tritiated hydrogen gas \\
\hline HTO & tritiated water \\
\hline HVAC & heating, ventilation, and air conditioning \\
\hline IEEE & Institute of Electrical and Electronics Engineers \\
\hline ISMS & Integrated Safety Management System \\
\hline ITS & issues tracking system \\
\hline IWS & integration work sheet \\
\hline LCS & laboratory control sample \\
\hline LLNL & Lawrence Livermore National Laboratory \\
\hline
\end{tabular}




\begin{tabular}{|c|c|}
\hline LSC & Liquid Scintillation Counting \\
\hline LWRP & Livermore Water Reclamation Plant \\
\hline MCL & maximum contaminant level \\
\hline MRP & Monitoring and Reporting Program \\
\hline NARAC & National Atmospheric Release Advisory Center \\
\hline NEPA & National Environmental Policy Act \\
\hline NESHAPs & National Emission Standards for Hazardous Air Pollutants \\
\hline NIF & National Ignition Facility \\
\hline NIST & National Institute for Standards and Technology \\
\hline NOAA & National Oceanic and Atmospheric Administration \\
\hline NPDES & National Pollutant Discharge Elimination System \\
\hline NTU & Nephelometric Turbidity Unit \\
\hline NWS & National Weather Service \\
\hline OBT & organically bound tritium \\
\hline PCB & polychlorinated biphenyl \\
\hline PIC & Pressurized Ion Chamber \\
\hline $\mathrm{PM}_{10}$ & particulate matter with diameter equal to or less than 10 micometers \\
\hline POTW & publicly owned treatment works \\
\hline PPMRP & Pollution Prevention and Monitoring and Reporting Plan \\
\hline $\mathrm{P} 2 \mathrm{~S}$ & Pollution, Prevention \& Sustainability \\
\hline PST & Pacific Standard Time \\
\hline QA & quality assurance \\
\hline QC & quality control \\
\hline $\mathrm{R} \& \mathrm{D}$ & research and development \\
\hline RCRA & Resource Conservation and Recovery Act \\
\hline $\mathrm{RCT}$ & radiological control technician \\
\hline $\mathrm{RDX}$ & Hexahydro-1,3,5-trinitro-1,3,5-triazine \\
\hline RHWM & Radioactive and Hazardous Waste Management (Division) \\
\hline RL & reporting limit \\
\hline
\end{tabular}


RML

Radiation Measurements Laboratory

RMMA

Radioactive Materials Management Area

ROD

record of decision

RPM

Remedial Program Manager

RSL

reduced to sea level

RTAL

Retention Tank Analysis List

RTMN

Real Time Monitoring Network

RWQCB

regional water quality control board

Sandia/California

Sandia National Laboratories, California

SDF

Sewer Diversion Facility

SFBRWQCB

San Francisco Bay Regional Water Quality Control Board

SJVAPCD

San Joaquin Valley Air Pollution Control District

SIU

Significant Industrial User

SL

statistical limit of concentration

SMC

Sewer Monitoring Complex

SOP

standard operating procedure

SOW

Statement of Work

SRDT

solar radiation-delta $\mathrm{T}$

STAR

Sample Tracking and Receiving system (Worker Safety \& Health)

SW-MEI

sitewide maximally exposed individual

SWPPP

Storm Water Pollution Prevention Plan

SWRCB

State Water Resources Control Board

TDS

total dissolved solids

TEDA

triethylene diamine

TEIMS

Taurus Environmental Information Management System

TLD

thermoluminescent dosimeter

TOC

total organic carbon

TOX

total organic halides

TSS

total suspended solids 
TTO

TTU

VOC

WAMA

WAPA

WDAR

WDR

WMU

WRD

WSH

XRF

XRFS total toxic organics

transportable treatment unit

volatile organic compound

Water, Air, Monitoring \& Analysis

Western Area Power Administration

Wastewater Discharge Authorization Record

Waste Discharge Requirement

waste management unit

Water Resources Division

Worker Safety \& Health

$\mathrm{x}$-ray fluorescence

$\mathrm{x}$-ray fluorescence spectroscopy 

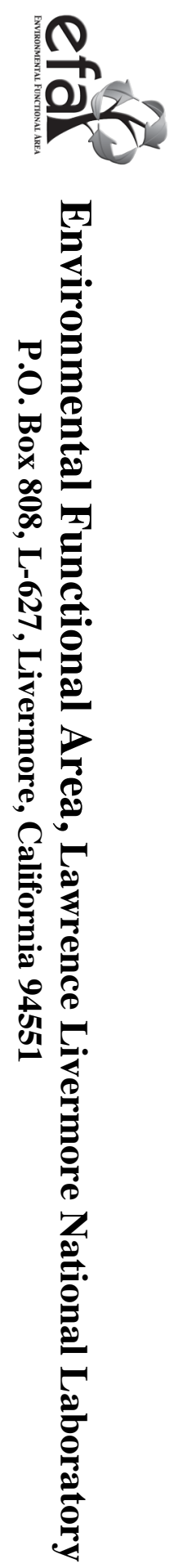